Geological Survey, Bulletin no. 370.

The fire-resistive properties of various building materials. 



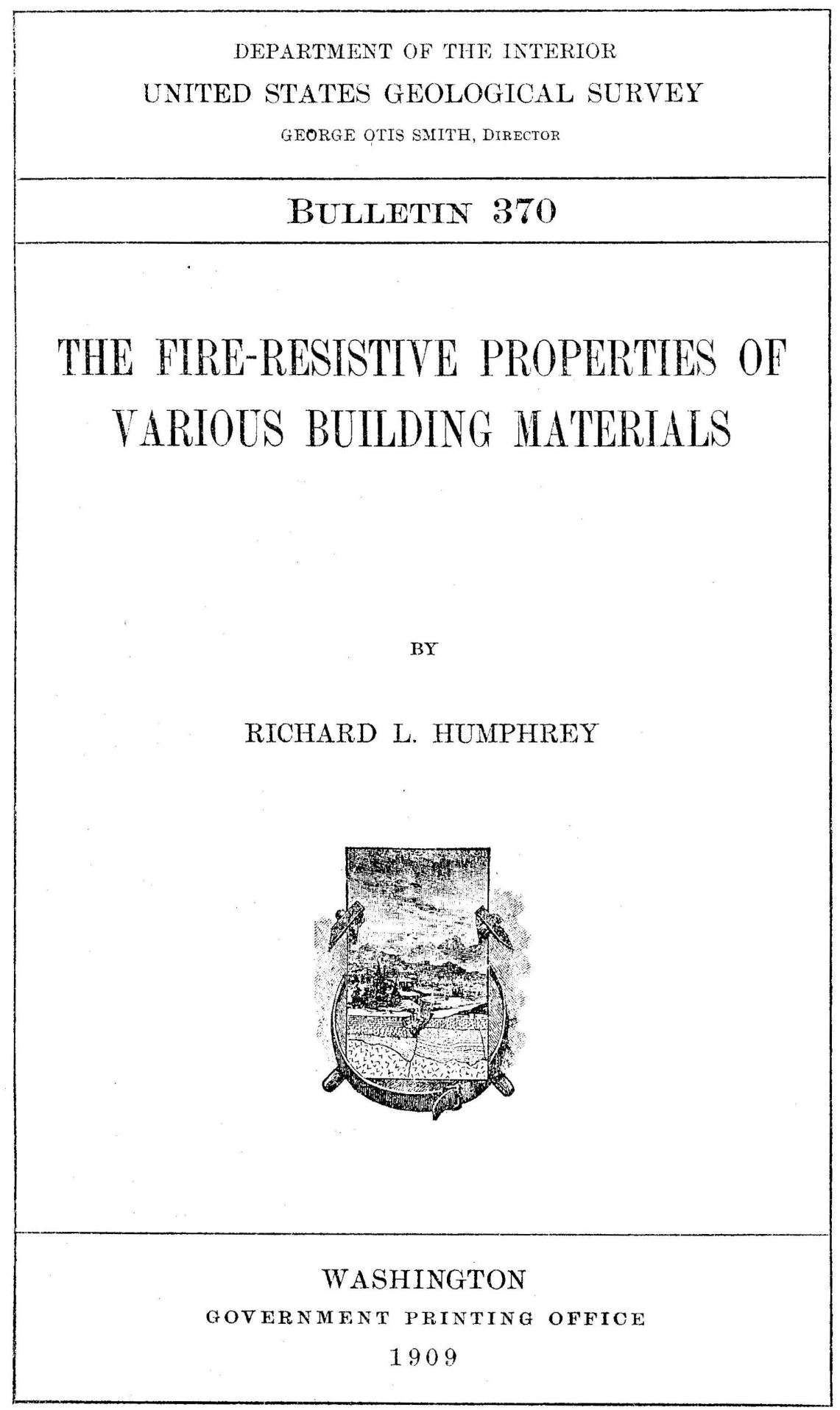



DEPARTMENT OF THE INTERIOR

UNITED STATES GEOLOGICAL SURVEY

GEORGE OTIS SMITH, DIRECTOR

BULLETIN 370

\section{THE FIRE-RESISTIVE PROPERTIES OF VARIOUS BUILDING MATERIALS}

BY

RICHARD L. HUMPHREY

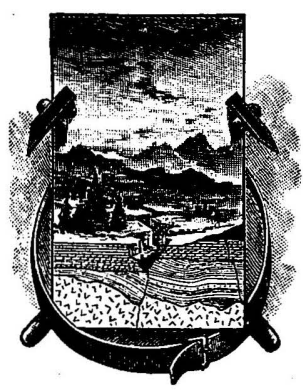

WASHINGTON

GOVERNMENT PRINTING OFFICE

1909

LIBRARY

TEXAS TECHNOLOGICAL COLLEG LUBBOCK, TEXAS 



\section{CONTENTS.}

Page.

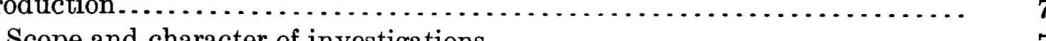

Scope and character of investigations...................... 7

Synopsis of tests. . . . . . . .

Acknowledgments. . . . . . . . . . . . . . . . 12

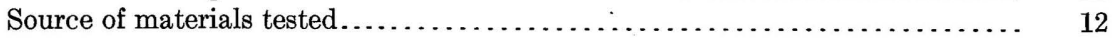

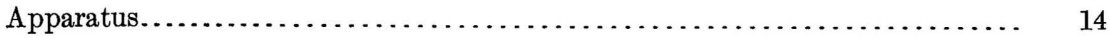

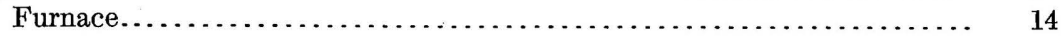

Apparatus for measuring temperatures......................... 15

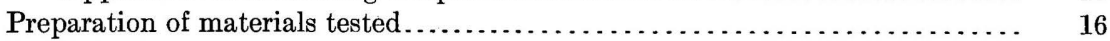

Method of conducting tests.......................... 17

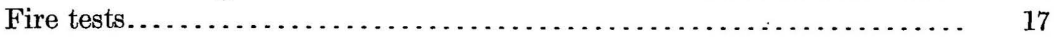

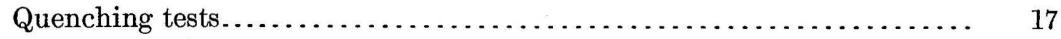

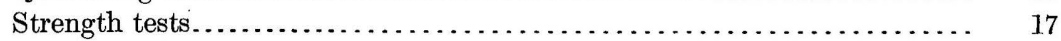

Results of tests. . . . . . . . . .

Panel 1 (mortar building blocks) . . . . . . . . . . . . . . . . . . . 17

Panel 2 (mortar building blocks) . . . . . . . . . . . . . . . . . . . . . $\quad 19$

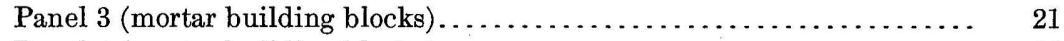

Panel 4 (mortar building blocks) . . . . . . . . . . . . . . . . . . . . . . 23

Panel 5 (mortar building blocks) . . . . . . . . . . . . . . . . . . . . . 25

Panel 6 (mortar building blocks) . . . . . . . . . . . . . . . . . . . . . 25

Panel 7 (mortar building blocks) . . . . . . . . . . . . . . . . . . . . $\quad 27$

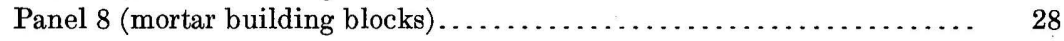

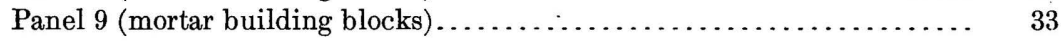

Panel 10 (mortar building blocks) . . . . . . . . . . . . . . . . . . . . . 35

Panel 11 (brick) . . . . . . . . . . . . . . . . . . . . . . . . . . . . . . 37

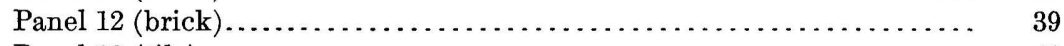

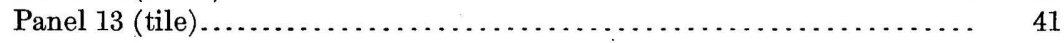

Panel 14 (mortar building blocks)............................. 42

Panel 15 (mortar building blocks). . . . . . . . . . . . . . . . . . . . . 44

Panel 16 (mortar building blocks) . . . . . . . . . . . . . . . . . . . . . 46

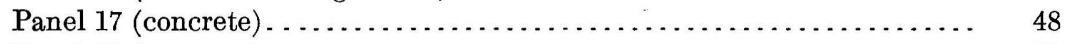

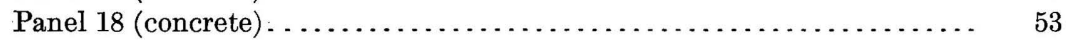

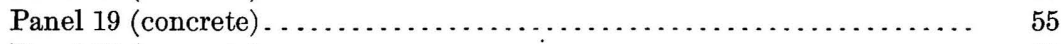

Panel 20 (concrete) . . . . . . . . . . . . . . . . . . . . . . . . . . . . 55

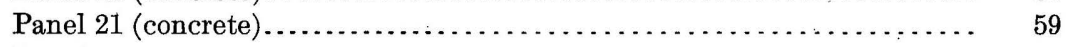

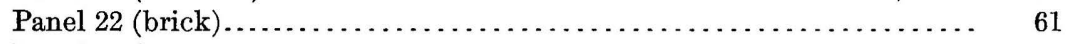

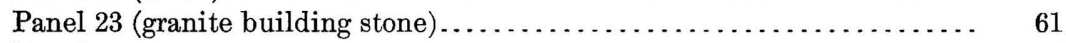

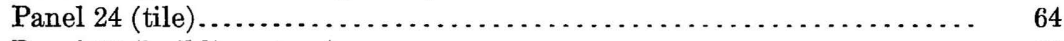

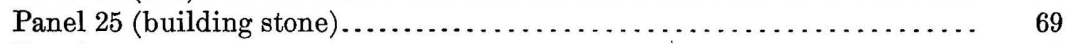

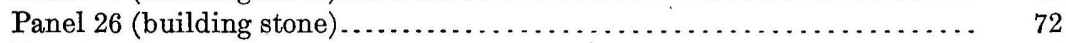

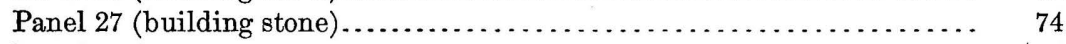

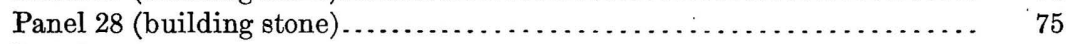

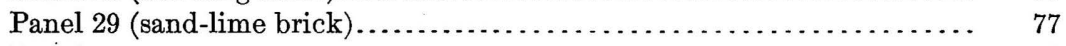

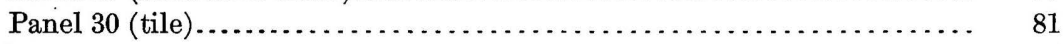

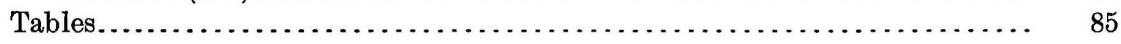

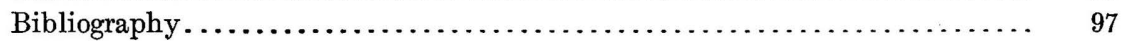




\section{TABLES.}

Table 1. Panel 1: Results of compression tests made on fragments of one-piece double-air-space mortar building blocks after fire test. . . . . . . . .

2. Panel 2: Results of compression tests made on fragments of one-piece single-air-space mortar building blocks after fire test. . . . . . . . . .

3. Panel 3: Results of compression tests made on fragments of one-piece double-air-space mortar building blocks after fire test. . . . . . . . . .

4. Panel 4: Results of compression tests made on fragments of one-piece single-air-space mortar building blocks after fire test. . . . . . . . .

5. Panel 5: Results of compression tests made on fragments of one-piece single-air-space mortar building blocks after fire test. . . . . . . . . . .

6. Panel 6: Results of compression tests made on fragments of one-piece single-air-space mortar building blocks after fire test. . . . . . . . . .

7. Panel 7: Results of compression tests made on fragments of one-piece single-air-space mortar building blocks after fire test. . . . . . . . .

8. Panel 8: Results of compression tests made on fragments of one-piece single-air-space mortar building blocks after fire test. . . . . . . . .

9. Panel 9: Results of compression tests made on fragments of two-piece mortar building blocks after fire test. . . . . . . . . . . . . . .

10. Panel 10: Results of compression tests made on fragments of twopiece mortar building blocks after fire test. . . . . . . . . . . . . . .

11. Panel 11: Physical properties of brick before firing...............

12. Panel 12: Physical properties of hydraulic-pressed brick before

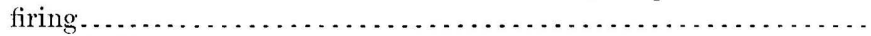

13. Panel 22: Physical properties of common clay brick before firing....

14. Panel 29: Physical properties of sand-lime brick before and after

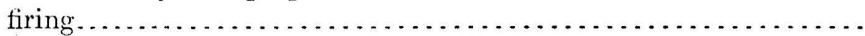




\section{ILLUSTRATIONS.}

Page.

II. $A$, Interior view of furnace; $B$, View of back of panel............ 16

III. View showing method of quenching a panel after firing......... 16

IV. Diagram of thermocouples, cold junction bottles, and galvanometer 16

V. Face views of panels 1 and 2 after cooling.................. 18

VI. Face and back views of panel 3 after quenching.............. 20

VII. Face and back views of panel 4 after quenching.............. 22

VIII. $A$, Panel 4 during dismantling; $B$, Face of panel 5 after quenching. $\quad 24$

IX. Views of panel 5 after quenching and during dismantling....... 24

$\mathrm{X}$. Face and back views of panel 6 after quenching............. 26

XI. $A$, Panel 6 during dismantling; $B$, Face of panel 7 after cooling... $\quad 28$

XII. $A$, Panel 7 during dismantling; $B$, Face of panel 8 after cooling... $\quad 30$

XIII. $A$, Face of panel 9 after quenching; $B$, Panel 8 during dismantling. $\quad 32$

XIV. Views of panel 9 after quenching and during dismantling....... 32

XV. Face and back views of panel 10 after cooling................. 34

XVI. $A$, Panel 10 during dismantling; $B$, Face of panel 11 after quenching. $\quad 36$

XVII. Face views of panels 12 and 13 after quenching.............. 40

XVIII. Back of panel 13 and face of panel 14 after quenching.......... 42

XIX. Views of panel 14 after quenching and during dismantling........ 44

XX. Views of panel 15 after quenching and during dismantling....... 46

XXI. Views of panel 16 after quenching and during dismantling........ 48

XXII. Face and back views of panel 17 after quenching............. 52

XXIII. Face and back views of panel 18 after quenching............. 54

XXIV. Face and back views of panel 19 after quenching............. 56

XXV. Face and back views of panel 20 after quenching............. 58

XXVI. Views of panel 21 before firing and after collapse.............. 60

XXVII. Face views of panel 22 before firing and after quenching........ 60

XXVIII. Face views of panel 23 before and after quenching............. 64

XXIX. $A$, View of stones from panel $23 ; B$, Face of panel 24 after quenching. $\quad 66$

XXX. $A$, Back of panel 24 after quenching; $B$, Face of panel 25 before firing........................................... 70

XXXI. Face and back views of panel 25 after testing............... 72

XXXII. Face views of panel 26 before and after firing................ 74

XXXIII. Face and back views of panel 26 after quenching............. 74

XXXIV. Face and back views of panel 27 after quenching.............. 76

XXXV. $A$, Face of panel 28 after firing and before quenching; $B$, Stones

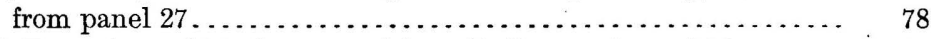

XXXVI. $A$, Face of panel 28 after quenching; $B$, Stones of panel $28 \ldots \ldots \ldots .78$

XXXVII. Face views of panel 29 before and after quenching............ 80

XXXVIII. Face views of panel 30 before and after quenching.............. 82

XXXIX. $A$, Face of panel 30 after quenching, with all loose pieces removed; $B$, Back of panel 30 after quenching..................... 82 
1. Diagram showing temperature conditions of panel 1.... 18

2. Diagram showing temperature conditions of panel $2 \ldots \ldots \ldots \ldots \ldots .20$

3. Diagram showing temperature conditions of panel $3 \ldots \ldots \ldots \ldots \ldots .22$

4. Diagram showing temperature conditions of panel $4 \ldots \ldots \ldots \ldots \ldots .24$

5. Diagram showing temperature conditions of panel $5 \ldots \ldots \ldots \ldots \ldots .26$

6. Diagram showing temperature conditions of panel $6 \ldots \ldots \ldots \ldots \ldots .28$

7. Diagram showing temperature conditions of panel $7 \ldots \ldots \ldots \ldots \ldots . \quad 30$

8. Diagram showing temperature conditions of panel 8.......... 32

9. Diagram showing temperature conditions of panel $9 \ldots \ldots \ldots \ldots \ldots .34$

10. Diagram showing temperature conditions of panel $10 \ldots \ldots \ldots \ldots \ldots . .36$

11. Diagram showing temperature conditions of panel $11 \ldots \ldots \ldots \ldots . . .638$

12. Diagram showing temperature conditions of panel $12 \ldots \ldots \ldots \ldots \ldots .40$

13. Sketch of glazed building tile used in panel $13 \ldots \ldots \ldots . . . . . . .41$

14. Diagram showing temperature conditions of panel $13 \ldots \ldots \ldots \ldots \ldots .43$

15. Diagram showing temperature conditions of panel $14 \ldots \ldots \ldots \ldots \ldots .45$

16. Diagram showing temperature conditions of panel $15 \ldots \ldots \ldots \ldots \ldots .47$

17. Diagram showing temperature conditions of panel $16 \ldots \ldots \ldots \ldots \ldots .49$

18. Diagram showing temperature conditions of panel $17 \ldots \ldots \ldots \ldots \ldots .51$

19. Diagram showing temperature conditions of panel $18 \ldots \ldots \ldots \ldots \ldots .54$

20. Diagram showing temperature conditions of panel $19 \ldots \ldots \ldots \ldots \ldots . \quad 56$

21. Diagram showing temperature conditions of panel $20 \ldots \ldots \ldots \ldots \ldots .58$

22. Diagram showing temperature conditions of panel $21 \ldots \ldots \ldots \ldots \ldots .60$

23. Diagram showing temperature conditions of panel $22 \ldots \ldots \ldots \ldots \ldots .62$

24. Diagram showing temperature conditions of panel $23 \ldots \ldots \ldots \ldots \ldots .65$

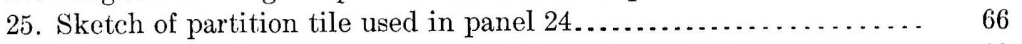

26. Diagram showing temperature conditions of panel $24 \ldots \ldots \ldots \ldots \ldots .68$

27. Diagram showing temperature conditions of panel $25 \ldots \ldots \ldots \ldots \ldots . \quad 71$

28. Diagram showing temperature conditions of panel $26 \ldots \ldots \ldots \ldots \ldots . \quad 73$

29. Diagram showing temperature conditions of panel $27 \ldots \ldots \ldots \ldots \ldots .76$

30. Diagram showing temperature conditions of panel $28 \ldots \ldots \ldots \ldots \ldots . \quad 78$

31. Diagram showing temperature conditions of panel $29 \ldots \ldots \ldots \ldots \ldots . \quad 80$

32. Diagram showing temperature conditions of panel $30 \ldots \ldots \ldots \ldots \ldots . .64$ 


\section{THE FIRE-RESISTIVE PROPERTIES OF VARIOUS BUILDING MATERIALS.}

By Richard L. Humphrey.

\section{INTRODUCTION.}

SCOPE AND CHARACTER OF INVESTIGATIONS.

This bulletin contains the results of tests of thirty panels of various building materials, made by the United States Geological Survey with a furnace in the Underwriters' Laboratories, Chicago, Ill., to determine the effect of fire and subsequent quenching with water on mortar building blocks made of river and slag sands; common, hydraulic-pressed, and sand-lime brick; gravel, cinder, limestone, and granite concrete; glazed building and partition terra-cotta tile; and limestone, sandstone, granite, and marble building stone. The mortar building blocks and the concrete were made in the structuralmaterials testing laboratories; the other materials, except some of the common brick, were obtained in the open market at Chicago, Ill.

The investigations herein reported are a preliminary part of a comprehensive series undertaken with the object of determining the fire-resistive properties and rates of heat conductivity of various building materials and the comparative efficiency of the various methods of fireproofing. These investigations have the further object of greatly lessening the liability of loss by fire in government buildings and greatly reducing their cost through more efficient methods of construction. While the tests are conducted primarily for the purpose of obtaining information of essential value to the Government it is believed that the results will prove to be of much importance to the general public.

The materials were subjected to the direct application of heat for two hours and were then, except in five panels, immediately quenched with water. Wherever possible, tests were made to determine the compressive strength of the materials after this treatment. Temperatures were observed at intervals, and the behavior of the materials during the test and the condition of their surfaces before and after the heating and quenching were noted. Photographs of the panels were taken to show the effects of the tests. 
The tests of the different materials were carried on under as nearly identical conditions as possible, but there was some unavoidable variation in the conditions. The furnace had never been used for such tests, and the operators were inexperienced. The furnace was in almost constant use by the Underwriters' Laboratories, and it was necessary to arrange the tests so as not to interfere with the regular work of those laboratories. It was also necessary to make half the tests in winter and the other half in summer, and many of the building blocks used in the first tests were subjected to freezing weather just prior to testing.

Inasmuch as the tests herein recorded present many features of considerable importance, it has been deemed highly desirable to publish a detailed account of them, although the results are preliminary and inconclusive, and are presented solely for the purpose of making public the information acquired. They should not therefore be used as a basis for drawing conclusions, but merely as preliminary data regarding the relative fire-resistive qualities of the building materials tested.

\section{SYNOPSIS OF TESTS.}

The conditions under which these tests were made were unusually severe and none of the material passed perfectly. The temperatures used would hardly be reached in an ordinary fire. It was recognized from the beginning that these tests would not be comparable with those made by other investigators. The relatively few tests that have been made of the fire-resistive qualities of building materials nearly all consisted of subjecting floor slabs and columns to the heat of a wood fire. There is reason to believe that the tests herein described, made in a gas furnace, are more severe than the tests made with a wood fire, even though the latter show higher temperatures and last longer. In the gas furnace the flames are forced by a blast of air against the panel from the beginning to the end of the test; with a wood fire the heat fluctuates and falls decidedly when the furnace door is opened and fresh fuel is added.

Much of the damage done to the building materials in this series of tests was occasioned by internal stresses, the gas flame heating one face of the test pieces much more rapidly than the other face. All the materials tested, including the hydraulic-pressed brick, cracked more or less. The concrete cracked least, but the tests indicate the necessity for using metal reinforcement in concrete walls to distribute the effect of the expansion.

The average temperature attained by the faces of the panels 10 minutes after the gas was lighted was about $324^{\circ} \mathrm{C}$. $\left(615.2^{\circ} \mathrm{F}\right.$.), and nearly half of the panels had been subjected to freezing weather just prior to the tests. The average temperature of the face of one panel of building blocks rose from $0^{\circ}$ to $450^{\circ} \mathrm{C}$. $\left(32^{\circ}\right.$ to $842^{\circ} \mathrm{F}$.) in 
the first 10 minutes of firing, while that of another panel of the same material ranged from $22^{\circ}$ to $600^{\circ} \mathrm{C}$. $\left(71.6^{\circ}\right.$ to $1,112^{\circ} \mathrm{F}$.) during the same interval.

Although the results obtained from these tests will not be critically analyzed in this bulletin, a few of the more important features will be pointed out.

A fact brought out most clearly by these tests is the low heattransmission rate of Portland cement mortars and concretes. This is one of the desirable qualities in materials intended for fireproofing purposes. For marking the cement blocks linen tags were fastened by wire nails to the interior walls at the time of molding. Most of these tags remained in place during the test, and when the walls were dismantled the tags in every case were found entirely undamaged.

A study of the curves at the bottom of the diagrams (figs. 1-12, 14-24, 26-32) will show the comparatively slight increase in the temperatures of the backs of the blocks during the test. The rise in temperature of the backs of the building blocks made of riversand mortar varied from $25^{\circ}$ to $40^{\circ} \mathrm{C}$. $\left(77^{\circ}\right.$ to $104^{\circ} \mathrm{F}$.), while the rise in the average temperatures of the faces of the cement blocks ranged from $650^{\circ}$ to $900^{\circ} \mathrm{C}$. $\left(1,202^{\circ}\right.$ to $1,652^{\circ} \mathrm{F}$.). The backs of the mortar blocks, made of slag sand, showed a rise of temperature of only $10^{\circ} \mathrm{C}$. $\left(30^{\circ} \mathrm{F}\right.$.), while the faces were heated up to $800^{\circ} \mathrm{C} .\left(1,472^{\circ} \mathrm{F}\right.$.). The low rate of heat conductivity of the mortar blocks is shown by the slowness with which the temperature of the backs of the panels increased in comparison with that of the faces.

An average of all the tests shows that about 90 per cent of the maximum temperatures attained by the faces of the panels were reached in one hour, while in the case of the mortar blocks the increase in temperature of the backs of the panels in one hour was only about 20 per cent of the total increase in the two hours. Of the solid concrete panels the cinder concrete showed the smallest increase in the temperatures of the backs of the walls, and the granite concrete the largest. The total increase in the temperatures of the mortar panels was about the same as the total increase in the temperatures of the backs of the concrete, but the increase in one hour was somewhat greater in the case of concrete.

The damage done to the faces of the mortar and concrete panels would probably be caused at a temperature about half that of the maximum temperatures reached, owing to the water of crystallization being driven from the mortar. This thin layer of dehydrated mortar may have formed a protective coating and prevented deep dehydration.

The backs of the brick panels also showed a small increase in temperature, but the natural building stones and the tiles proved poorer 
nonconductors of heat. The temperature of the back of a panel composed of plastered tiles increased to $128^{\circ} \mathrm{C}$. $\left(262.4^{\circ} \mathrm{F}\right.$.).

It is apparent that the strength of the webs of ordinary hollow blocks is insufficient to resist the stresses set up in these tests, as in many tests the rapid rise in temperature and the subsequent quenching of one of the faces of the blocks caused the webs to split. It was noticeable that the richer the mortars used in these blocks the better they withstood the tests. The amount of water used in mixing the mortars had a similar effect on the fire-resistive qualities; the mortars mixed with the greatest percentage of water gave the best results. This may be clearly seen in the photographs of the mortar blocks after the water treatment, where the wetter, richer mixtures often stand out apparently undamaged, in contrast with the spalled, damaged faces of the leaner, drier blocks.

When blocks were cracked or spalled before the application of the water the damage appeared to be greater in the dry mixtures containing the greatest percentage of sand, and it was further observed during the fire test that the richer mixtures warmed up more slowly than the others. It is apparent that one of the causes of weakness in the hollow cement building blocks under these fire tests was the weakness of the concrete, a too dry and lean mixture, which, coupled with the thinness of the webs, provided insufficient strength to resist the stress due to the rapid expansion of the face. It is quite possible, as was shown in some of the block tests, to make blocks which will pass the conditions perfectly; the web must be thick enough to give the necessary strength.

A close examination of the blocks that had not been quenched showed that the 1:2 blocks were seldom affected by heat to a greater depth than $\frac{3}{4}$ inch, while the 1:8 blocks frequently showed the effect of the fire to a depth of 2 inches. The blocks made of slag sand resisted the test better than those made of river sand. Before the water was applied to the slag-sand blocks no damage was apparent, although it inust be remembered that close examination of the panels between the fire and water treatments could not be made on account of the heat. After the quenching the faces of the $1: 1 \frac{1}{2}$ slag-sand blocks were found to be washed away to a depth of $\frac{1}{4}$ to $\frac{3}{8}$ inch; and those of the $1: 2 \frac{1}{2}$ to a depth of $\frac{1}{2}$ to $\frac{5}{8}$ inch; while the $\frac{1}{4}$ mixtures were damaged only to a depth of $\frac{1}{2}$ to $\frac{3}{4}$ inch. The surfaces were rough and pitted, but hard. In only one block was the web cracked through.

There was great difficulty in getting accurate results from strength tests of irregularly shaped fragments from the backs and fronts of blocks after the fire and quenching tests, and the results are too inconsistent to be conclusive. The average compressive strength of the faces of blocks was about two-thirds to three-fourths of that of their backs, varying with the proportions and consistencies. 
The brick panels probably withstood the tests better than the other materials. The common brick tested comprised unused new Chicago brick, and used St. Louis brick. Fifty per cent of the new bricks were split, while 60 to 70 per cent of the old bricks were not damaged. Lime knots seemed to be responsible for most of the damage to the new bricks, as they were found at the bottom of nearly all the cracks. The bricks at the back of the panels were entirely unaffected. While the strength tests are not conclusive, there is apparently little difference in the strength of these bricks before and after firing.

The hydraulic-pressed brick withstood the test very well. No damage was apparent after the firing and before the water was applied, and although a number of the bricks cracked, 70 per cent of them were found to be sound after quenching.

The sand-lime brick did not withstand the test as well as expected, but the sample tested, which was purchased at random, appeared to be somewhat below average quality.

It was difficult to determine whether the limestone, granite, gravel, or cinder concrete sustained the least damage. The faces of all the panels were more or less pitted by the fire and washed away by the stream of water. The test was unfair to the cinder concrete, as the cinder was very poor, containing a large percentage of unburned coal; however, the sample selected was the best of six or eight investigated in St. Louis. During the fire test the coal ignited and left the surface of the concrete very rough and badly pitted. The limestone aggregate in the face calcined, and the granite aggregate split and broke away from the surface mortar. The granite concrete probably behaved the best. The damage in no case extended deeply, probably not more than $1 \frac{1}{2}$ inches. The evidence shows that even at this depth the temperature was comparatively low. The high stresses produced in the panels by the rapid rise of temperature of the faces while the backs remained cool caused cracks. On taking down the panels the blocks of concrete were found to be cracked vertically for some distance back from the face.

The serious damage to the various natural building stones precludes any comparison among them.

The tile tested was bought in the open market, and in one panel was taken from a lot of material about to be erected in a building. Large percentages of the faces of the tiles were washed away by the water, and the material composing the faces became soft and could be easily crumbled in the fingers. There was a comparatively rapid rise in the temperature of the back of the panels. The plaster on the panel of partition tile fell off a few minutes after the test was started.

Heretofore fire tests of building material have been made at random and scarcely any two tests are comparable one with the other; 
it is therefore hoped that the next series of tests made in this type of furnace, where with the experience gained the conditions can be more closely controlled, will lead to much more valuable results.

\section{ACKNOWLEDGMENTS.}

These investigations were made possible through the hearty cooperation and proffer of facilities by the Underwriters' Laboratories, Inc., located at 382 Ohio street, Chicago, Ill. The courtesies and cooperation of Prof. R. Burnham, of the Armour Institute, in whose laboratories the compression tests on the treated test pieces were made, are hereby acknowledged.

The building-block machines used in making the mortar blocks were selected by a special committee of the United Concrete Block Machinery Manufacturers' Association; the machines represented different types and were loaned through the courtesy and cooperation of the following companies:

American Hydraulic Stone Company, Denver, Colo.
Cement Machinery Company, Jackson, Mich.
Dykema Company, Grand Rapids, Mich.
Miracle Pressed Stone Company, Minneapolis, Minn.
P. B. Miles Manufacturing Company, Jackson, Mich.

The cement used in the building blocks and the concrete was a mixture of a number of brands of cement which were donated by the following companies:

Atlas Portland Cement Company, Hannibal, Mo.

Edison Portland Cement Company, New Village, N. J.

Iola Portland Cement Company, Iola, Kans.

Lehigh Portland Cement Company, Mitchell, Ind.

Omega Portland Cement Company, Jonesville, Mich.

St. Louis Portland Cement Company, St. Louis, Mo.

Virginia Portland Cement Company, Fordwick, Va.

The sand referred to as "Meramec River sand," used in the building blocks and concrete, was contributed by the Union Sand and Material Company, of St. Louis, Mo. The slag sand used in a few of the blocks was contributed by the Carnegie Steel Company of Pittsburg, Pa.

\section{SOURCE OF MATERIALS TESTED.}

Common brick.- - Two samples of common brick were tested, one a Chicago brick selected in the yard of the makers, and the other a St. Louis brick taken from the foundation of a dismantled briquetting machine of the Government's fuel-testing plant, Forest Park, St. Louis, Mo.

Fydraulic-pressed brick.-The hydraulic-pressed brick was manufactured in Indiana and taken from a pile being used in the construction of a building in Chicago. 
Sand-lime brick.-The sand-lime brick was manufactured in Indiana and taken from a stock pile in Chicago.

Mortar building blocks. - The building blocks were molded at the Government's structural-materials testing laboratories, St. Louis, Mo., on five different designs of machines representing distinct types.

The blocks in tests 1 to 10 , inclusive, were made of sand dredged from Meramec River at Drake, Mo., and "typical Portland" cement. They were made in three different consistencies, damp, medium, and wet; and in three proportions, $1: 2,1: 4$, and $1: 8$. A'n equal number of each consistency made in the three proportions were tested in the same panel.

The Meramec River sand was of average quality and free from. silt, its grading being quite uniform. The results of a large number of tests with this sand and a description of the "typical Portland" cement, which is a thorough mixture of a number of brands, are given in Bulletin 331. ${ }^{a}$

The blocks in panel 14 were of "typical Portland" cement and slag sand, made of medium consistency and in the proportions of $1: 1 \frac{1}{2}, 1: 2 \frac{1}{2}$, and $1: 4$.

In panels 15 and 16 were tested two parallel series of Meramec sand blocks of medium consistency, mixed in proportions of $1: 2,1: 4$, and 1:8; those in panel 15 were cured in the moist room, while those in panel 16 were cured in dry air. These last two sets of blocks and the slag-sand blocks were made on the single-air-space type of machine only.

Terra-cotta tile.-Two kinds of terra-cotta tile were tested, one a hollow glazed building tile, 8 by 8 by 16 inches, having a $\frac{1}{2}$-inch web, with four core holes running throughout its length, and the other a partition tile, 5 by 12 by 12 inches, having a $\frac{5}{8}$-inch web and three core holes. The former tiles were taken from a stock pile in Chicago; the latter were obtained by purchase from a lot of material that had been delivered by the manufacturers at the site of a building in course of construction in which they were being used for fireproofing.

Concrete.-The concretes tested were pieces of broken beams that had been tested in the Government's structural-materials testing laboratories at St. Louis, Mo. The pieces were 8 by 11 inches in cross section and of various lengths. They were fired with the 11-inch face exposed. In making the concretes four distinct types of aggregate had been used-limestone, granite, gravel, and cinder. The aggregate was sized to pass a 1-inch screen and be retained on a $\frac{1}{4}$-inch screen. The concretes had been mixed in proportions of 1 of cement, 2 of Meramec River sand, and 4 of aggregate, and were of medium consistency.

$a$ Humphrey, Richard L., and Jordan, William, jr., Portland cement mortars and their constituent materials: Bull. U.S. Geol. Survey No. 331, 1908. 
The limestone was obtained in St. Louis, Mo. The gravel was dredged from Meramec River at Drake, Mo.; it was clean, hard, and flinty. The granite was the red granite from Graniteville, Mo. The cinder, obtained from a large power house in St. Louis, was poor, containing 24.5 per cent of combustible material.

Building stone.-The four kinds of building stone tested-sandstone, limestone, marble, and granite-were obtained by purchase in the open market in Chicago, Ill. There were two kinds of limestone, one the Bedford limestone (Carboniferous) from Bedford. Ind., and the other a Niagaran magnesian limestone from Joliet, Ill, The sandstone was from the Carboniferous at Cleveland, Ohio. The marble was from Georgia, and the granite from Thousand Islands, Canada, except one sample of a granite from Maine, which was reported to be such as was used in the construction of the post-office building in Chicago, Ill.

\section{APPARATUS.}

Furnace.-The apparatus in which these tests were made is similar to that generally used in determining the fire-resistive qualities of fire doors and windows. It comprises a gas furnace with a movable steel-frame fire-brick wall or door 14 inches thick (A, Pl. I, $A$ ) that shuts off the furnace from a radiation chamber. The distance between the permanent back wall of the furnace and the movable wall is $13 \frac{1}{2}$ inches. The movable wall is hung from the lower flange of an I beam by rollers and is easily moved out of position by a weight (B, Pl. I, A) attached to a wire cable. The wall has an arched opening 6 feet wide and 9 feet high. The material to be tested is built up in this opening as a panel (PI. I, $B$ ).

The stationary back wall of the furnace contains holes through which air is admitted to control the temperature. Back of this wall are piping and valves for the control of the air and gas supply (Pl. I, $A$ ). The air pressure for the flame is maintained by a motor-driven fan (D, Pl. I, $A)$. Gas enters the fire chamber at the bottom through burners which are below the level of the floor and do not show in the accompanying view of the interior of the furnace (Pl. II, $A$ ). The piping against the face of the wall in this view is a water pyrometer.

When a panel is ready for testing it is drawn into position in front of the main wall by a hand winch (C, Pl. I, $A$ ) and held there by a latch. The opening around the edges is sealed by fire clay. Then the gas is turned on and lighted by a torch inserted through a small door (E, Pl. I, A). The observer can watch the behavior of the furnace and the materials under test through three small mica peep holes in the sides of the furnace (F, Pl. I, $A$ ).

At the end of the heat treatment the latch is released and the weight at once draws the wall from the furnace. In a regular test the material in the panel is immediately quenched with water from a nozzle. 


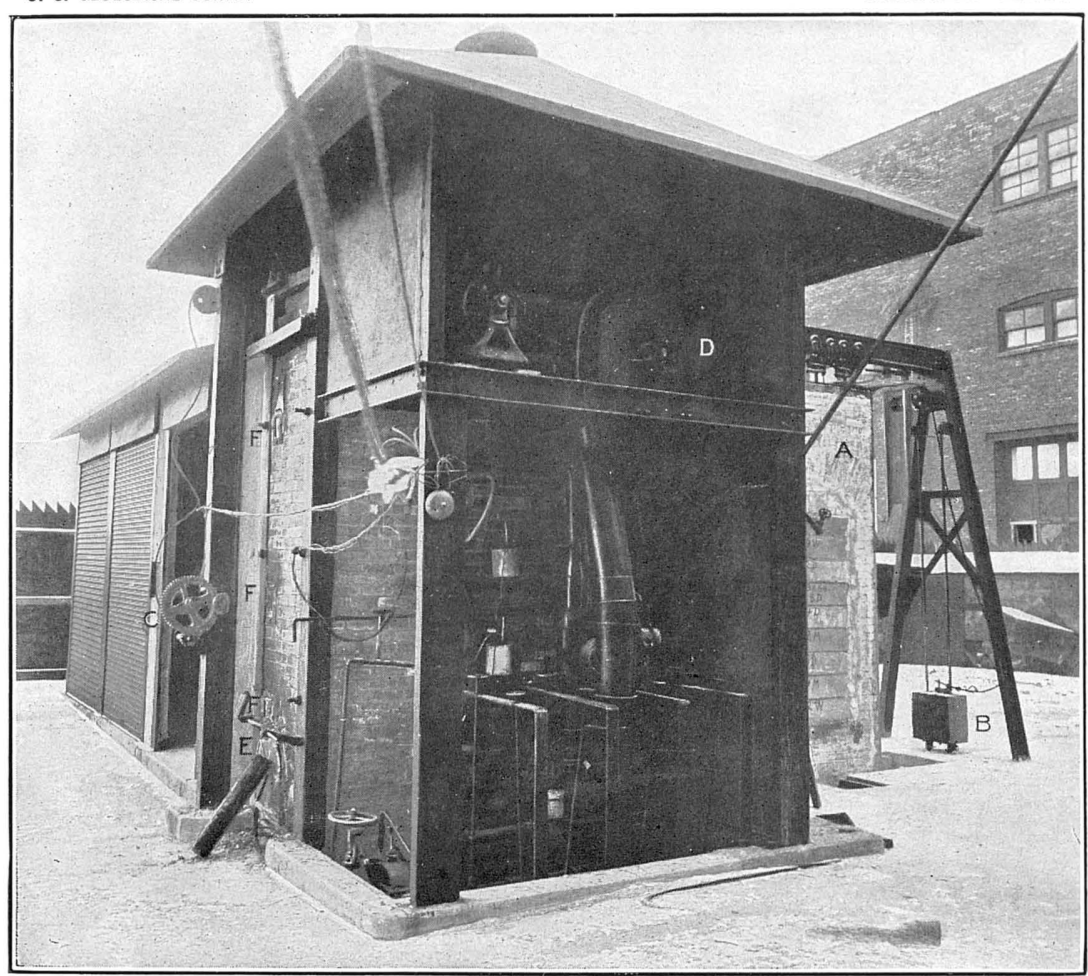

A. WEST VIEW OF FURNACE, SHOWING RADIATION CHAMBER AND PANEL (A) IN POSITION FOR QUENCHING.

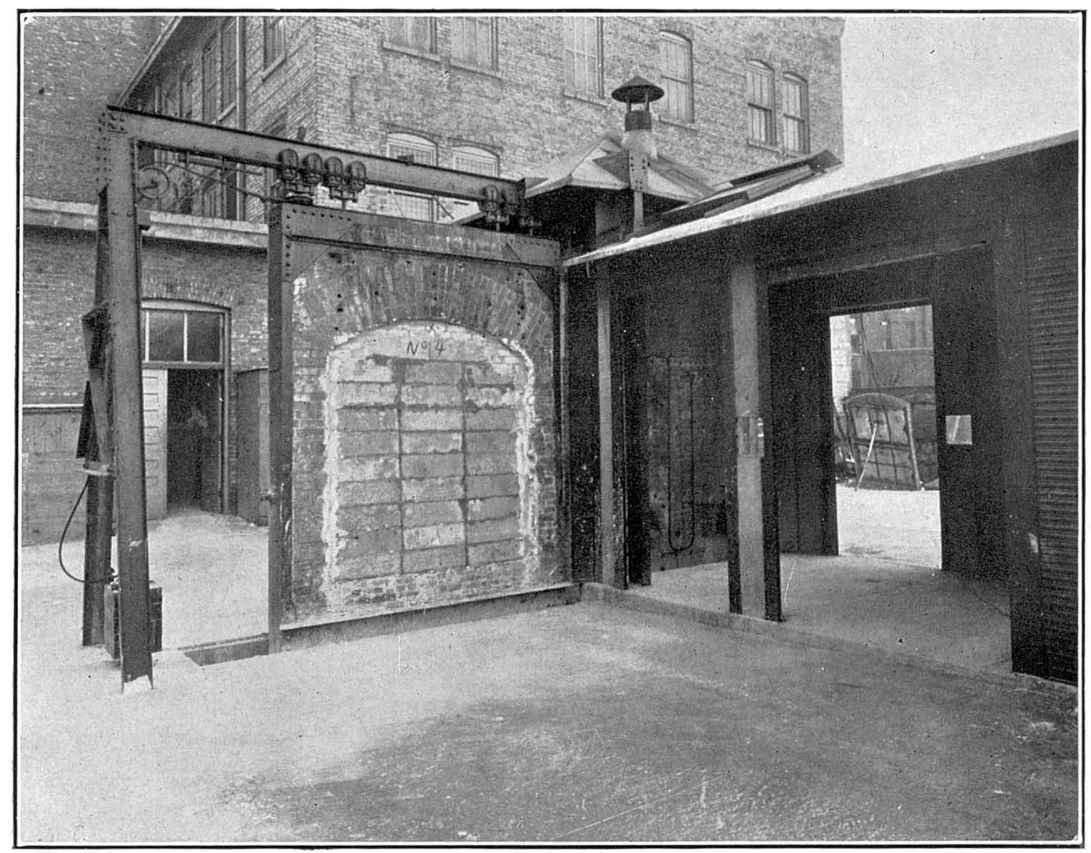

B. SOUTHEAST VIEW OF FURNACE, SHOWING FIRE CHAMBER AND PANEL BUILT UP IN MOVABLE WALL. 

Throughout this bulletin the side of the panel subjected to the heat of the furnace is referred to as the face of the panel; the opposite side, which is exposed to the air, is referred to as the back of the panel.

Apparatus for measuring temperature.-The temperatures of the furnace and of the face of the panel during the tests herein described were determined by means of platinum and iridium thermocouples; the temperatures of the back of the panel were measured by means of mercury thermometers. In addition, the average temperature of the interior of the furnace was found by the water pyrometer.

Four thermocouples were inserted through the back wall into the furnace chamber, each extending through a steel tube $3 \frac{1}{2}$ inches long and $\frac{3}{8}$ inch in diameter. Smaller clay tubing surrounded the couples and protected them from the steel tubing. The couples projected into the fire chamber about $4 \frac{1}{4}$ inches, but only the point of each couple, about $\frac{3}{8}$ inch, was exposed, the rest of the $4 \frac{1}{2}$ inches being protected from the fire by a cone of fire clay.

The temperatures of the face of the panel were measured by six thermocouples incased in clay tubing that passed through $\frac{3}{8}$-inch steel tubing laid in the mortar joints. The ends of the tubes extended within $\frac{1}{2}$ inch of the face of the panel, and the points of the couples were placed about $\frac{1}{16}$ inch back from the face and surrounded with a thin coating of fire clay. To the free ends of the couples were soldered pieces of copper wire about 3 feet long; cold junction bottles were used to keep the soldered junctions of the ends of the couples and the copper wire at a constant temperature. These bottles had large mouths closed by corks and were filled with water and surrounded with magnesia pipe covering. Through each cork were inserted two test tubes, about 6 inches long, and a thermometer. Each test tube held a junction. From the bottles the copper wires led through a switch to an Englehardt galvanometer. Prior to the tests the thermocouples were calibrated against this instrument.

The general arrangement of the thermocouples, cold junction bottles, switch, and galvanometer is shown in Plate IV. Plate II, $B$, shows the thermometers and cold junction bottles in position at the back of a panel.

The temperatures of the back of each panel, taken to determine the rate of heat transmission, were measured by thermometers held in contact with the surface of the panel by small lumps of fire clay.

The temperatures recorded by each couple, the water pyrometer, the thermometers against the back of the panels, and the thermometers in the junction bottles were platted after each test (figs. 1 to 12 , 14 to 24,26 to 32 ). The curve drawn through the platted points represents the average in each test. 
The Weather Bureau records of the minimum and maximum air temperatures, the humidity, and the wind direction for the particular day of each test are given below the diagrams showing the above curves.

\section{PREPARATION OF MATERIALS TESTED.}

Preparation of building blocks.-The methods used in molding and curing the concrete building blocks at the Government's structural-materials testing laboratories are described in Bulletin 329. ${ }^{a}$ The proportions, while stated in parts by volume, were actually by weight, allowance being made for the percentage of moisture in the sand, which was determined as used. The mixing was done in a $\frac{1}{3}$ cubic yard Chicago cubical concrete mixer, the sand and cement being thoroughly mixed before the water was added. The three consistencies, indicated by the terms "damp," "medium," and "wet," are defined as follows: (1) In damp consistency the per cent of water used gives the driest mixture which can be handled in all five types of block machines; (2) medium consistency is halfway between damp and wet consistencies; (3) in wet consistency the percentage of water used gives the wettest mixture which can be handled.

All the blocks, with the exception of those made on an American Hydraulic Stone Company machine, a pressure machine, were hand tamped, and great care was taken to tamp them all in the same manner and for the same length of time. The blocks in any one batch were not permitted to vary more than 1 per cent in weight. They remained on the pallets 60 hours, and then, with the exception of a set left in the air of the laboratory, were placed in a moist room, where they were sprinkled at 8-hour intervals.

For transportation to Chicago the blocks were packed in straw in a refrigerator car, and the car was filled with live steam and sealed. On reaching the Underwriters' Laboratories they were piled in a warm, dry room until tested. The length of time that each set of blocks remained in the moist room, in the car, and at the Underwriters' Laboratories is noted in the description of each test.

The blocks were built up in the panel without breaking the joints, in order to obviate the necessity of cutting any of the blocks.

Preparation of concrete.-The concrete, consisting of portions of unreinforced beams which had been tested, was stored in a moist room and sprinkled at 8-hour intervals, both before and after it was tested. For a description of the method of mixing and molding the concrete, see Bulletin 329.

Preparation of building stone, brick, and tile.-These building materials were placed in the panel, as nearly as space would allow, in exactly the same way that they would be laid in the wall of a building.

$a$ Humphrey, Richard L., Organization, equipment, and operation of the structural-materials testing laboratories at St. Louis, Mo.: Bull. U. S. Geol. Survey No. 329, 1908. 


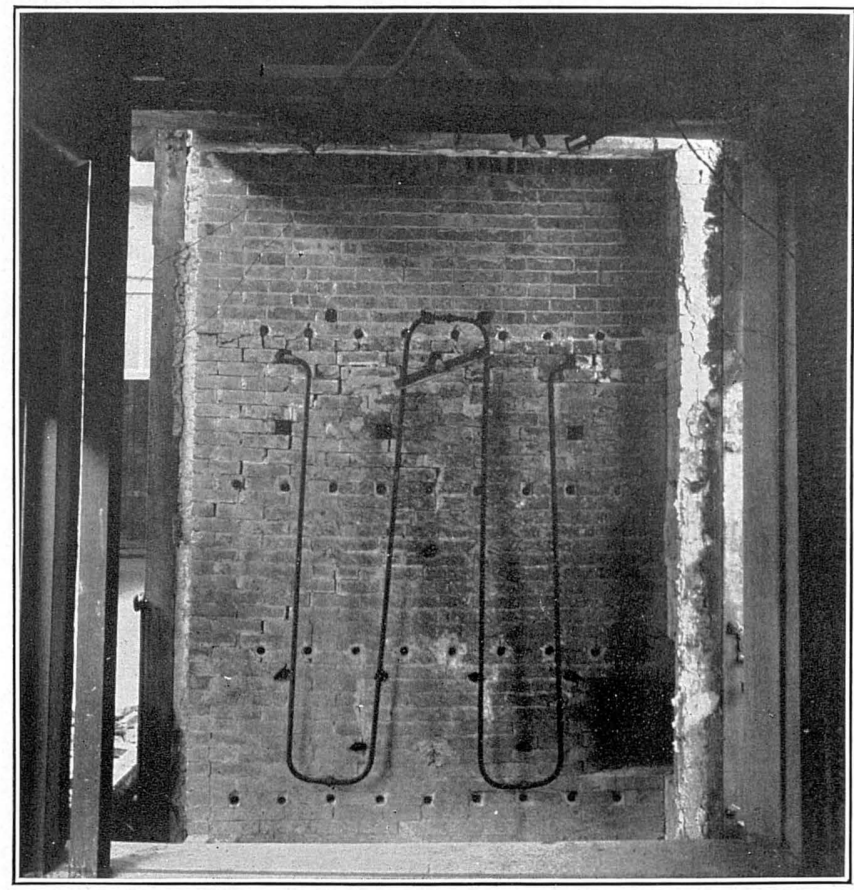

A. VIEW OF FURNACE WITH PANEL REMOVED, SHOWING SECONDARY AIR INLETS AND WATER PYROMETER.

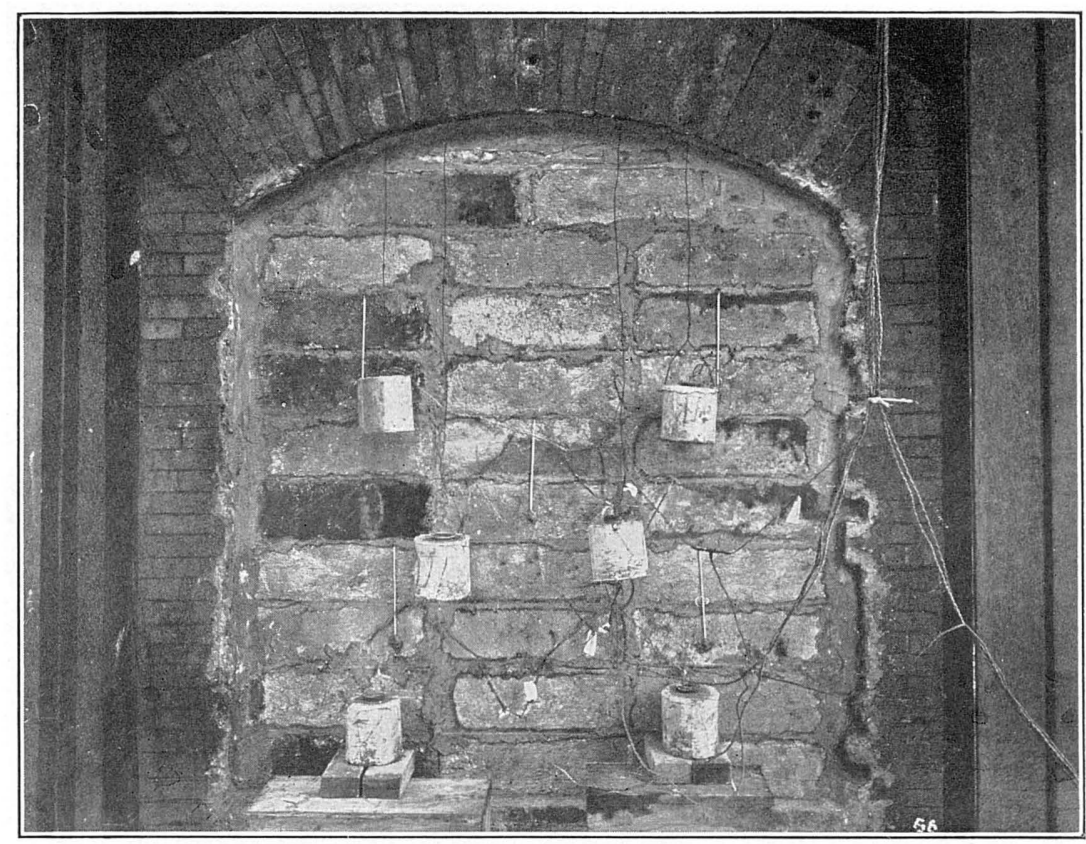

B. VIEW OF BACK OF PANEL, SHOWING THE COLD JUNCTION BOTTLES AND THERMOMETERS IN PLACE. 



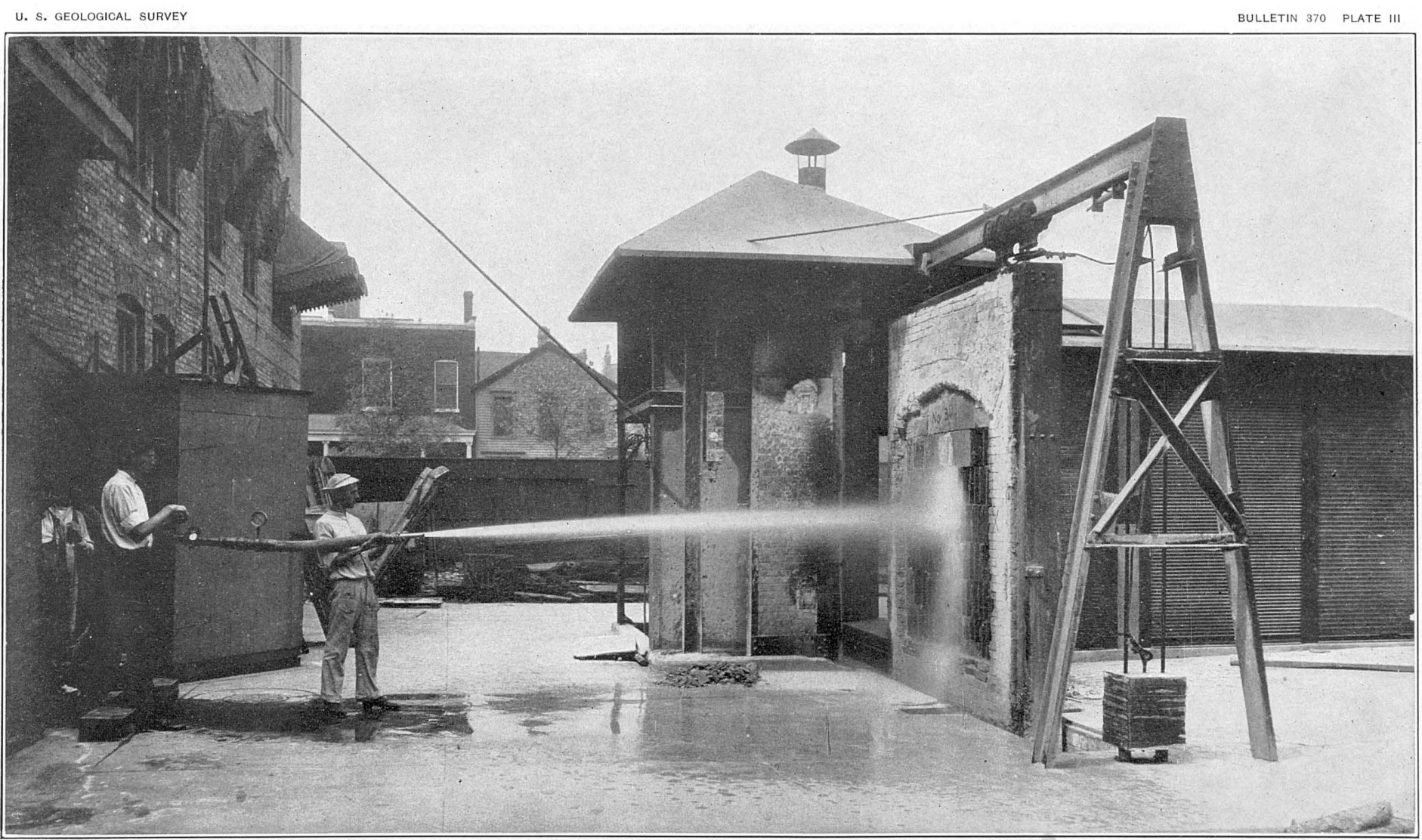

VIEW SHOWING THE METHOD OF QUENCHING A PANEL AFTER BEING SUBJECTED TO FIRE. 



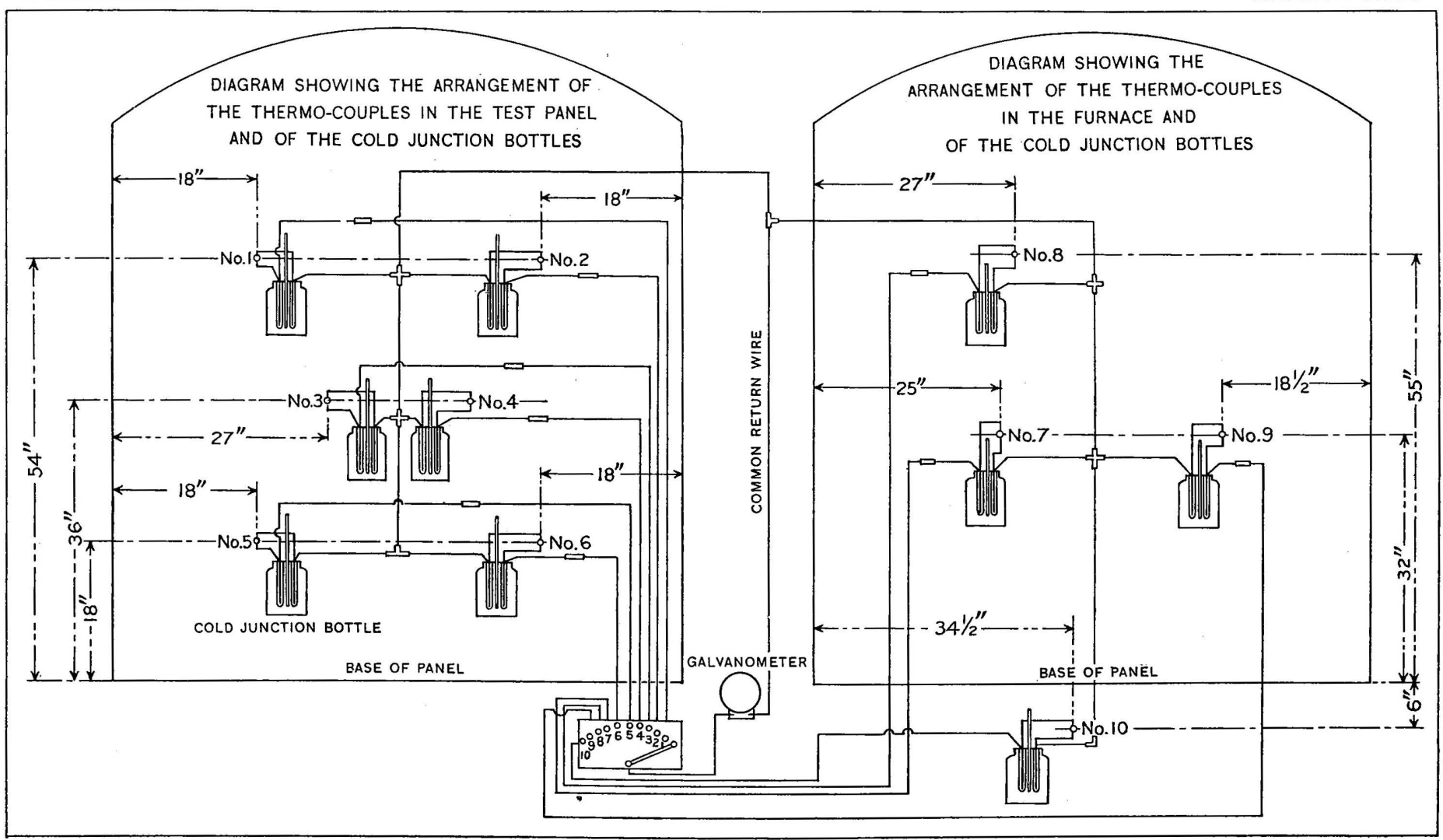

DIAGRAM SHOWING THE ARRANGEMENT OF THERMOCOUPLES, COLD JUNCTION BOTTLES, AND GALVANOMETER. 



\section{METHOD OF CONDUCTING TESTS.}

Fire tests.-The test wall with the panel filled with the material to be tested was allowed to dry out for several hours, and was then drawn into position by means of the winch, and latched. The openings around this wall and the furnace were sealed up with fire clay. The pyrometers were then placed in position in the joints and the thermometers were attached to the back of the panel, as shown in Plate II, $B$. The wires from each thermocouple (Pl. IV) led to a 10-point switch, connected with the galvanometer, placed on a table a short distance back of the panel. One of the operators, seated at this table, recorded the readings of the galvanometer on each of the ten couples at 10-minute intervals; the other operator regulated the supply of gas and air, read the thermometers, and noted the behavior of the furnace and of the panel under test.

An effort was made to obtain the maximum temperature $\left(1,700^{\circ} \mathrm{F}\right.$.) within one-half hour after starting the test, and to maintain this temperature as nearly constant as possible throughout the succeeding time. At the end of 2 hours the thermometers, thermo-couples; and cold junction bottles were quickly removed, the gas turned off, and the latch raised, allowing the wall to be pulled out by means of the counter weight.

Quenching tests.-As soon as the wall was free from the furnace the face of the panel which had been exposed to the heat was quenched by a stream of water. The water was applied for 5 minutes at a pressure of 50 pounds to the square inch through a $\frac{7}{8}$-inch nozzle held 20 feet from the face of the panel (Pl. III). The average interval between shutting off the gas and applying the water was 1 minute. Photographs were taken of the face and back of the panel both before and after the test.

Strength tests.-As soon as the panel had become cool enough to permit handling the test pieces, it was dismantled and such test pieces as could be obtained were hauled to the Armour Institute, Chicago, where they were tested for compressive strength by a 200,000-pound Olsen testing machine. The results of the strength tests are given in Tables 1 to 10, inclusive.

\section{RESULTS OF TESTS.}

\section{PANEL 1 (Mortar Building Blocks).}

Material.-Panel 1 was composed of 27 "typical Portland" cement and Meramec River sand one-piece double-air-space blocks, laid up in fire clay without breaking joints. There were three blocks each, of $1: 2,1: 4$, and 1:8 mixtures, damp, medium, and wet. The blocks had been stored in a moist room and sprinkled twice daily at the St. Louis laboratories 52 days, packed in straw in a refrigerator car which was 73087-Bull. 370-09-2 


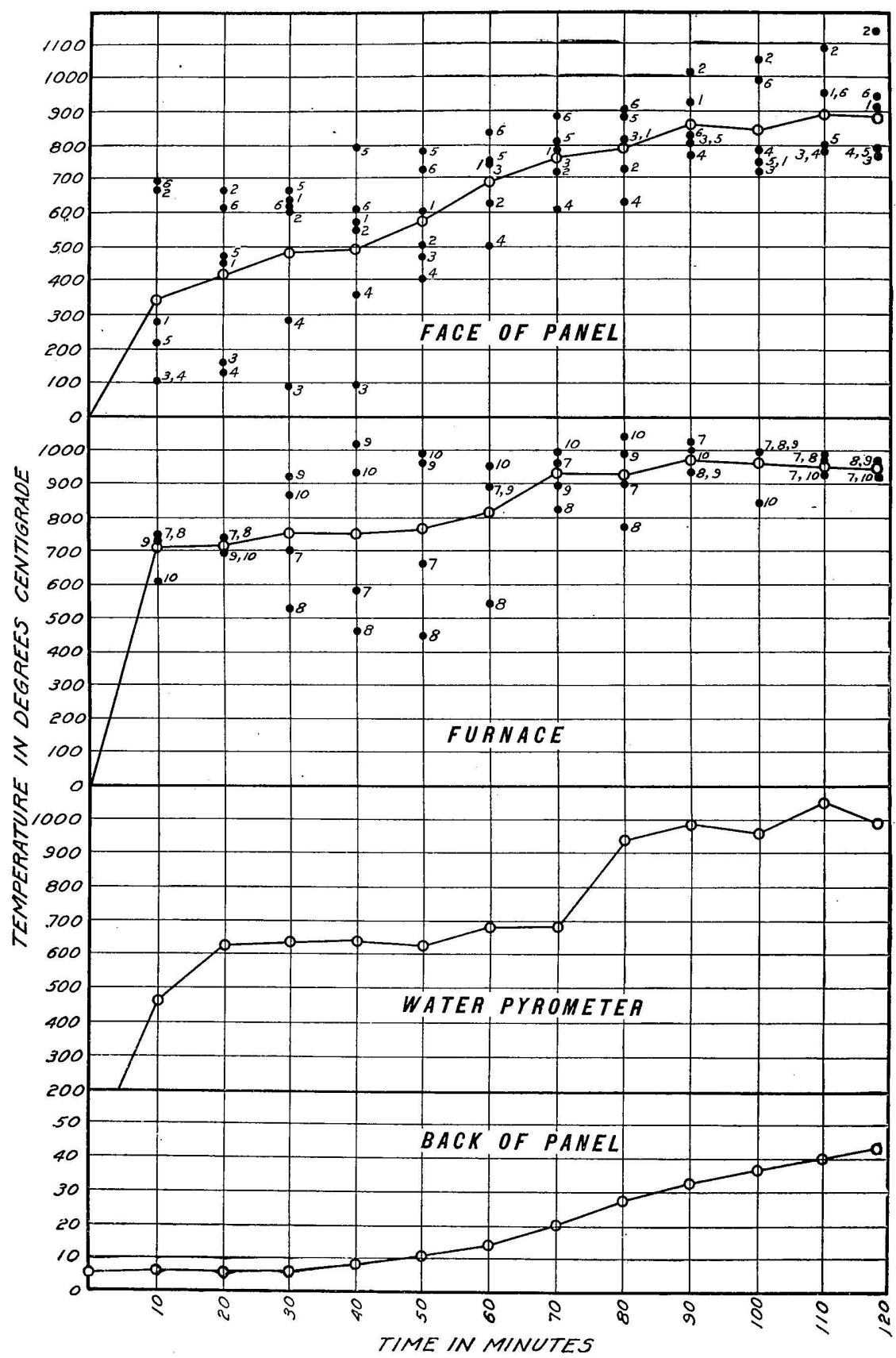

Figure; 1.-Diagram showing temperature conditions in the furnace and on the back of panel 1. Temperature: Maximum, $34^{\circ}$; minimum, $28^{\circ}$; mean, $31^{\circ}$. Relative humidity: 7 a. m., $95 ; 7$ p. m., s6. Direction of prevailing wind, east. 
U. S. GËOLOGICAL SURVËY

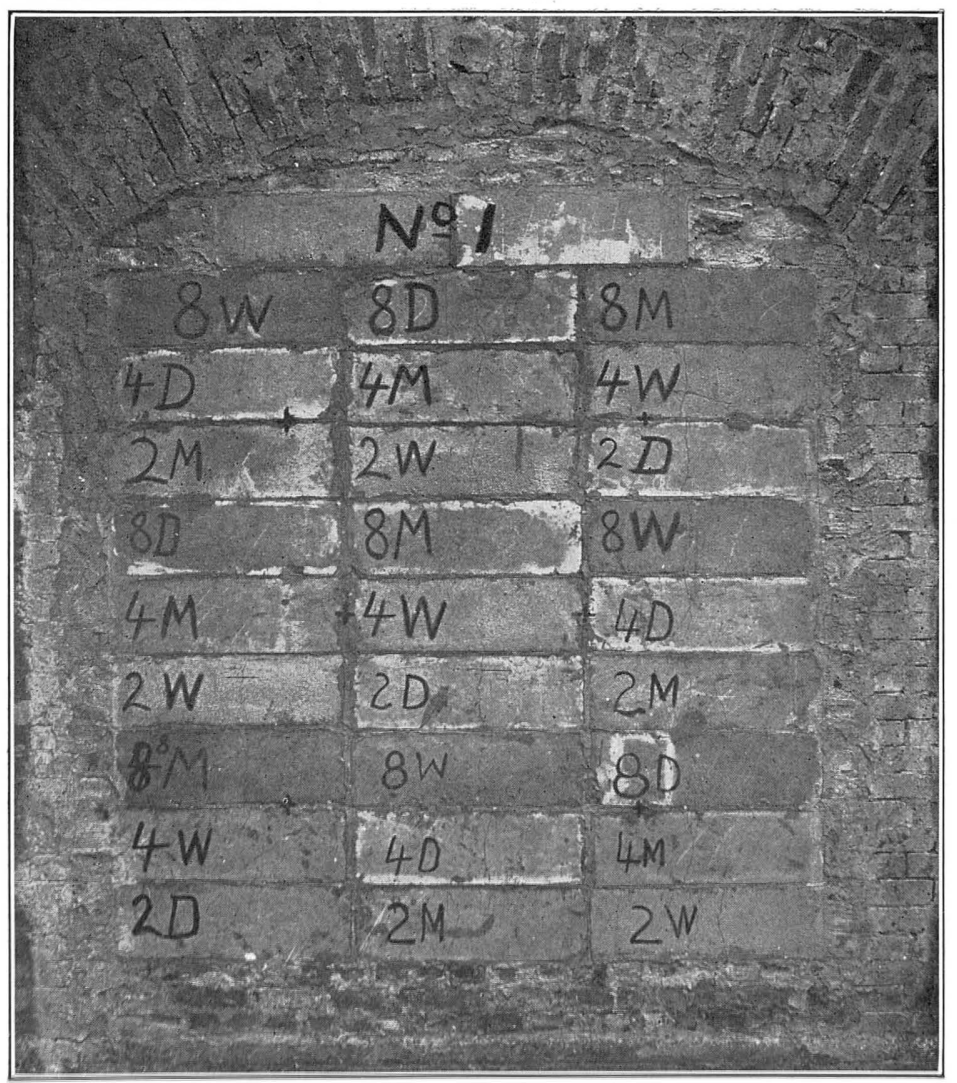

A. FACE OF PANEL 1, CEMENT MORTAR BUILDING BLOCKS, AFTER COOLING IN AIR.

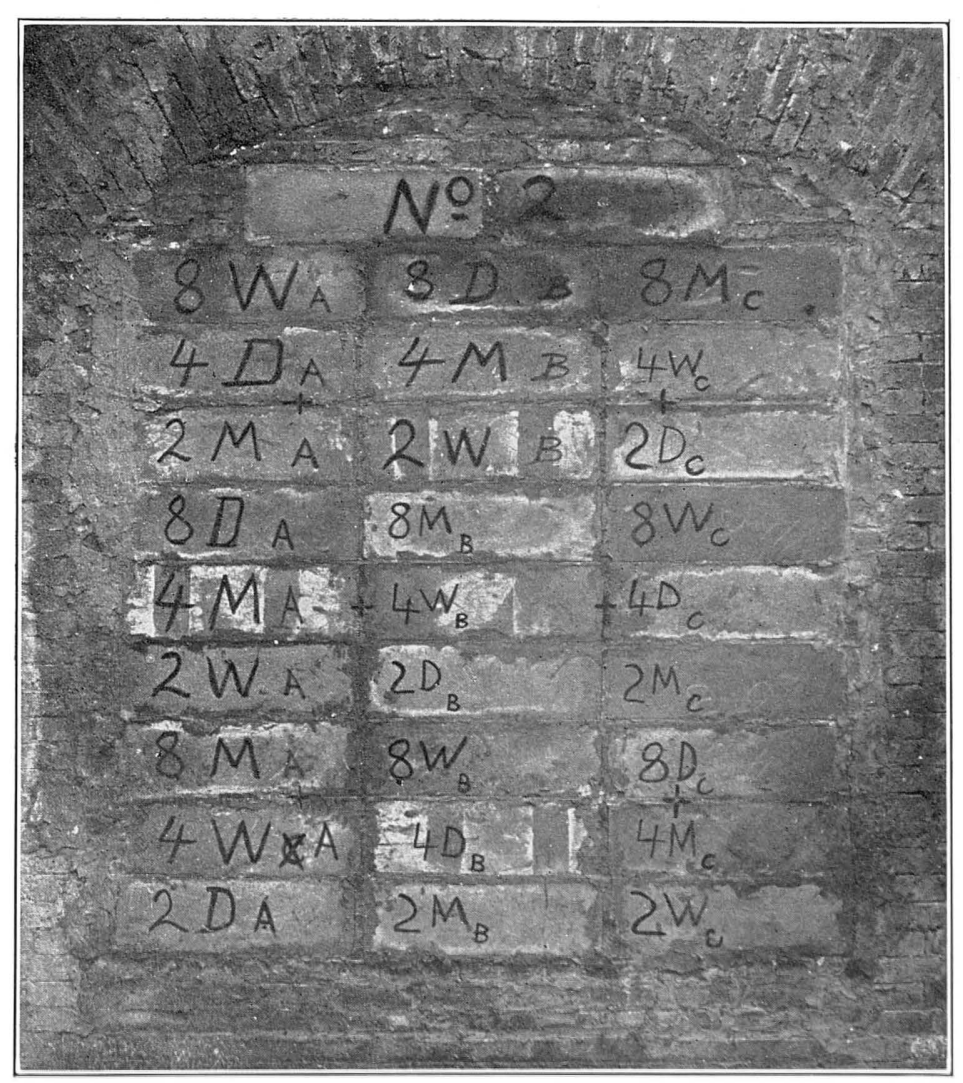

B. FACE OF PANEL 2, CEMENT MORTAR BUILDING BLOCKS, AFTER COOLING IN AIR. 

en route to Chicago 3 days, stored in a warm room in the Underwriters' Laboratories 8 days, and were finally tested at the age of 63 days. The panel was laid up in freezing weather.

Test.-Firing started at 2:10 p. m. January 17, 1907, and continued for 2 hours $3 \frac{1}{2}$ minutes. The panel was cooled in air after the test without the application of water.

In 38 minutes steam appeared through the joints at the top of the panel. At the expiration of 55 - minutes the blocks began to sweat; particularly those of $1: 2$ and $1: 4$ proportions. The top of the panel was warmer than the middle and the lower portions, especially the 1:8 blocks. The back of the $1: 8$ blocks felt warmer than the backs of those of the richer mixtures.

The variations of temperature of the furnace, determined by the water pyrometer and the thermocouples, of the temperature of the face and back of the panel, and of the cold junction bottles are shown in figure.1.

Results.-Plate V, A, shows the face of the panel after cooling. Vertical cracks along the webs, clearly shown in the plate, developed in each row of blocks. There were no signs of spalling. The surface of the 1:8 blocks could be rubbed away easily with the finger, that of the 1:2 blocks with difficulty. The faces of the $1: 2$ blocks were discolored by the heat to a depth of $\frac{1}{2}$ to $\frac{3}{4}$ inch, that of the $1: 4$ to a depth of about $\frac{1}{2}$ to 1 inch, and that of the $1: 8$ to a depth of about $1 \frac{1}{2}$ to 2 inches. The damp, medium, and wet consistency blocks showed no difference in appearance. The back of the panel showed no apparent change.

On dismantling the panel it was found that every block had cracked across the web and split out at the face, leaving the inner web intact. All consistencies and proportions failed in about the same manner.

The results of the compression tests on the fragments of blocks after the fire tests are given in Table 1.

PANEL 2 (Mortar Building Blocks).

Material.-Panel 2, one-piece single-air-space blocks, was made up the same as panel 1, but had been in the St. Louis laboratories one day less and in Chicago one day more.

Test.-Firing started at 3.11 p. m. January 18, 1907, and continued for 2 hours 1 minute. The panel was cooled in air without application of water.

In 30 or 40 minutes after starting steam began to come through the mortar joints. At 60 minutes the back of the wall began to sweat and to get warm to the hand, getting warmer faster at the top 


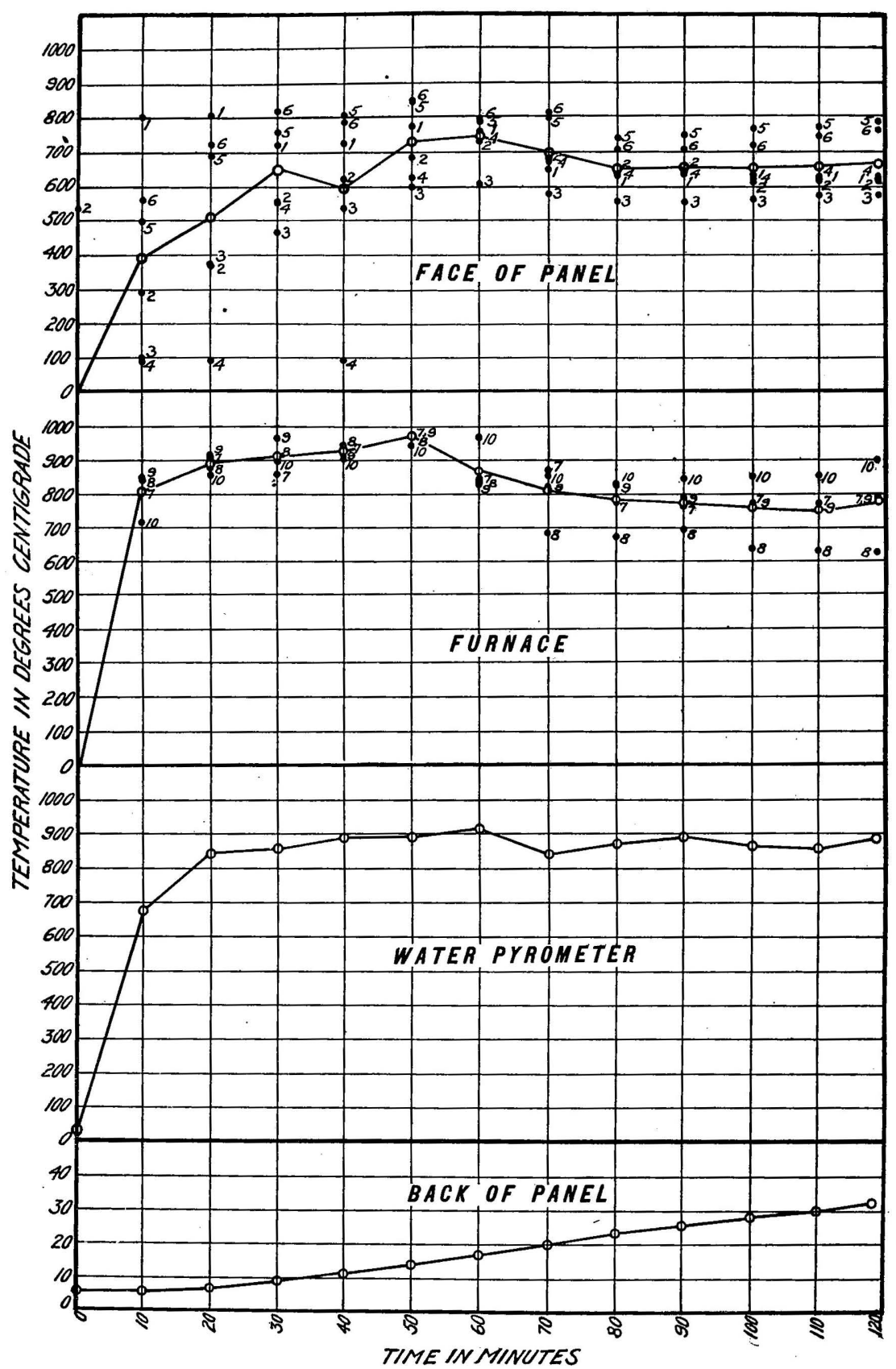

FIGURE 2.-Diagram showing temperature conditions in the furnace and on the back of panel 2. Temperature: Maximum, $37^{\circ}$; minimum, $34^{\circ}$; mean, $36^{\circ}$. Relative humidity: 7 a.m., $91 ; 7$ p.m., 94 . Direction of prevailing wind, southeast. 


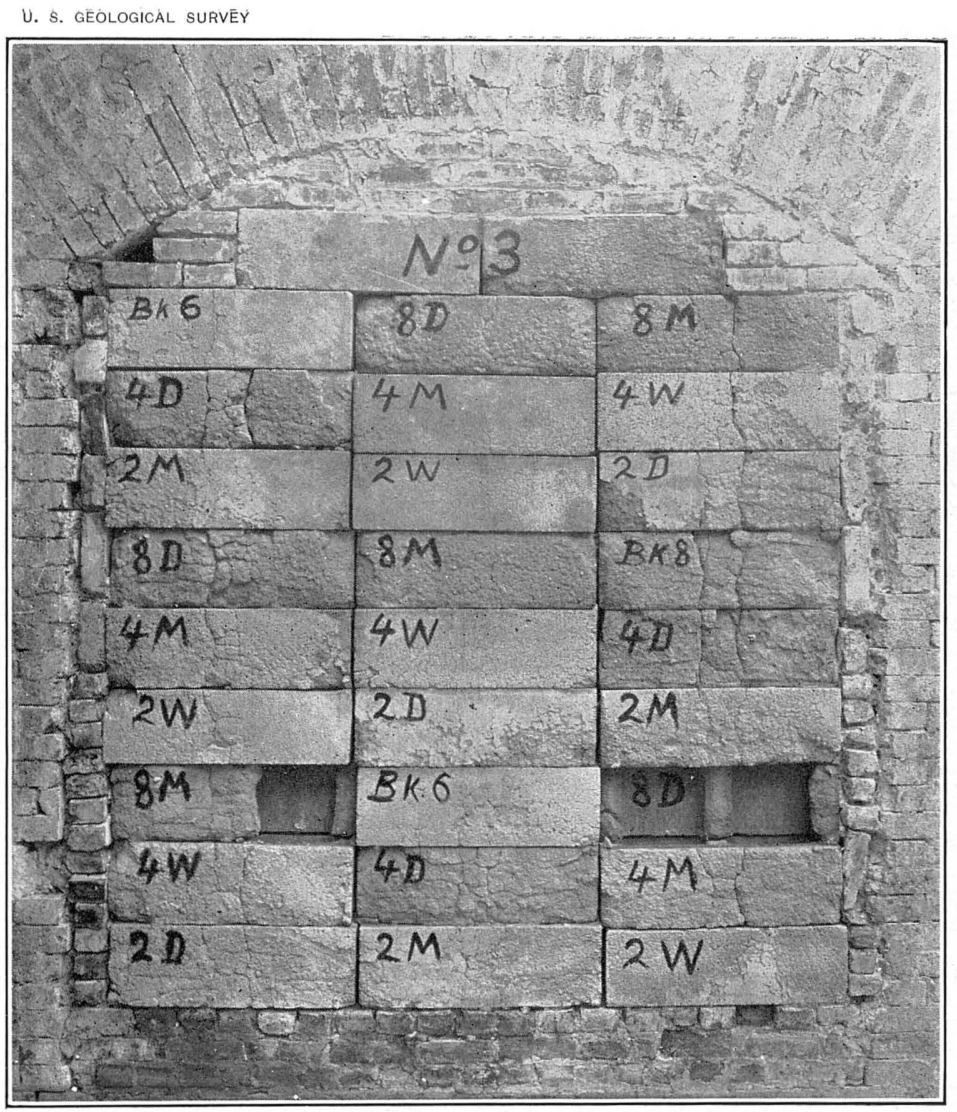

A. FACE OF PANEL 3, CEMENT MORTAR BUILDING BLOCKS, AFTER FIRING AND QUENCHING.

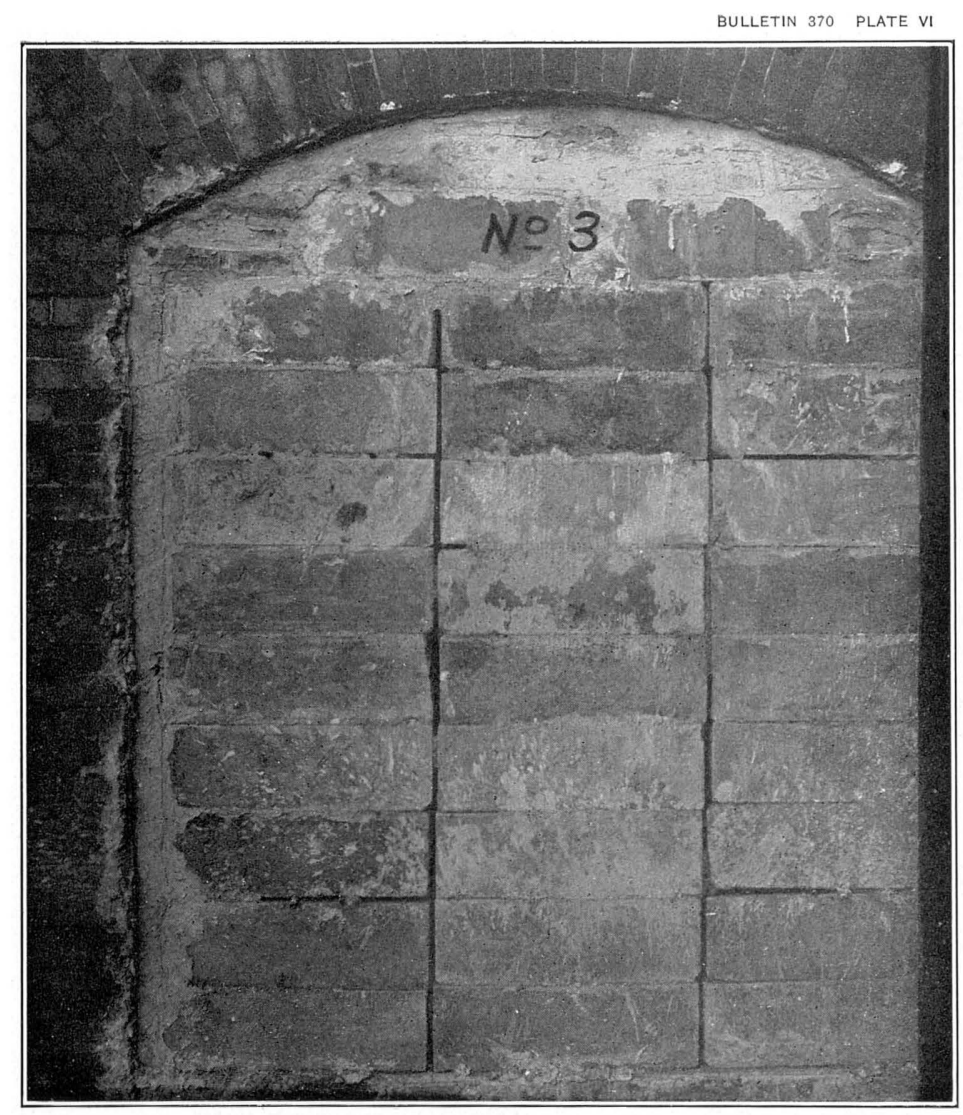

B. BACK OF PANEL 3, CEMENT MORTAR BUILDING BLOCKS, AFTER FIRING AND QUENCHING. 

than at the bottom. The 1:2 blocks warmed more slowly than those of leaner proportions.

Curves showing the variations of the temperature are given in figure 2 .

Results.-When removed from the furnace no cracks were visible, but while cooling small hair cracks developed all over the blocks. On the 1:2 blocks; especially the wet mixtures, these cracks were very fine, but on the 1:4 and 1:8 blocks they were coarser and more extensive. The surfaces appeared smooth, but could be easily scratched. Plate V, $B$, shows the face of the panel after cooling in air. The hair cracks are too small to be visible in the photographs. On taking the panel down all the blocks were found to have cracked across the web nearest the fired side. To remove the detached fired face without cracking it vertically was difficult.

Table 2 gives the results of the strength tests on fragments of the fired blocks, one column giving the strength of the face of the block exposed to the fire and another the strength of the back of the blocks. The table shows conclusively the loss in strength of the fired face.

PANEL 3 (Mortar Building Blocks).

Material.-Panel 3 consisted of one-piece double-air-space blocks exactly like those in panel 1, except that they had been made four days later and therefore were four days less time in St. Louis, and the same length of time longer in Chicago. The panel was laid up in the afternoon of January 19, 1907, during a rain storm. The temperature on January 20 was below freezing all day.

Test.-Firing started at 3 p. m. January 21 , and continued for 2 hours. Water at a temperature of $36^{\circ} \mathrm{F}$. was applied to the panel for 5 minutes, but not until 19 minutes after the gas was turned off, as the door stuck in the furnace.

From 3 to 5 minutes after starting the test considerable snapping was audible, but no cracks became visible. In 10 minutes a 1:8 dry block opposite an air jet spalled at one corner, and 5 minutes later the spalling continued across the block and the lower edge became loose. At 20 minutes another 1:8 dry block spalled along the lower edge and the right-hand side. This spalling extended up 3 to 4 inches, though it did not penetrate more than $\frac{1}{2}$ to $\frac{3}{4}$ inch. At 70 minutes the blocks began to sweat and steam came from the joints.

Curves showing the variations of the temperature throughout the test are given in figure 3.

Results. - Vertical cracks on each side of the center webs showed plainly before the application of the water. Plate VI, $A$, shows the face and Plate VI, $B$, the back of the panel after quenching. These views show clearly how different blocks met the tests, the richer wet 


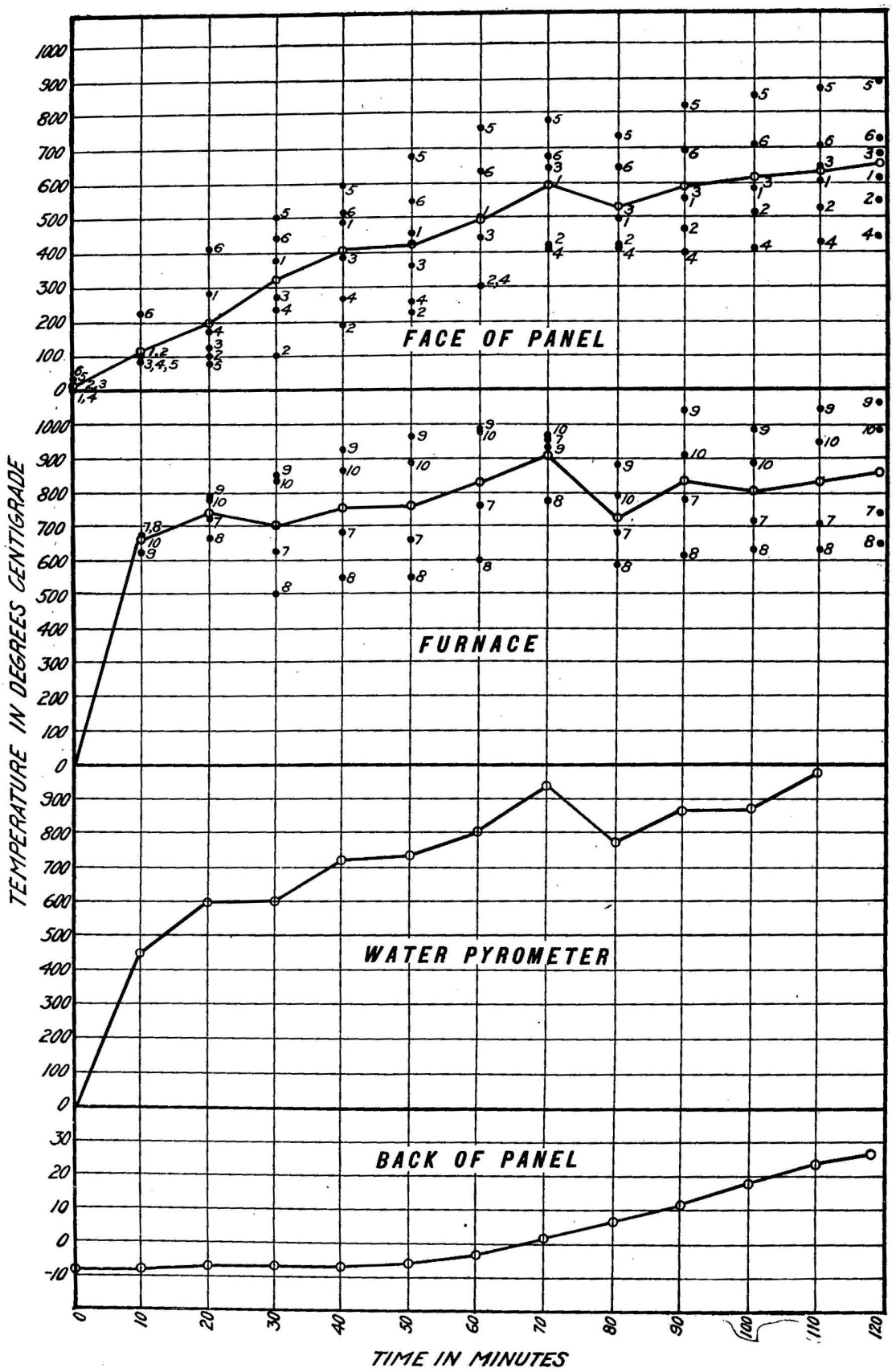

Figure 3.-Diagram showing temperature conditions in the furnace and on the back of panel 3 . Temperature: Maximum, $27^{\circ}$; minimum, $4^{\circ}$; mean, $16^{\circ}$. Relative humidity: 7 a.m., $86 ; 7$ p. m., 83 . Direction of prevailing wind, southeast. 
U. S. GEOLOGICAL SURVEY

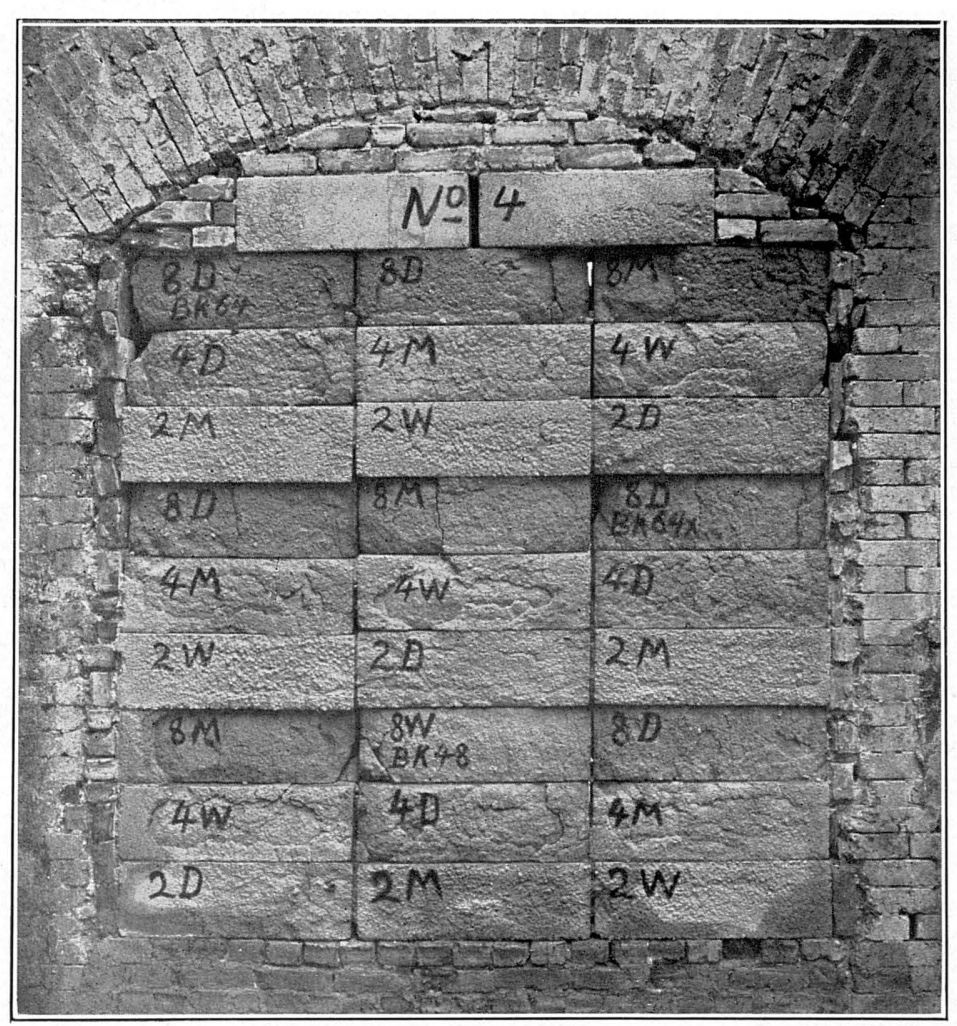

A FACE OF PANEL 4, CEMENT MORTAR BUILDING BLOCKS, AFTER FIRING AND QUENCHING.

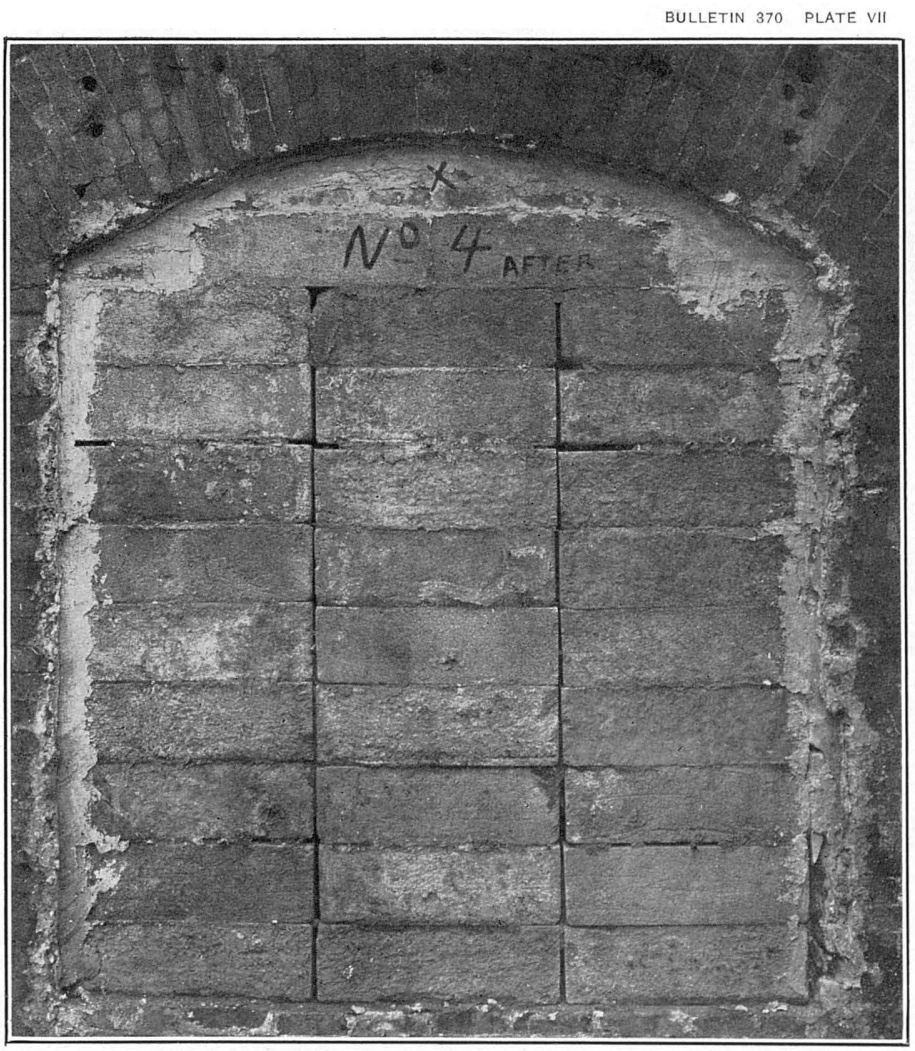

B. BACK OF PANEL 4, CEMENT MORTAR BUILDING BLOCKS, AFTER FIRING AND QUENCHING. 

blocks withstanding it much better than the lean damp blocks. A peculiarity of the behavior of this type of block during the test may be seen in Plate VI, $B$. The end webs split away from and parallel to the face of the blocks, but the middle web remained intact and the face split away from it at each side, leaving from 1 to 4 inches of the face in place.

Table 3 gives the compressive strength of the fragments.

\section{PANEL 4 (Mortar Building Blocks).}

Material.-Panel 4 was made of one-piece single-air-space blocks exactly like those in panel 2 , except that they were made and tested 5 days later, and therefore remained in St. Louis 5 days less time and in Chicago 5 days longer.

Test.-Firing started at 2.36 p. m. January 23,1907 , and continued for 2 hours and 1 minute. Water at a temperature of $36^{\circ} \mathrm{F}$. was applied for 5 minutes and 20 seconds, beginning within 1 minute after the gas was turned off.

In 20 minutes a block on the left-hand side, third row from the bottom, opposite an air jet, bulged out at the center about $\frac{1}{4}$ inch and cracked horizontally at about the center. At 26 minutes a block on the right-hand side in the sixth row bulged and cracked vertically. At 32 minutes the block on the left-hand side in the third row bulged still more, and 2 minutes later the face fell off. At $37 \mathrm{~min}$ utes the center block in the third row opposite an air jet bulged about $\frac{1}{4}$ inch. At 80 minutes the blocks began to sweat and steam came through the joints.

The curves showing the variations of the temperature throughout the test are given in figure 4.

Results.-Plate VII shows the face and back after firing and quenching. Plate VIII, $A$, shows the condition of the blocks during dismantling. When the panel was withdrawn from the fire the surfaces of the blocks were smooth except where the blocks had spalled. No cracks were visible. During the application of the water all the blocks spalled, but, as may be seen from the plates, this spalling was most severe on the lean damp blocks. The fourth and seventh rows from the bottom in Plate VII, $A$, are 1:2 blocks; the rows next beneath are 1:8 blocks. The difference in the damp, medium, and wet consistency blocks in the two rows is perceptible. The 1:8 and 1:4 proportions were badly spalled and washed away.

On dismantling the panel all the blocks were found to be split across the webs. These cracks were along the fired face except in two or three cases, where the webs split away from both the face and the back. A piece of wood left in the interior of one of the blocks, was slightly scorched, but not at all charred.

The strengths of the fragments are given in Table 4 . 


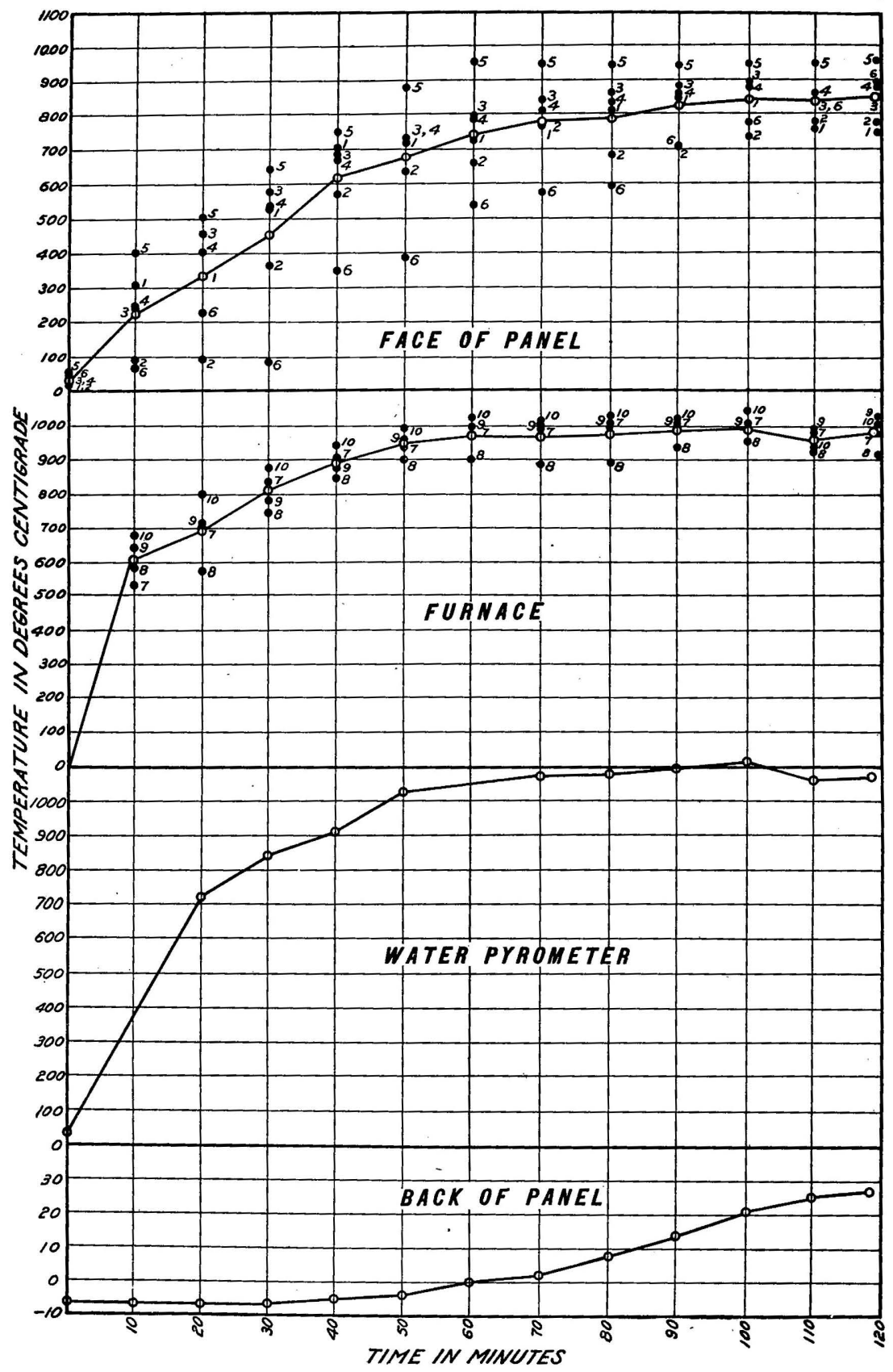

FIGURE 4.-Diagram showing temperature conditions in the furnace and on the back of panel 4. Temperature: Maximum, $22^{\circ}$; minimum, $6^{\circ} ;$ mean, $14^{\circ}$. Relative humidity: 7 a. m., $83 ; 7$ p.m., 85 . Direction of prevailing wind, northwest. 


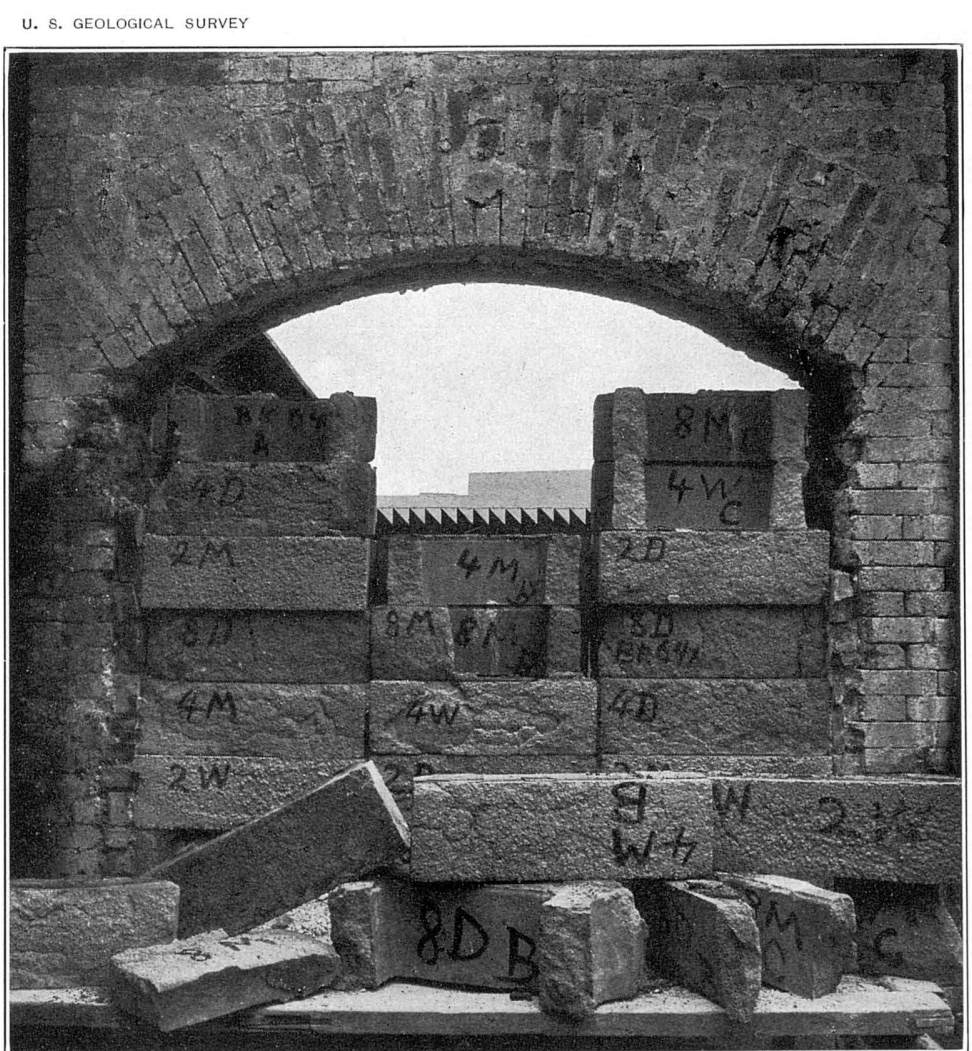

A. PANel 4, Cement mortar building Blocks, DURING Dismantling.

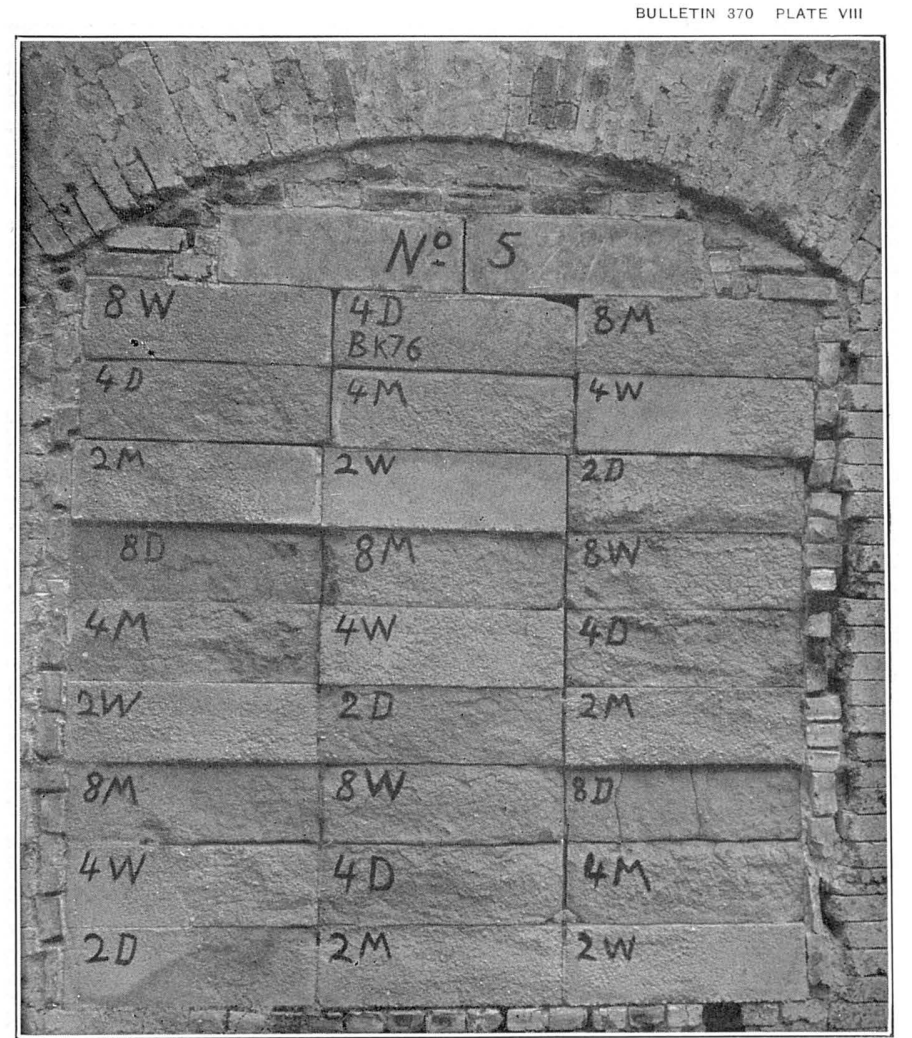

B. FACE OF PANEL 5, CEMENT MORTAR BUILDING BLOCKS, AFTER FIRING AND QUENCHING. 



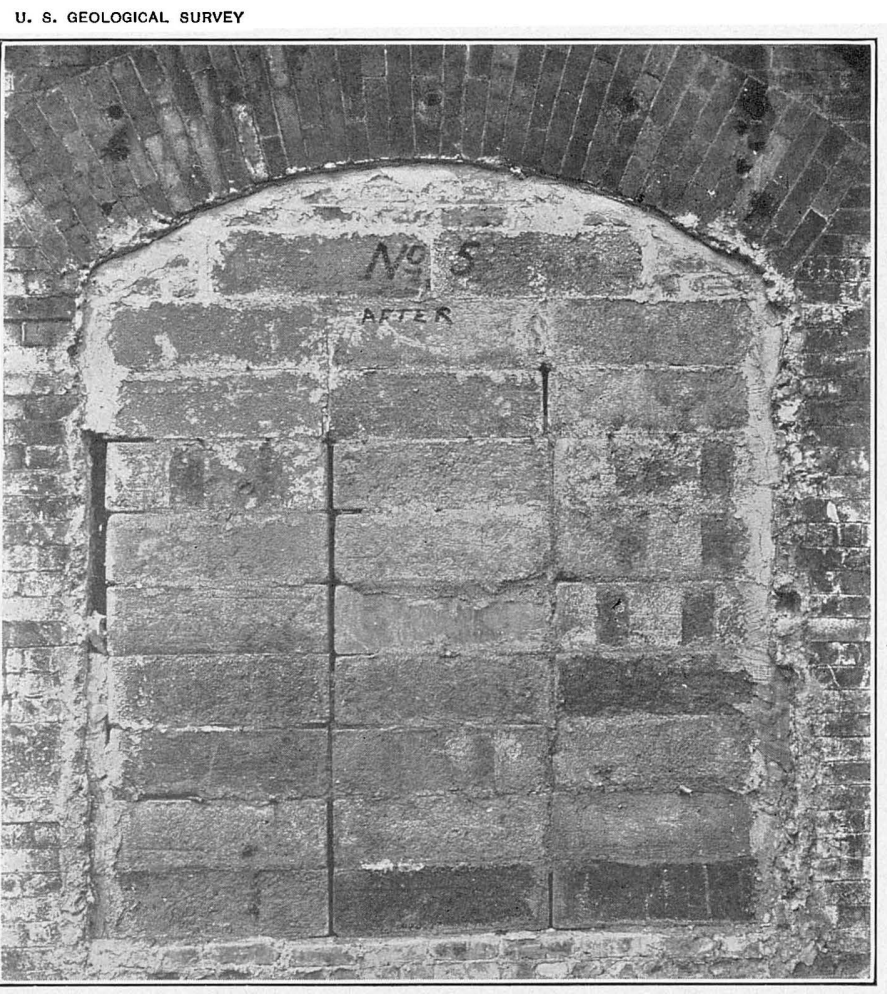

4. BACK OF PANEL 5, CEMENT MORTAR BUILDING BLOCKS, AFTER FIRING AND QUENCHING.
BULLETIN 370 PLATE IX

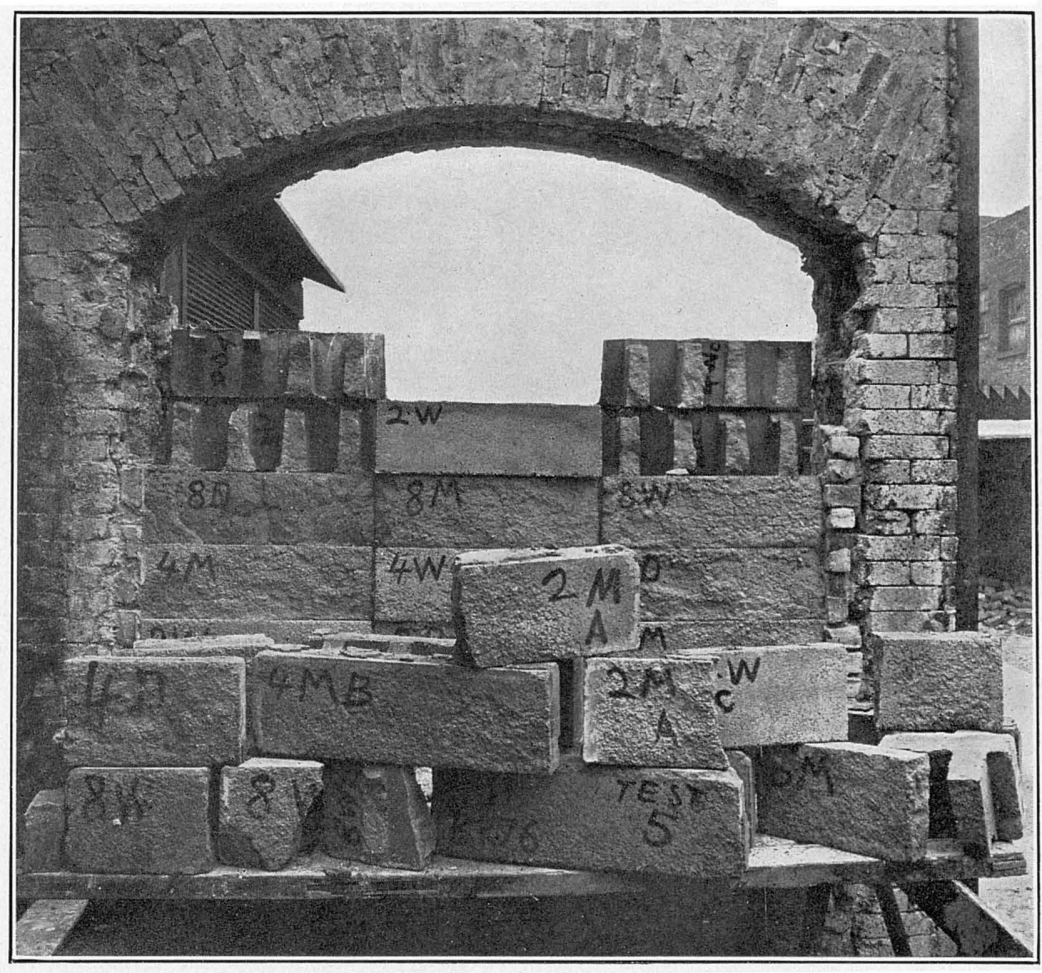

B. PANEL 5, CEMENT MORTAR BUILDING BLOCKS, DURING DISMANTLING. 

PANEL 5 (Mortar Building Blocks).

Materials.-Panel 5 consists of one-piece single-air-space blocks made in the same way and of the same proportions and consistencies as those previously tested. They were stored in a moist room at St. Louis 45 days and at Chicago 16 days, and were tested at the age of 64 days. The panel was laid up in freezing weather and was frozen when the test began.

Test.-Fire started 10,14 a. m. January 25, 1907, and continued for 2 hours and 5 minutes, after which the panel was quenched with water at a temperature of $36^{\circ} \mathrm{F}$., applied for 5 minutes. The fire worked badly, the panel at the top not heating up as well as desired. There was considerable snapping and cracking at the start, which stopped as soon as the panel became well heated.

In 25 minutes a block on the right-hand side, third row, spalled slightly at the center and showed some horizontal cracks. During the remainder of the test the panel showed no change.

Curves showing the variations of the temperature throughout the test are given in figure 5 .

Results.-As the top of the furnace did not heat up properly, the blocks in the upper part of the panel were not affected as much as those in the lower and middle portions. Plate VIII, $B$, shows the face of the panel after the test, Plate IX, $A$, the back of the panel after the test, and Plate IX, $B$, the panel during dismantling. The surfaces of the blocks were badly pitted, but no cracks appeared except in the 1:8 damp blocks. The 1:4 blocks spalled badly; the $1: 2$ blocks slightly. The difference in the behavior of the rich wet blocks and the lean damp blocks can clearly be seen in Plate VIII, $B$.

On dismantling the panel the blocks were found to be all cracked along the webs, so that the faces could be removed without disturbing the backs. It was also found that the faces of the blocks were cracked vertically, though the cracks did not show badly; yet fẹw of the faces could be removed in one piece. Most of the webs cracked close to the fired face, but in a few the crack developed near the back of the block and the fired face remained attached to the web.

The strength tests of the fragments of these blocks are given in Table 5.

\section{PANEL 6 (Mortar Building Blocks).}

Material.-Panel 6 consisted of one-piece single-air-space blocks, made in the same way and of the same proportions and consistencies as those previously tested. They were stored in a moist room in St. Louis 41 days and in Chicago 20 days and were tested at the age of 64 days. 


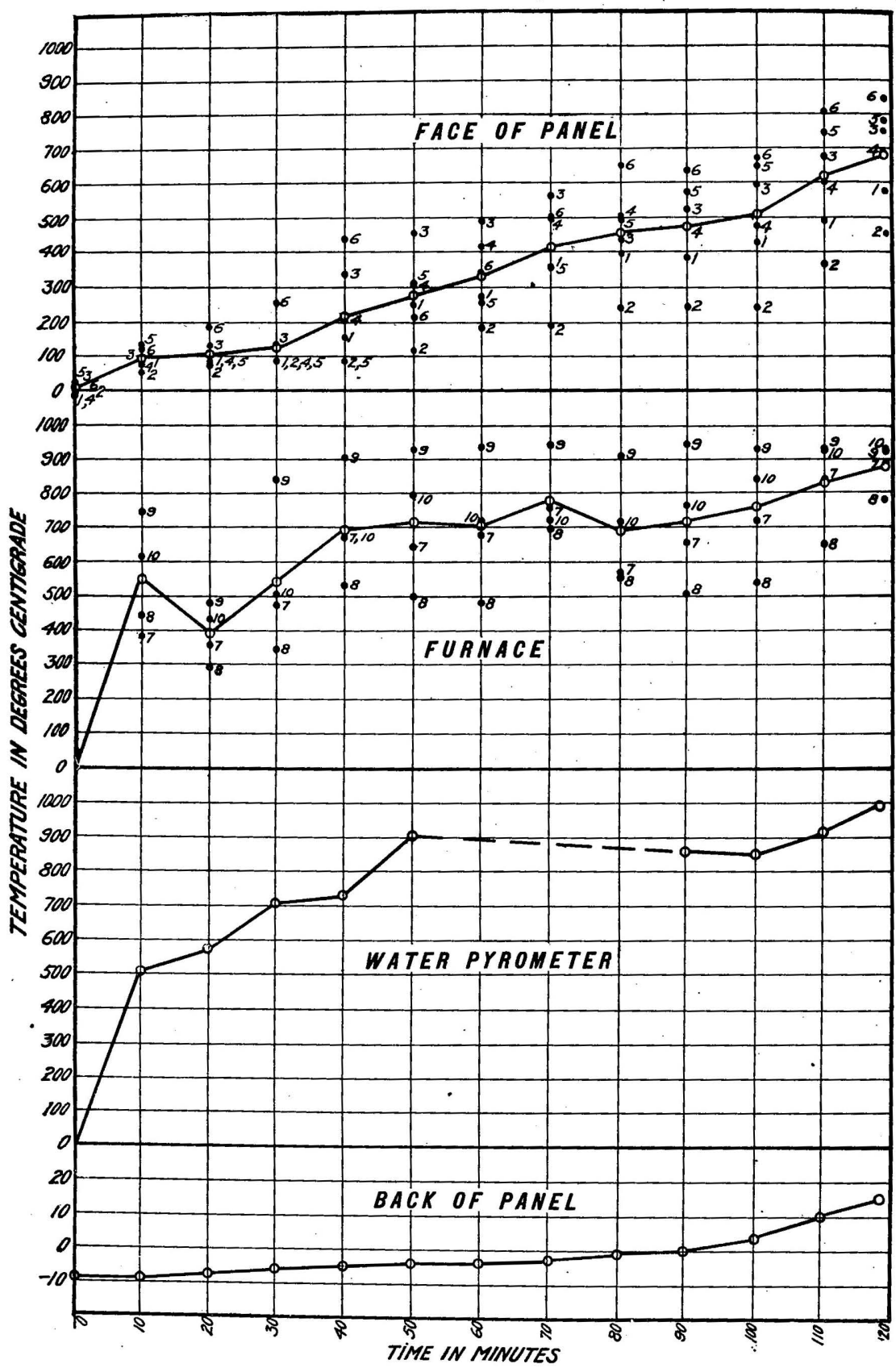

Figure 5.-Diagram showing temperature conditions in the furnace and on the back of panel 5. Tempera ture: Maximum, $24^{\circ}$; minimum, $-1^{\circ} ;$ mean, $12^{\circ}$. Relative humidity: 7 a.m., $82 ; 7$ p. m., 62 . Direction of prevailing wind, northwest. 
U. S. GEOLOGICAL SURVEY

BULLETIN 370 PLATE $X$

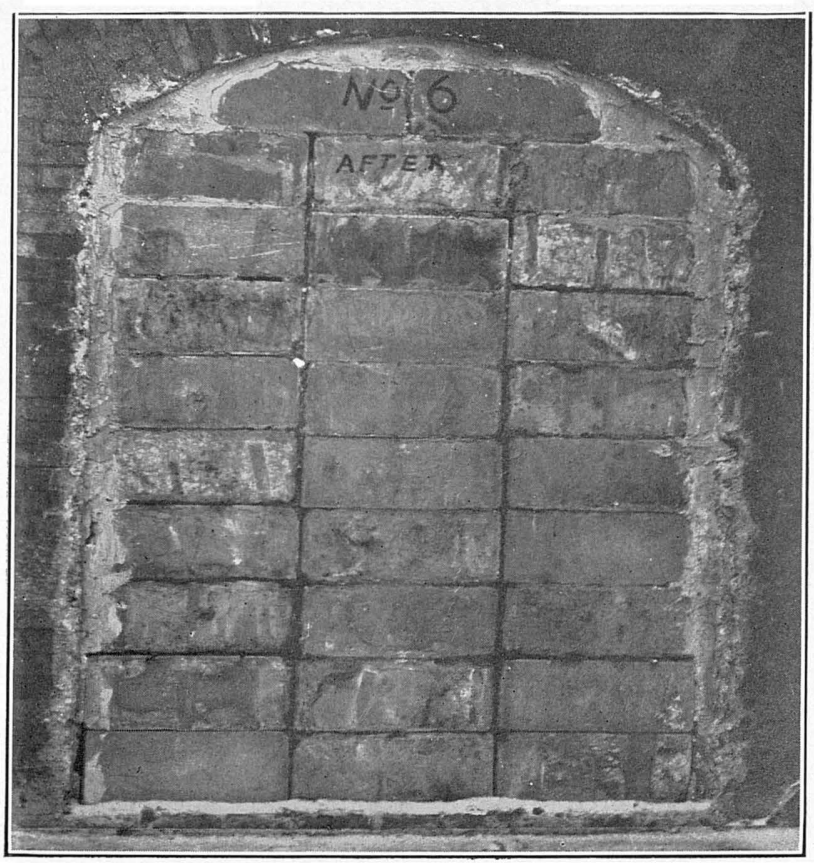

A. BACK OF PANEL 6 , CEMENT MORTAR BUILDING BLOCKS, AFTER FIRING AND QUENCHING.

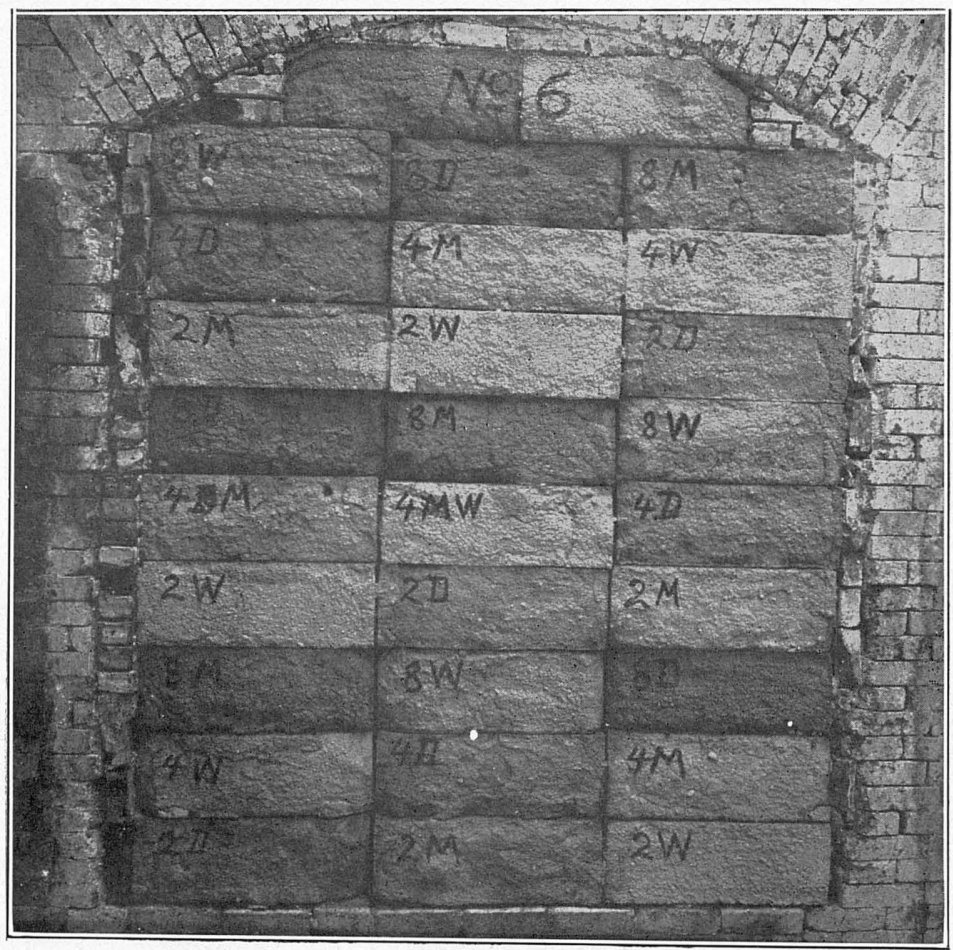

B. FACE OF PANEL 6, CEMENT MORTAR BUILDING BLOCKS, AFTER FIRING AND QUENCHING. 

Test.-Firing started at 12.35 p. m. January 29, 1907, and continued for 2 hours and 1 minute. The panel was then quenched with water at a temperature of $36^{\circ} \mathrm{F}$. for 5 minutes. The fire gave a uniform temperature from the start.

In 10 minutes the right-hand and left-hand blocks in the third row spalled off around the inner edges. At 30 minutes the left-hand block in the sixth row spalled around the bottom edge to a depth of about 1 inch. The spalling extended upward over the block to a height of about 3 or 4 inches, and the material became loose and fell off. The center blocks in the top row spalled similarly, but less severely. At 60 minutes steam began to appear through the mortar joints.

Curves showing the variations of the temperature throughout the test are given in figure 6 .

Results.-Plate X, $B$, shows the face of the panel and Plate X, $A$, the back of the panel after the test, and Plate XI, $A$, the panel during removal. Before quenching the faces of the blocks seemed little affected, but after the application of the water the surfaces appeared badly spalled and washed away. The photograph (Pl. X, B) shows that, as in previous tests; the lean damp blocks were the most severely affected, but the $1: 8$ wet and the $1: 8$ medium suffered little less than the 1:8 damp. The 1:2 blockss showed no signs of surface cracks, but were almost as badly washed away as the $1: 4$ blocks. The 1:2 wet blocks were affected considerably less than the $1: 2$ medium and 1:2 damp blocks. The 1:4 medium, wet, and damp blocks seemed affected about equally. Only two of the blocks could be taken from the wall intact. These were a 1:4 wet and a 1:4 damp in the center row. All the others were cracked across the end webs, and in most cases the faces of the blocks split vertically along the inner web. In a few cases the end webs cracked near the back face, but in all cases the center web remained attached to the back face. This web in many cases was attached to a small piece of the front face, the front face having cracked away from it on either side.

The strength tests on these blocks are given in Table 6.

PANEL 7 (Mortar Building Blocks).

Material.-Panel 7 was made of one-piece single-air-space blocks, similar to those in panel 6. They were stored in the moist room in St. Louis 37 days and in Chicago 23 days, and were tested at the age of 63 days. The panel was laid up in freezing weather.

Test.-Firing started at 9.14 a. m. February 1, 1907, and continued 2 hours and 2 minutes, after which the panel was cooled in the air without quenching. The fire was apparently uniform over the entire panel. 


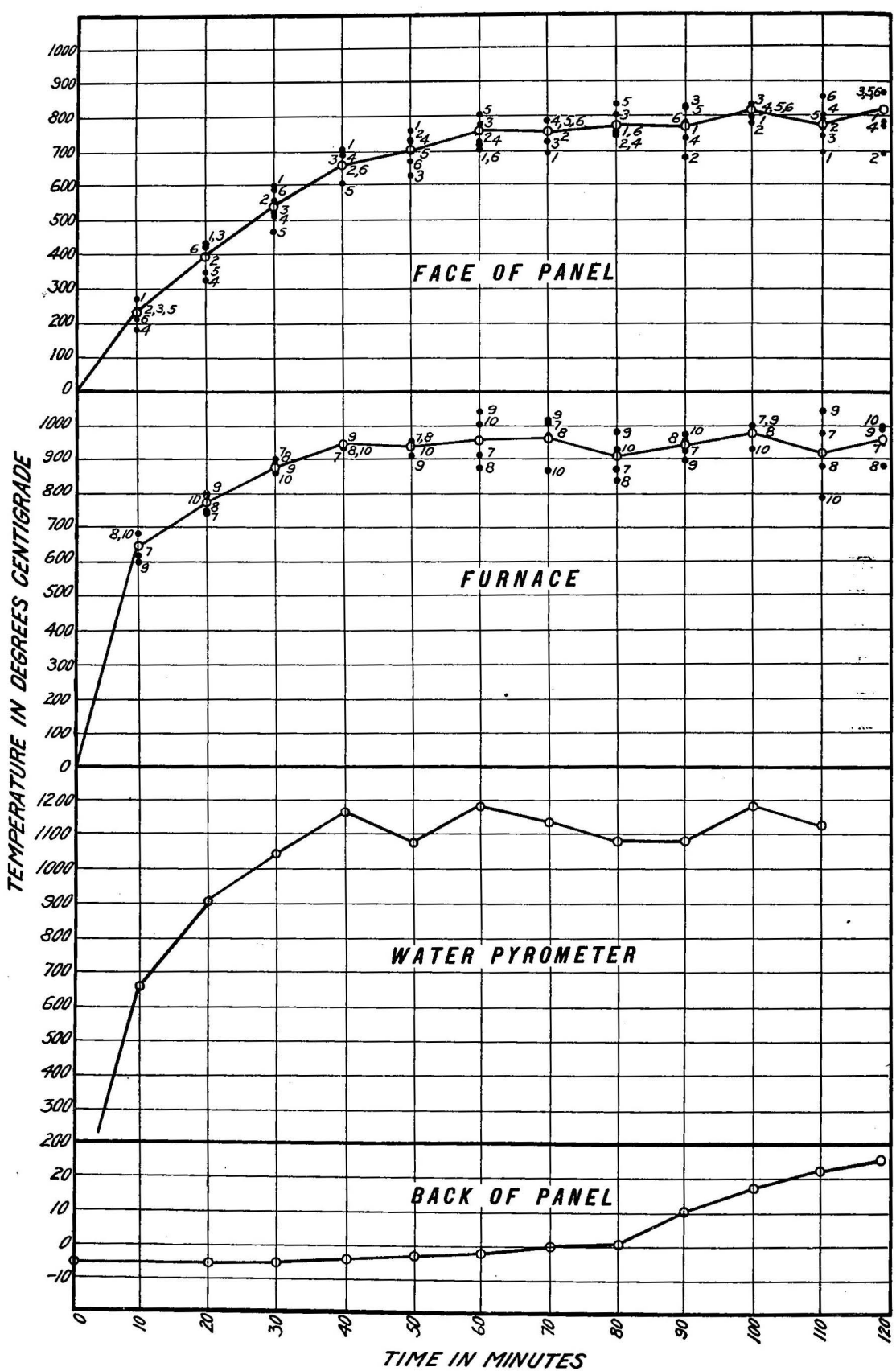

FIGURE 6.-Diagram showing temperature conditions in the furnace and on the back of panel 6 . Temperature: Maximum, $28^{\circ}$; minimum, $17^{\circ}$; mean, $22^{\circ}$. Relative humidity: 7 a. m., $92 ; 7$ p. m., 100 . Direction of prevailing wind, southeast. 


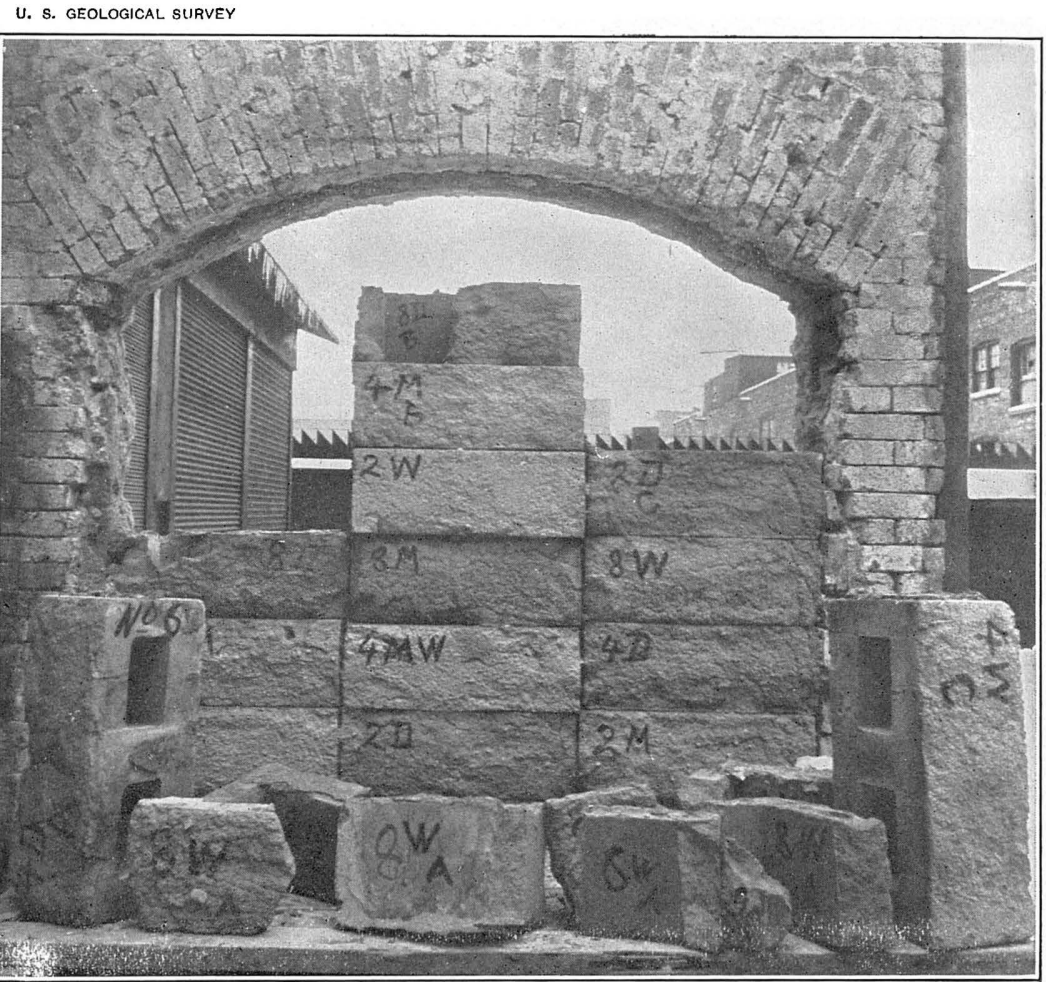

A. PANEL 6, CEMENT MORTAR BUILDING BLOCKS, DURING DISMANTLING.

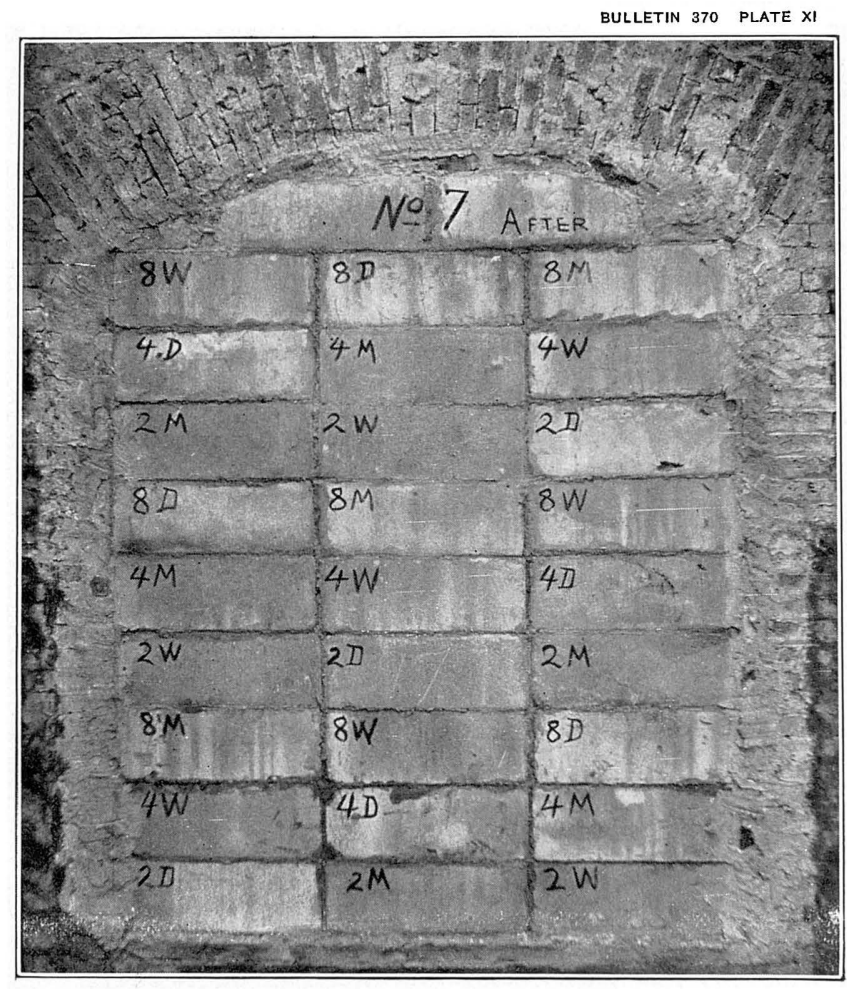

B. FACE OF PANEL 7, CEMENT MORTAR BUILDING BLOCKS, AFTER COOLING IN AIR. 

There was no cracking or spalling up to 70 minutes, when the block on the left-hand side of the panel in the eighth row cracked vertically on the back close to the center web on the outer edge. No crack on the fired side or face of this block could be detected. During the remainder of the test no other feature of importance was observed.

Curves showing the variation of the temperature throughout the test are given in figure 7.

Results.-Plate XI, $B$, is reproduced from a photograph of the face of the panel after the test; Plate XII, $A$, from a photograph of the panel during dismantling. On removing the door from the furnace two of the blocks were found to be cracked. As the cooling proceeded irregular hair cracks developed on the face of all the blocks, but were most pronounced on the 1:8 damp blocks. In the 1:2 blocks the cracks were very fine and apparently did not penetrate to any great depth. After the door had cooled for several hours cracks developed in each tier, running vertically through all the blocks. In the left-hand and center tiers the cracks were to the right of the center web, while in the right-hand tier they were on the left of the center web. The surfaces of the 1:8 blocks were found to be so soft that they could be brushed away with the finger to a depth of about $\frac{1}{4}$ inch, difference in consistency having had little effect. The 1:2 blocks were considerably harder. The surfaces of the blocks were apparently affected by the heat and were discolored from a depth of 1 inch to $1 \frac{1}{2}$ inches in the case of the $1: 8$, from $\frac{3}{4}$ inch to $1 \frac{1}{4}$ inches in the 1:4, and from $\frac{1}{2}$ to 1 inch in the $1: 2$ blocks. The blocks of wet consistency were apparently in better condition than those of damp and medium consistency, but the difference was slight.

On dismantling the wall, it was found that none of the blocks were intact, all having cracked across the webs. In nearly every case the crack across the web was near the face, but in one or two cases it was near the back, the web remaining attached to the face.

The strength tests of the fragments of these blocks are given in Table 7.

PANEL 8 (Mortar Building Blocks).

Material.-Panel 8 consisted of one-piece single-air-space blocks made in the same manner and of the same proportions and consistencies as those previously tested. They were stored in a moist room in St. Louis 35 days and in Chicago 26 days, and were tested at the age of 64 days. The panel was laid up in freezing weather.

Test.-Firing started February 4, 1907, and continued for 2 hours and 1 minute, after which the panel was cooled in air without the application of water. The fire was uniform and under good control. 


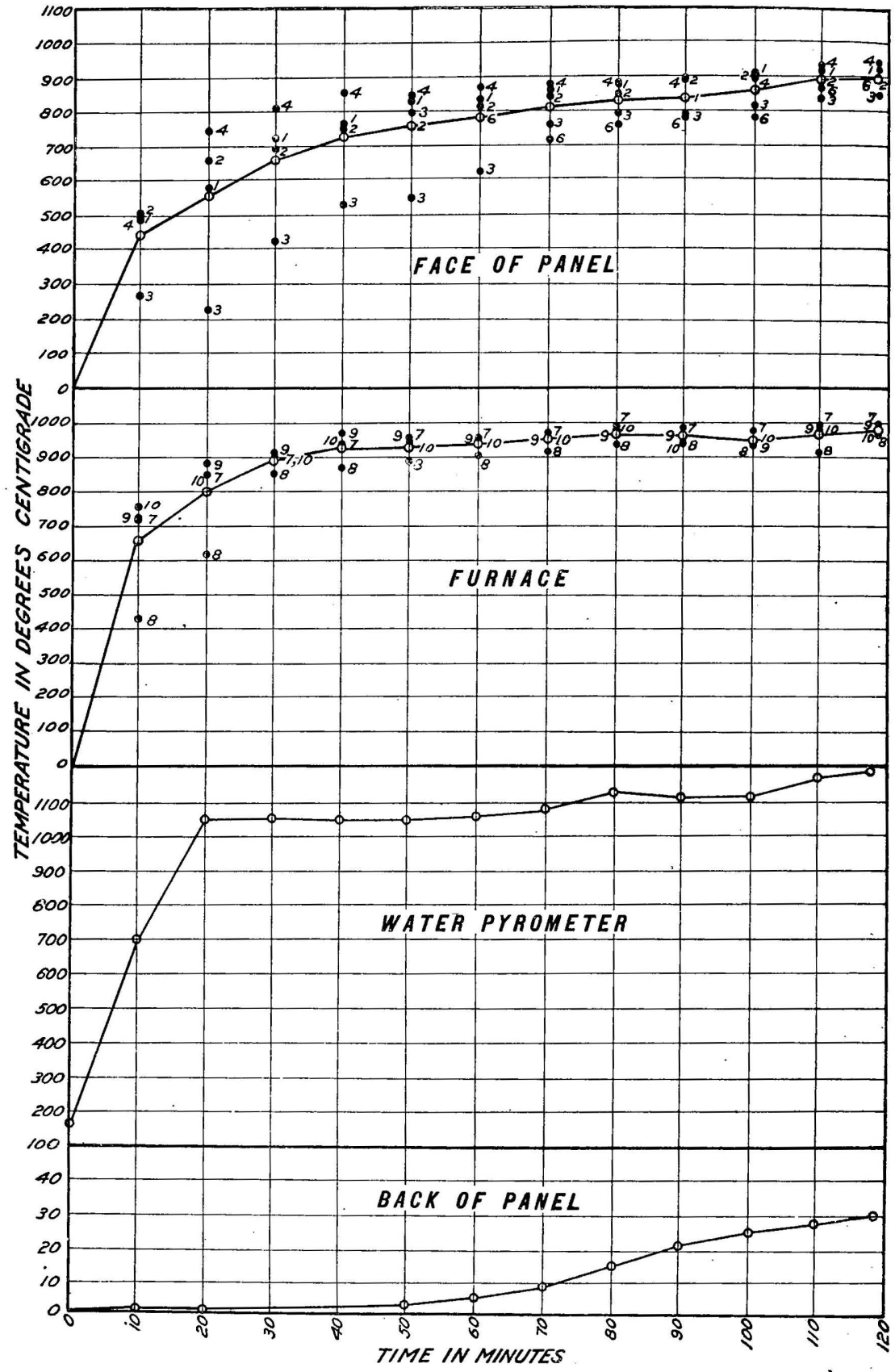

FIGURE 7.-Diagram showing temperature conditions in the furnace and on the back of panel 7 . Temperature: Maximum, $37^{\circ}$; minimum, $27^{\circ}$; mean, $32^{\circ}$. Relative humidity: 7 a. m., $91 ; 7$ p. m, 85 . Direction of prevailing wind, southwest. 


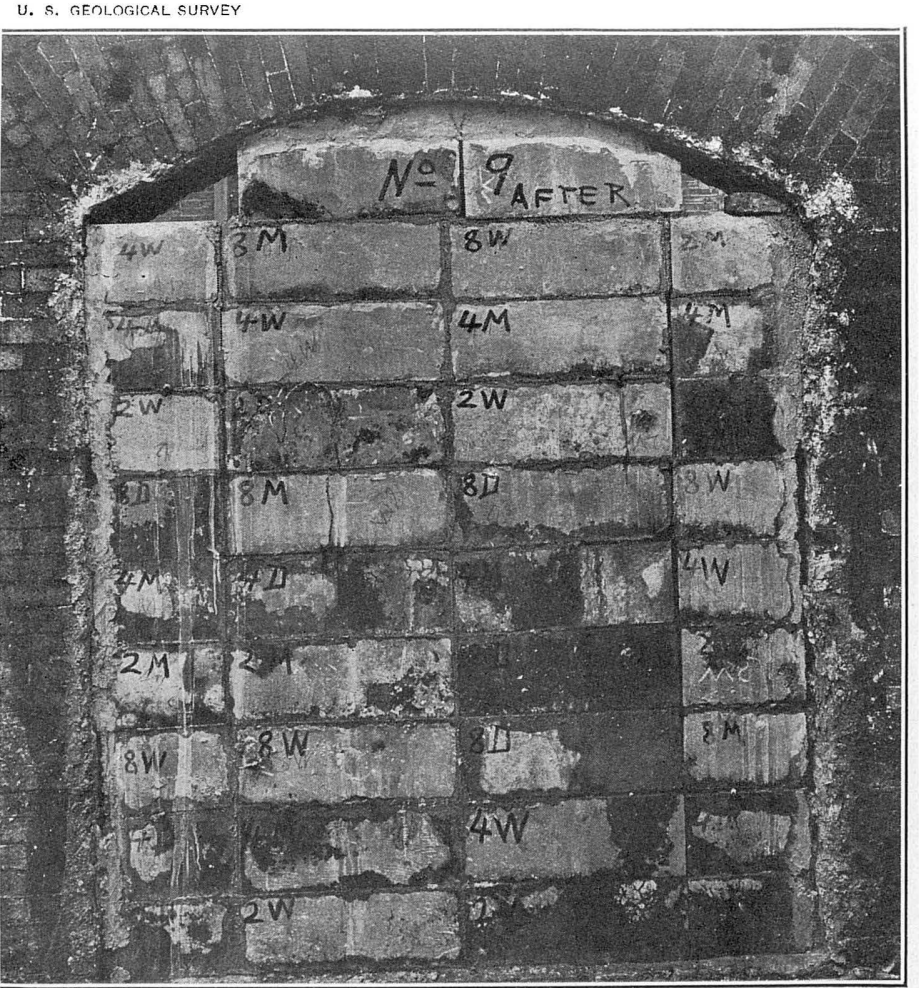

4. BACK OF PANEL 9 CEMENT MORTAR BUILDING BLOCKS, AFTER FIRING AND QUENCHING.

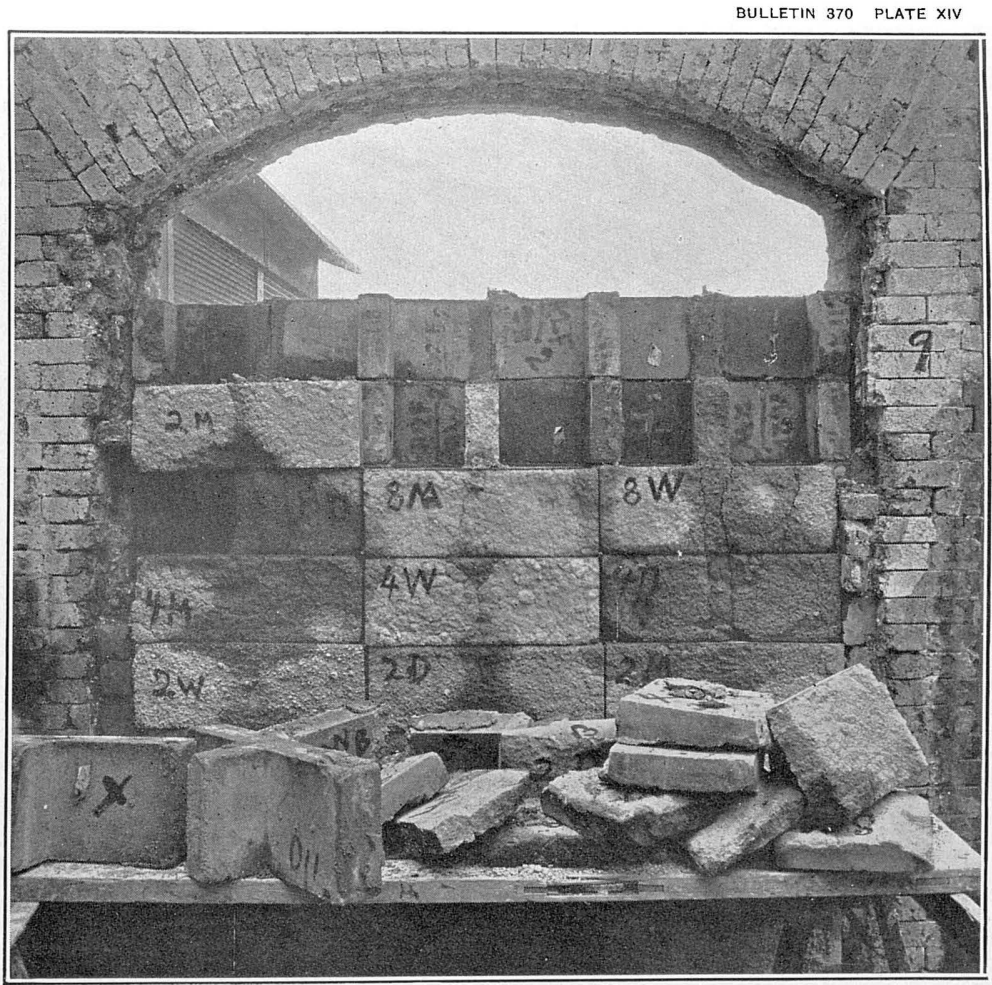

B. PANEL 9, CEMENT MORTAR BUILDING BLOCKS, DURING DISMANTLING. 

In 15 minutes the right-hand block in the third row bulged at the center, projecting about $\frac{3}{4}$ inch, but no cracks were visible. At 20 minutes, however, a vertical crack developed at the center, and the block bulged out about 1 inch. At 22 minutes the block in the center of the third row spalled on the lower edge to a depth of about $\frac{3}{4}$ to 1 inch, and the spalling extended diagonally toward the right-hand corner, about one third of the surface becoming loose. The spalling then extended toward the left-hand side, and a piece about $\frac{3}{4}$ inch in depth and 2 inches wide on the left of the block came off. At 27 minutes the block in the center of the second row spalled on the left side; after which the entire surface became loose and fell off. At this time the right-hand block in the third row, first mentioned, bulged about 2 inches at the center, and the surface fell off to a depth of about $1 \mathrm{inch}$. The fresh surface exposed was comparatively smooth, indicating that a seam may have formed in the manufacture of the block. At 30 minutes the center block in the sixth row spalled, the crack starting at the center and extending in both directions toward the ends. A portion about 6 inches square and $\frac{1}{2}$ inch deep at the center fell off. At 45 minutes the block in the center of the second row, above mentioned, bulged out to about $\frac{1}{4}$ inch, and the remaining portion of the face fell off. At 62 minutes the block in the second row center bulged to the extent of about $\frac{3}{4}$ inch, and the remaining pieces of the face on the right-hand side fell off. The control of the furnace became difficult owing to the clogging of the burners by the fallen pieces. At 70 minutes the block in the center of the third row, before mentioned, spalled considerably more, and a small piece to the left of the center at the bottom fell off. During the remainder of the firing no further changes were noted.

The temperature curves are shown in figure 8.

Results.-Plate XII, $B$, shows the face of the panel after cooling in air; a photograph of the back showed no noticeable damage. Plate XIII, $B$, shows the condition of the blocks while being removed from the panel. On cooling, irregular hair cracks were found over the surface of the blocks, which were largest and most numerous on the 1:8 blocks. No vertical cracks were observed. The surfaces of most of the blocks, as may be seen in the photographs, were found more or less spalled, especially the 1:8 mixtures. The surfaces could be easily broken off on the $1: 8$ blocks. The $1: 4$ blocks were not so badly spalled, but the surfaces could be crumbled with the fingers. The 1:2 damp blocks were slightly spalled on the edges. The 1:2 medium and wet blocks showed no signs of spalling, but to a depth of $\frac{1}{4}$ inch the faces were soft. The concrete was discolored by heat to a depth of $1 \frac{1}{2}$ to $1 \frac{3}{4}$ inches in the $1: 8, \frac{3}{4}$ inch to $1 \frac{1}{2}$ inches in the $1: 4$, and $\frac{1}{2}$ to 1 inch in the $1: 2$. The different consistencies of any one proportion suffered about equally. 


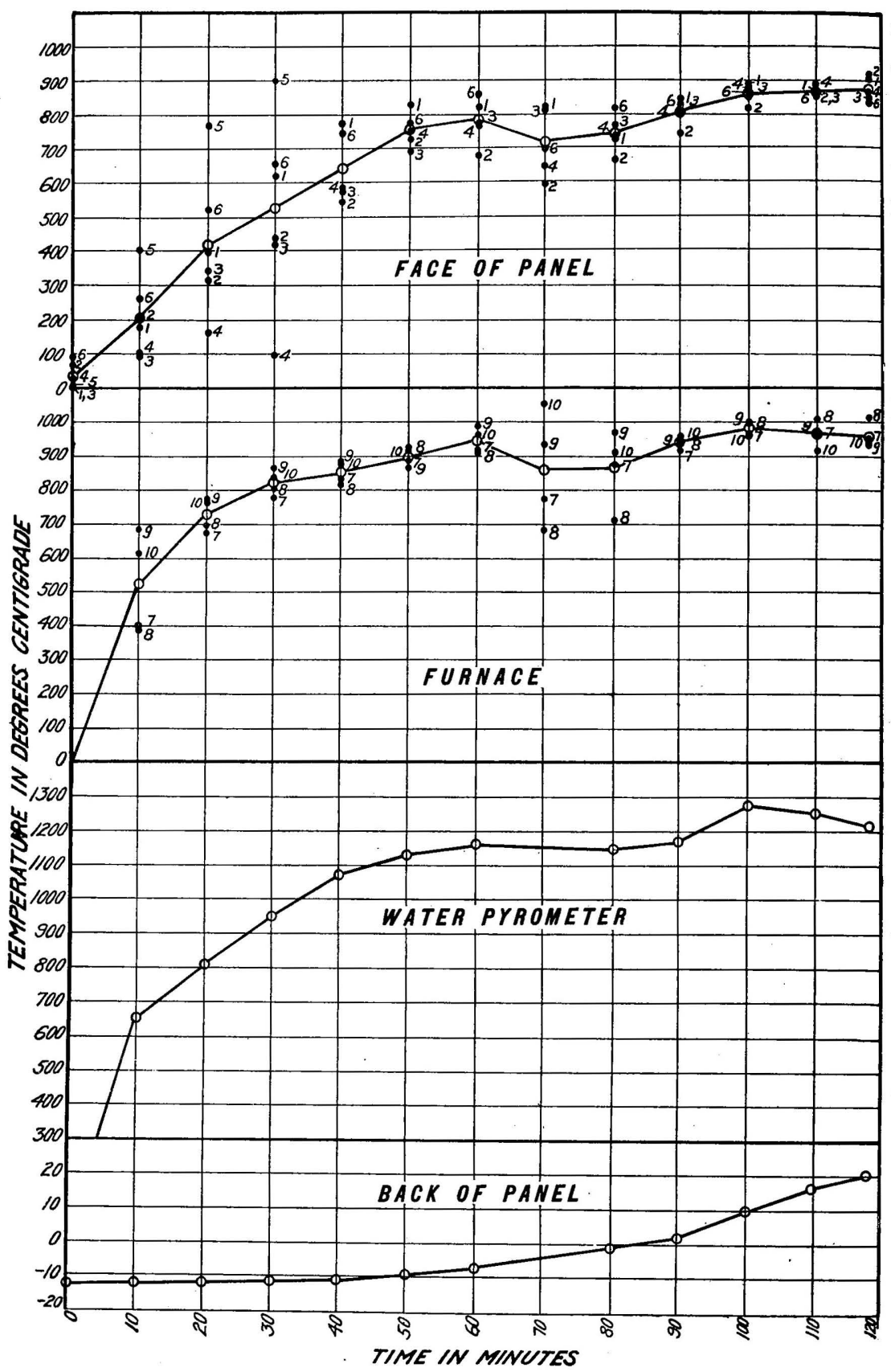

FIGURE 8.-Diagram showing temperature conditions in the furnace and on the back of panel 8. Temperature: Maximum, $17^{\circ}$; minimum, $2^{\circ}$; mean, $8^{\circ}$. Relative humidity: 7 a. m., $88 ; 7$ p. m., 90 . Direction of prevailing wind, northwest. 
U. S. GEOLOGICAL SURVEY

BULLETIN 370 PLATE XIII

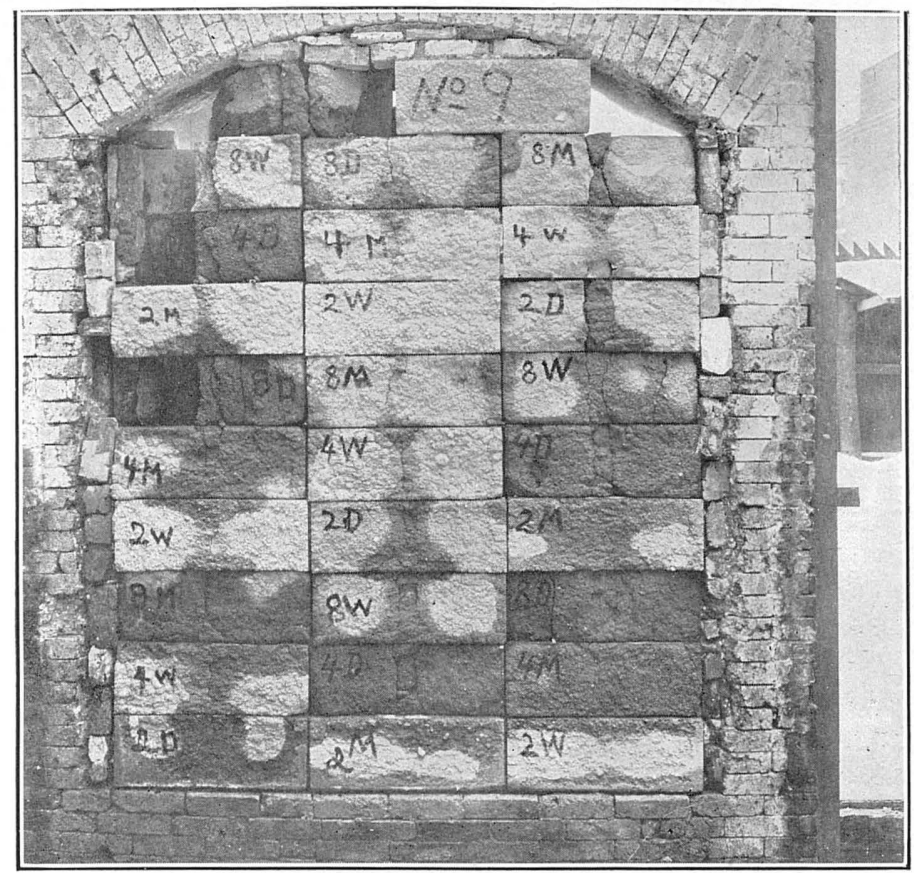

A. FACE OF PANEL 9, CEMENT MORTAR BUILDING BLOCKS, AFTER FIRING AND QUENCHING.

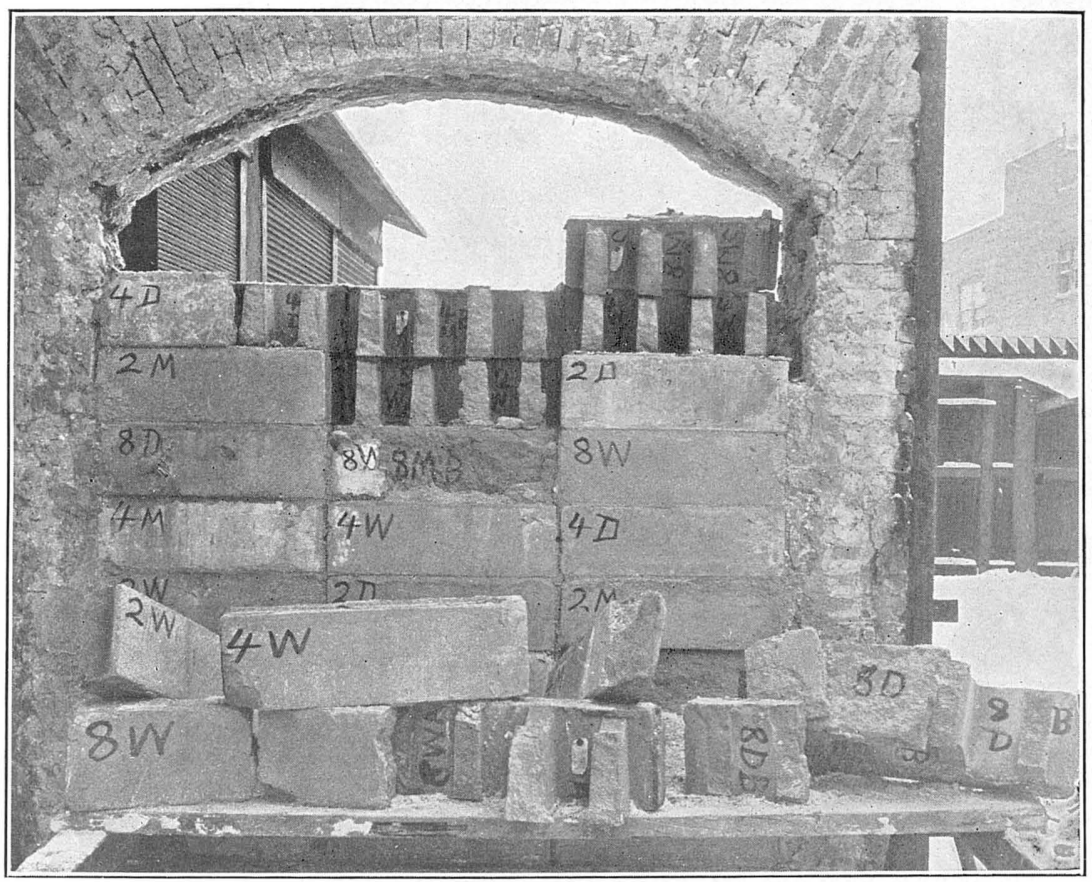

B. PANEL 8, CEMENT MORTAR BUILDING BLOCKS, DURING DISMANTLING. 



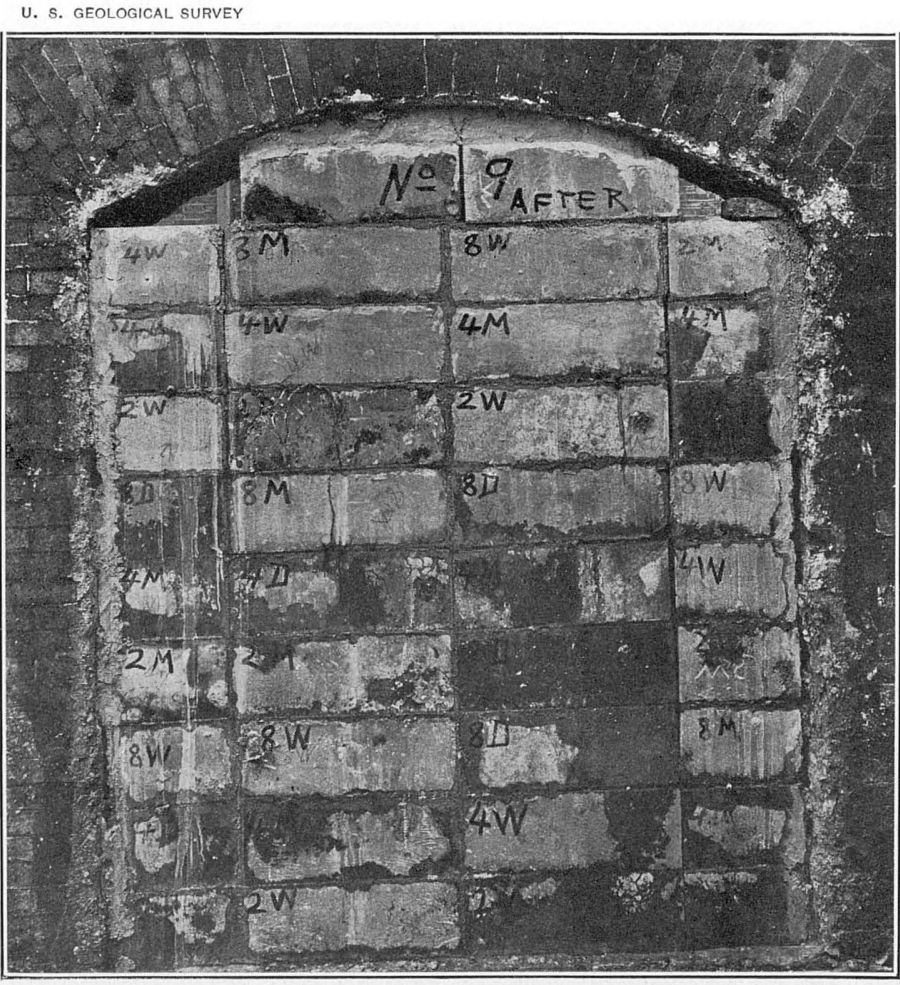

A. BACK OF PANEL 9, CEMENT MORTAR BUILDING BLOCKS, AFTER FIRING AND QUENCHING.

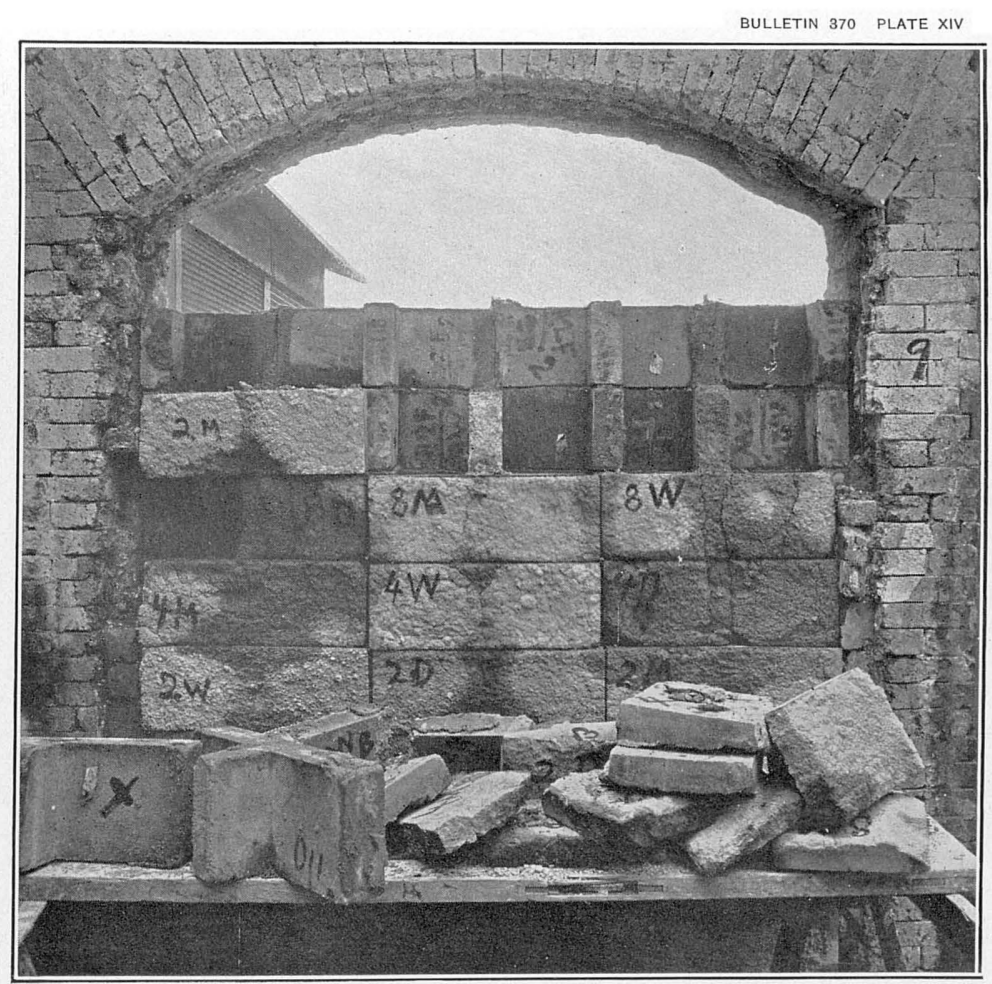

B. PANEL 9, CEMENT MORTAR BUILDING BLOCKS, DURING DISMANTLING. 

On dismantling the panel, it was found that every block had failed across the web. As a rule the failure was near the face, but one or two webs cracked off at the back and remained attached to the fired side. In the case of one block the face cracked across its center web, one half coming loose from the web and the other remaining attached to the web on the other end of the block. The small linen marking tags, one of which was fastened against the back of each block in one of the core holes, were not damaged at all by the test. Three of these tags may be seen in Plate XIII, $B$.

The strength tests on the fragments of these blocks are given in Table 8.

\section{PANEL 9 (Mortar Building Blocks).}

Material.-Panel 9 consisted of two-piece blocks made in the same way and of the same proportions and consistencies as those previously tested. They were stored in the moist room in St. Louis 32 days and in Chicago 29 days, and were tested at the age of 64 days.

The face of the panel was laid up in three tiers without breaking the joints, while the back was laid up with two tiers of whole blocks and two tiers of half blocks on each side. This was necessary in order that the blocks might be staggered to bond them. The views of the face and back of the panel (Pls. XIII, $A$, and XIV, $A$ ) show the arrangement of the blocks. The panel was laid up in freezing weather.

Test.-The fire was started at 9.16 a. m., February 7, 1907, and continued for 2 hours and $1 \frac{1}{2}$ minutes, after which water was applied for 5 minutes at a temperature of $36^{\circ} \mathrm{F}$. A fairly uniform fire was obtained from the start.

For 20 minutes there was considerable snapping. In 60 minutes the right-hand block in the third row spalled at the outer edge. At 78 minutes the right-hand block in the sixth row spalled at the center and small pieces cracked off. No further change was observed during the remainder of the test.

The temperature curves are given in figure 9.

Results.-Plate XIII, $A$, shows the face and Plate XIV, $A$, the back of the panel after the test, and Plate XIV, $B$, the condition of the blocks during removal. On removing the panel from the furnace the blocks appeared to be smooth and no cracks were noticeable. After the application of the water all the blocks were cracked through on each side of the center webs with the exception of the $1: 2$ mixtures on the bottom row. The surfaces were rough and pitted and washed away from $\frac{1}{4}$ to $\frac{1}{2}$ inch on the $1: 2$ blocks, from $\frac{1}{2}$ to $\frac{3}{4}$ inch on the $1: 4$ blocks, and from 1 inch to 2 inches on the 1:8 blocks.

On dismantling the wall it was found that all the blocks had cracked away from their webs or the blocks had cracked on either 73087-Bull. 370-09-3 


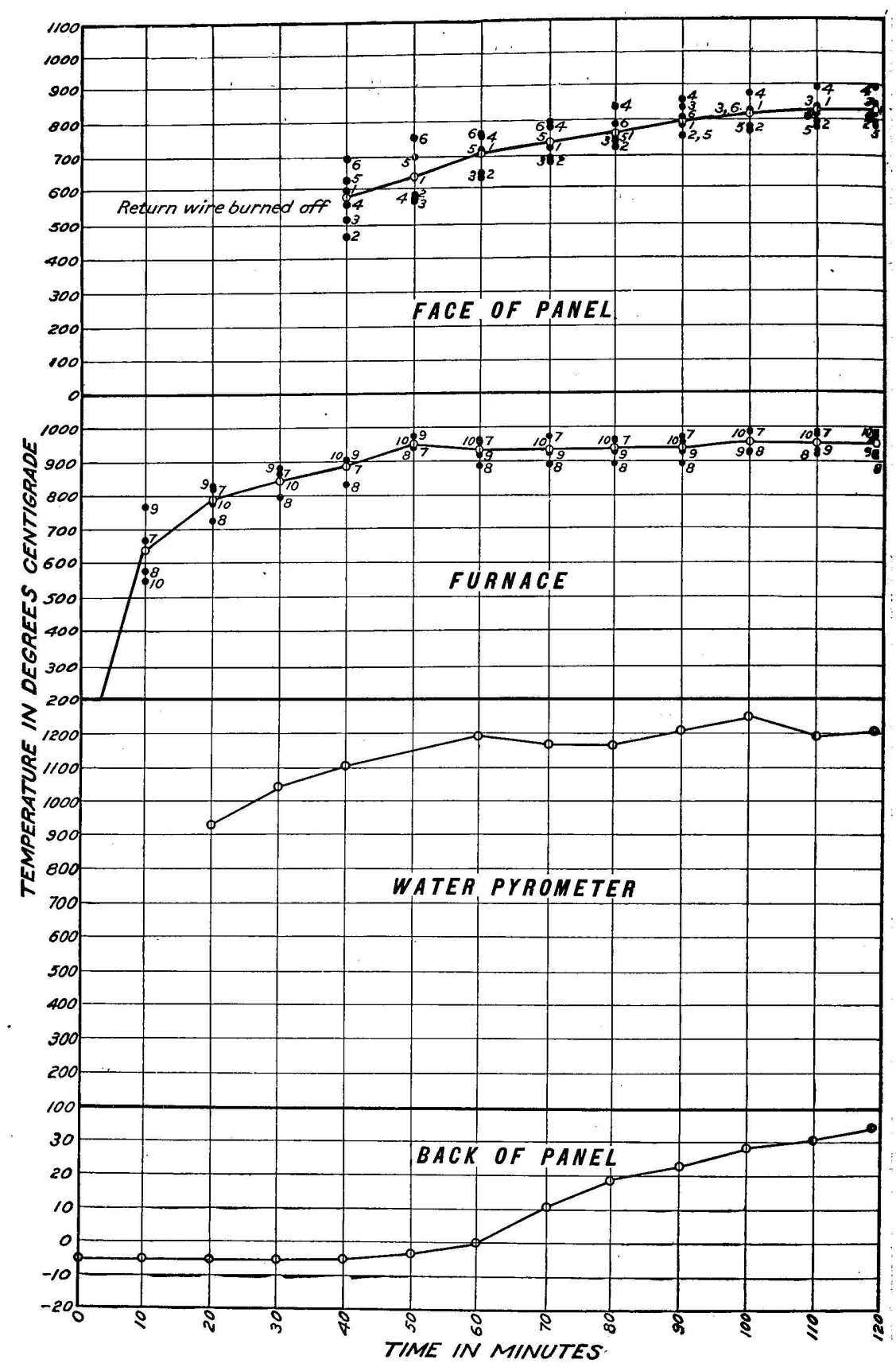

FIGURE 9.-Diagram showing temperature conditions in the furnace and on the back of panel 9. Temperature: Maximum, $24^{\circ}$; minimum, $10^{\circ}$; mean, $20^{\circ}$. Relative humidity: 7 a. m., $95 ; 7$ p. m., 85 . Direction
of prevailing wind, southeast. 
U. S. GEOLOGICAL SURVEY

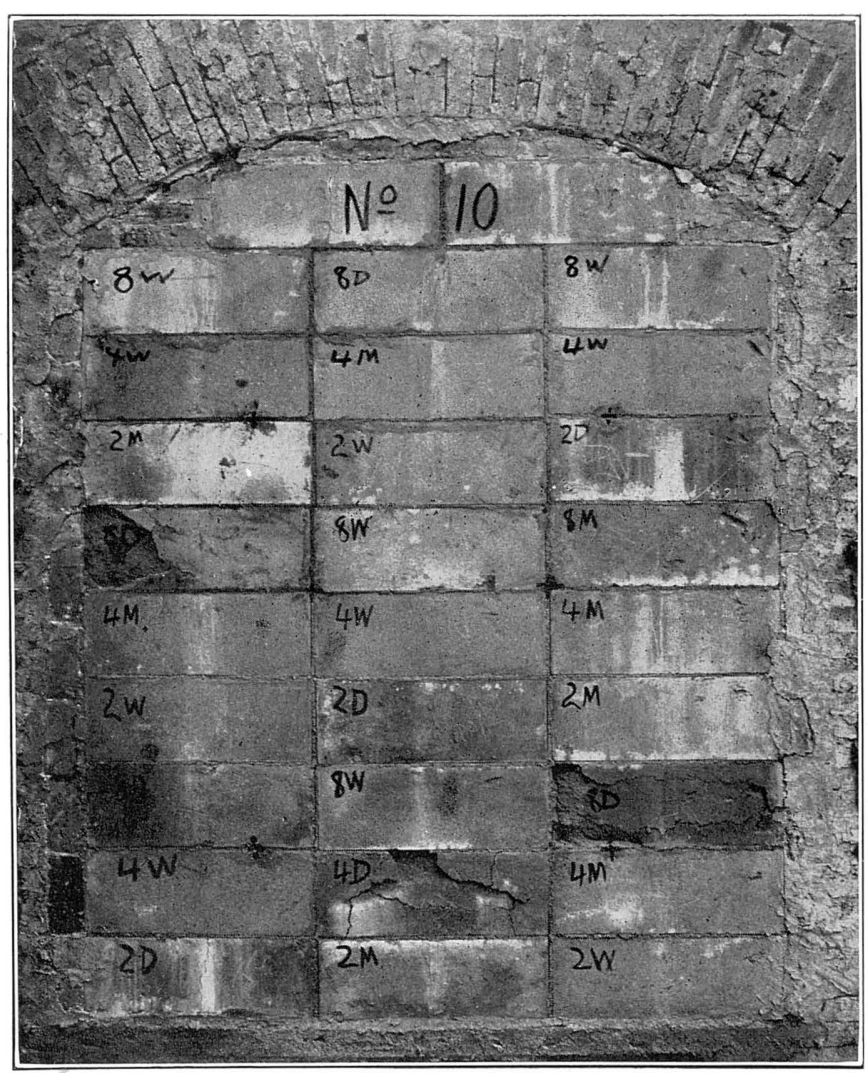

A. FACE OF PANEL 10, CEMENT MORTAR BUILDING BLOCKS, AFTER COOLING IN AIR.

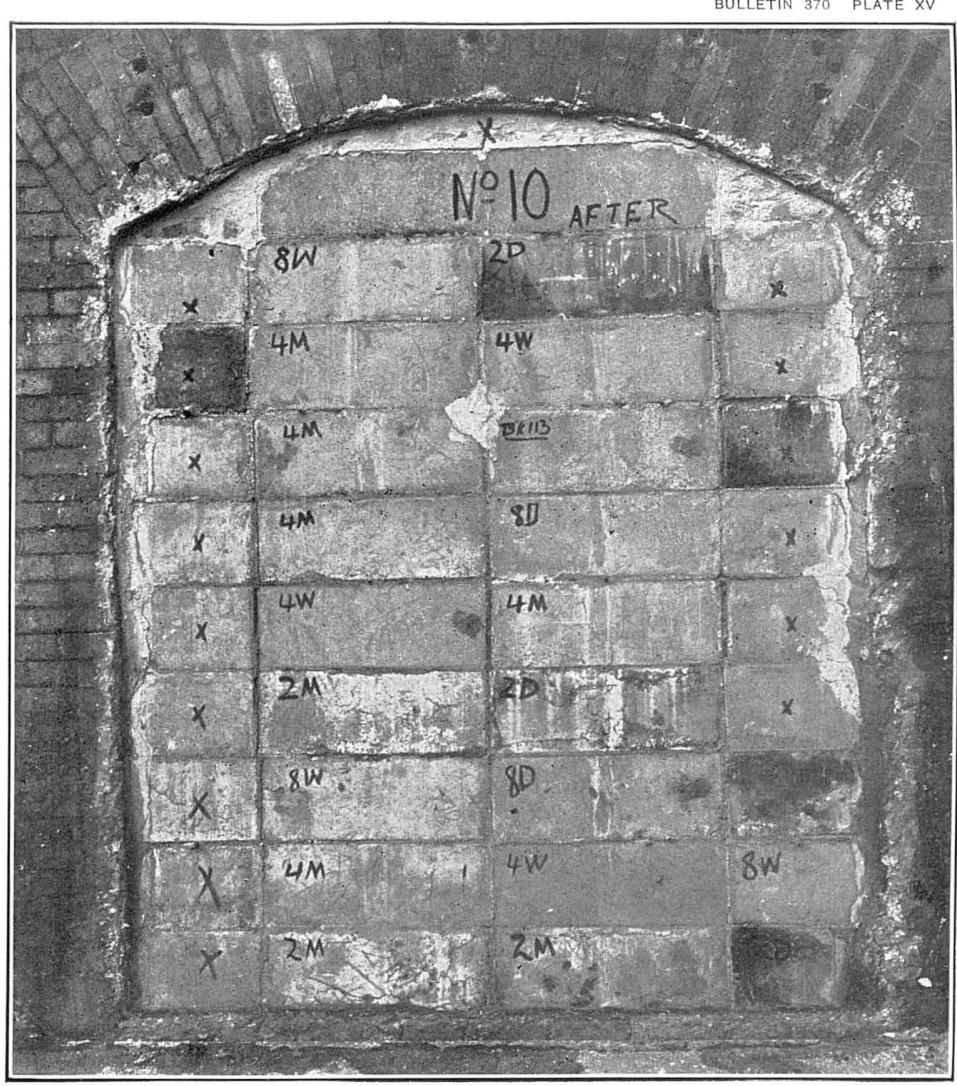

B. BACK OF PANEL 10, CEMENT MORTAR BUILDING BLOCKS, AFTER COOLING IN AIR. 

side of the web, leaving a small piece of the face of the block attached. The webs of two or three of the blocks on the back of the panel were also cracked off. The 1:8 mixtures were badly crumbled and broken into small pieces when taken from the wall. This was true to a considerable extent in the 1:4 blocks, while the $1: 2$ blocks were not broken except at the webs. The blocks composing the back of the wall were apparently undamaged except for one or two cracked webs.

The results of the strength tests are given in Table 9.

PANEL 10 (Mortar Building Blocks).

Material.-Panel 10 was made of two-piece blocks exactly like those tested in panel 9, but was not subjected to the quenching after the fire test. The blocks were stored in the moist room at St. Louis 28 days and at Chicago 32 days, and were tested at the age of 63 days. The panel was laid up in freezing weather.

Test.-Firing was started at 2.11 p. m., February 11, 1907, and continued for 2 hours and 3 minutes, after which the panel was cooled in air, without the application of water. The fire was fairly uniform, but not as hot at the top as at the bottom and center.

In 8 minutes snapping and cracking was observed. At 12 minutes the second block in the second row spalled at the center, the cracks running off at the edges on all four sides. A small piece about 4 inches long. and $\frac{1}{2}$ inch thick fell out on the top edge. The righthand block in the third row spalled from a depth of about 2 inches along the edge to a depth of about $\frac{1}{2}$ inch at the center. The lefthand block in the sixth row spalled and a piece 9 inches long, $\frac{1}{2}$ to $\frac{3}{4}$ inch thick, and the width of the block, fell out. At 70 minutes steam began to come through the joints, especially at the top. No further change was observed.

The temperature curves are shown in figure 10.

Results.-Plate XV, $A$ and $B$, shows the face and back of the panel after the test, and Plate XVI, $A$, the condition of the blocks during the dismantling. On removing the panel from the furnace it was found that, with the exception of the blocks that had already spalled, the surface was comparatively smooth. In about 5 minutes many hair cracks developed over the surface of the blocks. They were more pronounced in the lean mixtures than in the rich ones. As cooling progressed these cracks became more pronounced and covered more of the surface. Vertical cracks running along the webs were not present in this panel. The surfaces of the blocks were found to be very soft, especially in the 1:8 blocks, which could be easily rubbed away with the finger. In the $1: 2$ blocks the surface could be easily scratched with a tool to the depth of $\frac{1}{2}$ inch, in the $1: 4$ blocks to a 


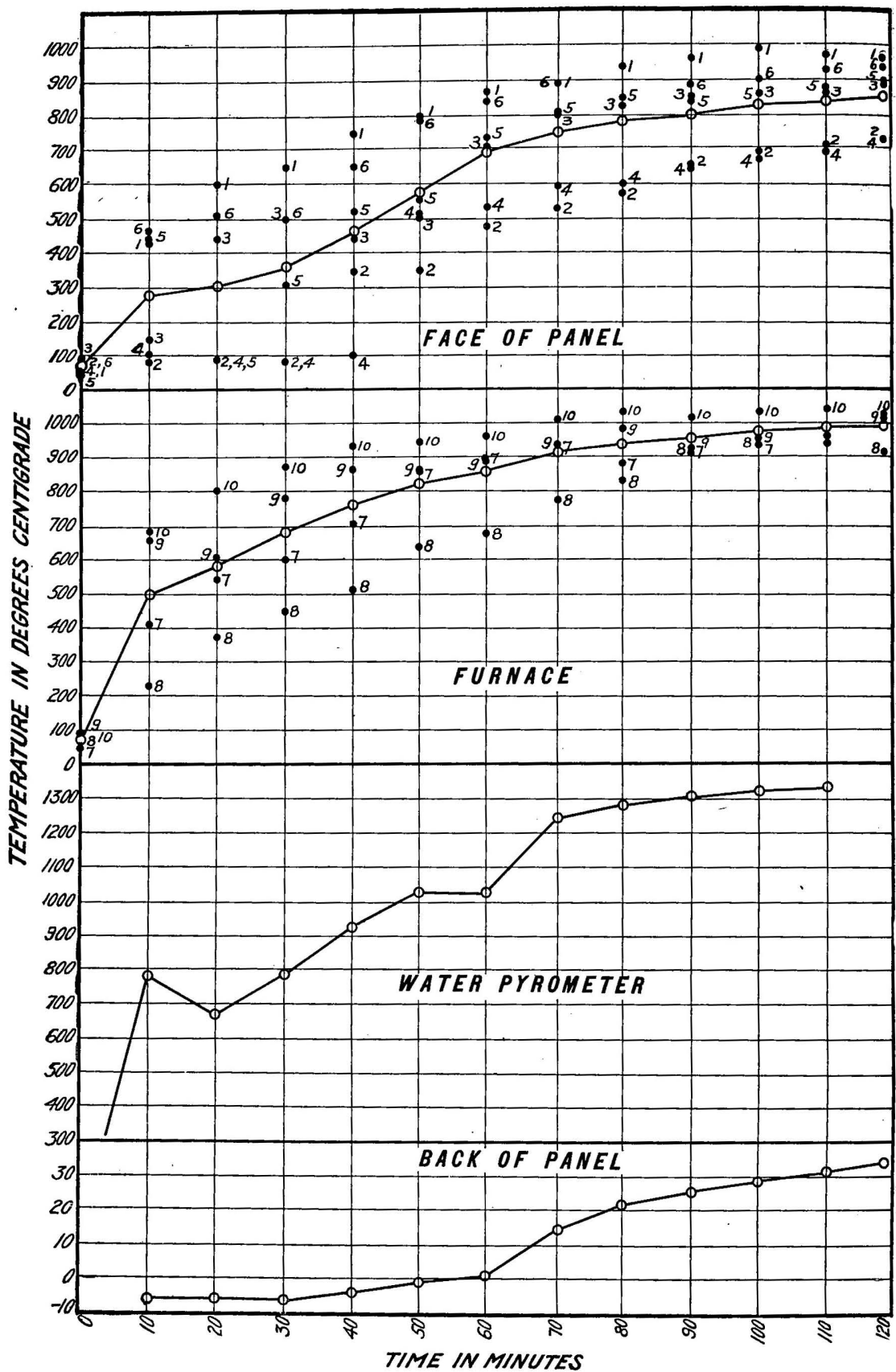

Figure 10.-Diagram showing temperature conditions in the furnace and on the back of panel 10. Temperature: Maximum, $33^{\circ}$; minimum, $18^{\circ}$; mean, $26^{\circ}$. Relative humidity: 7 a. m., $71 ; 7$ p. m., 64 . Direction of prevailing wind, south. 


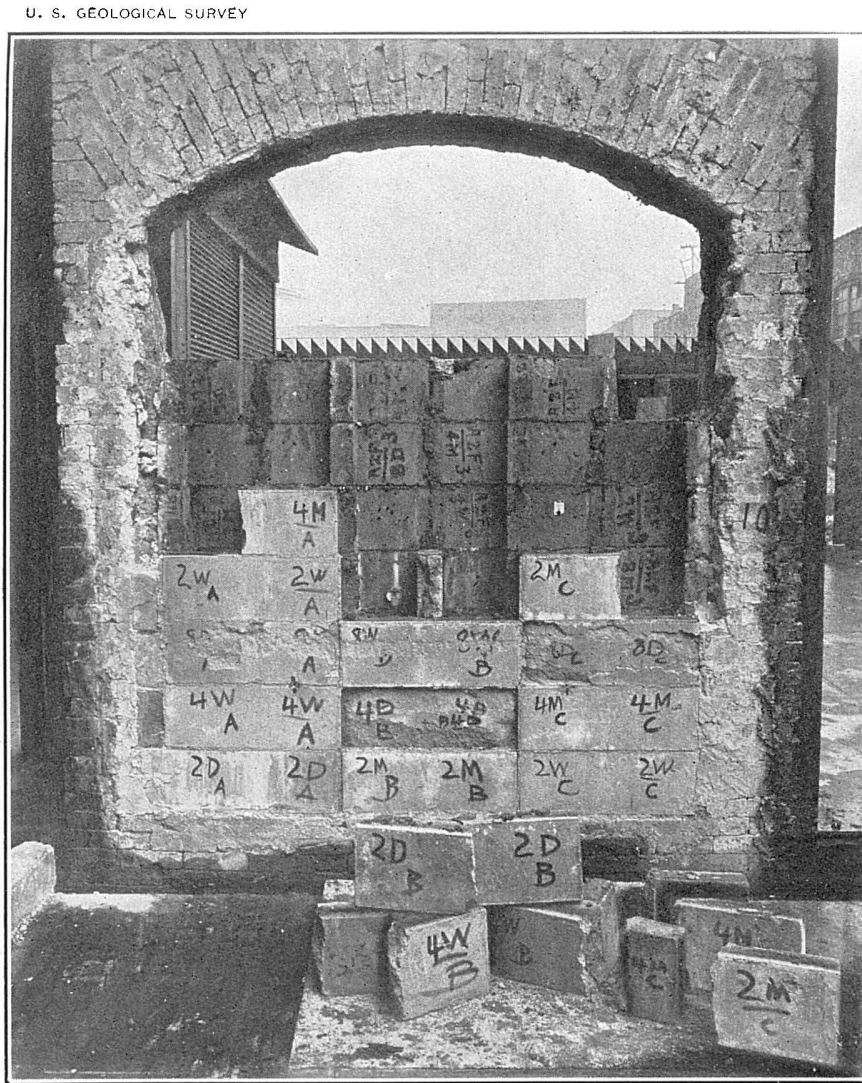

A. PANEL 10, CEMENT MORTAR BUILDING BLOCKS, DURING DISMANTLING.
DULLETIN MA PLATE XVI

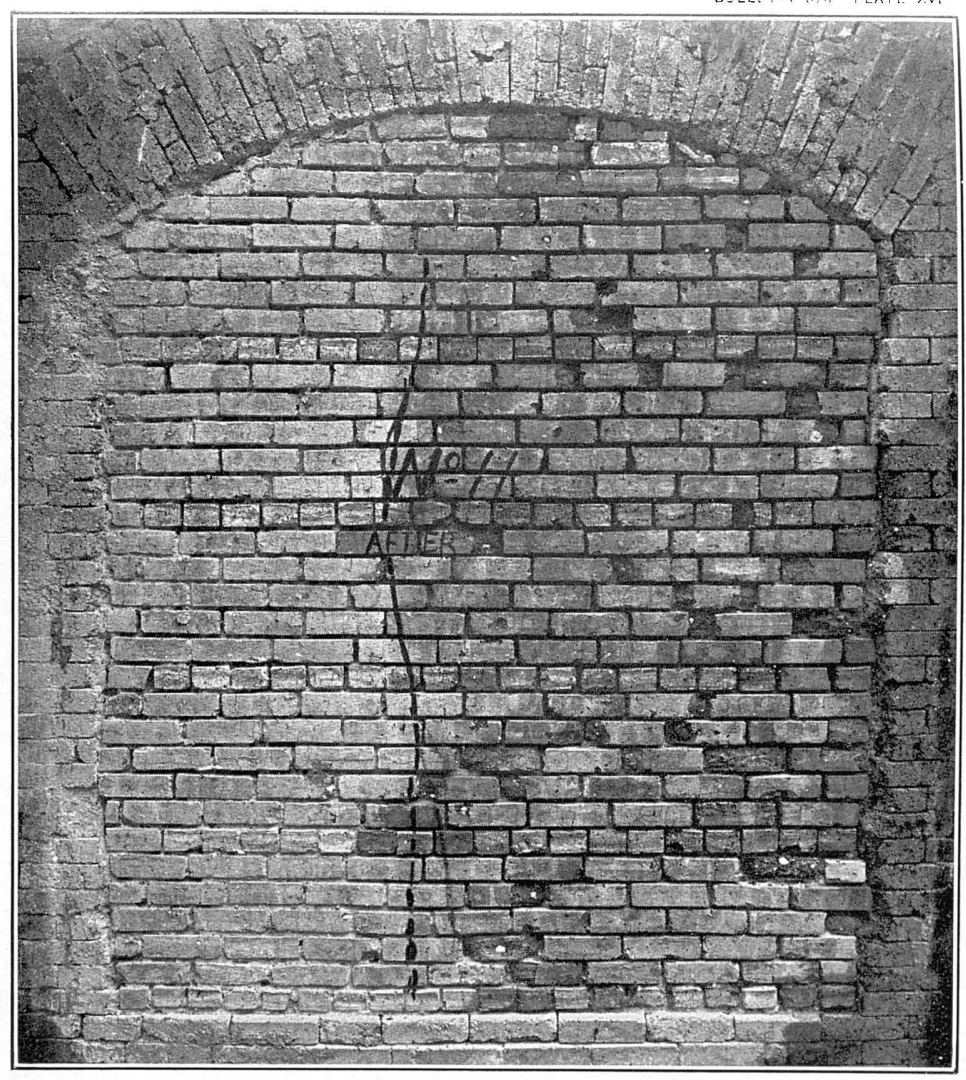

B. FACE OF PANEL 11, COMMON BRICK, AFTER FIRING AND QUENCHING. 

depth of $\frac{3}{4}$ inch, and in the 1:8 blocks to a depth of $1 \frac{1}{2}$ inches. The consistencies apparently had little to do with the behavior of the materials.

On dismantling the panel it was found that the blocks had all cracked across the webs, and in nearly every case across the face near the webs. The blocks were not as a rule broken in small pieces, as was the case (in panel 9) where the water was applied, but the surfaces were easily broken away from the remainder of the materia]. The blocks composing the back of the panel were unaffected, as far as could be observed, and only one or two of the webs were cracked off.

The strength tests of the fragments of these blocks are given in Table 10.

\section{PANEL 11 (Brick).}

Material.-Panel 11 consisted of hard-burned clay bricks of good quality. These bricks were of a light salmon color and contained scattered small lime nodules, which made small black spots at the surface. The physical properties of the bricks are given in Table 11. In this table the transverse strength of the bricks before firing, the compressive strength of the bricks before firing and after firing, the compressive strength after being immersed in water 48 hours before firing, and the percentage of moisture absorbed in 30 minutes, 4 hours, and 48 hours are given.

The panel was built up as a standard 12-inch wall, with headers every seventh row, cement mortar being used.

Test.-The test was made on February 15, 1907, and the firing continued 2 hours and 1 minute, after which the panel was quenched in water for 5 minutes, the water being at a temperature of $36^{\circ} \mathrm{F}$. The fire was uniform over the entire panel.

In 15 minutes there was considerable snapping, which lasted 5 minutes. No cracks or chipping of the bricks was noticed at this time. At 25 minutes it was noticed that two or three of the bricks had pitted and that small pieces of the surfaces had split off, showing small lime nodules, which had probably expanded and burst. These pits were $\frac{1}{4}$ to $\frac{3}{8}$ inch deep. At 75 minutes part of the faces of two bricks cracked off and exposed lime nodules about $\frac{1}{2}$ inch in diameter. No further changes were noticed.

In removing the door a delay of about 3 minutes occurred from the time the fire was shut off until the water was applied, owing to the door's sticking. The 12-inch brick panel loaded the frame somewhat beyond its capacity, so that the counterweights were not heavy enough to draw the door out. In prying the door from the furnace with a crowbar it was severely shaken, but apparently none of the bricks were cracked by the shaking. When the door was halfway 


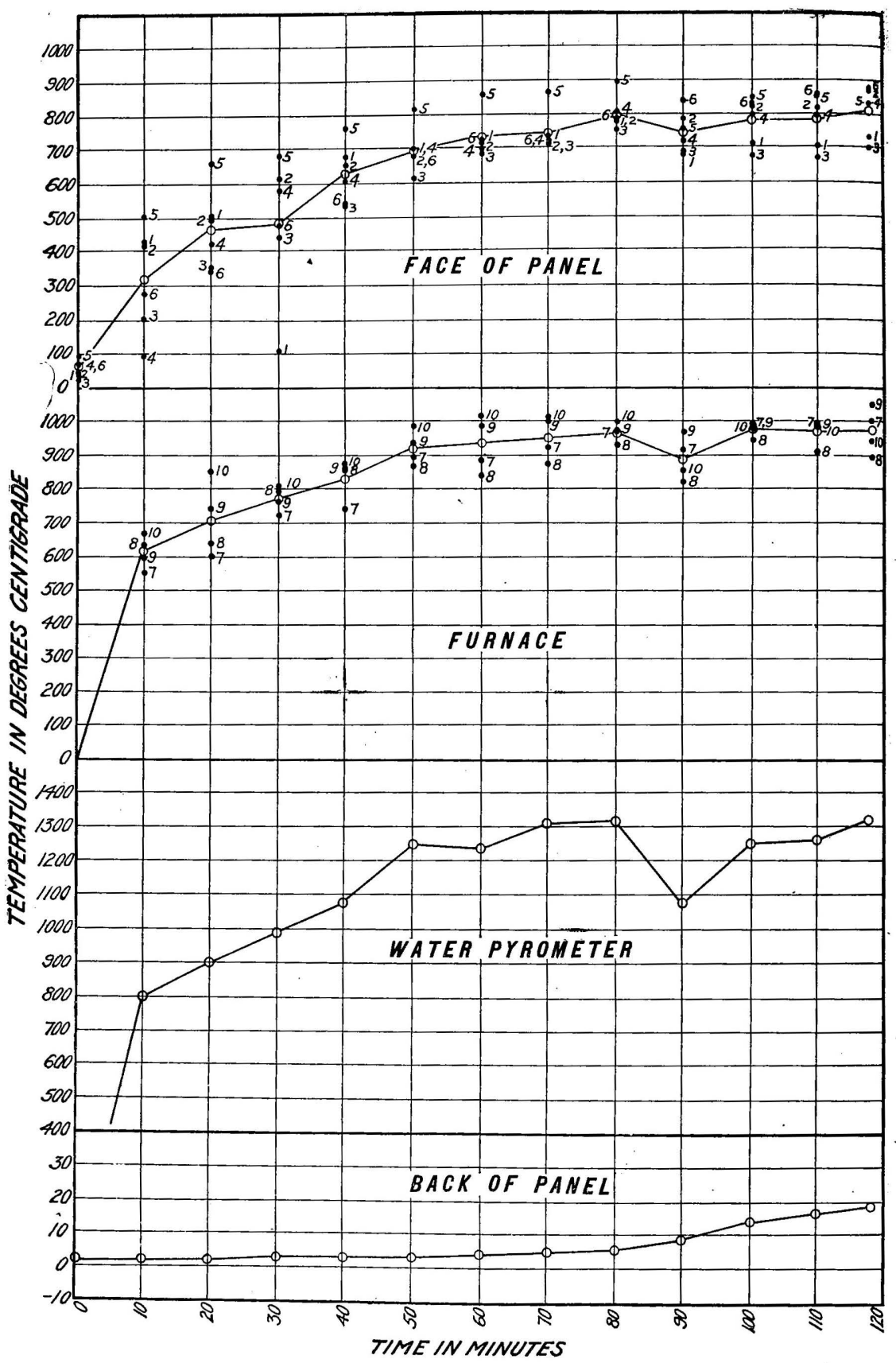

FIGURE 11.-Diagram showing temperature conditions in the furnace and on the back of panel 11. Temperature: Maximum, $50^{\circ}$; minimum, $25^{\circ}$; mean, $38^{\circ}$. Relative humidity: 7 a. m., $76 ; 7$ p. m., 61 . Direction of prevailing wind, southwest. 
out, the attempt to move it farther was abandoned, and the water was applied to the half of the panel which stuck out from the furnace. The portion of the panel which was subjected to the stream of water is shown to the right of the vertical line in Plate XVI, $B$.

The temperature curves are given in figure 11.

Results.-Plate XVI, $B$, shows the face of the panel after the test. About 18 or 20 per cent of the bricks were split and small pieces of the surface were washed away. After cooling, 60 or 70 per cent of the bricks were found to be cracked and split sufficiently to permit picking off portions. In most cases this splitting extended into the brick from $\frac{1}{2}$ inch to $1 \frac{1}{4}$ inches. Where water did not strike directly upon the panel, the bricks were not so badly broken, and from only a small percentage of them could portions be picked.

On dismantling the panel, however, it was found that about 60 per cent of the bricks not exposed to the water were cracked, but the depth of these cracks was not as great as in the bricks exposed. to the water. In nearly every crack a lime knot was found at the bottom. The bricks on the back of the panel and the fillers were apparently unaffected, and the mortar holding these two layers together was apparently as hard as before the test. The mortar on the face was washed away about $\frac{1}{2}$ inch.

PANEL 12 (Brick).

Material.-The face of panel 12 was composed of hydraulic-pressed bricks of a dark-red color, uniform in size, with square edges and corners. The surfaces were fine grained and free from knots and cracks. The back of the panel was composed of common bricks taken from panel 11. The bricks were laid as an 8-inch wall, with blind headers every sixth row, in cement mortar, the faces being laid in lime putty, as is customary with this class of brick. The panel was frozen when the test began.

The physical tests of these bricks are given in Table 12.

Test.-This panel was fired February 19, 1907, for 2 hours and 1 minute, and cooled by quenching with water for 5 minutes, the water being at a temperature of $36^{\circ} \mathrm{F}$. At the start the fire was well distributed and of a uniform color throughout.

In 15 minutes no snapping had been noted. During the entire test no cracking or spalling of the bricks could be observed. The heat was apparently well distributed except that there was a deposit of soot on the lower and central parts of the panel.

Curves showing the variations in temperature are given in figure 12. Results.-Plate XVII, $A$, shows the face of the wall after the test. On removal from the furnace one-third of the bricks were badly discolored. Only seven were seen to be cracked or pitted before the application of the water, and these defects were on the corners and 


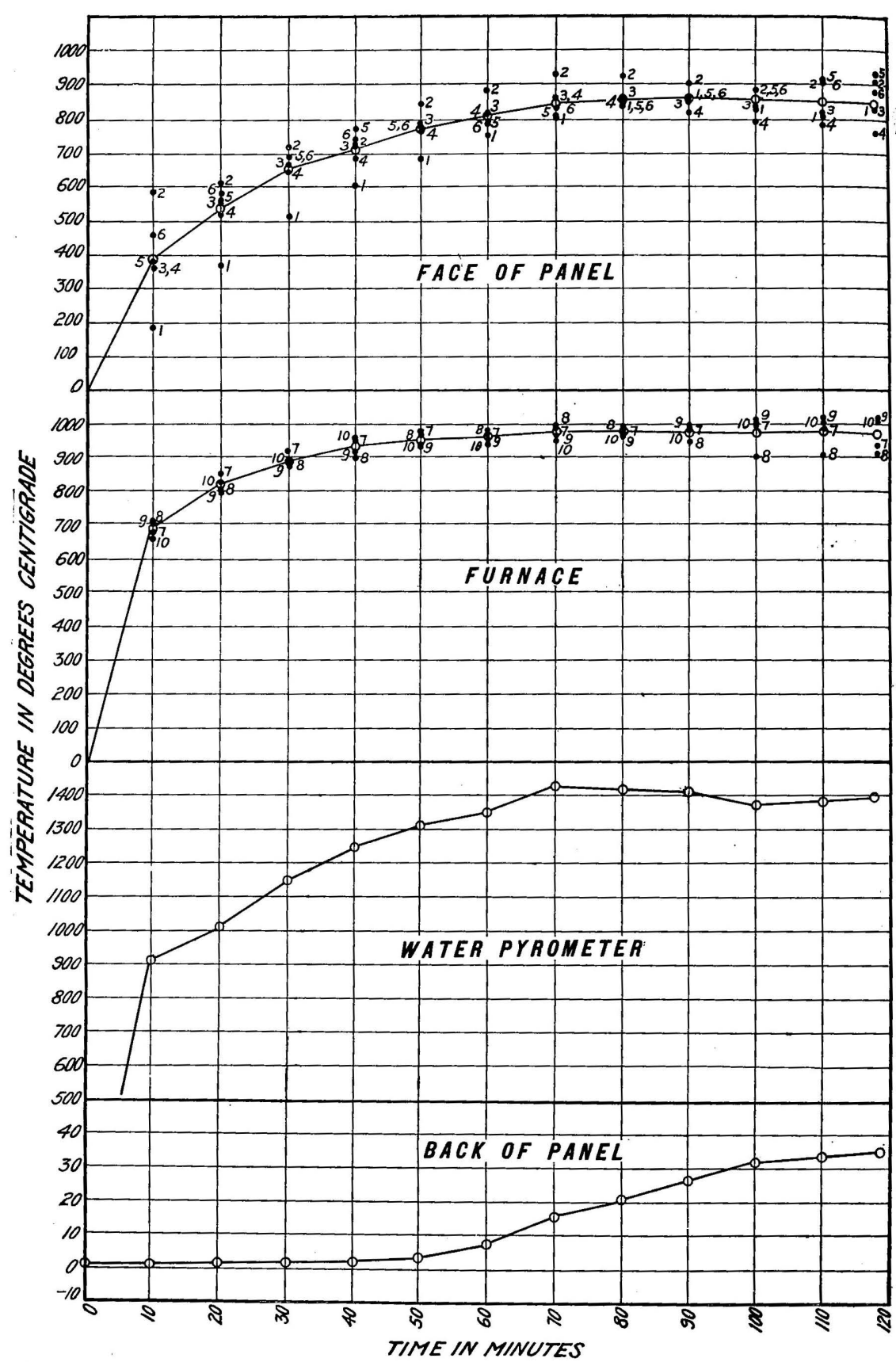

FIGURE 12.-Diagram showing temperature conditions in the furnace and on the back of panel 12. Temperature: Maximum, $45^{\circ}$; minimum, $32^{\circ}$; mean, $38^{\circ}$. Relative humidity: 7 a. m., $70 ; 7$ p. m., 53. Direction of prevailing wind, west. 


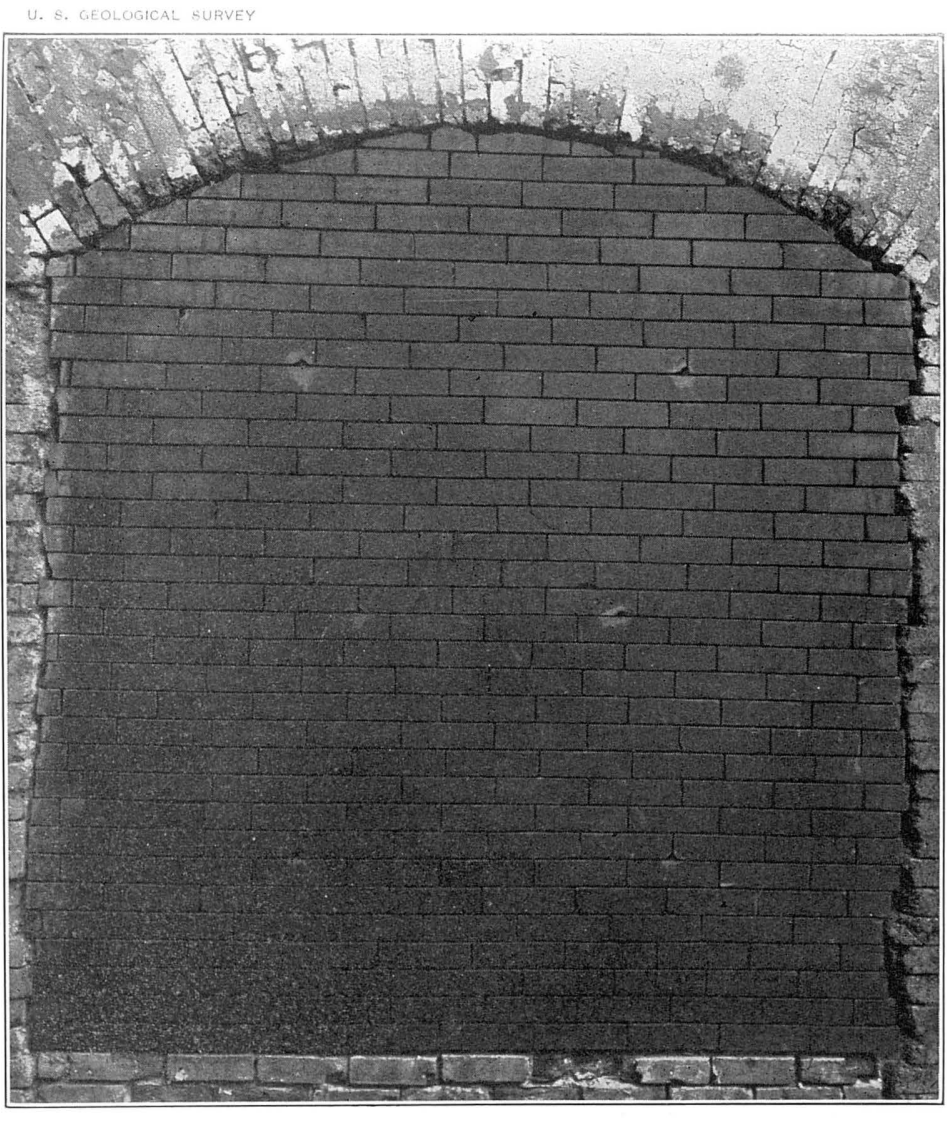

A. FACE OF PANEL 12, HYDRAULIC PRESSED BRICK, AFTER FIRING AND QUENCHING.

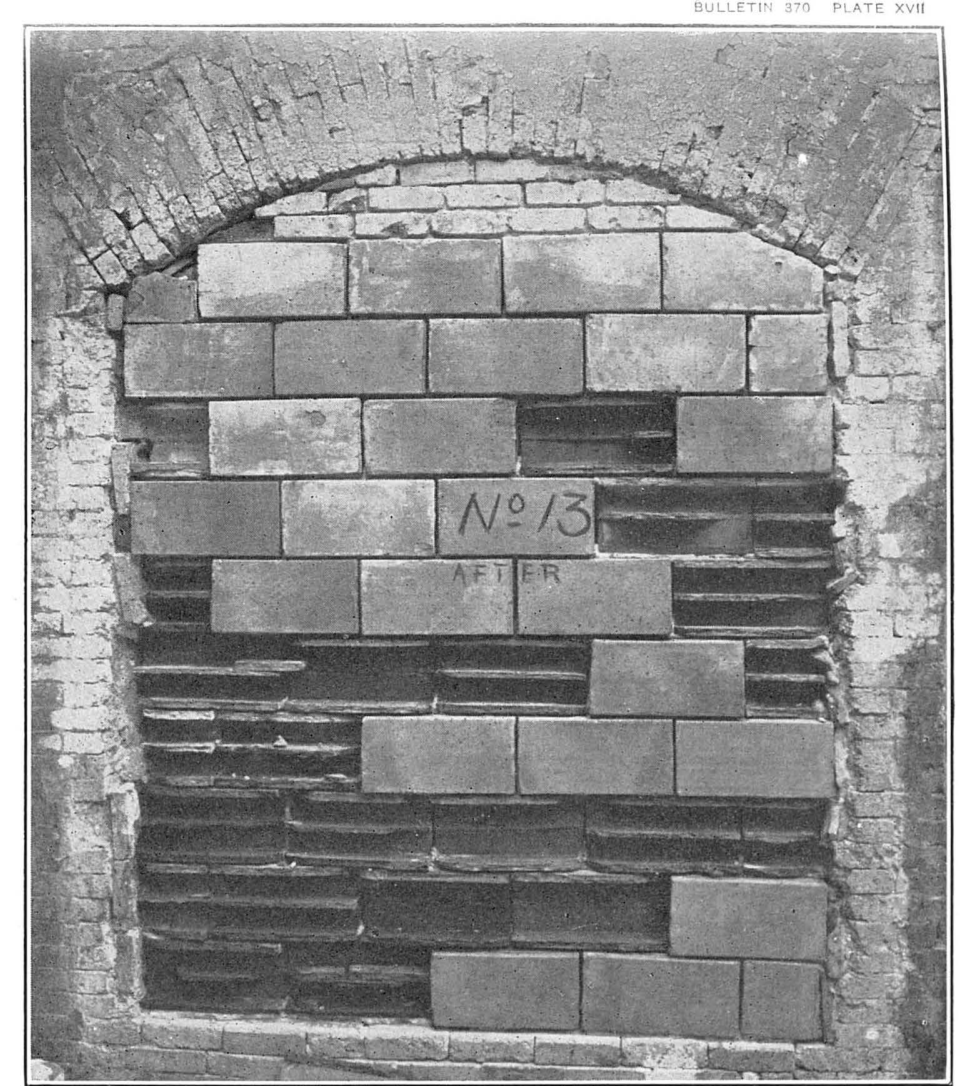

B. FACE OF PANEL 13, BUILDING TILE, AFTER FIRING AND QUENCHING. 

represented a very small area of the bricks. After quenching with water about 18 per cent of the bricks were cracked through. None of them except those above mentioned were found to be spalled. After the test the wall was found to be apparently sound, though smoke stained. It could have been left standing and the injured bricks replaced by new ones without impairing its strength.

On dismantling, about 70 per cent of the bricks were found to be apparently sound.

\section{PANEL 13 (Tile).}

Material.-Panel 13 consisted of semiporous glazed building tile (figure 13), of a light-brown color, but of several shades. The webs

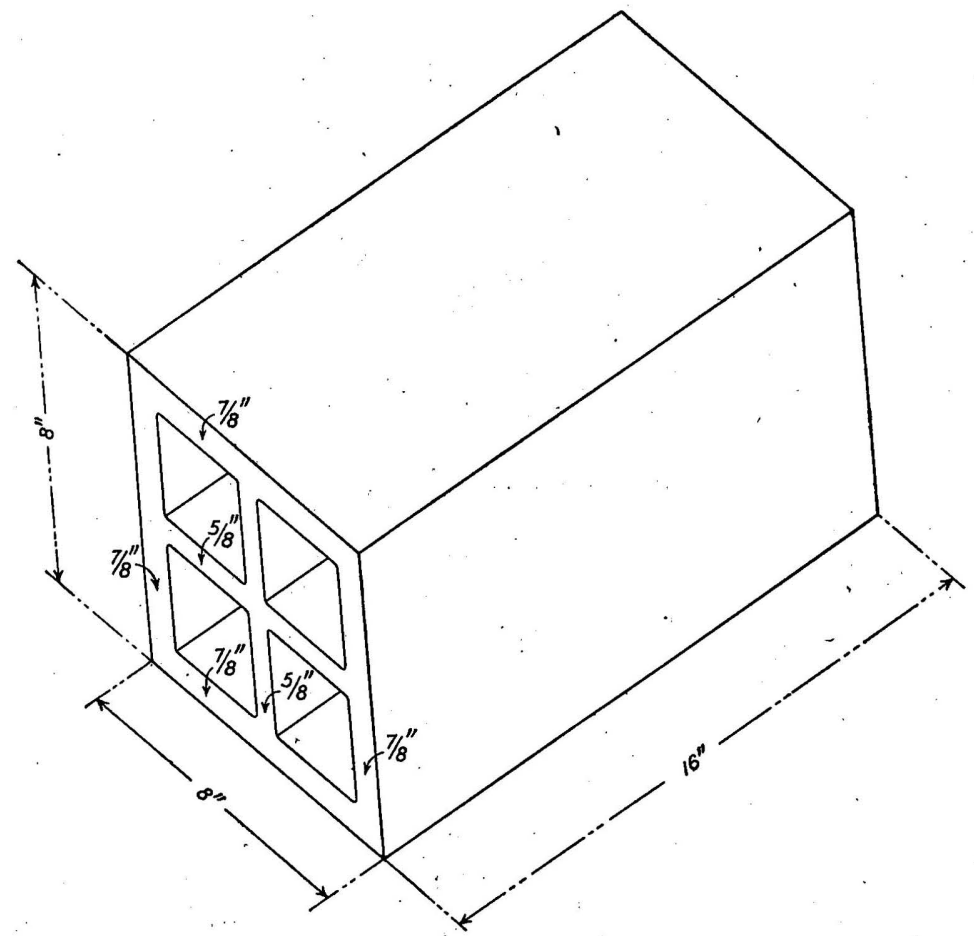

FIGURE 13.-Sketch of glazed building tile used in panel 13.

of the tiles were more or less cracked and checked, especially where they joined the faces. The webs were very small and apparently did not prevent this condition of affairs. The faces were more or less rough and warped.

The tiles were laid on an 8-inch face, in cement mortar, with their long dimension in the horizontal plane. The joints were about $\frac{1}{2}$ inch and were broken. This exposed an 8-inch face to the fire. The panel was laid up in freezing weather.

Tests. - The panel was fired February 26, 1907, for 2 hours and 1 minute and quenched with water for 5 minutes, the water being ata 
temperature of $36^{\circ} \mathrm{F}$. An even fire was obtained at the start, and the fire was about uniform over the entire panel. No crackling or snapping was observed at any part of the test.

In 30 minutes a tile in the ninth row, third from the left side, split horizontally just under the center web. At 50 minutes a tile in the center of the eighth row spalled on the surface and a small piece (about 2 inches) came off. During the remainder of the test no further changes were observed.

The temperature curves are given in figure 14 .

Results.-Plates XVII, $B$, and XVIII, $A$, show the face and back of the panel after quenching. On removing the panel from the furnace none of the faces were apparently cracked, but in the quenching about 45 per cent of the faces fell off. During the first 2 minutes of the water treatment the tiles snapped and crackled appreciably, but not until about 2 minutes had elapsed did any of the faces actually fall from the panel.

After cooling, it was found that about 80 per cent of the tiles were badly cracked; on gently tapping those that remained in place the faces came off many of them. The faces that remained in place were found to be badly cracked, but firmly attached. The surfaces of the tiles had the same appearance as before the fire, except that small irregular hair cracks covered the entire face. The material composing the face could be easily broken in the hand. In nearly every case the webs failed near the fired face. In a few cases the failure was diagonally across the web where the web joined the center web. The back of the panel was apparently uninjured, and in but few cases were cracks observed in the webs lying in a vertical plane. The mortar was washed out of the joints from 1 inch to 3 inches deep, and between a few tiles it was entirely washed out so that the water passed through the joints and ran down the back of the panel.

PANEL 14 (Mortar Building Blocks).

Material.-Panel 14 consisted of 27 "typical Portland" cement and slag-sand mortar one-piece single-air-space blocks made of a medium consistency of $1: 1 \frac{1}{2}, 1: 2 \frac{1}{2}$, and $1: 4$ mixtures. The specimens were 63 days old when tested. They were cured in a moist room and sprinkled twice daily for 14 days and were then cured in air, being protected from the sun, for 49 days. The blocks were laid in fire clay with the joints not broken. This was done to avoid cutting the specimens to make them fit the door.

Test.-The panel was fired on May 23, 1907, for 2 hours and 2 minutes and was cooled by the application of water at $50^{\circ} \mathrm{F}$. for 5 minutes. One minute elapsed between the time of removing the door from the furnace and the application of the water. The temperature of the furnace was even from the start. Curves showing 


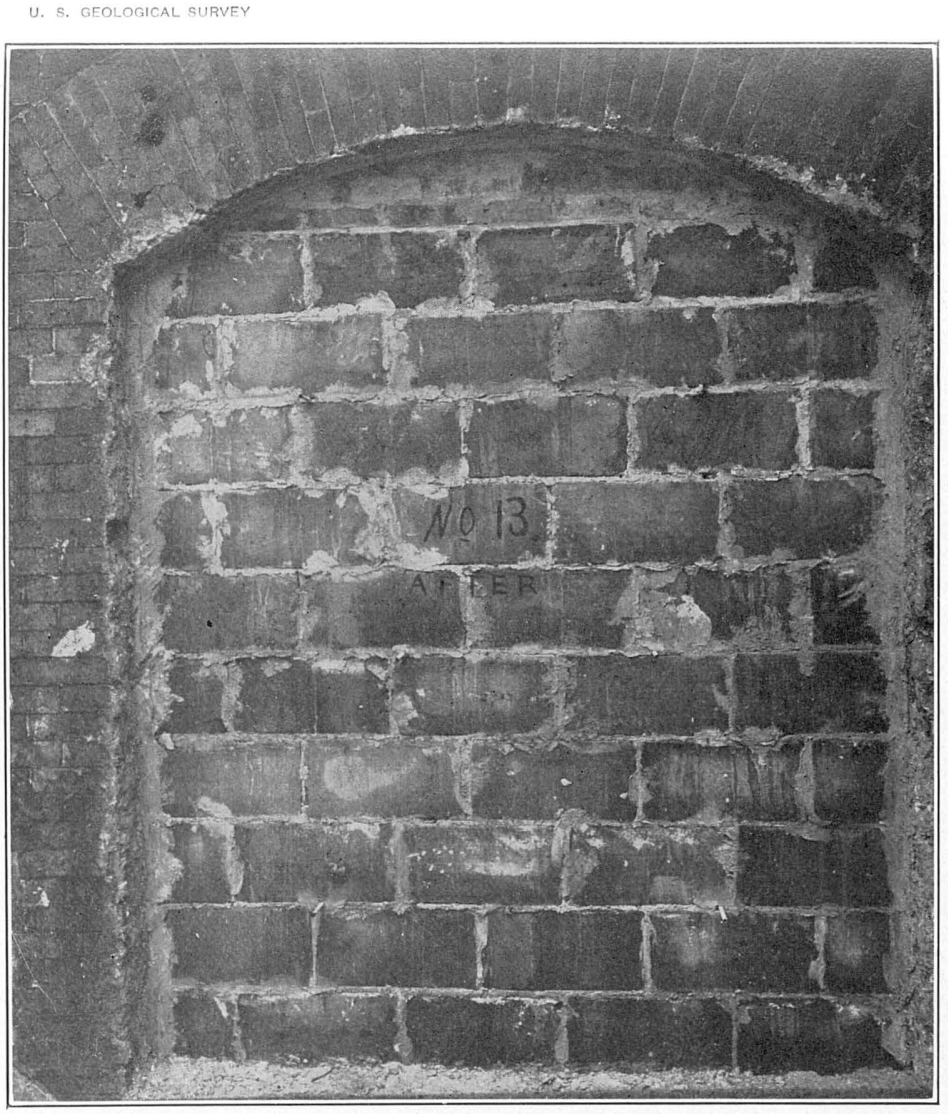

A. BACK OF PANEL 13, BUILDING TILE, AFTER FIRING AND QUENCHING.

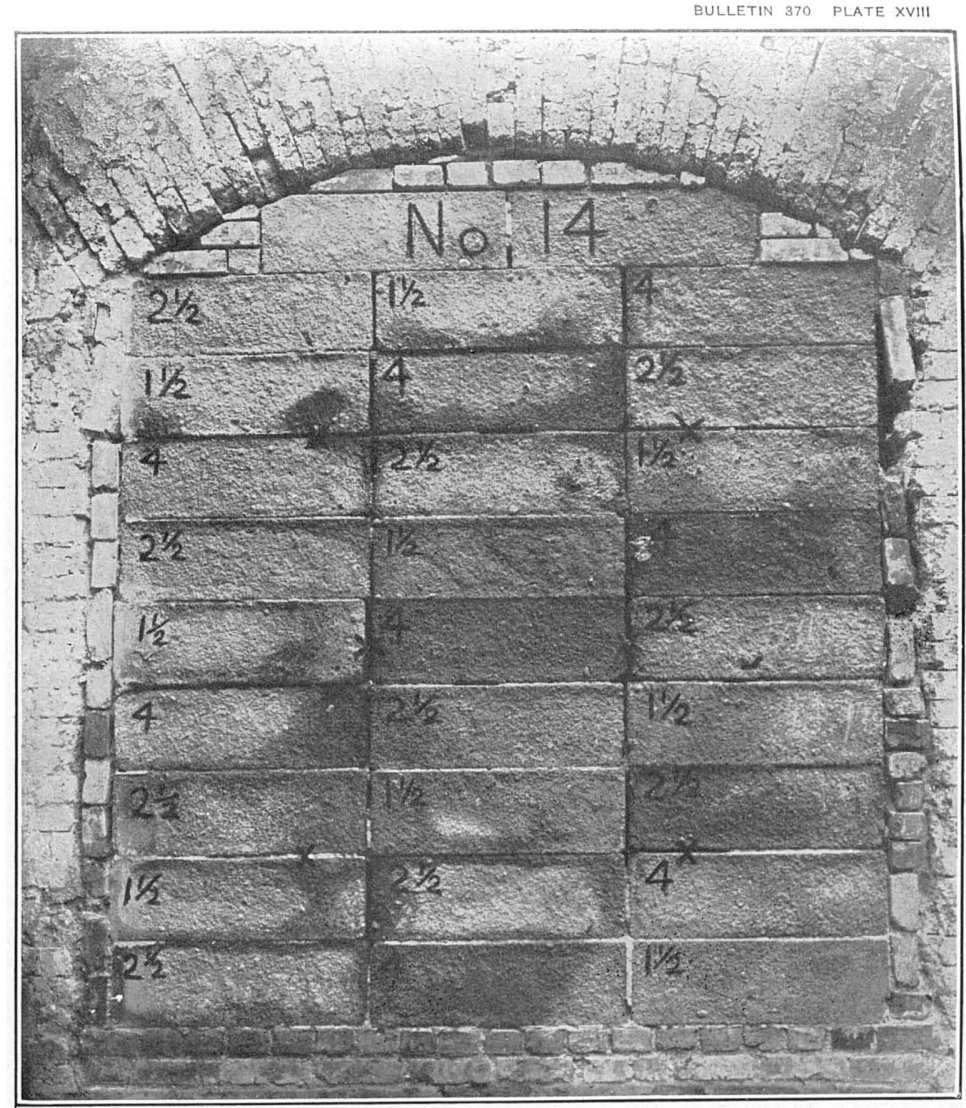

B. FACE OF PANEL 14, CEMENT MORTAR BUILDING BLOCKS, AFTER FIRING AND QUENCHING. 



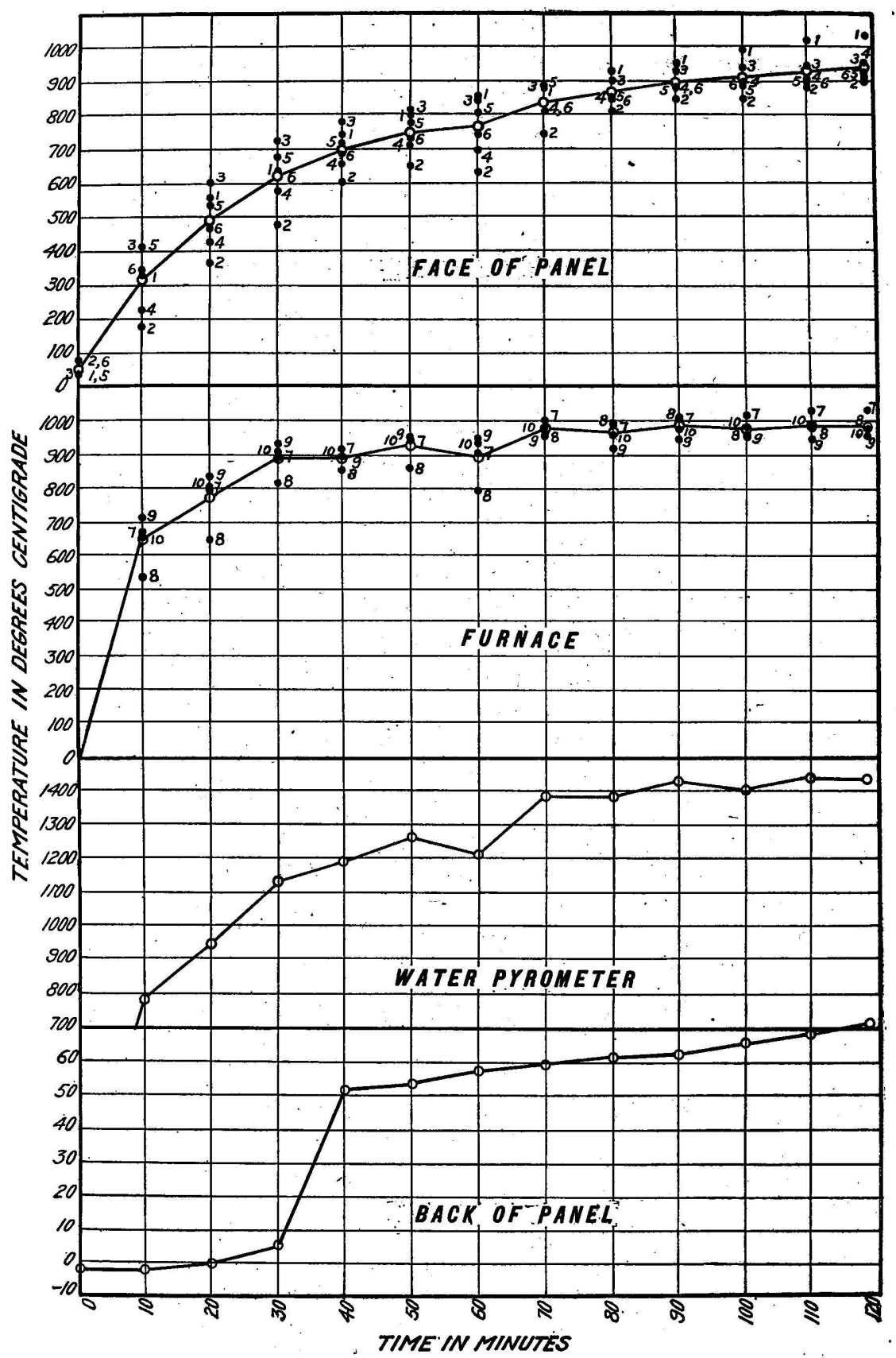

FIGURE 14.-Diagram showing temperature conditions in the furnace and at the back of panel 13. Temperature: Maximum, $37^{\circ}$; minimum, $26^{\circ}$; mean, $32^{\circ}$. Relative humidity: 7 a. m., $79 ; 7$ p. m., 78 . Direction or prevarung wind, southeast. 
the various temperatures recorded during the test are given in figure 15 .

In 13 minutes the blocks began to turn dark red. No snapping was noted throughout the test. At 55 minutes the blocks in the second row on the right end cracked in lower left corner, and a small piece, about $\frac{1}{2}$ inch thick by 2 square inches in area, fell out. During the remainder of the test no apparent change occurred.

Results.-On removal of the panel from the furnace, before the water was applied, there were no cracks or spalled places observed. The face of the panel was badly smoke stained, especially at the bottom and about halfway up the panel at the center. The effect of the water was to wash the spalled portion away to the depth of about $\frac{1}{4}$ to $\frac{3}{8}$ inch on the $1: 1 \frac{1}{2}$ mixtures, $\frac{1}{2}$ to $\frac{5}{8}$ inch on the $1: 2 \frac{1}{2}$ mixture, and $\frac{1}{2}$ to $\frac{3}{4}$ inch on the $1: 4$ mixture. The resulting surfaces were rough and pitted, but were nearly as hard as the unaffected portions of the block. That the $1: 1 \frac{1}{2}$ proportion had not been as well mixed as the others was shown by small lumps of cement appearing on the surface.

Plate XVIII, $B$, shows the panel face after firing, and Plate XIX, $A$, the back of the panel after firing. Plate XIX, $B$, is reproduced from a photograph taken while dismantling the panel.

Only one block, a 1:4 mixture, had split through the webs; the cracks developed across the webs close to the fired side. The face of this block which had been exposed to the fire was apparently uncracked and was lifted from the wall intact. The remainder of the blocks were strong enough to be handled and were later tested for transverse and compressive strength.

\section{PANEL 15 (Mortar Building Blocks).}

Material.-Panel 15 consisted of 27 mortar blocks made on a single-air-space block machine. A medium consistency was used for the three mixtures, 1:2, 1:4, 1:8, "typical Portland" cement and Meramec River sand being the ingredients. The specimens were cured in a moist room for 10 days and in air protected from the sun's rays for 53 days, making them 63 days old when tested.

Test.-The panel was fired at 9.12 a. m. May 27, 1907, for 2 hours and 1 minute, at the end of which time a stream of water at $51^{\circ} \mathrm{F}$. was played on the hot wall for 5 minutes. One minute elapsed between the time the furnace was shut down and the application of the water.

The blocks were laid in fire clay without breaking the joints. The temperature of the whole panel was quite uniform from the start: No snapping was observed during the test and no spalling or cracking was observed up to the time of the application of water. 
U. S. GEOLOGICAL SURVEY

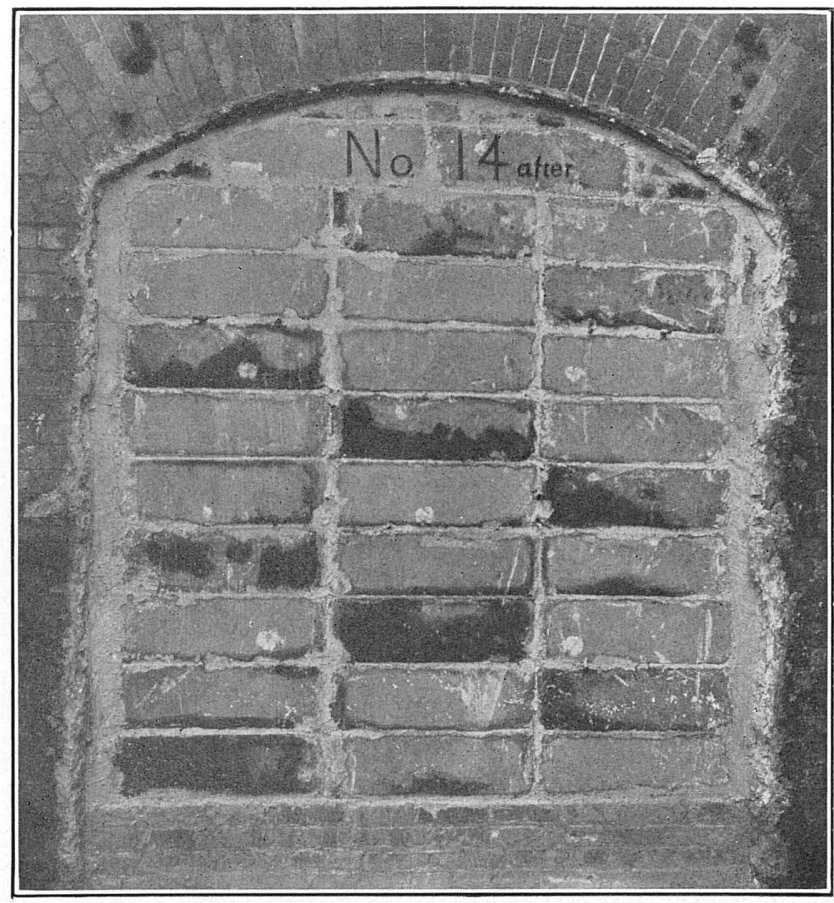

A. BACK OF PANEL 14, CEMENT MORTAR BUILDING BLOCKS, AFTER FIRING AND QUENCHING.

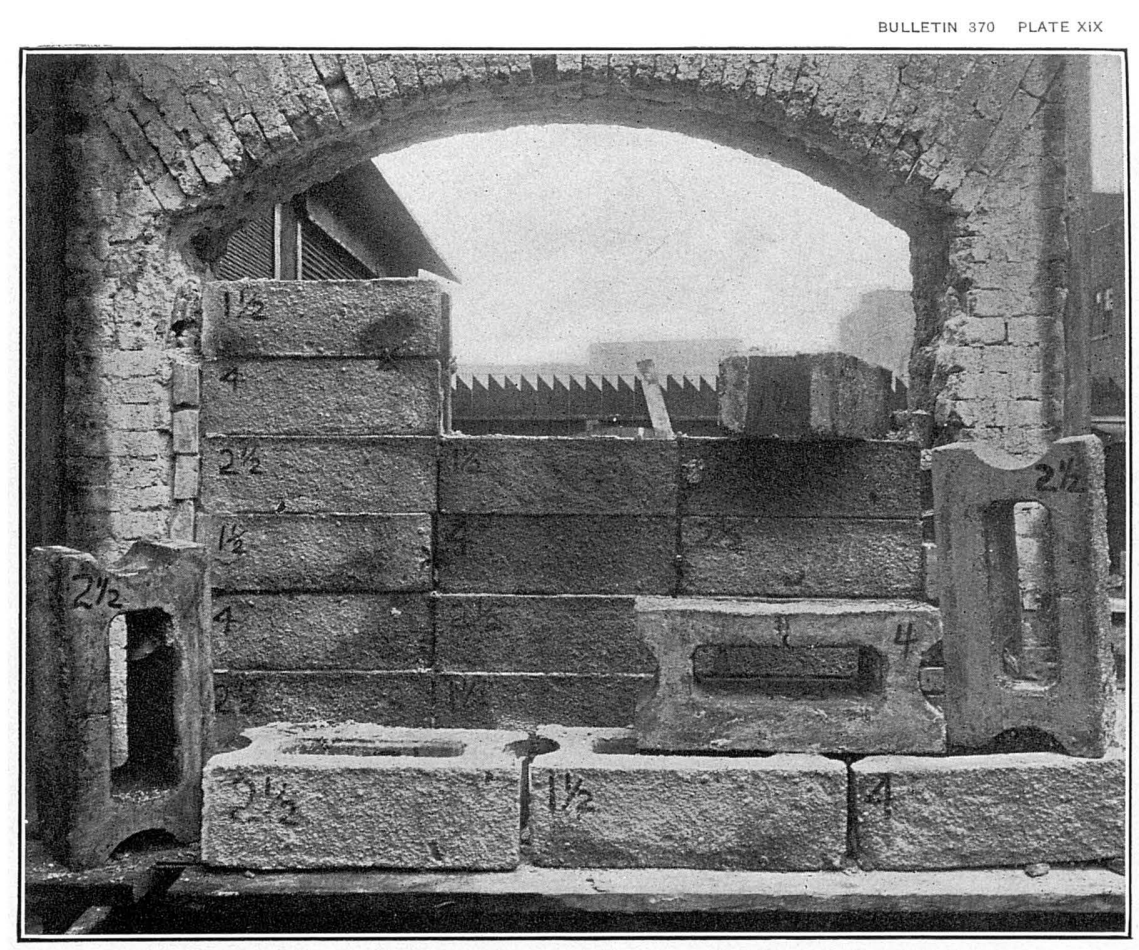

B. PANEL 14, CEMENT MORTAR BUILDING BLOCKS, DURING DISMANTLING. 



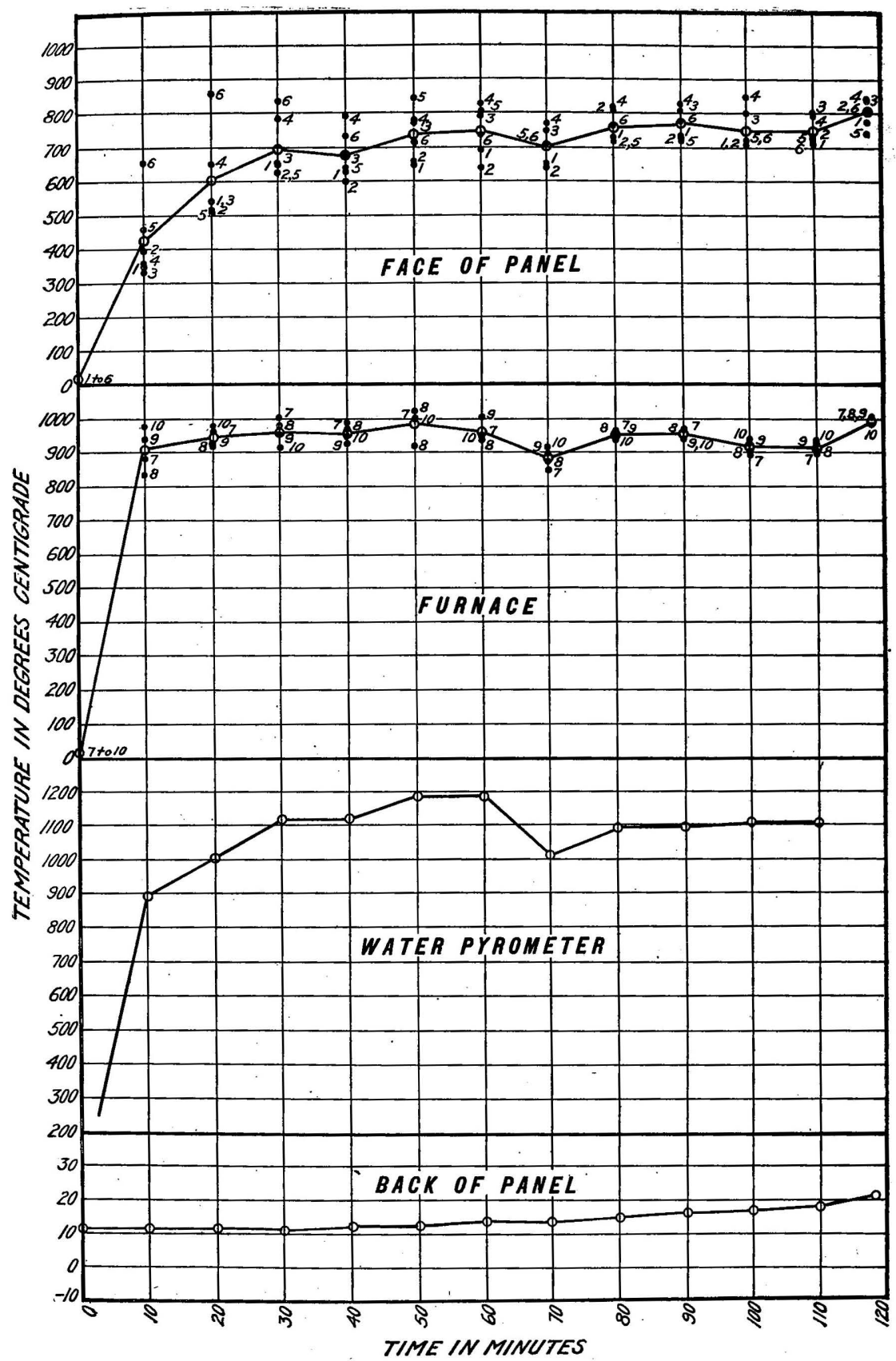

FIGURE 15.-Diagram showing temperature conditions in the furnace and at the back of panel 14. Tem perature: Maximum, $51^{\circ}$; minimum, $46^{\circ}$; mean, $48^{\circ}$. Relative humidity: 7 a.m., $97 ; 7$ p. m., 94 . Direc tion of prevailing wind, northeast. 
Curves showing the variations of temperature observed during the test are given in figure 16.

Results.--In removing the panel from the furnace it failed to slide clear, and consequently a strip about 10 inches wide on the left side was not exposed to the direct stream of water. The 1:2 mixture spalled to a depth of about $\frac{1}{8}$ to $\frac{1}{2}$ inch, the $1: 4$ to about $\frac{3}{4}$ inch to 2 inches, and the $1: 8$ about the same as the $1: 4$. On all the $1: 2$ specimens portions of the surface remained intact, but were covered with small hair cracks and could be easily crumbled with the fingers. The remainder of the blocks were hard, but in every case they were badly cracked and pitted. This was particularly true of the $1: 8$ mixtures. One block of a 1:8 mixture, in the seventh row, right-hand side, was cracked on the back side. This was the only specimen which cracked in this manner in any of the tests on mortar blocks.

Plate XX, $A$, shows the face of the wall after firing, and Plate $\mathrm{XX}, B$, shows the condition of the wall while being dismantled. On taking down the panel it was found that all the blocks except one 1:8 block had cracked across the web at the fired side. One web of this block was cracked on the fired side, while the other cracked across to the back side of the block. The faces of all the 1:8 blocks crumbled and fell to pieces when removed from the panel, and a few of the $1: 4$ blocks were found to be cracked through the fired side. This was also found to be the case with one of the 1:2 blocks. The portions of the blocks on the fired side were seemingly intact and hard, but on gentle tapping could be broken into very small pieces. The back surfaces and the attached webs were as hard as before the fire treatment, and there was apparently no change in their condition.

PANEL 16 (Mortar Building Blocks).

Material.-Panel 16 was composed of 27 one-piece single-air-space building blocks, 9 each of $1: 2,1: 4$, and 1:8 "typical Portland" cement and Meramec River sand. These blocks were tested when 63 days old, having been cured in a moist room for 3 days, being sprinkled twice daily, in air under cover for 7 days and exposed to the weather, but protected from the direct rays of the sun for 53 days.

Test.--The fire was started at 1.19 p. m. May 28, 1907, and continued for 2 hours and 1 minute. Immediately on removing the panel from the furnace it was quenched by a stream of water at $51^{\circ}$ F. for 5 minutes. No snapping was observed during the test.

In 40 to 45 minutes a black spot was observed on the right side and about the middle of the panel, indicating a drop in temperature at this point. At 60 minutes the burner on the right side of the furnace became clogged and caused the temperature on that side of the panel to drop a little. The black spot above mentioned had disappeared in the interval. At 70 minutes the furnace was readjusted 


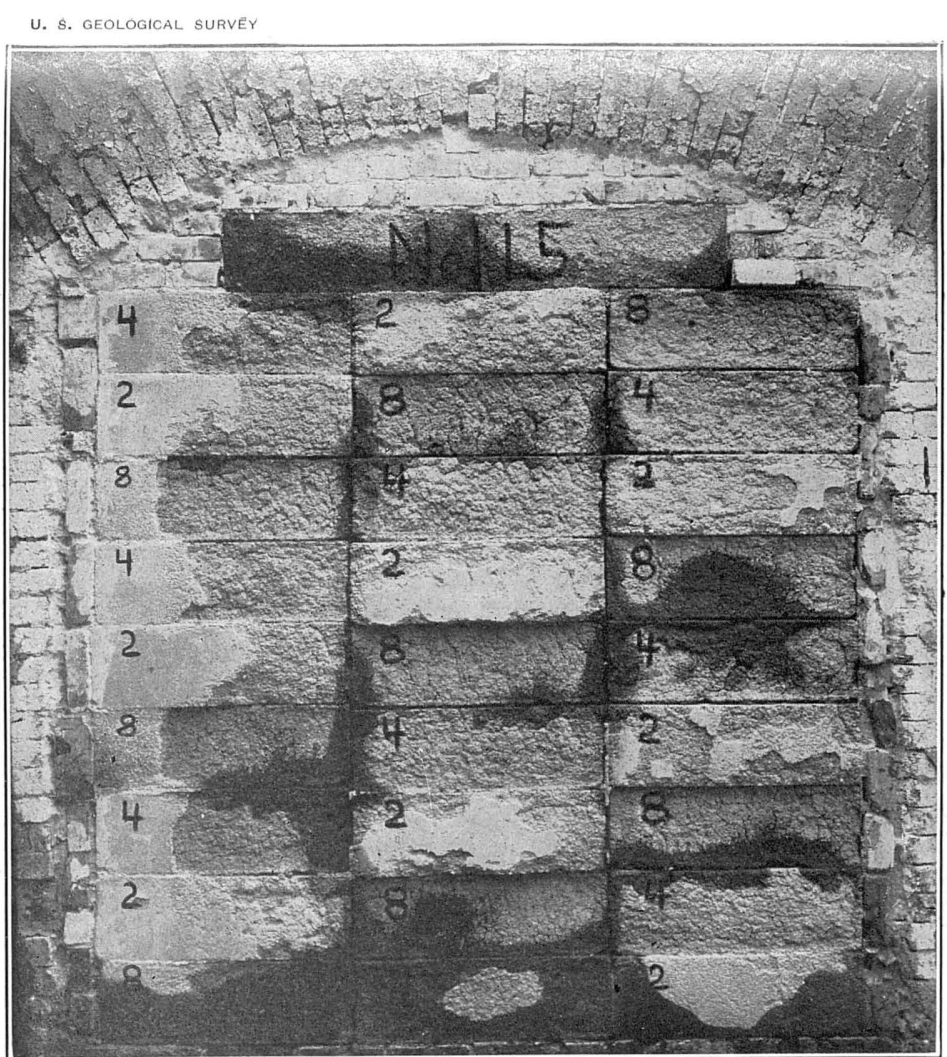

4. FACE OF PANEL 15, CEMENT MORTAR BUILDING BLOCKS, AFTER FIRING AND QUENCHING.

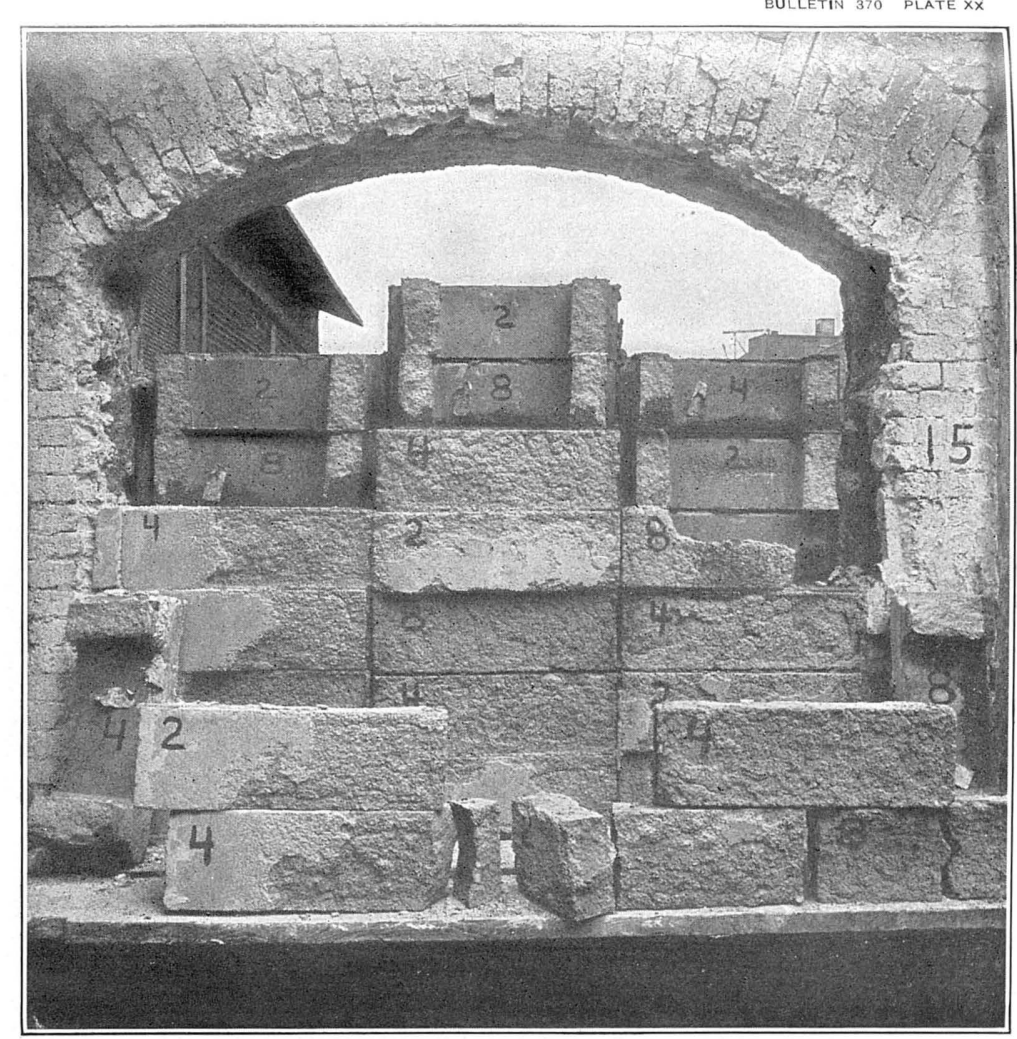

B. PANEL 15, CEMENT MORTAR BUILDING BLOCKS, DURING DISMANTLING. 



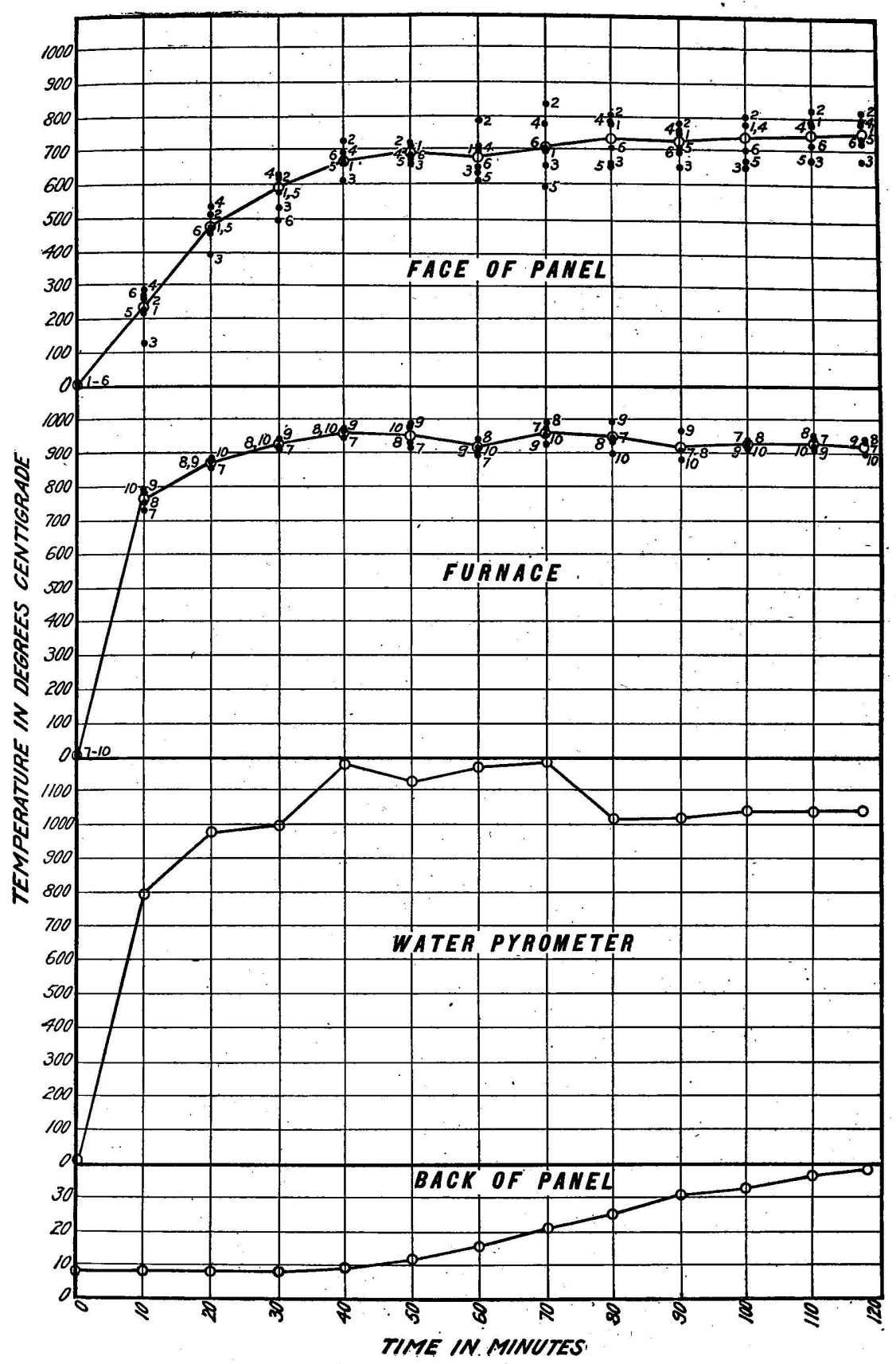

FIGURE 16.-Diagram showing temperature conditions in the furnace and on the back of panel 15. Temperature: Maximum, $52^{\circ}$; minimum, $38^{\circ}$; mean, $45^{\circ}$. Relative humidity: 7 a. m., $83 ; 7$ p. m., 64 . Direction of prevailing wind, northwest. 
and the right-hand side of the panel was brought up to the normal temperature. No signs of spalling were noticed up to the time the panel was removed from the furnace.

Curves showing the variations of temperature observed during the test are given in figure 17.

Results.--On taking the panel down it was found that all the blocks had cracked across the webs and that the faces of all the 1:8 mixtures were so badly cracked that these blocks could not be removed intact. On gently tapping the material it fell to pieces and crumbled very badly. Two or three of the 1:4 blocks behaved in a similar manner, but each half of the $1: 2$ specimens was removed intact. The back half of all the blocks was apparently unaffected and free from cracks.

Plate XXI, $A$, shows the face of the panel after the test. Plate $\mathrm{XXI}, B$, shows the panel being removed from the door. On the application of water the face of the $1: 4$ and $1: 8$ blocks spalled to the depths of $\frac{3}{4}$ to 1 inch and 1 inch to 2 inches, respectively. On two of the 1:2 mixtures part of the face was left apparently intact, but on examination it was found that this part crumbled easily in the hand. With the exception of the surface the remaining concrete was found to be quite hard. There were apparently no vertical cracks running through any of the blocks.

\section{PANEL 17 (Concrete).}

Materials.-Panel 17 consisted of four kinds of concrete, as follows: A 1:2:4 medium consistency (10 per cent water) limestone crushed to pass $a \frac{3}{4}$-inch screen and be retained on a $\frac{1}{4}$-inch screen; a 1:2:4 medium consistency (21 per cent water) cinder containing 24.5 per cent of combustible material. These cinders were screened to pass a $1 \frac{1}{2}$-inch screen; a 1:2:4 medium consistency (9 per cent water) granite crushed to pass a $\frac{3}{4}$-inch screen and remain on a $\frac{1}{4}$-inch screen; a 1:2:4 medium consistency (9 per cent water) gravel screened to pass a $\frac{3}{4}$-inch screen and remain on a $\frac{1}{4}$-inch screen.

The sand and cement mixed with the above coarse aggregates were Meramec River sand and "typical Portland" cement. The specimens fired were sections - of plain beams previously tested in the Governmerut's structural-materials testing laboratories at St. Louis. They measured 8 by 11 inches in cross section and varied in length from 18 to 36 inches. The test pieces were laid in fire clay on their 8-inch side, thus exposing the 11-inch face to the fire. This arrangement permitted a section 22 inches high by 6 feet long of each material, except the limestone concrete, to be exposed to the fire in the same panel. Only one piece of the limestone concrete, about 20 inches long, was tested, as that was all of this character of concrete which could be obtained at the time the shipment was made from St. Louis. 


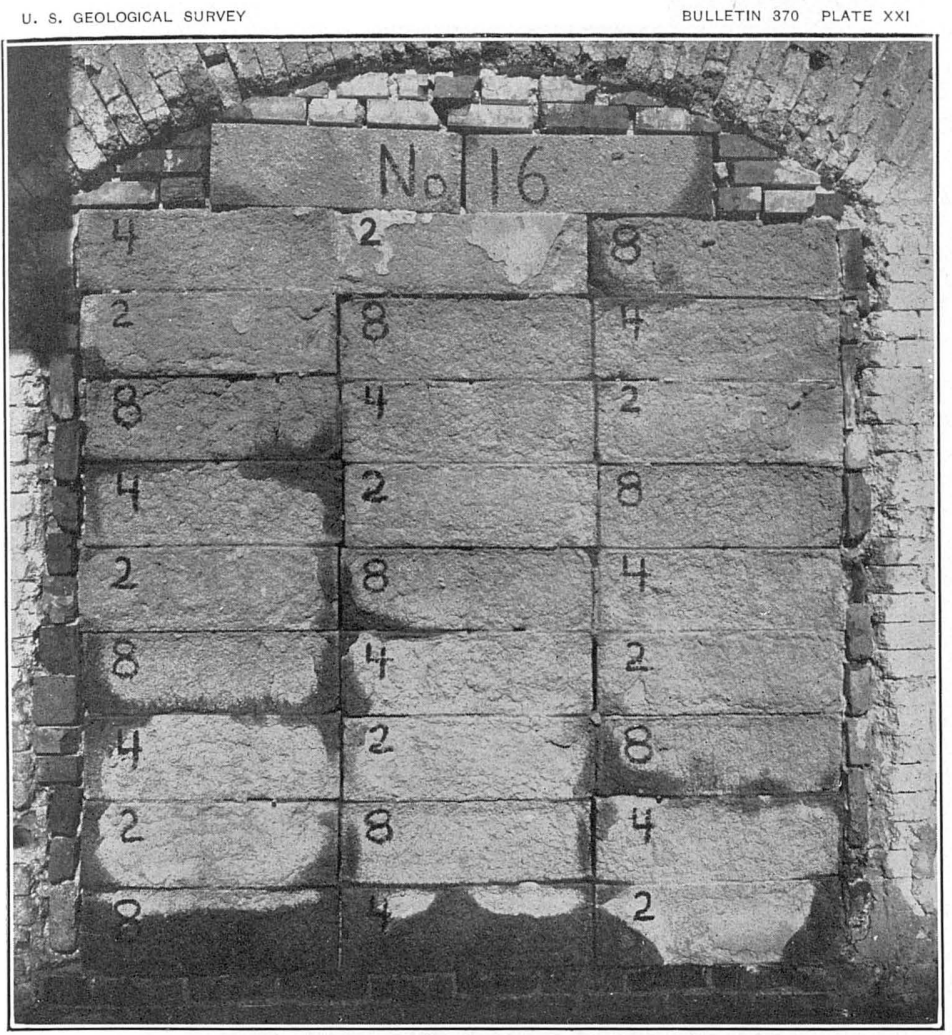

A. FACE OF PANEL 16, CEMENT MORTAR BUILDING BLOCKS, AFTER FIRING AND QUENCHING.

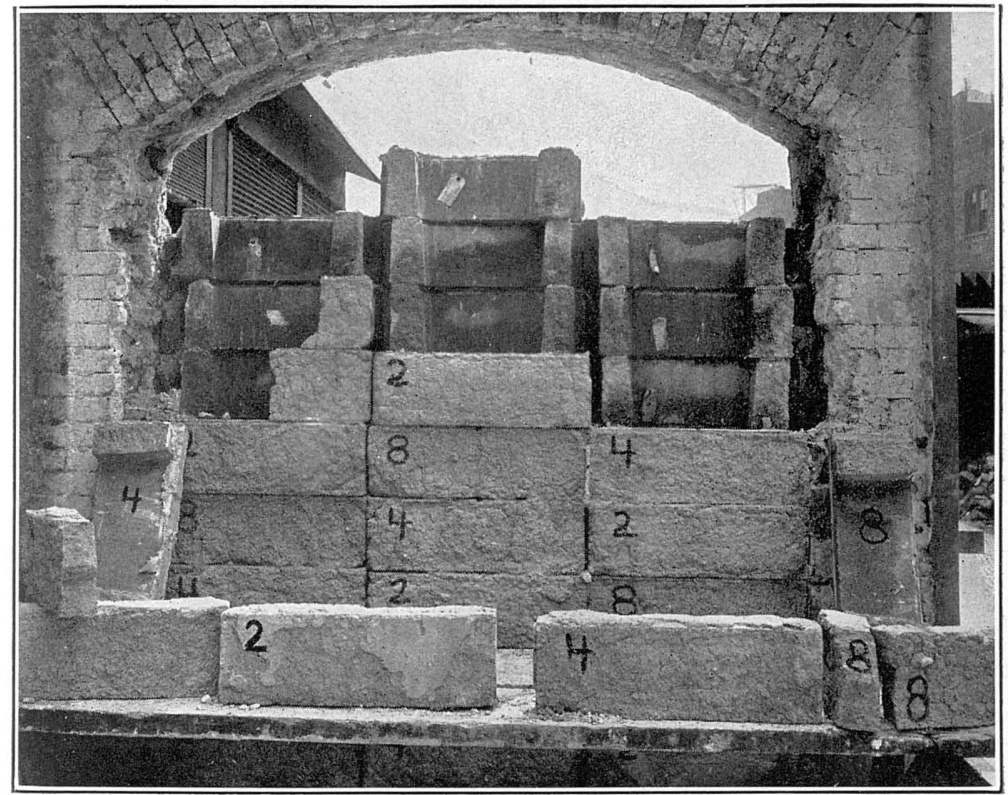

B. PANEL 16, CEMENT MORTAR BUILDING BLOCKS, DURING DISMANTLING. 



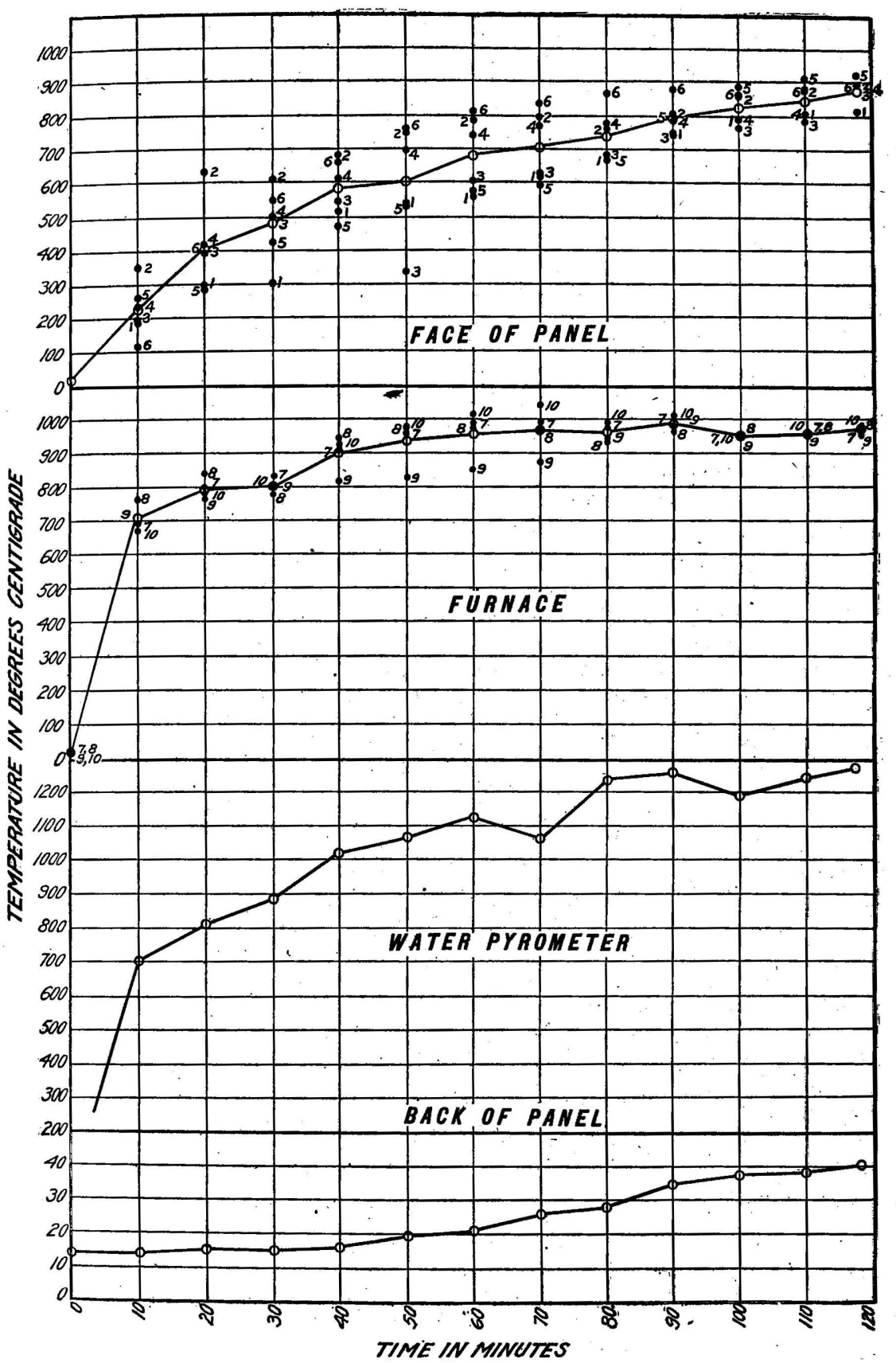

FIgURE 17.-Diagram showing temperature conditions in the furnace and on the back of panel 16. Temperature: Maximum, $65^{\circ}$; minimum, $45^{\circ}$; mean, $55^{\circ}$. Relative humidity: 7 a. m., $66 ; 7$ p. m., 51 . Direction of prevailing wind, southwest.

73087-Bull. $370-09-4$ 
Test.-The firing was started at 10.52 a. m. June 7, 1907, and continued for 2 hours and 3 minutes, after which the panel was quenched with water for 5 minutes. The temperature of the water was $52^{\circ} \mathrm{F}$.

At the start of the test the back of the panel was wet, owing to rain the night previous. The burners started with a fairly uniform temperature and under good control; the top was not as hot, however, as the lower part of the panel. In 25 minutes a slight pitting was noticed on all four kinds of concrete and small pieces, about $\frac{1}{4}$ inch deep and 1 inch in area, fell out from the faces. The cinder concrete developed bright red spots, from which small flames issued. These spots covered the greater part of the surface of the cinder concrete and were about 8 or 10 inches apart. At 45 minutes steam was noticed passing through the joints on the back of the wall. At 65 minutes the cinder concrete was quite badly pitted, though of a uniform color, the entire surface having attained the same color as the bright red spots before mentioned. A number of small bulges projected out from the wall about $\frac{1}{8}$ to $\frac{1}{4}$ inch. Pits developed as these bulging portions fell away. The limestone and gravel concrete were pitted all over to a depth of $\frac{1}{4}$ to $\frac{1}{2}$ inch.

Curves showing the variations of temperature observed during the test are given in figure 18.

Results.-On the application of water portions of the surface of all four varieties of concrete washed away. The limestone washed away from $\frac{1}{4}$ to $\frac{1}{2}$ inch, but the remaining surface was very smooth and the exposed stones showed the effect of calcination. The surrounding concrete, however, was apparently hard, free from cracks, and showed no signs of discoloration or calcination. The surface had very much the appearance of concrete which has been vigorously brushed while green.

The stone was discolored to a depth of about 1 inch. Back of this the stone did not show any signs of heat treatment. The material on the surface had a very dead sound when tapped gently with the hammer, but on the back side it had the usual metallic ring.

In the case of the gravel, where the mortar portion of the concrete was rather deep, the surface was still intact, but the greater portion of the surface was pitted and washed away to an average depth of $\frac{1}{2}$ inch. The surface was very rough and the exposed pieces of gravel were dark brown and very easily broken under a hammer. In several cases they were split and parts of the stone could be pulled out. with the fingers. The particles of gravel in the concrete were discolored to a depth of about 4 inches. The mortar in this layer was apparently normal, and appeared as hard as that of the unaffected product. It was but slightly cracked on the surface only. Throughout all the pieces vertical cracks running back from the fired side 


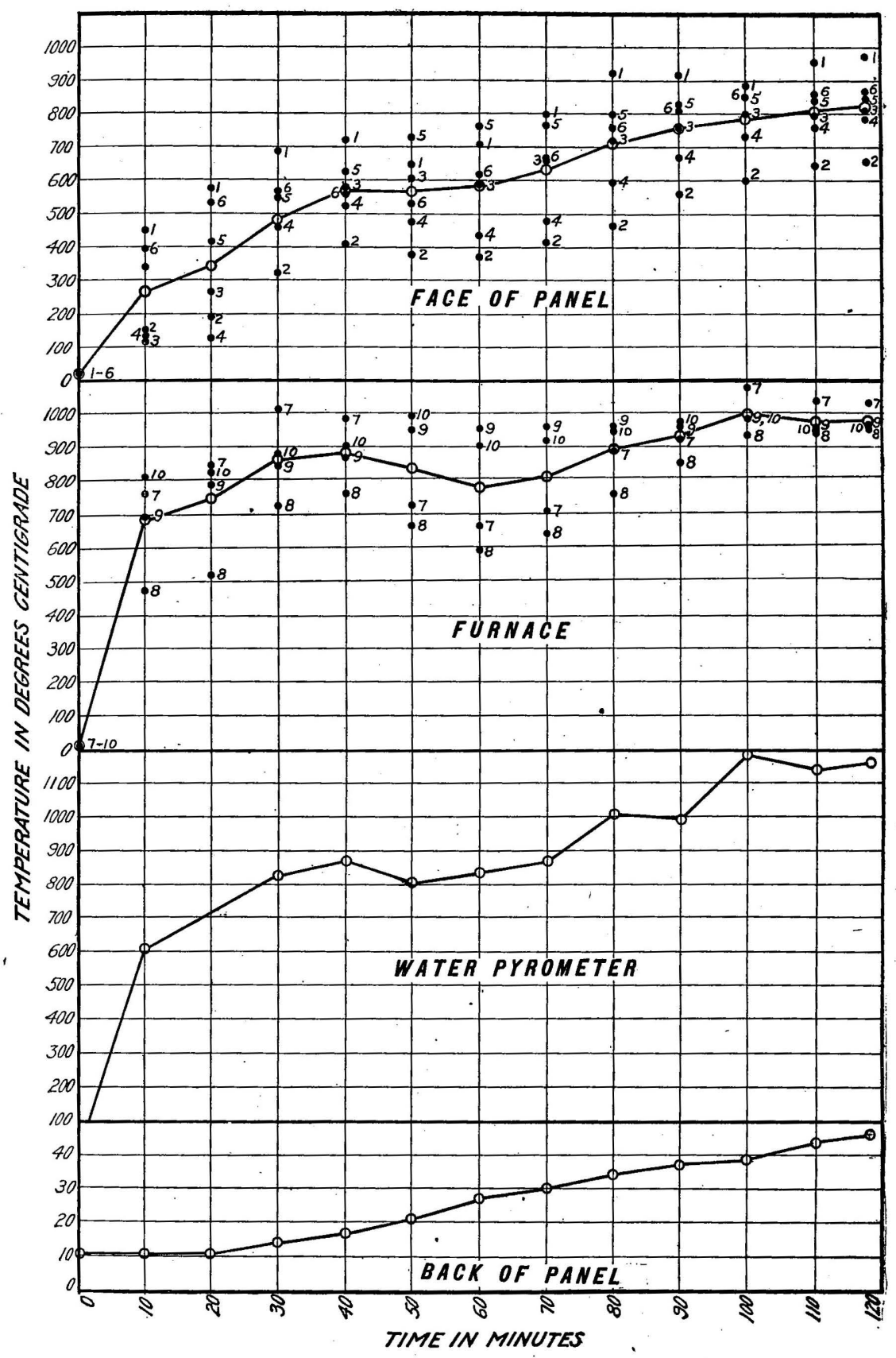

FIGURE 18.-Diagram showing temperature conditions in the furnace and on the back of panel 17. Tempernture: Maximum, $56^{\circ}$; minimum, $50^{\circ}$; mean, $53^{\circ}$. Relative humidity: 7 a. m., $94 ; 7$ p. m., 100. Direction of prevailing wind, northeast. 
were observed; they were about 4 to 10 inches apart and extended back from the face about 2 to 4 inches. They were nearly straight in direction and could be found on both the bottom and top of each beam. The face of the portion in which the gravel was discolored had a very dead sound when tapped with a hammer, while the back had a good metallic ring.

In the case of the granite there was a considerable portion from which the mortar surface had not been washed away. The remaining surfaces were washed away about $\frac{1}{4}$ to $\frac{3}{4}$ inch. The exposed pieces of stone were slightly discolored, being lighter than the unaffected material, but in most cases were hard and broke but little more easily than the unheated ones. The mortar was soft and crumbled about $1 \frac{1}{2}$ inch. For about 3 inches in from the face the mortar had turned a light straw color, but was quite hard. For about 6 inches from the face the concrete had a whitish tinge, which indicated that the free moisture had been driven entirely out. This whitish layer was apparently as hard as the layer on the back. To a depth of about 2 inches the pieces of stone had a rather cloudy look.

Vertical cracks ran directly back from the face on both the top and bottom of the beam; they were from 2 to 6 inches apart and extended back from the face 4 inches. By tapping, the beams could be broken across these cracks. The face had a very dead sound when tapped with the hammer; the back had the usual metallic ring.

In the case of the cinder a part of the face was still intact after the application of water. However, it is very likely that the upper lefthand corner was more or less protected from the intense heat to which the remainder of the panel was subjected. On the other parts of the cinder concrete the spalling from the fire and water was from $\frac{3}{4}$ to $1 \frac{1}{4}$ inches deep. The surface was rough and very badly pitted, although no cracks could be observed. For about an inch the concrete was black and looked very spongy, because the particles of combustible material had been entirely burned out. In a layer about $\frac{1}{2}$ to $\frac{3}{4}$ inch in depth, directly behind this spongy layer, the concrete was black and looked as if it had been badly smoked. The combustible material in the center of this layer was caked. Back of this layer was a strip 3 to $3 \frac{1}{4}$ inches wide showing no discoloration, but the mortar, whiter than the normal cuncrete, indicated that the uncombined water had been driven away. The remainder of the beam was apparently normal.

Vertical cracks running back from the fired face were found in only two or three cases, and extended back only from 2 to 4 inches. The surface had a very dead sound and could be easily crumbled, while the back of the beam was unaffected and had the usual metallic sound.

Plate XXII shows the face and the back after quenching. 


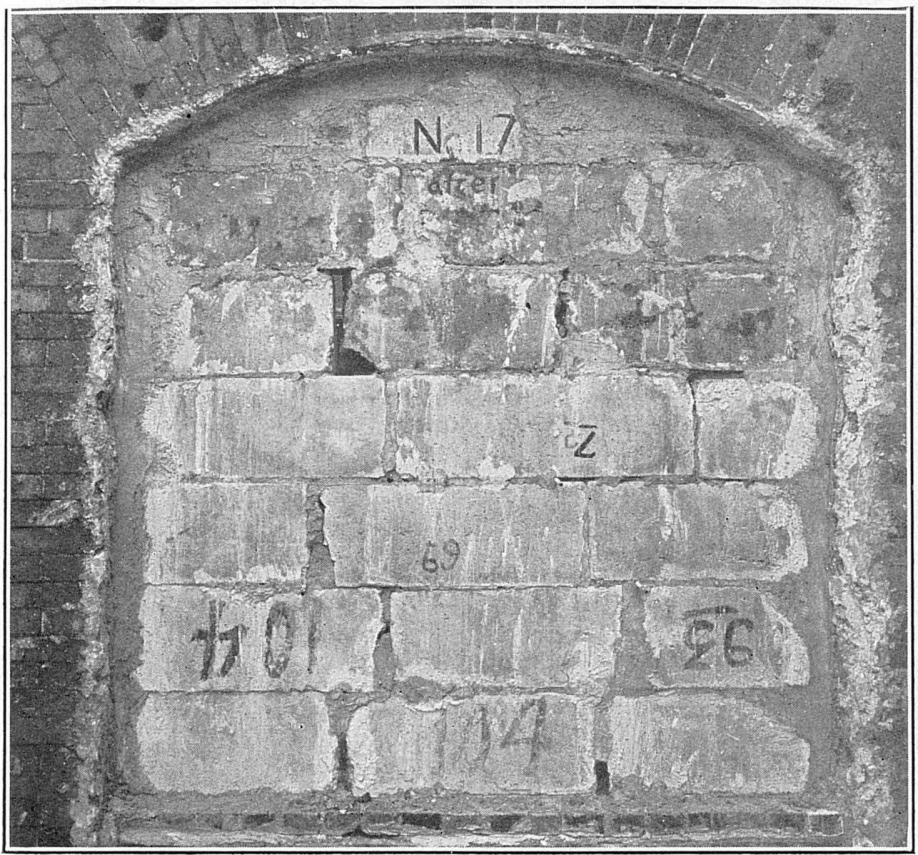

A. BACK OF PANEL 17, CONCRETE WITH DIFFERENT AGGREGATES, AFTER FIRING AND QUENCHING.

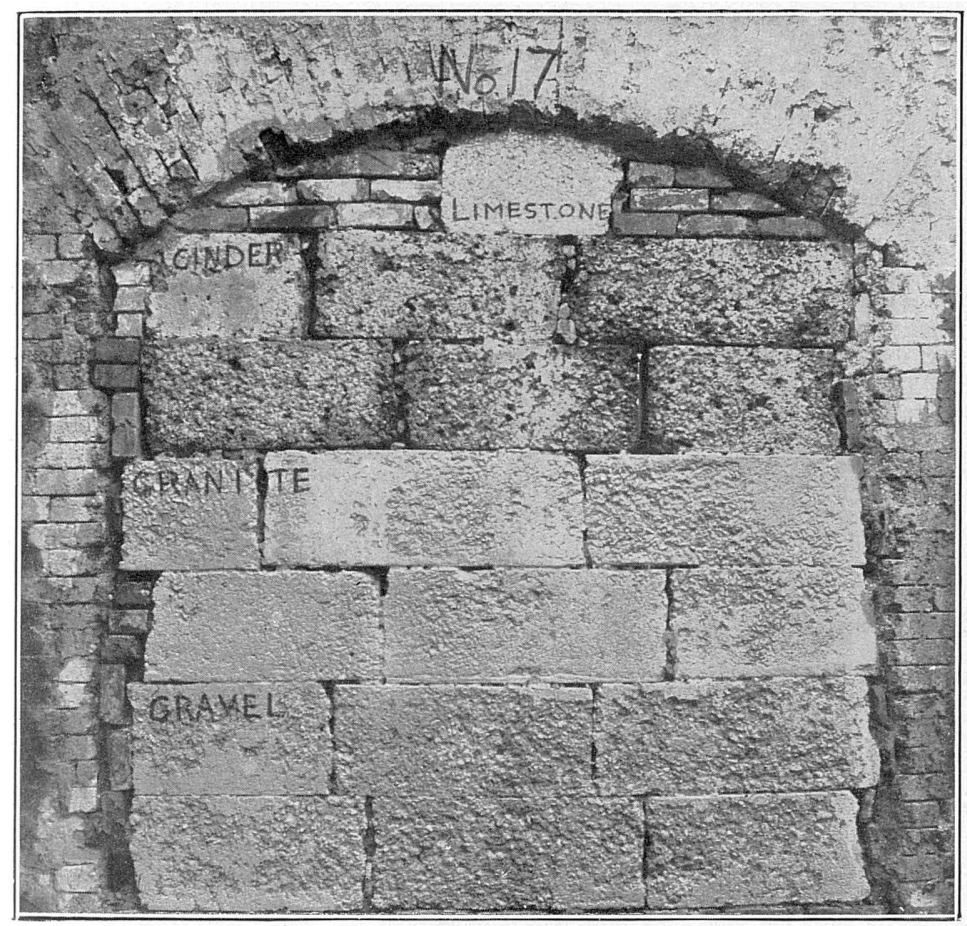

B. FACE OF PANEL 17, CONCRETE WITH DIFFERENT AGGREGATES, AFTER FIRING AND QUENCHING. 

PANEL 18 (Concrete).

Material.-Panel 18 was made up of short lengths of plain granite concrete beams 8 by 11 inches in cross section and in lengths varying from 18 inches to $2 \frac{1}{2}$ feet. The concrete was a $1: 2: 4$ mixture of "typical Portland" cement, Meramec River sand, and Missouri red granite, mixed to a medium consistency (about 9 per cent water). The stone was screened to pass a $\frac{3}{4}$-inch screen and be retained on a $\frac{1}{4}$-inch screen. The panel was laid up in fire clay with broken joints. The specimens were laid on their 8-inch side, thus exposing the 11-inch face to the fire.

Test.-The test occurred on June 10, 1907, and firing continued for 2 hours and $\frac{1}{2}$ minute. After firing the face of the panel was quenched with water at $51^{\circ} \mathrm{F}$. for 5 minutes.

In 15 minutes snapping was noted, which continued for about 5 minutes. At 25 minutes hot water was forced back through the joints and washed off the fire clay, which held the back-wall thermometers in place. This water was considerably warmer than the back-wall surface, consequently the thermometers there attached showed unduly high temperatures. At 40 minutes the top of the panel began to dry out, the bottom portion still remaining wet with the water which leaked through the joints. At 63 minutes a slight spalling was observed in several places, principally at the top of the wall. At 75 minutes the back-wall face of the panel had entirely dried out, but steam came through the joints on the top of the panel. During the remainder of the time no further change was noted.

Curves showing the variations in temperature observed during the test are giten in figure 19.

Results.-After quenching with water it was found that some portions of the surface of the concrete had spalled and had been washed away, while in other places the surface was nearly all intact.and the mortar still adhered; but it was cracked, and crumbled easily in the fingers. The exposed particles of stone were found to be of a cloudy whitish color and quite hard, although more easily broken than the unchanged stone. The stone had whitened to a depth of about 1 inch and the mortar to about $3 \frac{1}{2}$ inches.

Vertical cracks running back from the fired face occurred about 4 to 6 inches apart, and extended back from the face about 4 inches. By tapping with a hammer the beam could be broken where these cracks occurred. The surface had a very dead sound when tapped with the hammer, but the back was apparently normal.

Plate XXIII, $A$ and $B$, shows the face and back of the panel after firing. 


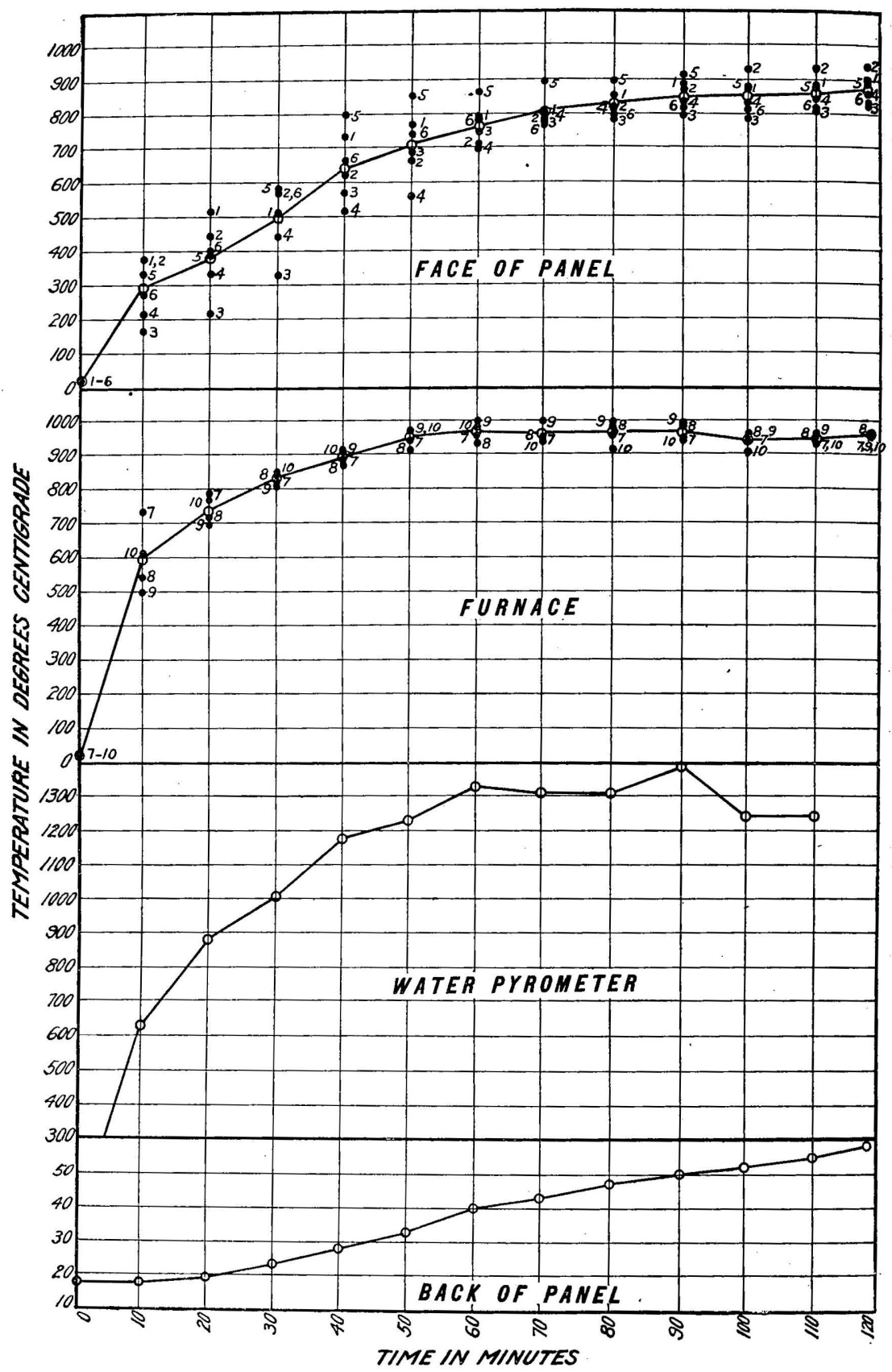

FIGURE 19.-Diagram showing temperature conditions in the furnace and on the back of panel 18. Temperature: Maximum, $79^{\circ}$; minimum, $58^{\circ}$; mean, $68^{\circ}$. Relative humidity: 7 a. m., $78 ; 7$ p. m., 79 . Direction of prevailing wind, southeast. 


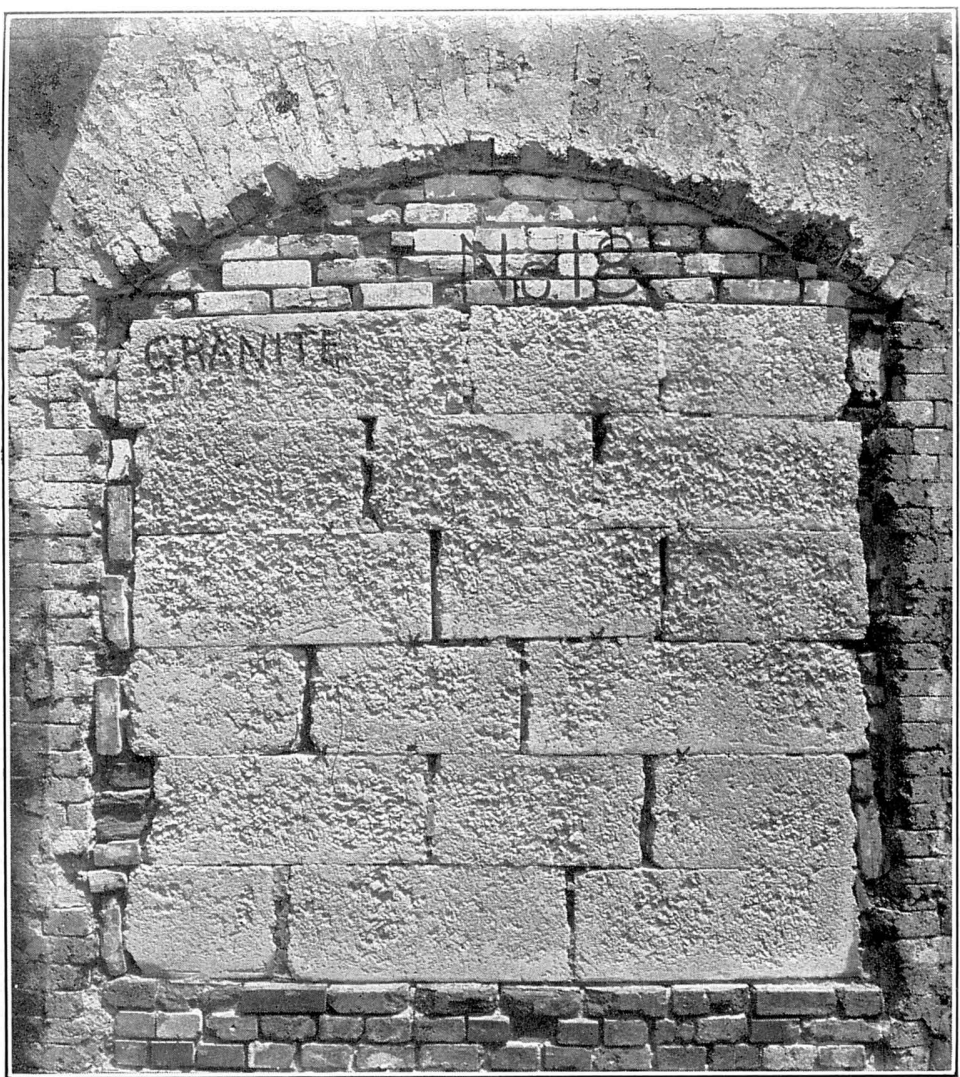

4. FACE OF PANEL 18, GRANITE CONCRETE, AFTER FIRING AND QUENCHING.

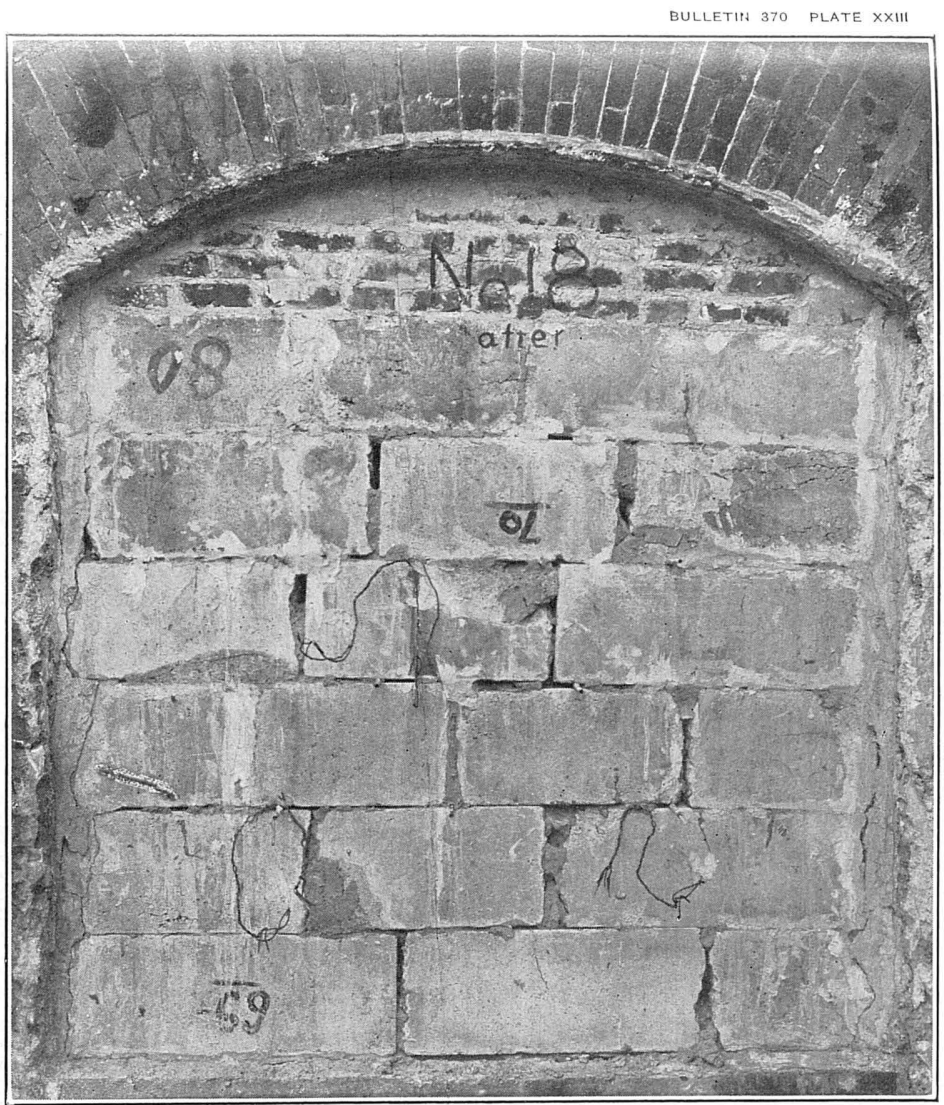

B. BACK OF PANEL 18, GRANITE CONCRETE, AFTER FIRING AND QUENCHING. 

PANEL 19 (Concrete).

Material.-Panel 19 was composed of similar-sized sections of gravel concrete beams, laid as described for panel 18. The mixture and consistency were the same as in panel 18, being 1:2:4 medium consistency. The gravel passed a $\frac{3}{4}$-inch screen and was retained on a $\frac{1}{4}$-inch screen, and was of the Meramec flint variety.

Test.-The test took place on June 11, 1907, at 2.25 p. m., and continued for 2 hours 3 minutes, followed by quenching with water at $53^{\circ} \mathrm{F}$. for 5 minutes. At the outset the temperature at the top of the panel seemed higher than that at the bottom.

In 16 minutes water came through the joints on the back of the wall and ran down, washing away the fire clay holding the thermometer in place. Up to 25 minutes no snapping had occurred. At 45 minutes the greater part of the surface of the concrete had spalled and pitted in small spots. These small pits exposed stones which had probably cracked and expanded sufficiently to force the mortar away from the face. At 80 minutes the pitting and cracking away of small portions of the surface was very general over the lower and left-hand side of the panel. No further change was noted and the surface of the panel seemed to resist any further pitting.

Curves showing the variations in temperature observed during the test are given in figure 20.

Results.-Plate XXIV, $A$ and $B$, shows the face and back of the panel after the test. On the application of water the surface washed away on the lower and left side of the panel, while on the upper and right side the surface was less severely affected. Particles of gravel were discolored to a depth of $2 \frac{1}{2}$. to 3 inches, turning a dark reddishbrown, while the mortar surrounding them remained about normal. Many gravel stones on the surface had split, but were apparently as hard as the sound ones. Vertical cracks from 2 to 4 inches apart ran back from the face to a distance of about 3 inches. These cracks could be opened up by tapping, and the layer containing the discolored gravel could be cracked off from the surface of the beam with a hammer. The back portions of the beams were not affected and had a good solid metallic ring, while the fired side sounded dead when struck with a hammer. Where the mortar had not been washed away the surface was covered with fine hair cracks and the material could be crumbled in the fingers. The gravel under this coating of mortar was not cracked, but was somewhat discolored.

PANEL 20 (Concrete).

Material.-Panel 20 was made up of $1 \frac{1}{2}$-inch to $2 \frac{1}{2}$-foot lengths of cinder concrete beams, 8 by 11 inches in section, laid on the 8-inch face. The concrete was of "typical Portland" cement, Meramec 


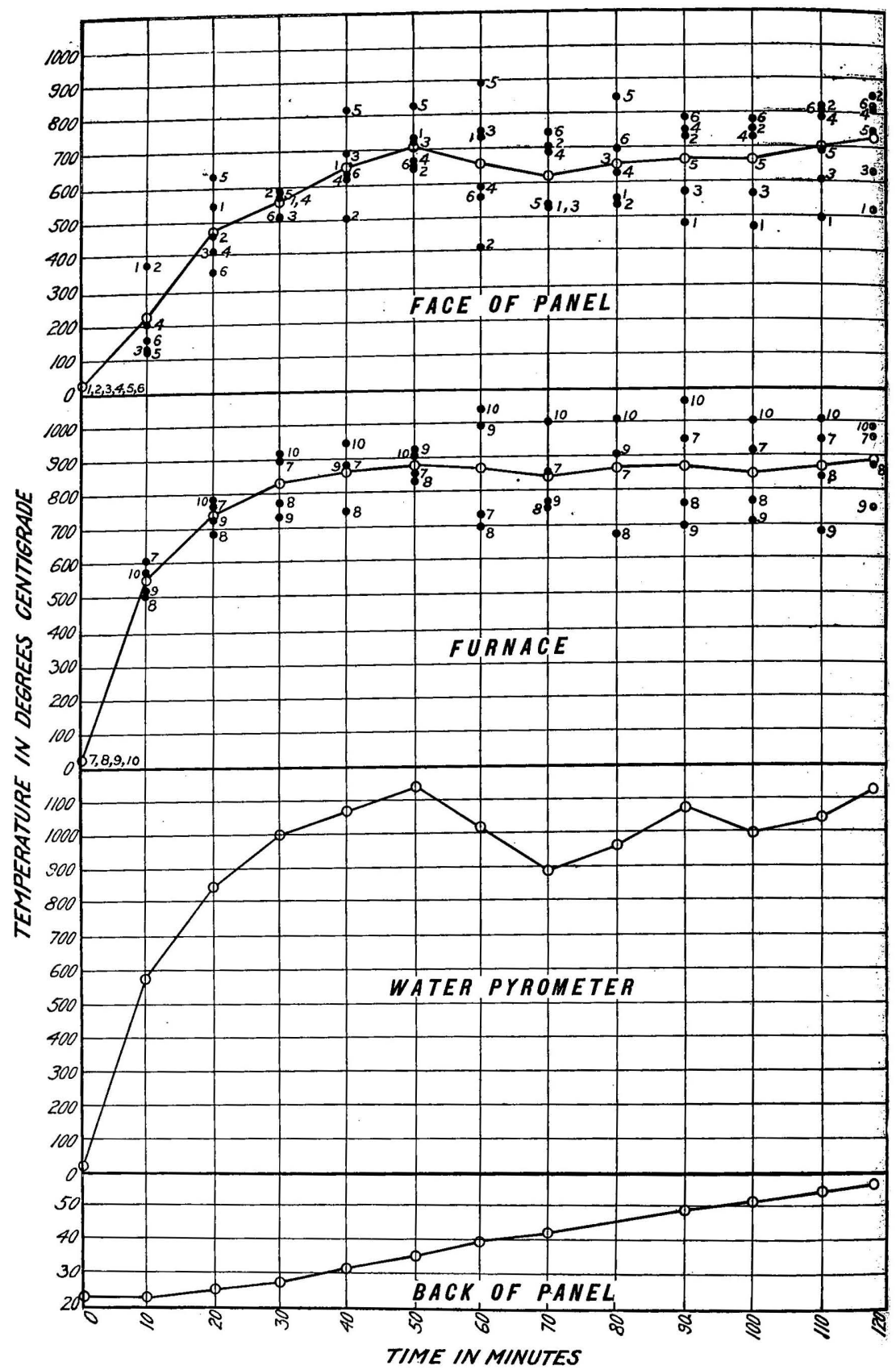

FIGURE 20.-Diagram showing temperature conditions in the furnace and on the back of panel 19. Temperature: Maximum, $78^{\circ}$; minimum, $59^{\circ}$; mean, $68^{\circ}$. Relative humidity: 7 a. m., $75 ; 7$ p.m., 96 . Diretion of prevailing wind, west. 
U. S. GEOLOGICAL SURVEY

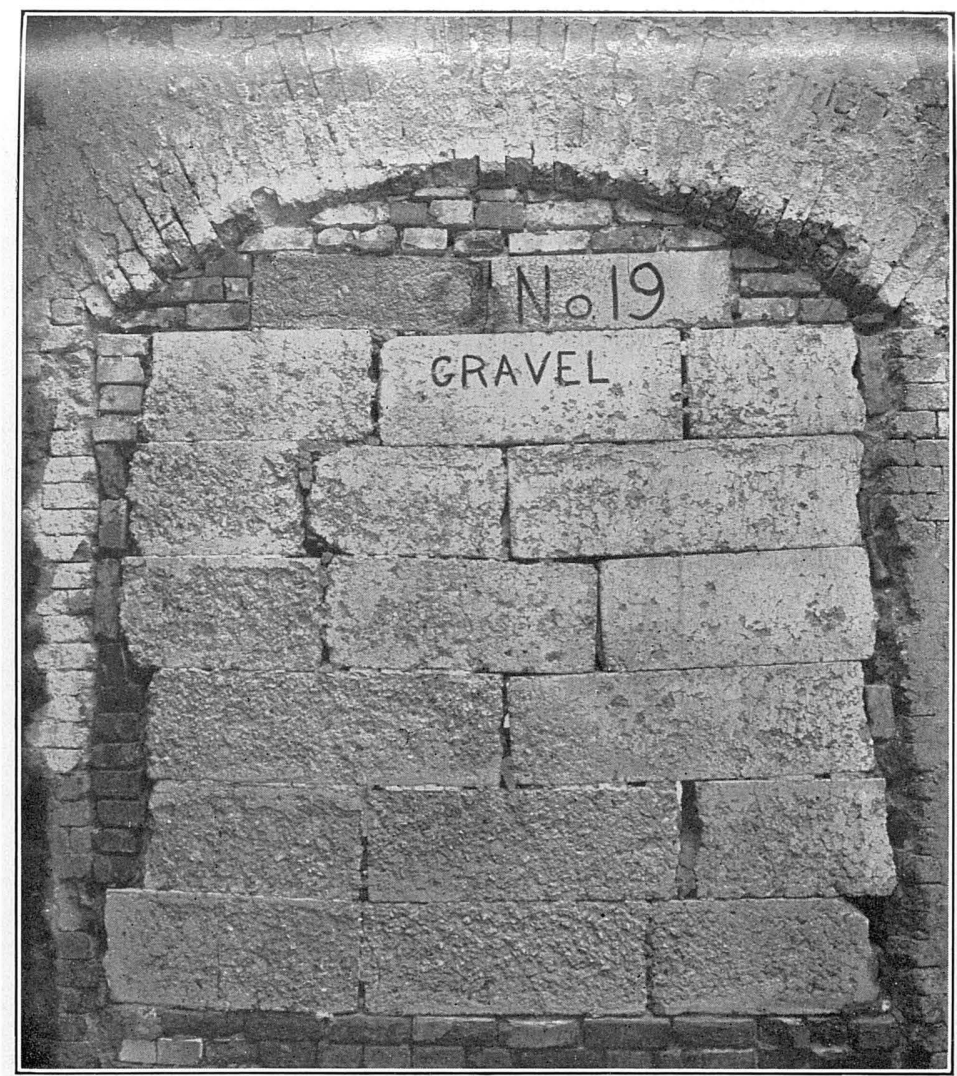

A. FACE OF PANEL 19, GRAVEL CONCRETE, AFTER FIRING AND QUENCHING.

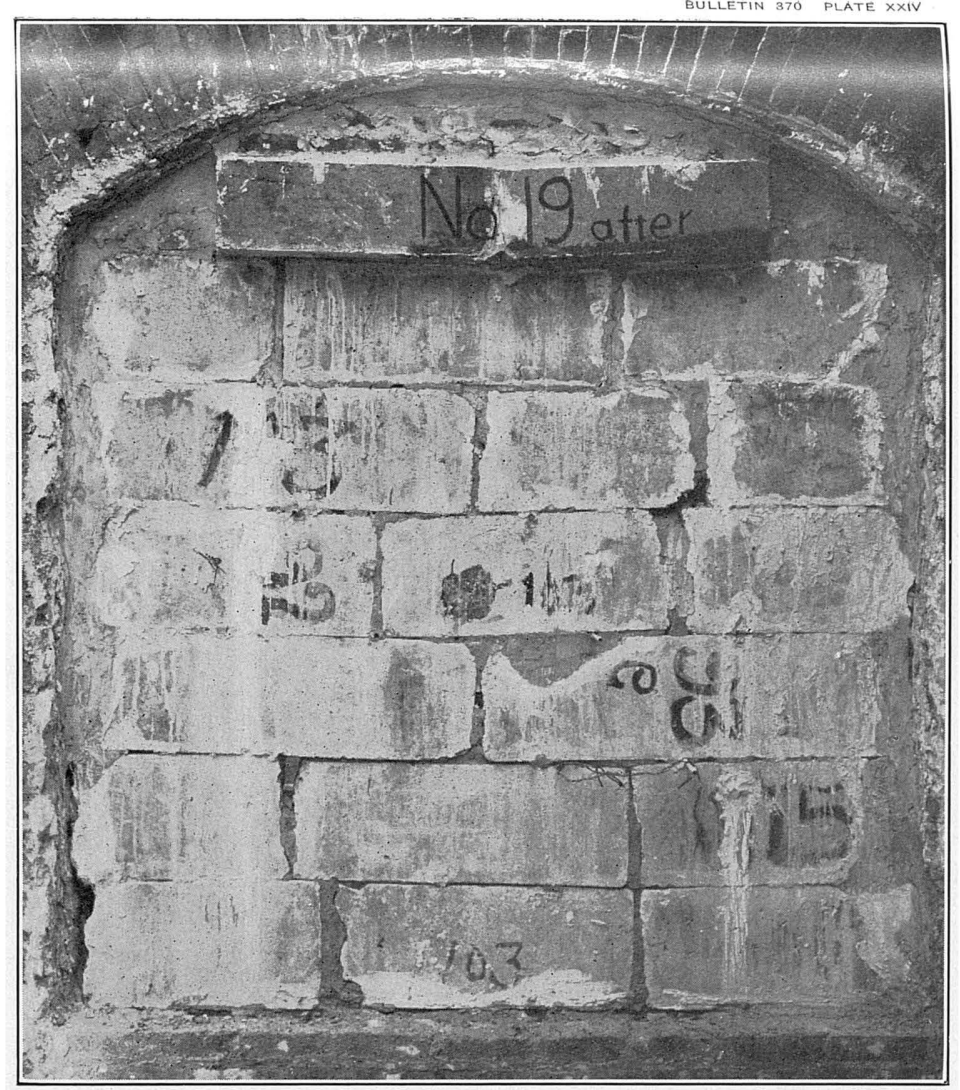

B. BACK OF PANEL 19, GRAVEL CONCRETE, AFTER FIRING AND QUENCHING. 

River sand, and soft coal cinders, containing 24.5 per cent of combustible material. The proportions were 1:2:4 by volume. The cinders were screened to pass a $1 \frac{1}{2}$-inch screen and be retained on a $\frac{1}{4}$-inch screen. The top row in the panel was composed of granite, gravel, and terra-cotta tile and was put in merely to fill up the space due to a shortage of the cinder specimens.

Test.-The panel was fired at 11.54 a. m. June 17, 1907, for 2 hours $2 \frac{3}{4}$ minutes, and was cooled by quenching with water at $57^{\circ} \mathrm{F}$. for 5 minutes.

In 7 minutes the concrete snapped quite badly and one or two small explosions forced off small portions of the surface of the beams. No. 7 couple was more exposed than usual on account of the fire-clay mounting being cracked off by a piece of the surface of the cinder concrete which blew across the furnace. At 18 minutes all the cinderconcrete surface had begun to pit and pieces about 1 inch in area and $\frac{1}{8}$ to $\frac{1}{4}$ inch in depth fell out. A piece on the second row from the bottom, about 6 inches square and $\frac{11}{2}$ inch in depth, was forced off with considerable violence, exposing several pieces of unburned coal. This was followed by several small explosions, and a piece of the surface about 8 inches square and $\frac{1}{2}$ inch thick, just adjoining the above-mentioned piece, came off. Small bright-red spots from which flames issued were distributed over the surface. At $30 \mathrm{~min}$ utes the burners became more or less clogged from the small pieces of concrete which had fallen into them. This somewhat impaired the control of the furnace. At 40 minutes the spalling became general over the surface and many small pieces of concrete continued to fall from the panel. The color became bright red and the small spots were no longer visible.

Curves showing the variations in temperature observed during the test are given in figure 21.

Results.-On removal of the door it was found that the greater part of the surface of the cinder concrete had cracked off; during the application of water a considerable portion of the surface was washed away, apparently to about the same depth $\left(\frac{1}{2}\right.$ inch). A very small portion of the face of each beam was still intact, but this portion was porous and crumbled easily in the hand. The surface was rough and the concrete was spongy and black to a depth of about 1 inch. The mortar in this layer was easily crumbled in the fingers. A layer 3 to 4 inches thick back of this was discolored, being turned almost black, and the particles of combustible material were practically turned to coke. The mortar in this layer was apparently hard. The remainder of the beam was about normal.

Plate XXV, $A$ and $B$, shows the face and back of the panel after testing. A few vertical cracks running back from the face of the beams were not very regular and did not open up readily when 


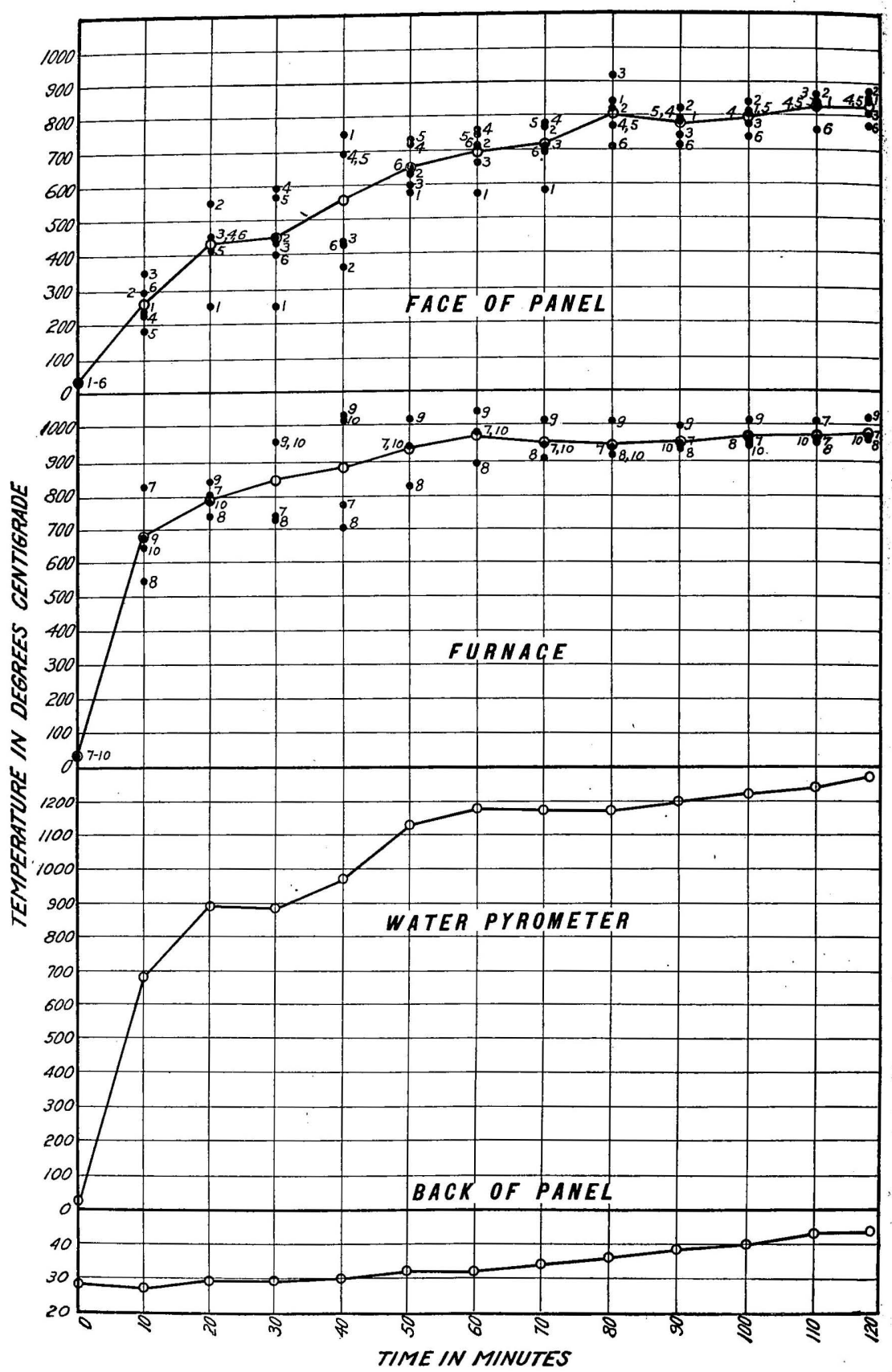

FIGURE 21,-Diagram showing temperature conditions in the furnace and on the back of panel 20. Temperature: Maximum, $91^{\circ}$; minimum, $70^{\circ}$; mean, $80^{\circ}$. Relative humidity: 7 a. m., $58 ; 7$ p. m., 41 . Direction of prevailing wind, southwest. 
U. S. GEOLOGICAL SURVEY

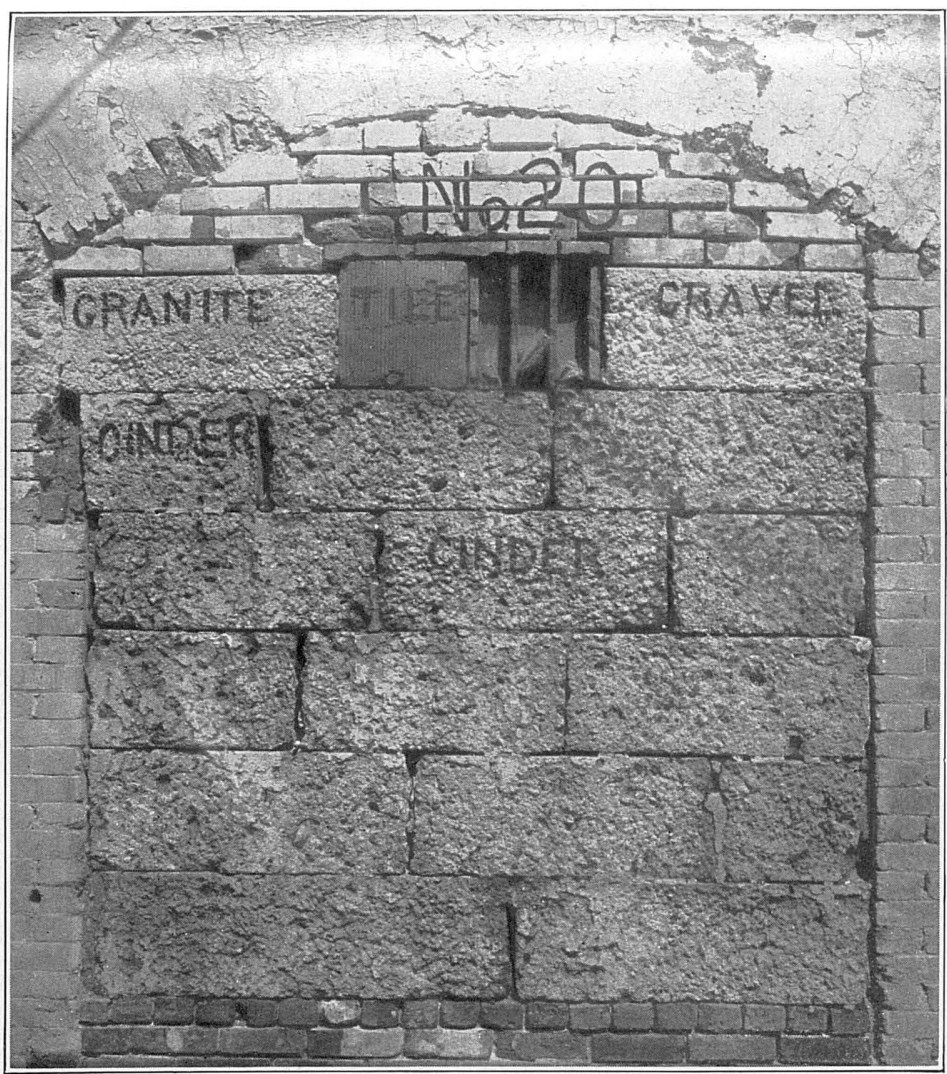

A. FACE OF PANEL 20, CINDER CONCRETE, AFTER FIRING AND QUENCHING.

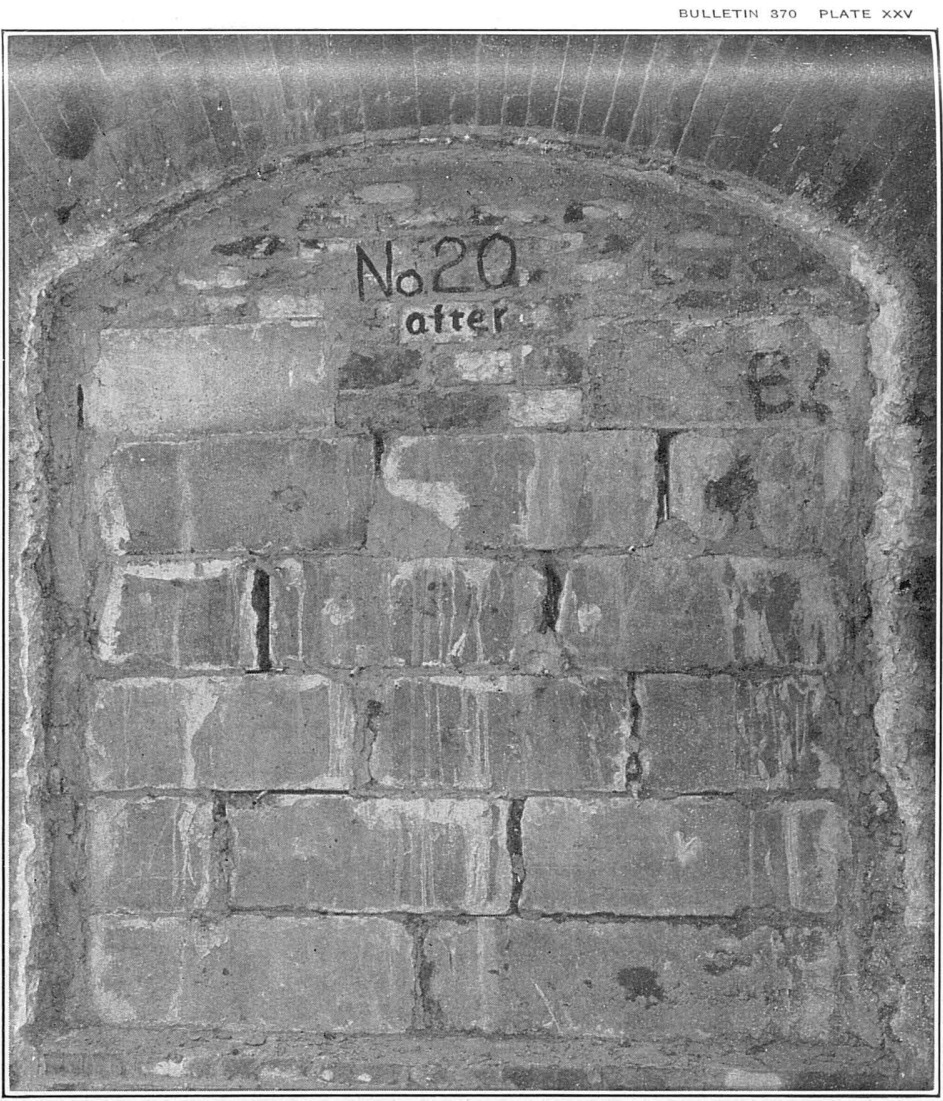

13. BACK OF PANEL 20, CINDER CONCRETE, AFTER FIRING AND QUENCHING. 

tapped rather hard with a hammer. The face of the concrete crumbled when tapped, while the back gave a good sound metallic ring. The affected portion-that is, a layer about $2 \frac{1}{2}$ inches thick-could be separated from the unaltered portion by tapping on the edges of the piece.

\section{PANEL 21 (Sandstone).}

Material.-Panel 21 consisted of pieces of cut sandstone, $7 \frac{3}{4}$ by 4 by 24 inches, laid on the natural bed in cement mortar, with the $7 \frac{3}{4}$-inch face to the fire. The joints were broken.

Test.-The panel was fired at $3.03 \mathrm{p}$. m. June 21, 1907, for 23 minutes.

In 10 minutes the wall bulged in toward the fire at the center of the panel about 2 inches and at the edges about $1 \frac{1}{2}$ inches. No snapping was noted up to this time. At 19 minutes a vertical crack in the fifth row in the center gradually developed through the mortar joints and extended into the pieces in the third and seventh rows. At 21 minutes vertical cracks developed in the seventh row on the left side, about 8 inches from the edge of the panel, and rapidly extended the entire length of the panel. A crack simultaneously developed on the other side of the wall about the same distance from the edge, running vertically from top to bottom. At 23 minutes the panel unexpectedly collapsed, falling into the fire chamber. The failure occurred by reason of the joint in the fifth row opening and allowing the bottom portion of the panel to fall forward into the chamber; then the top portion fell directly down. Although the panel appeared very weak, there was no snapping or crackling up to the time of the failure, and consequently the thermometers attached to the back side of the wall and thermal couples inserted through it were not removed. The failure carried these down and broke all the thermometers and cold junction bottles. The thermal couples, fortunately, were uninjured.

('urves showing the variations in temperature observed during the test are given in figure 22 .

Results.-After the collapse it was found that in all the test pieces cracks had developed across the face vertically and extended back within about 1 inch of the back side. Horizontal cracks along the bedding of the stone also developed, and by falling the layers were broken into small but rather regular pieces. The test pieces that did not break in two were found to be warped from $\frac{1}{32}$ to $\frac{1}{8}$ inch at the center, the bulging being toward the fired side.

The material was turned a light reddish brown to a depth of about $\frac{3}{4}$ to 1 inch on the fired side. The surface was apparently as hard as before being subjected to the fire, and there was no evidence of spalling or pitting. The surface was, however, very badly cracked 


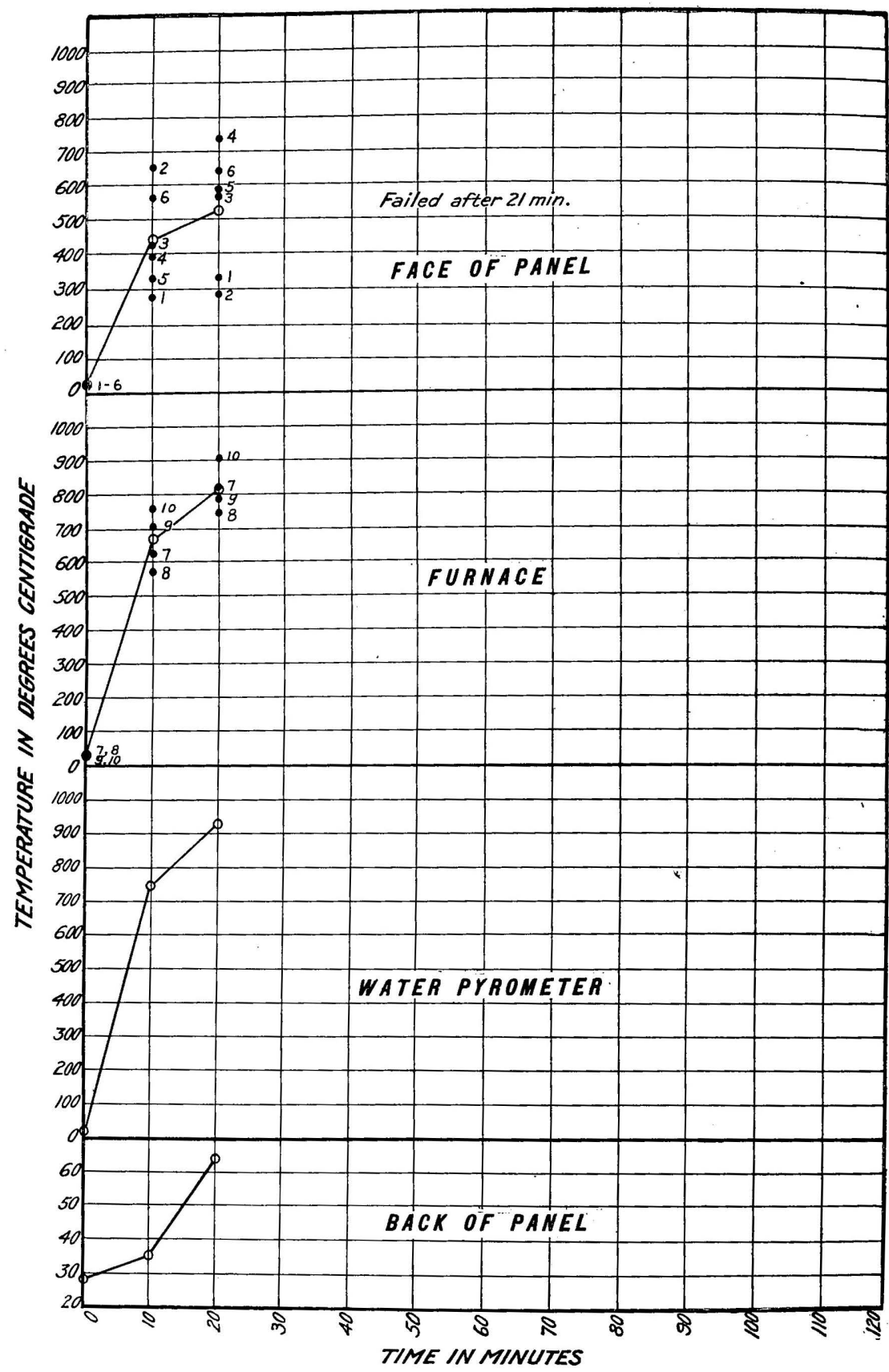

Figure 22.-Diagram showing temperature conditions in the furnace and on the back of panel 21 . Temperature: Maximum, $88^{\circ}$; minimum, $67^{\circ}$; mean, $78^{\circ}$. Relative humidity: 7 a. m., $73 ; 7$ p. m., 63. Direction of prevailing wind, southwest. 


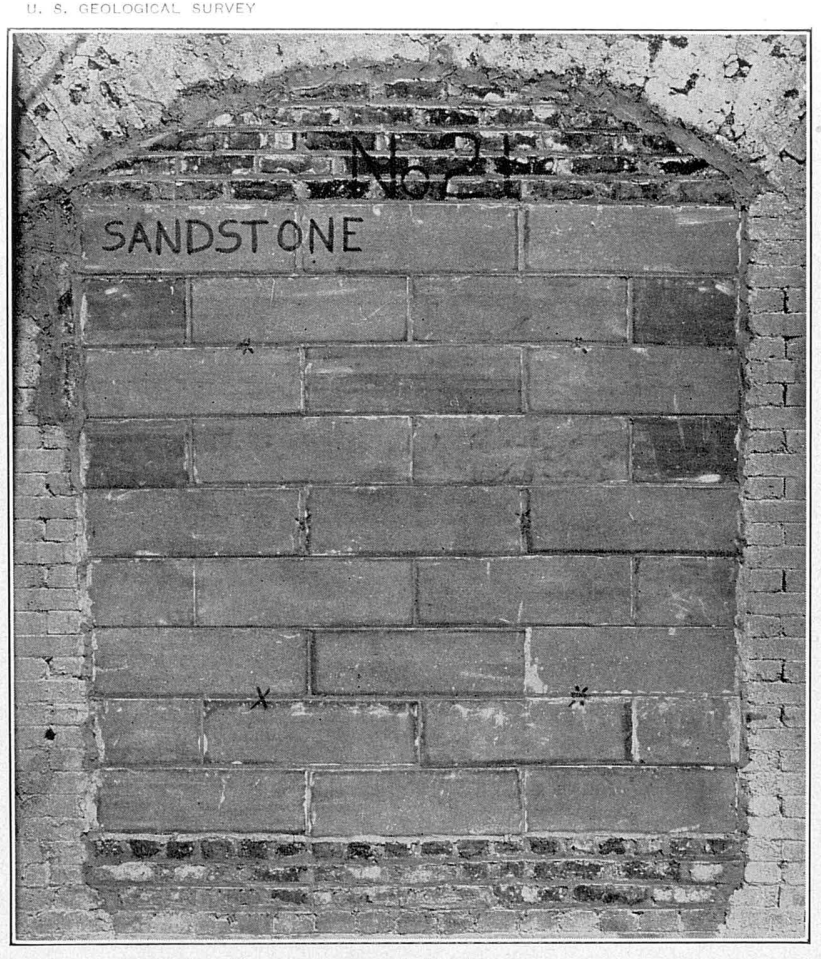

A. FACE OF PANEL 21, DRESSED SANDSTONE, BEFORE FIRING.

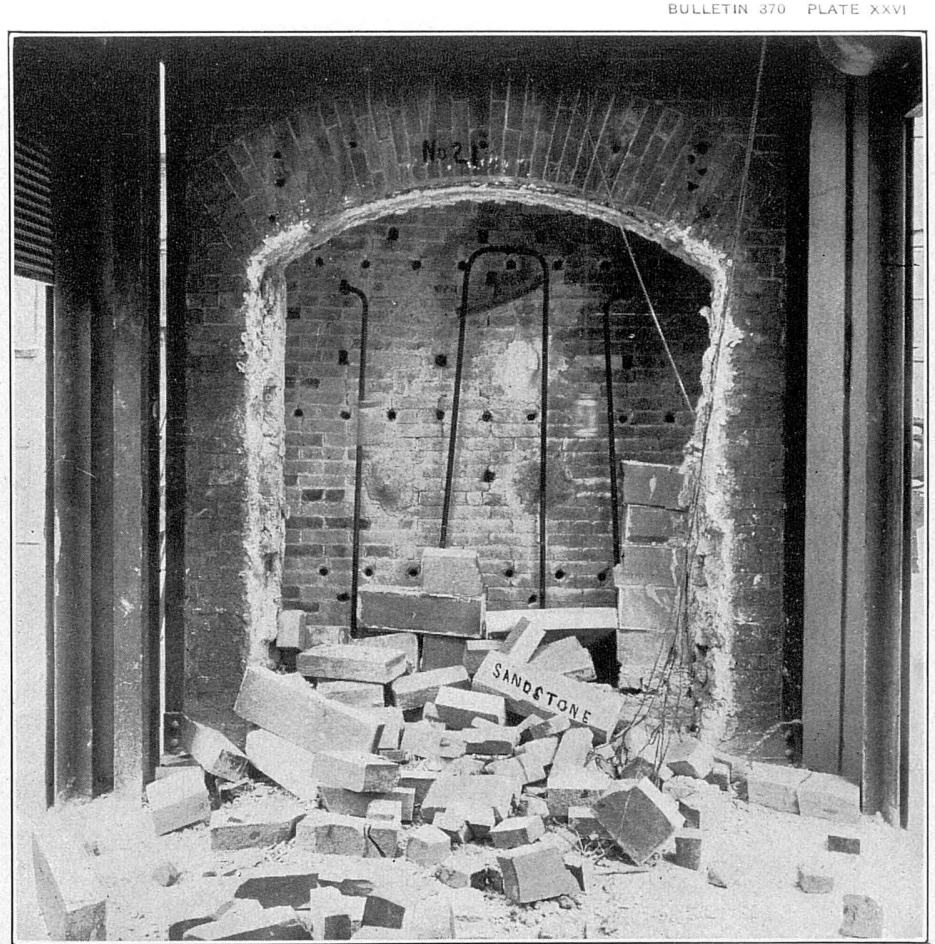

B. PANEL 21, DRESSED SANDSTONE, AFTER COLLAPSE. 



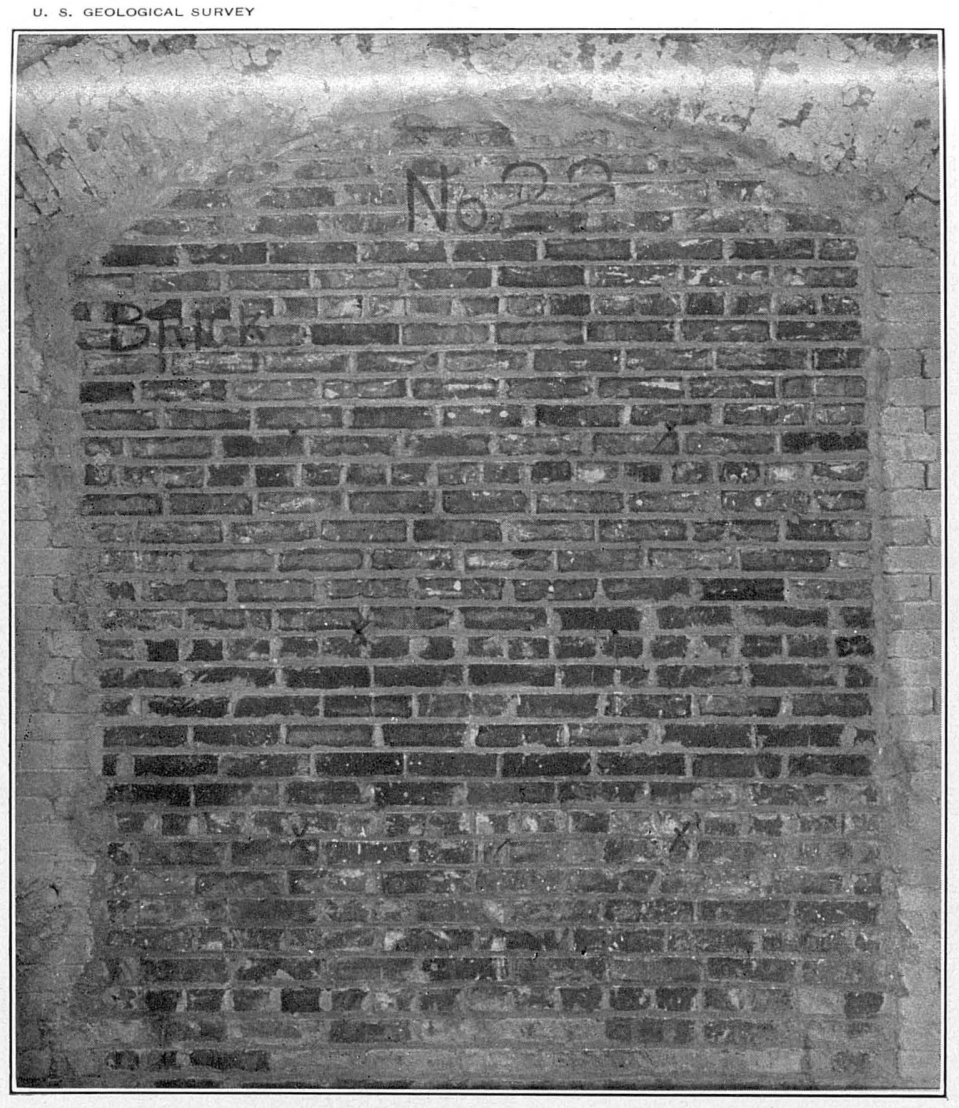

A. FACE OF PANEL 22, COMMON BRICK, BEFORE FIRING.

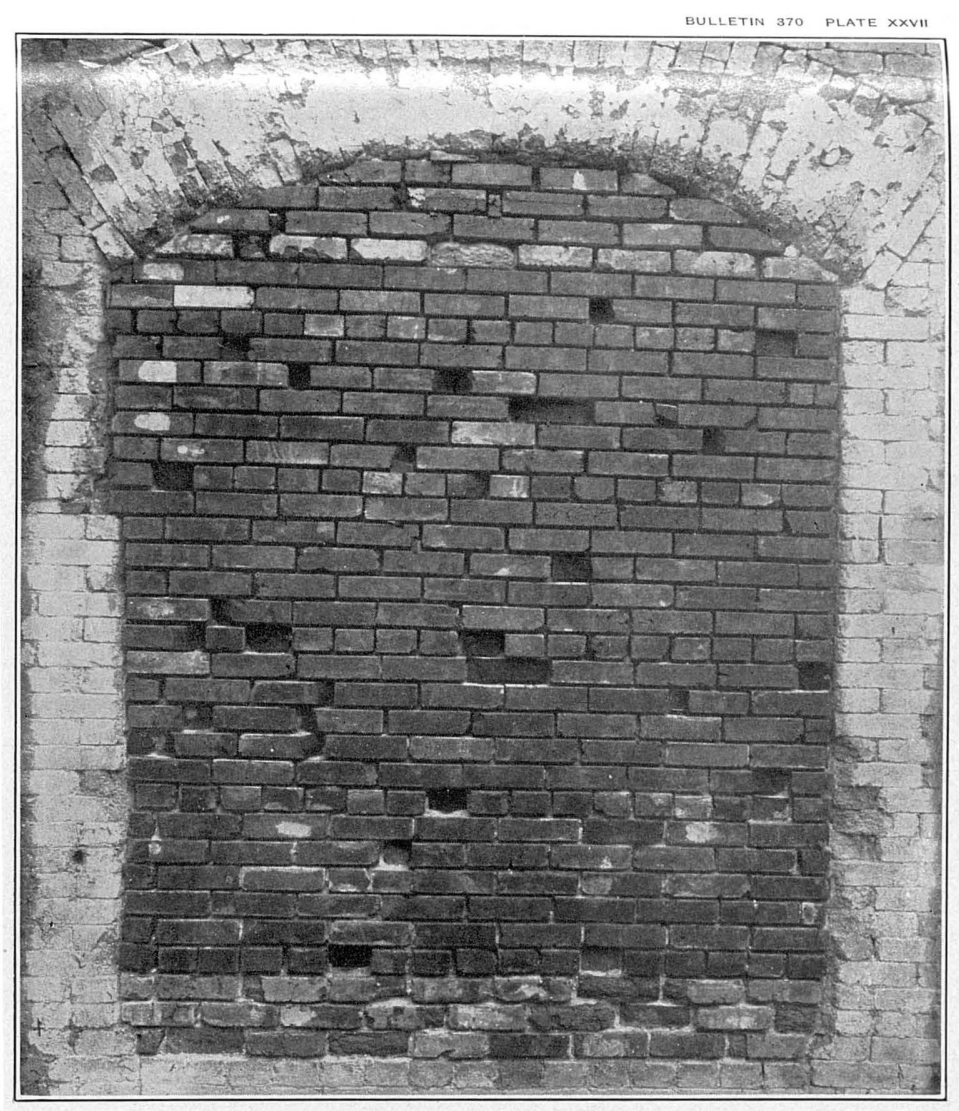

B. FACE OF PANEL 22, COMMON BRICK, AFTER FIRING AND QUENCHING. 

along the bedding of the stone, and also in lines vertical to this direction. No irregular hair cracks were observed. Plate XXVI, $A$, shows the face before testing. Plate XXVI, $B$, shows the wall after its collapse.

PANEL 22 (Brick).

Material.-Panel 22 consisted of common St. Louis brick from the foundation of the briquetting machine at the Government's fueltesting plant at St. Louis, where they had been placed about three years before they were tested for their fire-resisting properties. Physical tests of the bricks are given in Table 13. The bricks were laid in cement mortar with $\frac{1}{2}$-inch joints in a standard 8-inch wall, and bonded every sixth row. It was decided that a 12-inch wall was too heavy for the apparatus.

Test.-The panel was fired June 24, 1907. The duration of fire was 2 hours and 1 minute; then the panel was cooled by quenching with water for 5 minutes. The temperature of the water was $59^{\circ} \mathrm{F}$. The test was started at 2.20 p. m. A good uniform fire was obtained at the start.

In 20 minutes a slight snapping was observed. At 30 minutes steam appeared through cracks on the back of the wall. At 50 minutes the end of one of the header bricks cracked and fell off. The piece was about 1 inch in depth. No further changes were observed up to the time of removing the panel.

Curves showing the variations in temperature observed during the test are given in figure 23 .

Results.-About 15 per cent of the faces of the brick cracked and washed off during the application of the water. After cooling, it was found that about 50 per cent of the faces were' cracked and were easily pulled off with the fingers, or by prying gently with a screwdriver. The headers which seemed most damaged were split back about 1 inch. Some were cracked to a depth of $2 \frac{1}{2}$ inches. The faces of all the bricks were checked and cracked, and wherever a piece fell out it was usually about 1 inch in thickness. The entire wall was discolored to a depth of about 1 inch, the faces of the bricks turning almost black. The bricks on the back of the wall were apparently uninjured, no cracks being observed in any of them.

Plate XXVII, $A$, shows the face of the panel before firing and Plate XXVII, $B$, shows the face after quenching.

PANEL 23. (Granite Building Stone).

Material.-Panel 23 was composed of blocks of building granite laid in cement mortar with broken joints.

Test.-The test took place on June 26, 1907. The duration of the fire was 2 hours and $\frac{1}{2}$ minute, after which the panel was quenched for 5 minutes with water at $57^{\circ} \mathrm{F}$. 


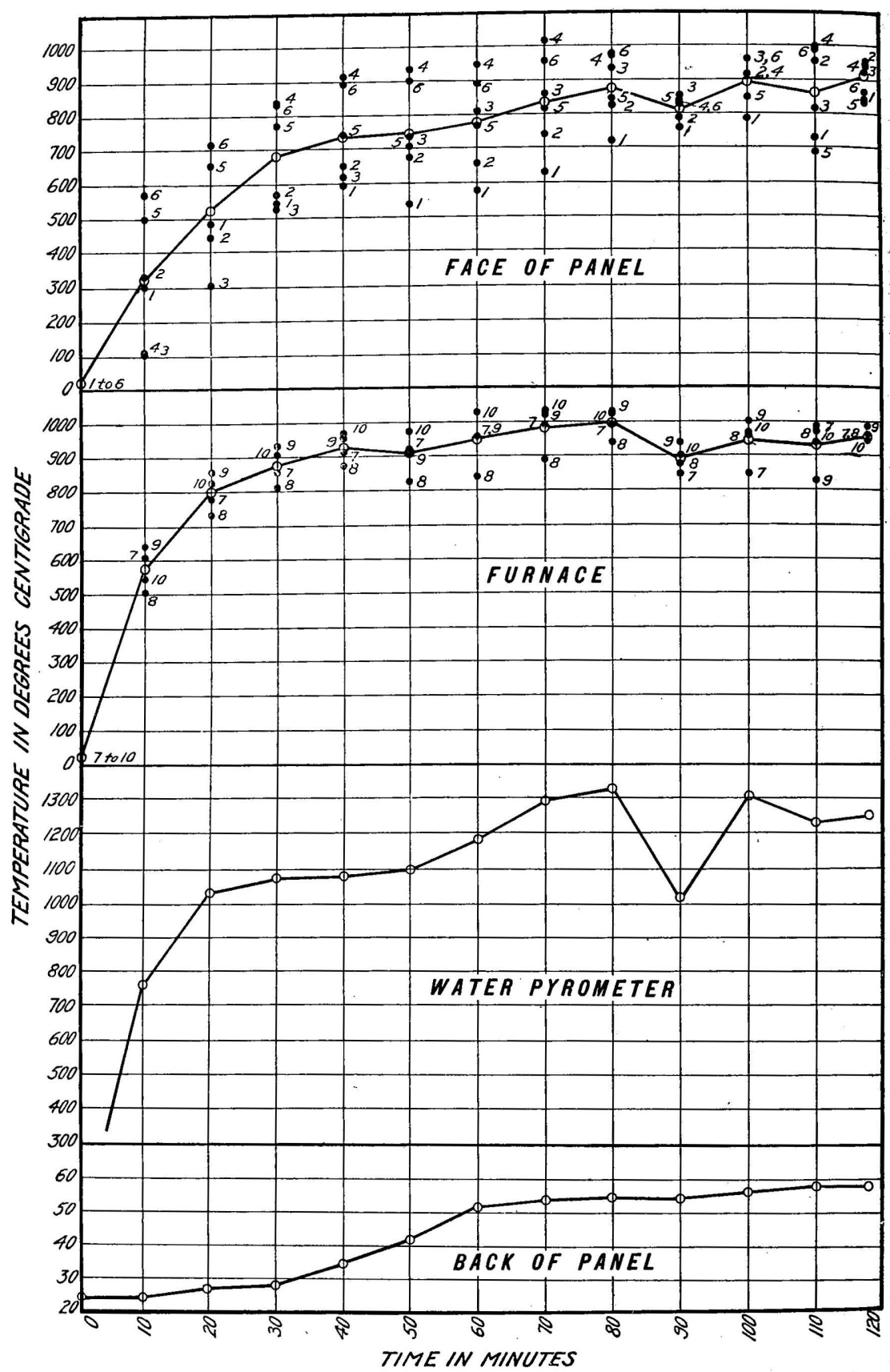

FIGURE 23.-Diagram showing temperature conditions in the furnace and on the back of panel 22. Temperature: Maximum, $80^{\circ}$; minimum, $69^{\circ}$; mean, $74^{\circ}$. Relative humidity: 7 a. m., $90 ; 7$ p. m., 63 . Direction of prevailing wind, southwest. 
The furnace started with a good, even temperature and in about 2 minutes considerable snapping was heard, although no cracks appeared either on the face or on the back of the panel.

At 5 minutes it was observed that the wall had bulged inward toward the fire about $\frac{1}{2}$ inch and horizontal cracks were observed in the mortar joints at the sides and bottom of the panel. At 10 minutes the wall had bulged $1 \frac{1}{8}$ inches. At 13 minutes a crack between the sill and the material in the panel had developed to about $\frac{1}{8}$ inch in width and extended the entire length of the panel. By this time the center of the door had bulged $1 \frac{1}{2}$ inches. Owing to this bulging it was feared that a collapse similar to that of panel 21 would be repeated. The thermocouples and thermometers were accordingly removed from the panel. At 17 minutes a block in the center of the seventh row began te spall, starting at the center of the block on the top and running diagonally to the lower left edge. The piece did not fall off. At 20 minutes the center of the panel had bulged $1 \frac{7}{8}$ inches. At 22 minutes the furnace was shut down for about 1 minute, in order that it might be more evenly adjusted. At 29 minutes a vertical crack developed in a block in the seventh row on the back of the panel. Also a block in the third row on the lefthand side cracked vertically on the back near the center, followed by a vertical crack 6 inches from the outer end and another vertical crack 4 inches from the inner end. These cracks did not show on the fired side, but it is very probable that they extended entirely through the stone. A't this time the panel had bulged $1 \frac{1}{1} \frac{5}{6}$ inches. At 33 minutes the seams at the side of the panel between the granite and the frame of the door had opened to a width of $\frac{3}{8}$ inch and extended the entire height of the wall. A vertical crack started in the lefthand block in the eighth row, about 8 inches from the inner end, developing on the back of the wall. At 35 minutes the wall had bulged $2 \frac{1}{8}$ inches. Small vertical cracks noted in nearly all the pieces were gradually increasing in size, running vertically. 'It was rare that one of these cracks was directly over another, which would show that they were due to internal stress rather than to stress set up in the panel as a whole. At 40 minutes the back of the blocks became too warm for the hand to be placed on them. At this time the wall had bulged $21_{16}^{6}$ inches. At 48 minutes, on the. back of the center block in the seventh row, three cracks opened up the entire width of the stone, one in the center and the others about 6 inches from each end. These cracks were about $\frac{1}{64}$ inch in width and apparently extended entirely through the piece. At 50 minutes a thermometer in the center of the wall was replaced, as it seemed that the panel would remain in the door.

At 54 minutes the wall bulged to the extent of $2 \frac{3}{4}$ inches. At 70 minutes the wall bulged to the extent of $2 \frac{11}{6}$ inches. At 105 minutes 
no further changes were observed in the condition of the face, and no more cracks had developed. The wall at this time had bulged $2 \frac{7}{8}$ inches. It was again feared that the wall would collapse, and a. picture was taken to show the condition of the cracks on the back. At 120 minutes the wall had bulged to the extent of 3 inches.

On removal of the door from the furnace there were only three stones that showed signs of spalling. One was in the seventh row, center; in another, in the third row on the right, the outer corner had spalled off but was in place; the third instance of spalling was at the upper outer corner of the stone in the third row on the left side. The condition of the surface was about the same as before fire treatment, except that the color had been turned to a brownish blue.

Before the water was applied it was impossible to observe any cracks except those mentioned. During the first 3 minutes of the water application the stone snapped and cracked audibly, but none of the surface fell off. After this the spalling and cracking became general, and large pieces varying in depth from 1 inch to $1 \frac{1}{2}$ inches came off. About one-fourth of the surface of the panel was apparently washed away.

Curves showing the variations in temperature observed during the test are given in figure 24 .

Results.-After the water treatment the panel was $2 \frac{3}{4}$ inches out of plumb. The stones on the face were of a reddish-gray color and were very badly cracked, and the surface that remained intact could be easily crumbled in the fingers. The portions back about 1 inch to $1 \frac{1}{2}$ inches from the face which had been uncovered were more or less hard, but badly split and spalled. The back of the panel was also changed in color, but not so much as the face.

On taking down the panel it was found that all the pieces were very badly cracked, both across the stones and in a plane parallel to the face. The blocks were as a rule broken into pieces about 4 to 8 inches long. The back sides of the stones were found to be badly cracked in every direction, and by gentle tapping with the hammer could be broken into fragments.

Plate XXVIII, $A$, shows the face of the panel after firing but before quenching. Plate XXVIII, $B$, shows the face after firing and quenching. Plate XXIX, $A$, shows the condition of the stone on being removed from the furnace.

\section{PANEL 24 (Tile).}

Material.-The material composing panel 24 was 5 by 12 by 12 inch partition tile, having three air spaces (fig. 25). The tiles were laid as a standard 5 -inch partition wall with about $\frac{1}{2}$-inch cement-mortar joints, having the core holes in a vertical position and broken joints. The face and back were plastered with a coat, about $\frac{1}{2}$ inch thick, of 


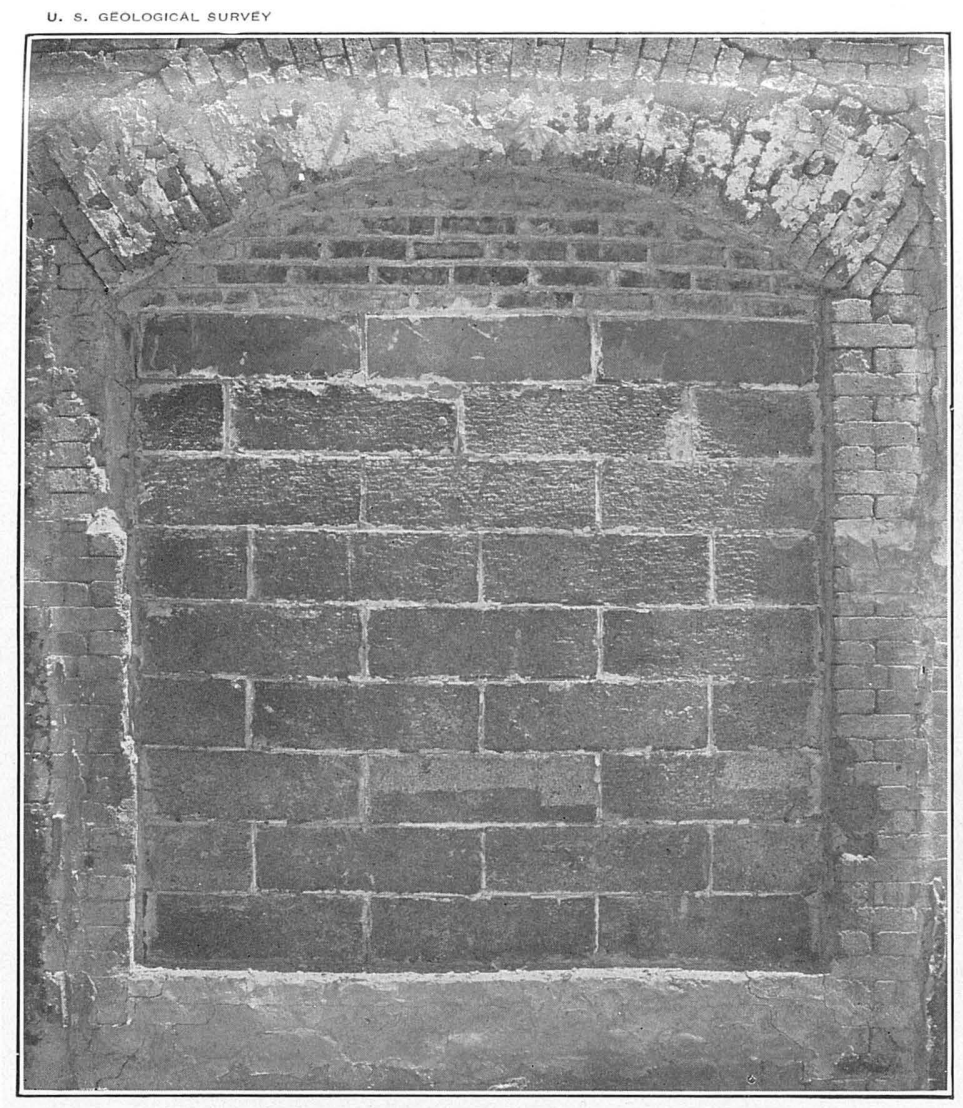

A. FACE OF PANEL 23, DRESSED GRANITE, AFTER FIRING BUT BEFORE QUENCHING.

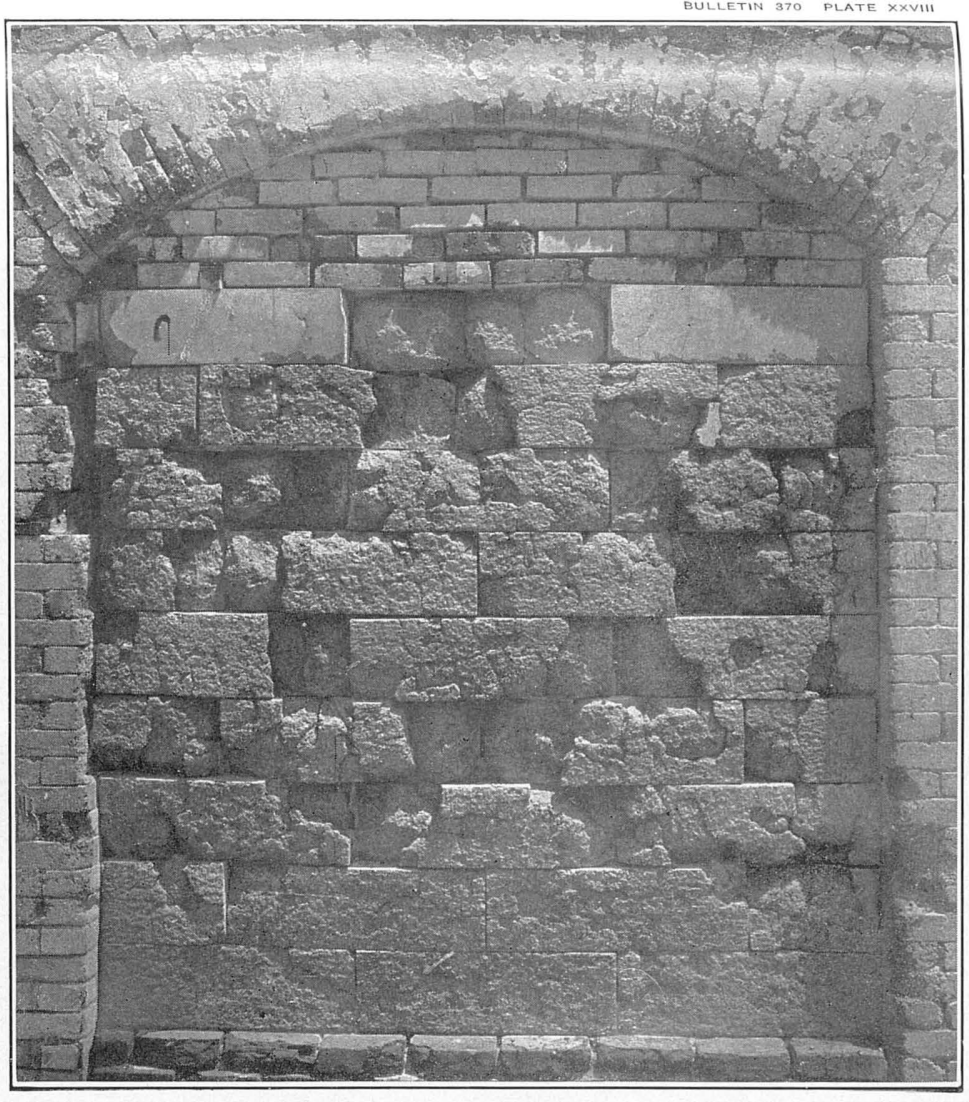

B. FACE OF PANEL 23, DRESSED GRANITE, AFTER FIRING AND QUENCHING. 



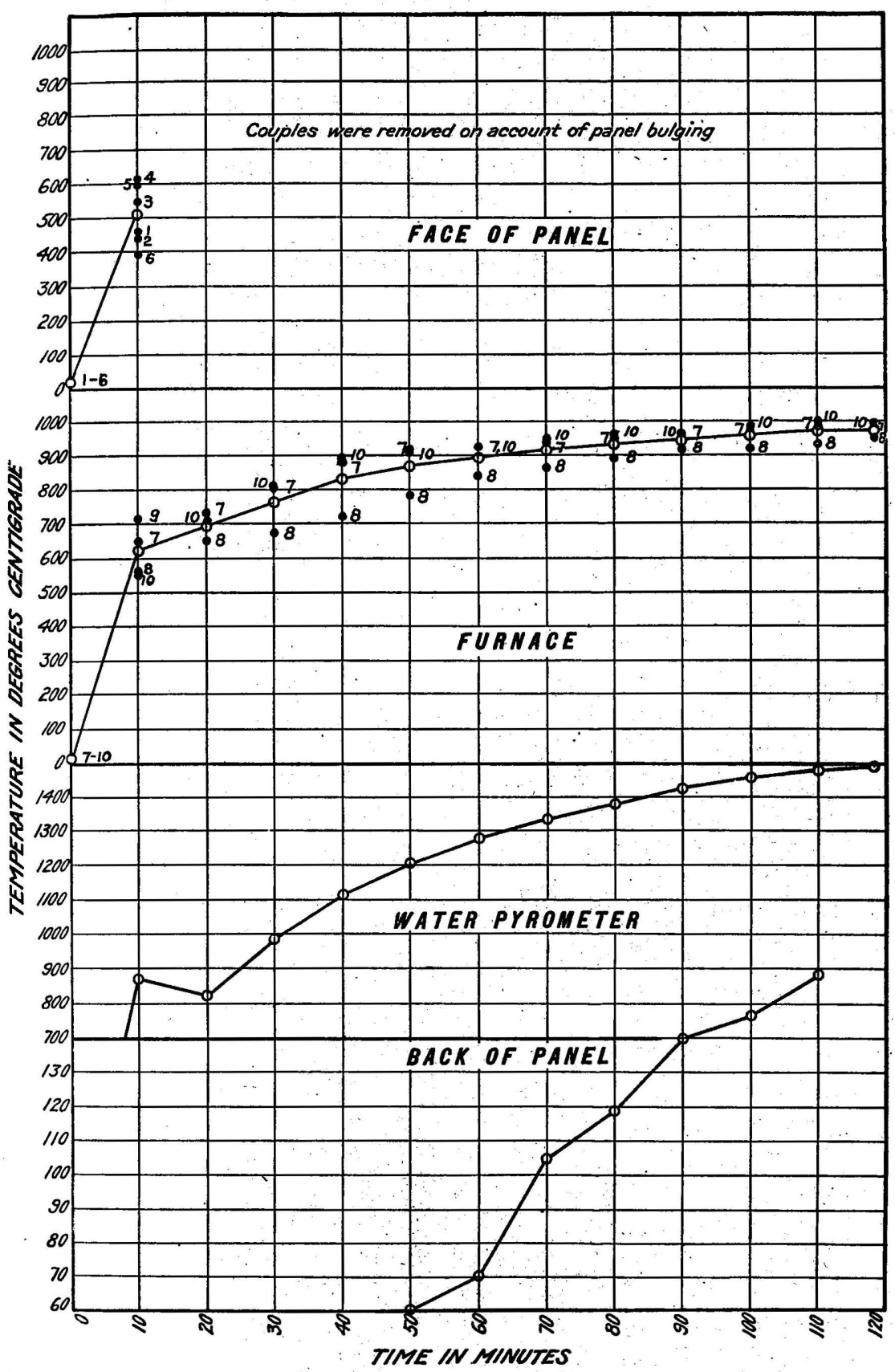

FIGURE 24.-Diagram showing temperature conditions in the furnace and on the back of panel 23.

Temperature: Maximum, $69^{\circ}$; minimum, $59^{\circ}$; mean, $64^{\circ}$. Relative humidity: 7 a. m., $73 ; 7$ p. m., 74 . Direction of prevailing wind, northwest.

73087-Bull. $370-09-5$ 
ordinary lime plaster containing a little hair. Over these two coats was placed a thin skim of plaster of Paris, put on as a hard finish in the usual way.

Test.- The tiles were laid up on the afternoon of June 26, 1907, plastered the morning of June 27, 1907, and fired July 1, 1907, at $9.27 \mathrm{a} . \mathrm{m}$. The actual duration of the fire was 2 hours and 1 minute, after which the panel was quenched for 5 minutes with water.

In 2 minutes the surface coat of plaster on the fire side fell off, coming off in large sheets, about one-third of the panel at a time. At

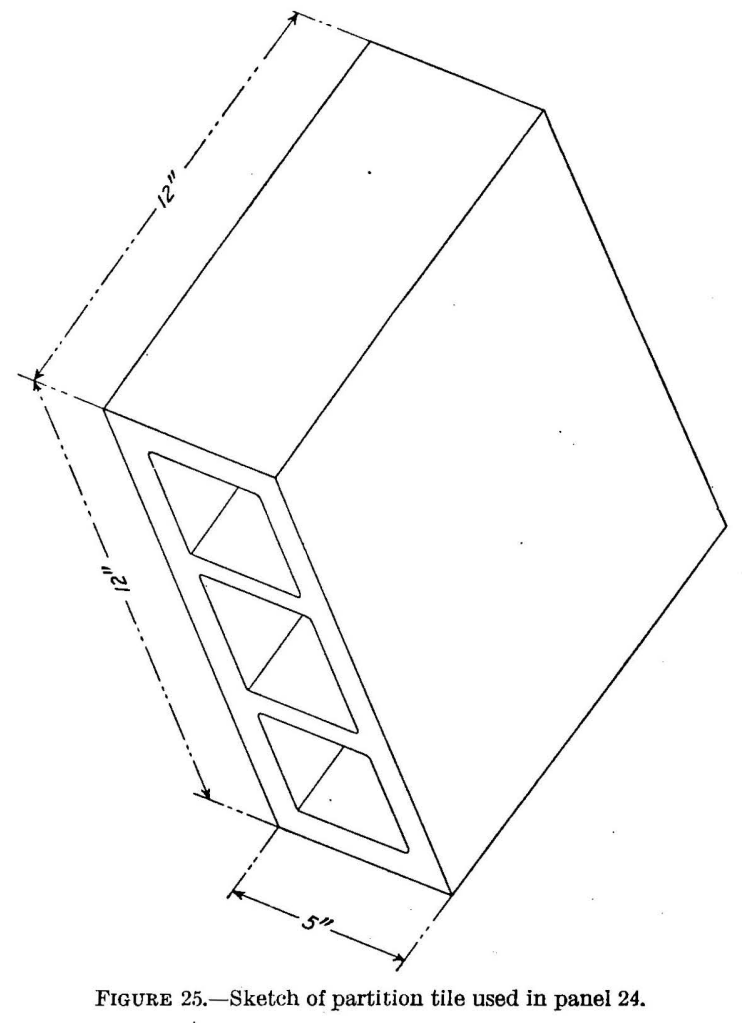

6 minutes the furnace was stopped for 5 minutes in order that the burners might be cleaned out. This 5-minute intermission was deducted from the elapsed time of fire treatment. At 10 minutes cracks developed on the back of the panel horizontally across the center at the joint on the top of the third row of tiles. At 15 minutes steam began to come through the mortar around the edges of the panel. At 18 minutes a portion of the lime plaster on the face, about 2 square feet in area and about 1 foot from the bottom, bulged out from the tile about 1 inch. At 33 minutes a crack developed on the back of the wall along the bottom of the panel, extending the 


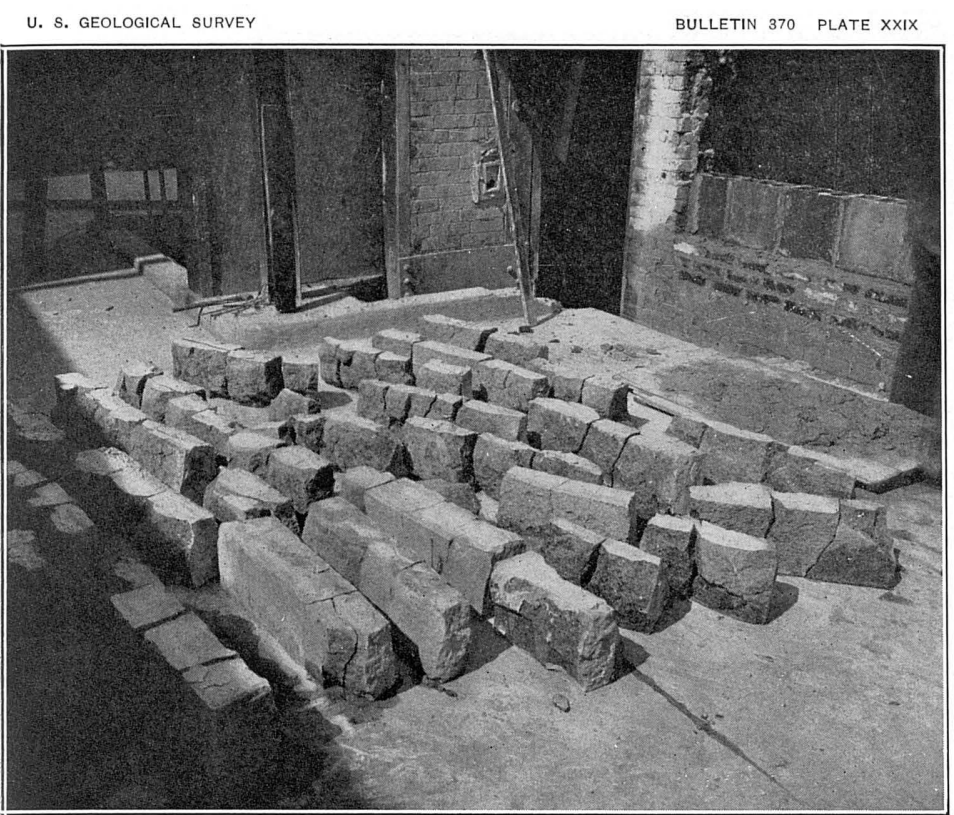

A. CONDITION OF DRESSED GRANITE ON REMOVAL FROM PANEL 23.

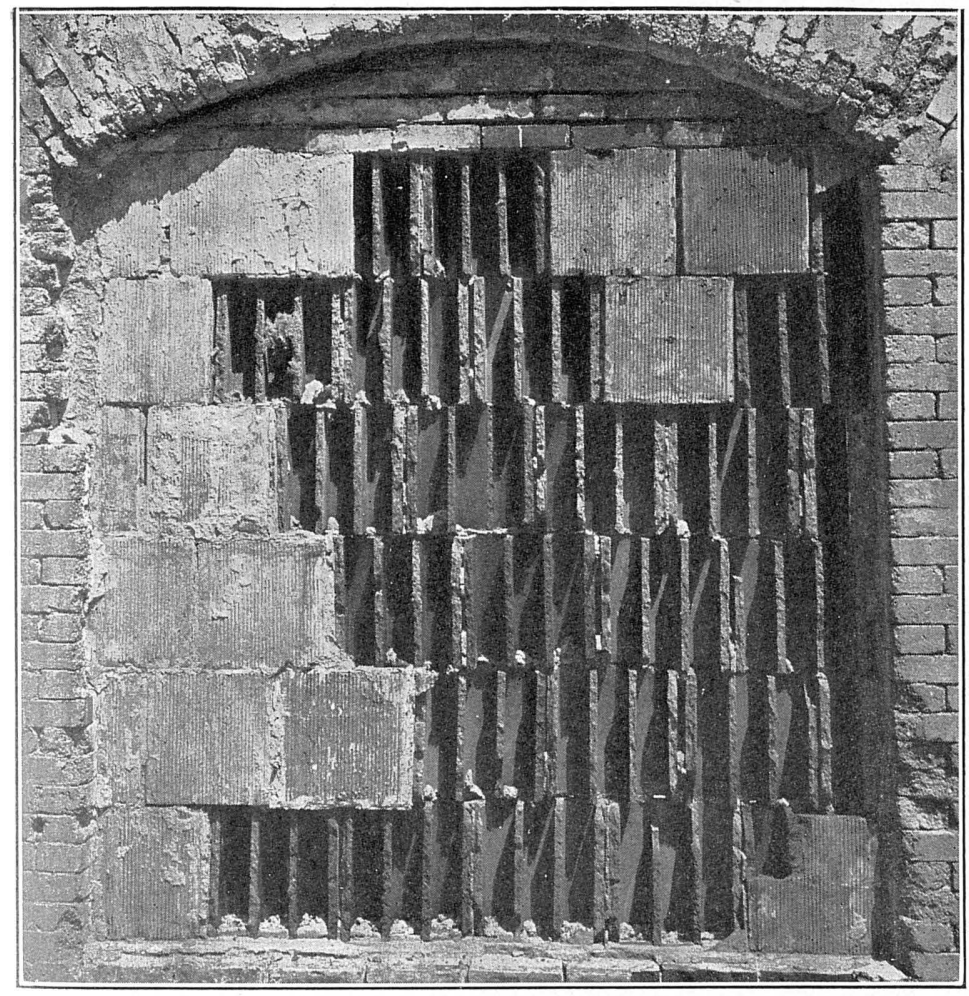

B. FACE OF PANEL 24, PARTITION TILE, AFTER FIRING AND QUENCHING. 

entire width. The crack across the center of the door, before mentioned, opened to the extent of about ${ }_{64}^{1}$ inch. These cracks could not be observed in the plaster on the fired side. At 55 minutes steam began coming through the joints around the individual tiles. This was more or less general all over the door. At 60 minutes a crack developed horizontally at the joint of the fourth and fifth rows of tiles and ran entirely across the door. At 95 minutes diagonal cracks developed at the upper left-hand side of the panel and ran about 2 feet out from the corner. At 117 minutes plaster on the right-hand side of the door, about halfway up the panel, bulged badly, but did not fall off.

Curves showing the variations in temperature observed during the test are given in figure 26 .

Results.-On shutting off the fire and undertaking to slide the panel from the furnace the door stuck and permitted the panel to come out only about halfway. In endeavoring to pry the door entirely open the panel was very badly shaken, and the plaster coating on the fired side, which had been intact up to this time, was shaken off. Thirty-seven minutes elapsed from the time the fire was shut off until the water was applied, this time being spent in trying to remove the door.

On applying the water, only about half of the door, the right-hand side, was subjected to the direct impact of the stream, though the remaining portion was more or less wet. The severe shaking which caused the plaster to fall off probably also cracked many of the faces of the tiles which were intact at the time the water was applied. By the water treatment the plaster was washed away on the lower portion of the back, and badly bulged at the middle height over the entire width of the panel.

About 65 per cent of the tiles that were-exposed directly to the stream were washed away, while those not so exposed were all intact, with the exception of two tiles at the bottom; they were, however, badly cracked.

After removing the door from the furnace it was found that about 75 per cent of the faces of the tiles of the entire panel had been washed away or would come off by gently tapping with the handle of a light screw-driver. The remaining 25 per cent were badly cracked, but were apparently rigidly attached to the back part of the tile. The faces remaining in place were very badly cracked, and could be easily. broken in the hand.

On taking down the panel it was found that none of the tiles could be taken out intact; they were all cracked across the webs. The back portion of the webs and the back faces of the tiles were appar- 


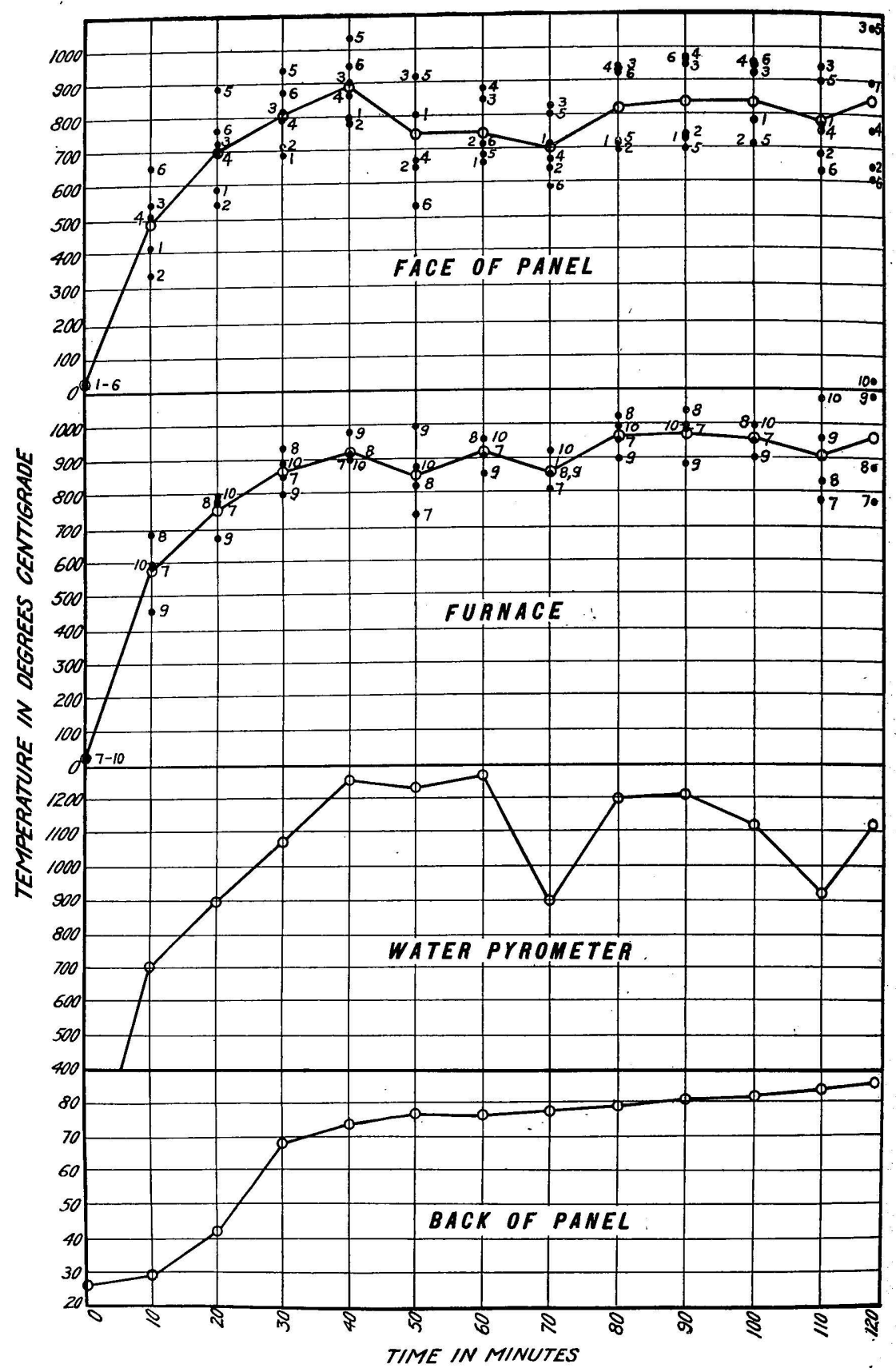

FIGURE 26.-Diagram showing temperature conditions in the furnace and on the back of panel 24 . Temperature: Maxiaum, $83^{\circ}$; minimum, $61^{\circ}$; mean, $72^{\circ}$. Relative humidity: 7 a. m., $91 ; 7$ p. m., 69 . Direction of prevailing wind, north west. 
ently as hard as before the fire treatment. Few cracks were observed in this portion.

Plates XXIX, $B$, and XXX, $A$, show the face and back of the panel after the completion of the test.

PANEL 25 (Building Stone).

Material.-Panel 25 consisted of five kinds of building stone, viz: Bedford limestone from Bedford, Ind.; limestone from Joliet, Ill.; sandstone from Cleveland, Ohio; marble from Tait, Ga.; and granite from the Thousand Islands, Canada.

The top layers of the panel were filled in with hollow terra-cotta tile in order to make the panel as light as possible. There were two courses of each kind of stone, laid in cement mortar with broken joints. One course of the limestone and one of the sandstone was laid on the natural bed; the other had the plane of the natural bed exposed to the fire. In one course the exposed face of each block was $7 \frac{3}{4}$ inches long and in the other $4 \frac{1}{2}$ inches. The panel was backed up with common brick to make it less liable to collapse during the test.

Test.-This test was started at 5.35 p.m. July 1, 1907, and continued for 2 hours. The panel was cooled by a stream of water at $57^{\circ} \mathrm{F}$. for 5 minutes. The bulge of the wall was measured on the limestone header which lay flat at the middle height.

In 10 minutes the panel bulged $\frac{1}{8}$ inch. At 12 minutes the sandstone block in the left center on the second row spalled to a depth of about $\frac{3}{4}$ inch over the entire face, the piece falling into the pit below. At 20 minutes the wall had bulged $\frac{11}{16}$ inch. The center block in the seventh row, composed of limestone, spalled, and a piece the entire length of the block and about 1 inch in depth fell off. At 24 minutes small vertical cracks on the back surface began to develop in nearly all the granite blocks. At 30 minutes the wall bulged $\frac{7}{8}$ inch, and small beads of water were collecting on the back side of the header of marble. At 33 minutes small vertical cracks developed in the header of Bedford stone. These cracks were about 8 inches apart and occurred in all three pieces on the back side of the wall. At 35 minutes the sandstone blocks in the second row, which had the plane of the natural bed parallel to the fired face, were both very badly spalled, and the stone on the right side in the second row had crumbled to a depth of about 3 inches at the end and about $1 \frac{1}{2}$ inches at the center. At 40 minutes the limestone turned white, having become calcined, and showed fine irregular cracks on the surface. The marble also showed signs of calcination, the surface becoming white, but cracks were not visible. At 50 minutes the wall had bulged 15 inch, and at 70 minutes $1 \frac{1}{8}$ inches, no apparent change in the surface 
of the stone being noted. At 120 minutes the wall had bulged $1 \frac{3}{18}$ inches. After quenching the wall bulged $\frac{7}{8}$ inch.

Curves showing the variations in temperature observed during the test are given in figure 27.

Results.-On removal of the panel it was found that the granite was badly spalled and cracked, but the face was still intact. The faces of the limestone were intact but very white, except the piece which fell out, before noted. The marble was very badly calcined and the face chalky white; no cracks were visible, and the entire face was intact. The Bedford limestone was badly cracked and the face considerably calcined. The sandstone showed deep seams in the pieces that were lying on their natural bed, and the other stones were more or less spalled.

During the application of the water the granite, limestone, and Bedford stone cracked and their faces washed away considerably.' The entire surface of the granite was washed away about $\frac{1}{4}$ inch; three of the stones were badly cracked, and the faces fell off to a depth of about 2 inches. The limestone was calcined to a depth of about $1 \frac{1}{4}$ inches, and most of the faces had fallen off to about this depth. The stones were cracked into small fragments ( 2 to 3 inches) by cracks which ran entirely through the pieces. This was true also of the Bedford limestone, but the calcining and spalling was only from $\frac{3}{4}$ inch to $1 \frac{1}{2}$ inches deep. The marble washed away under the water treatment from 1 inch to $1 \frac{1}{2}$ inches in depth, and the surface had a crystalline and very rough appearance; no cracks were visible in the pieces which had the $7 \frac{3}{4}$-inch face exposed. The pieces with the $4 \frac{1}{2}$-inch face exposed were cracked back from the face, the cracks being nearly vertical and more or less irregular. The sandstone washed away to a depth of about $\frac{1}{4}$ inch; the surfaces left were hard and had turned a dark red. The stones lying on the natural bed were not washed away as much as the others, but irregular vertical cracks ran all through them, and the seams had opened up. The pieces laid with the bedding planes on edge were badly cracked, and the water washed them away from $\frac{1}{4}$ inch to $1 \frac{1}{4}$ inches in depth. The surfaces were rough and of a reddish color and were very badly cracked.

On taking down the panel the granite was found to be broken into small pieces from 6 to 8 inches in length, the cracks running back from the fired face. The limestone came out in small pieces, having broken along nearly vertical and horizontal lines. The faces to a depth of about 1 inch to $1 \frac{1}{2}$ inches usually cracked away from the back portion. The marble was found to break into pieces about 4 to 6 inches in length; the cracks, which were not visible before the blocks were removed from the panel, were more or less irregular, but usually had a general vertical direction. The marble lying with the 


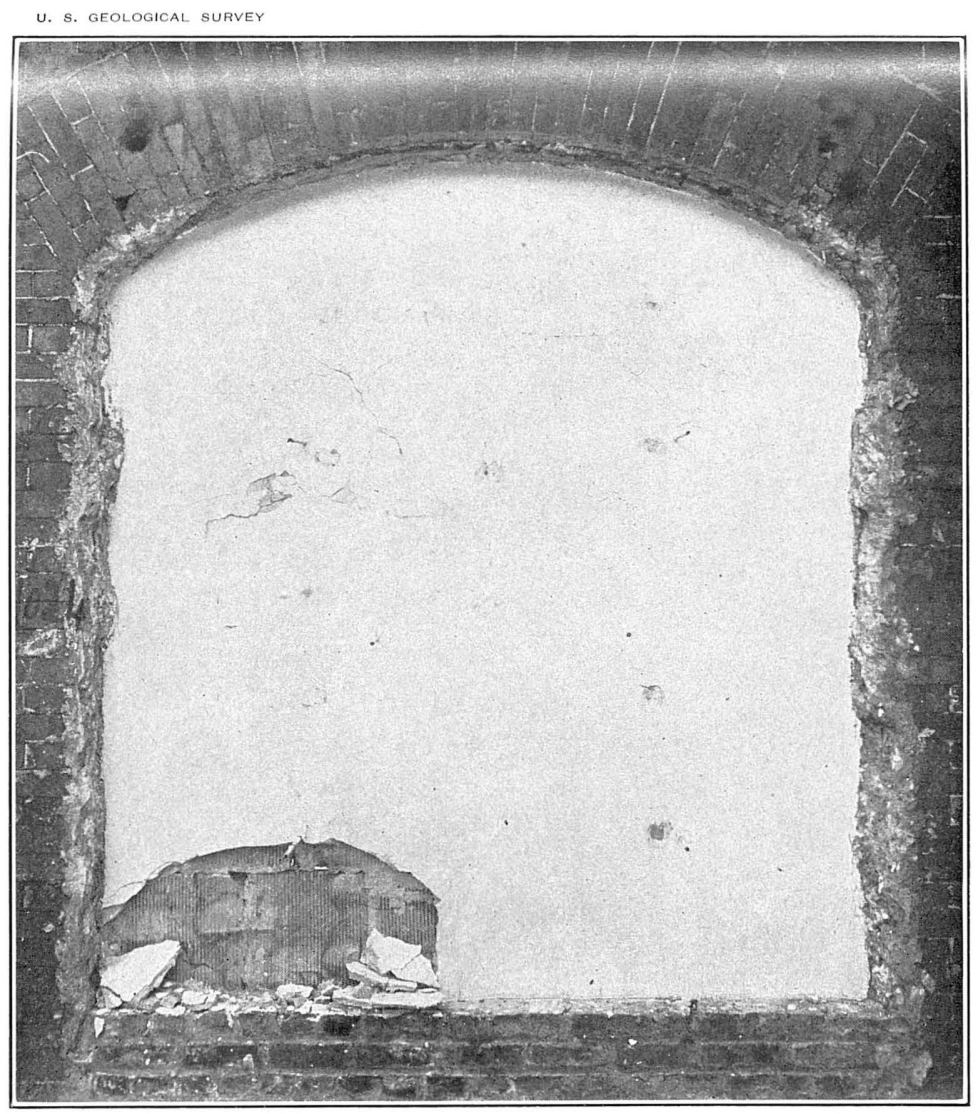

A. BACK OF PANEL 24, PARTITION TILE, AFTER FIRING AND QUENCHING.

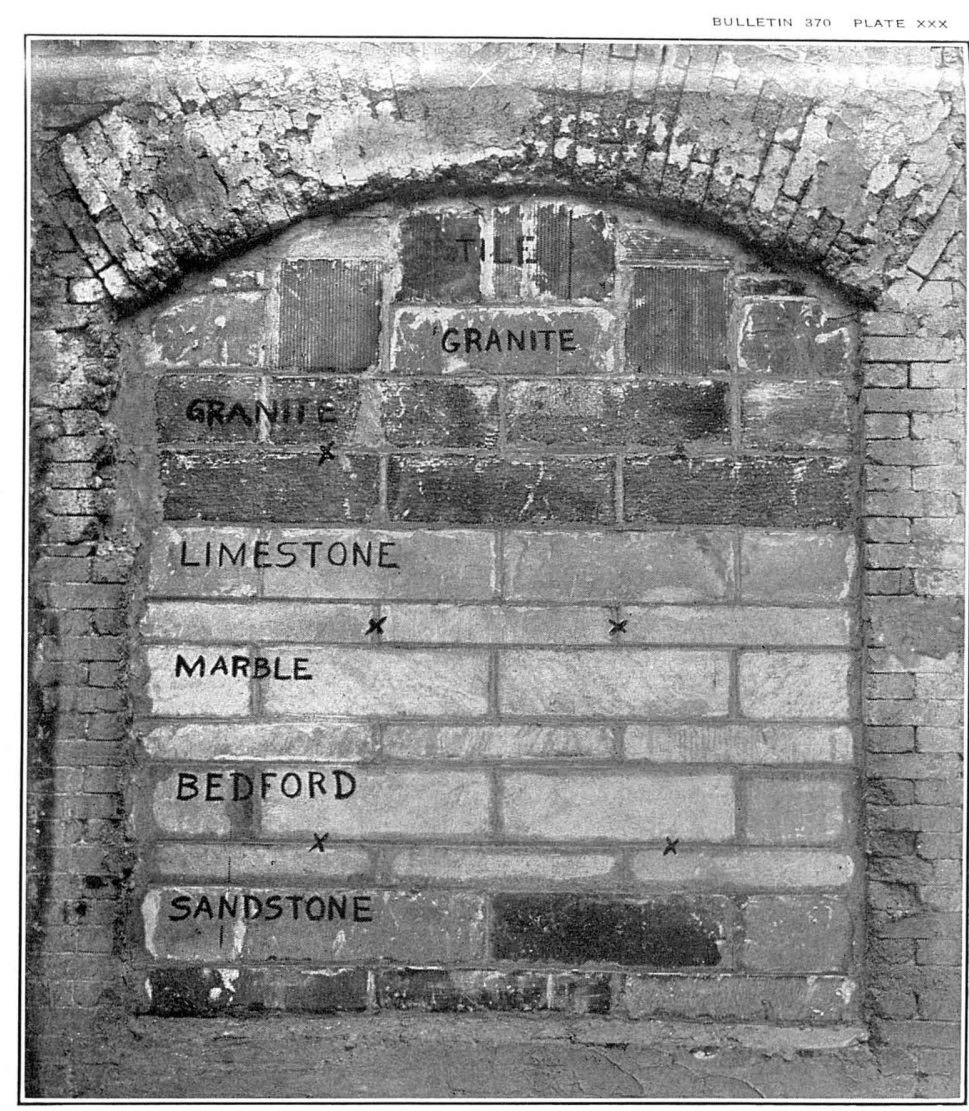

B. FACE OF PANel 25, VARIOUS BUILDING Stones, BEFORE FIRING. 



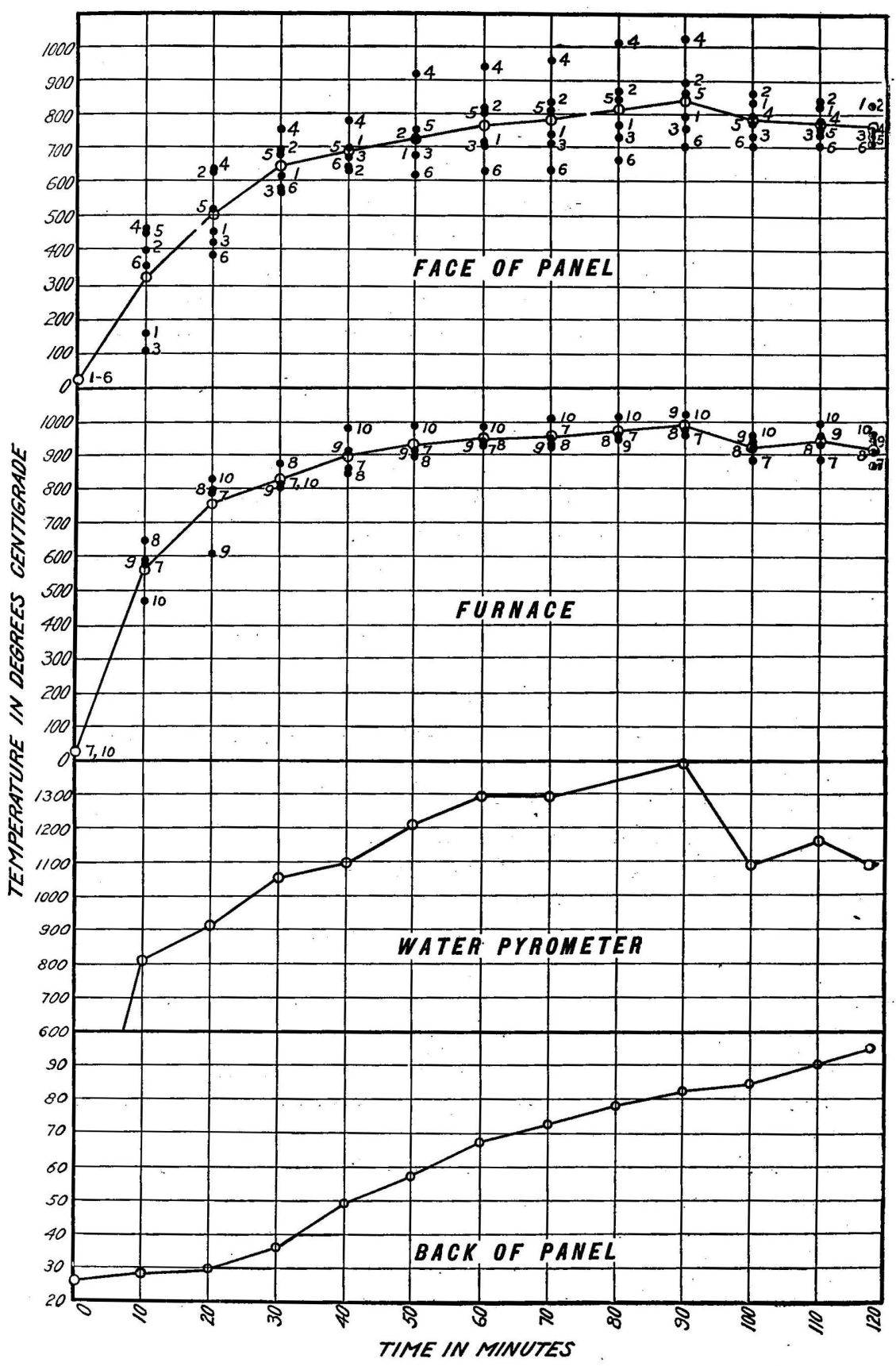

FTGURE 27.-Diagram showing temperature conditions in the furnace and on the back of panel 25. Temperature: Maximum, $83^{\circ}$; minimum, $61^{\circ}$; mean, $72^{\circ}$. Relative humidity: 7 a. m., 91; 7 p. m., 69. Direction of prevailing wind, northwest. 
$4 \frac{1}{2}$-inch face exposed was cracked in like manner. The Bedford limestone acted like the other limestone, except that the pieces were somewhat larger.

The sandstone was badly cracked along the stratification planes and also broke into small pieces by cracking perpendicularly to the bed. The blocks lying with the natural bed parallel to the fired face cracked more or less irregularly, and their faces were entirely gone. Those on the natural bed, however, except for perhaps $\frac{1}{4}$ or $\frac{1}{2}$ inch which had washed away, were intact, but split and cracked.

Plates XXX, $B$, and XXXI, $A$, show the face of the panel before and after testing. Plate XXXI, $B$, shows the back after testing.

PAYEL 26 (Building Stone).

Material.-Panel 26 consisted of blocks of Georgia marble laid with broken joints in cement mortar with 4-inch and $7 \frac{1}{2}$-inch faces exposed, as shown in Plate XXXII, $A$. The lower part of the panel was backed with common brick, and the upper portion was laid up with partition tile in order to make the panel as light as possible.

Test.- The test was started at 9.47 a. m. July 6, 1907, and firing continued for 2 hours and 1 minute. The panel was cooled by water at $61^{\circ} \mathrm{F}$. for 5 minutes. A fairly uniform fire was obtained, the top being slightly hotter than the bottom and the center of the panel. The bulging was measured at the center of the panel on the second stretcher of marble.

In 7 minutes cracks developed along the edge of the panel on both sides. At 10 minutes the panel had bulged toward the fire about $\frac{7}{8}$ inch. At this time control of the furnace was lost and the temperatures ran too high for three or four minutes. At 75 minutes vertical crácks developed on the back of the lower left-hand stone, one about 3 inches from the edge and one in the center. A vertical crack, starting at the top and running down to the bottom, showed near the middle of the center stone of the same row. At 120 minutes the wall had bulged $1 \frac{13}{16}$ inches. After quenching the bulging was $1 \frac{9}{16}$ inches.

Curves showing the variations of temperature throughout the test are given in figure 28 .

Results.-When the door was removed from the furnace the surface appeared to be smooth, but very chalky. On applying water the surface slacked for about a minute or two, and gradually washed away; then it became very rough, showing the crystalline structure of the rock, and washed away to a total depth of $\frac{1}{4}$ inch to $1 \frac{3}{4}$ inches. After cooling, the surface was found to be very rough and the crystalline structure showed very plainly. Dark streaks in the marble withstood fire and water better and stood out beyond the general surface. The narrow faces were apparently more badly damaged, being cracked back from the fired face into pieces from 4 to 18 inches 


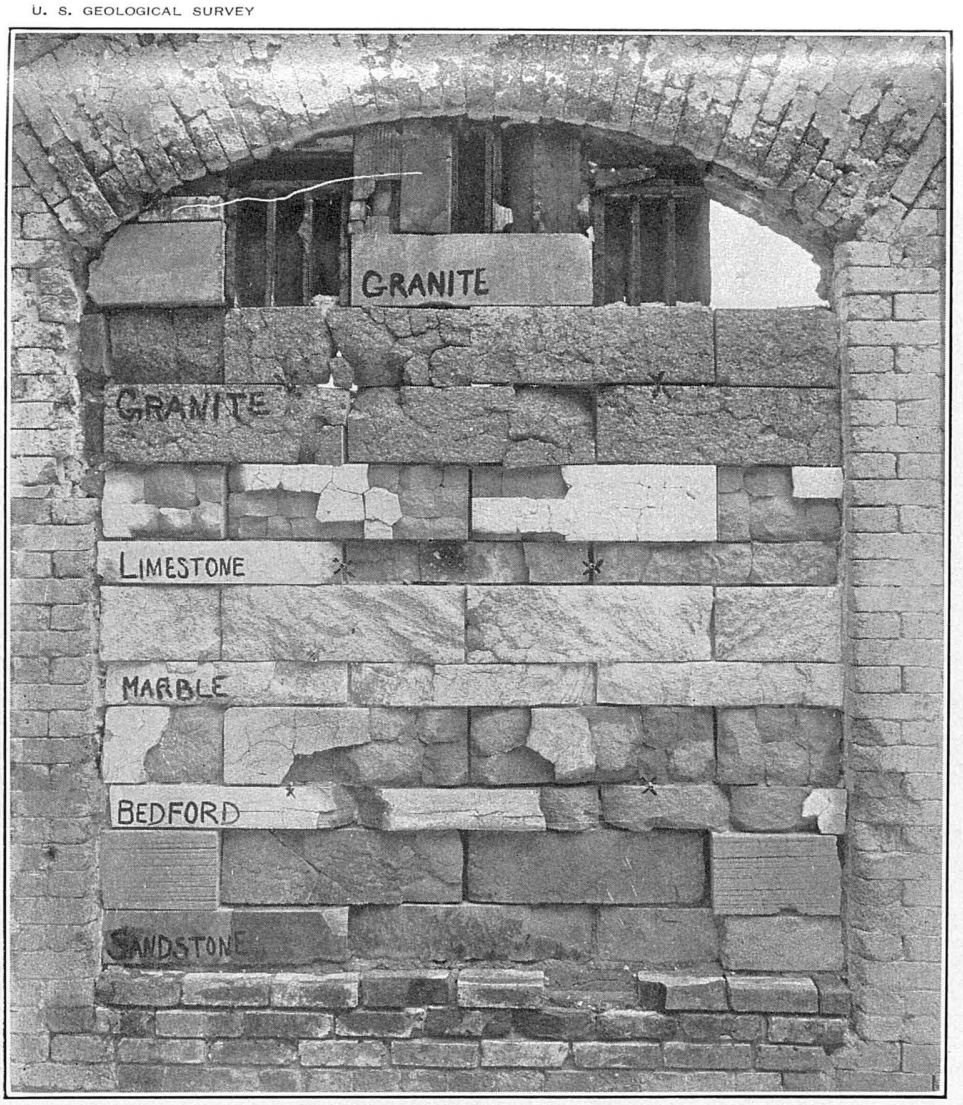

A. FACE OF PANEL 25 , VARIOUS BUILDING STONES WITH BRICK BACKING, AFTER TESTING.

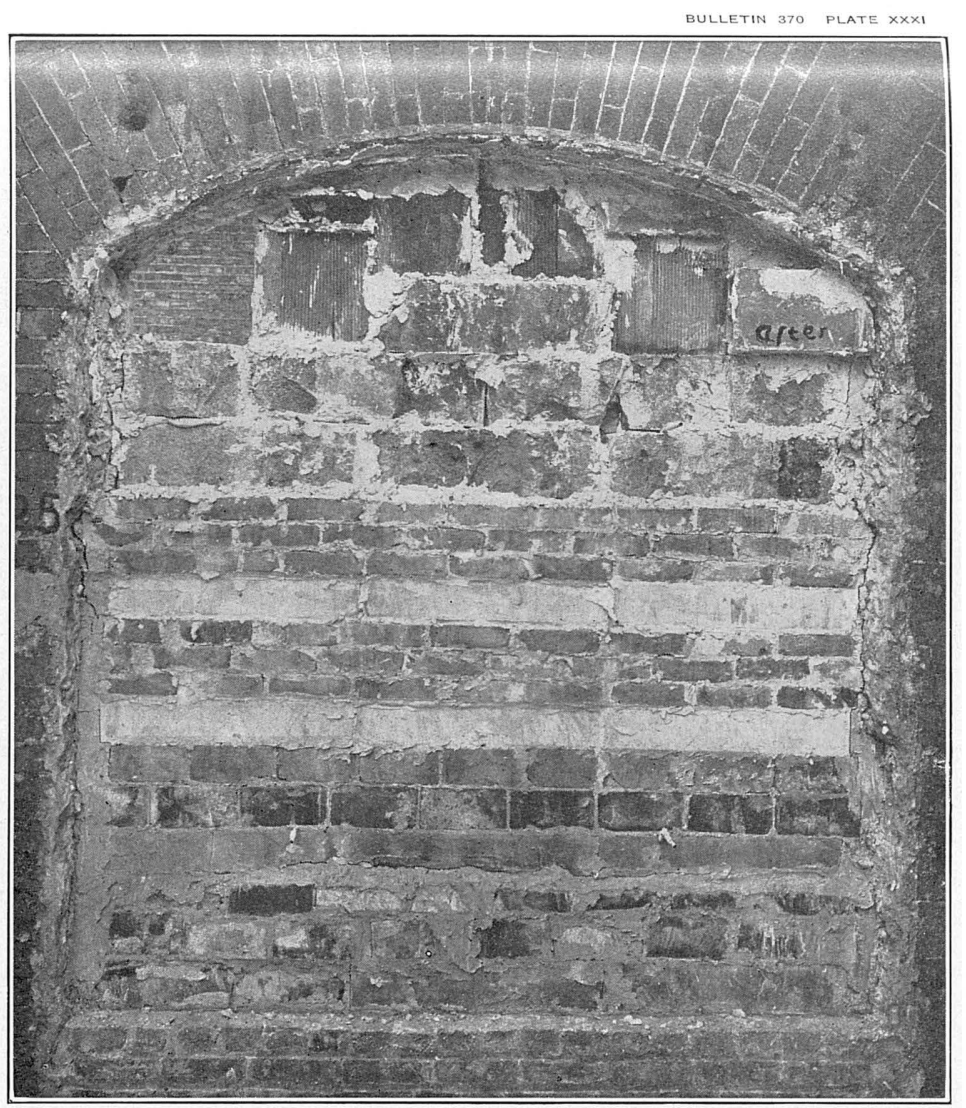

B. BACK CF PANEL 25, VARIOUS BUILDING STONES WITH BRICK BACKING, AFTER TESTING. 



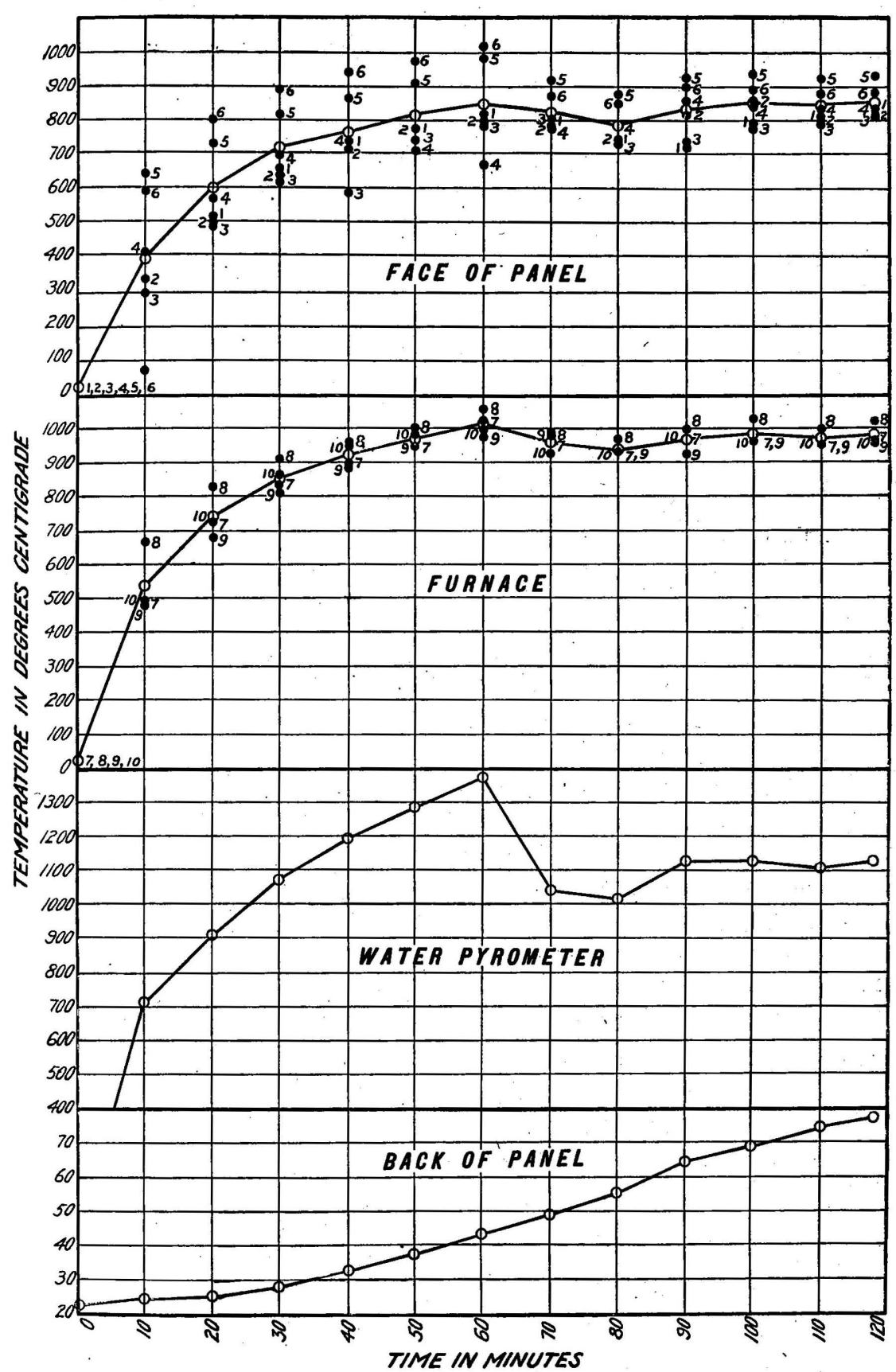

FTGURE 28.-Diagram showing temperature conditions in the furnace and on the back of panel 26. Temperature: Maximum, $79^{\circ}$; minimum, $65^{\circ}$; mean, $72^{\circ}$. Relative humidity; 7 a. m., $93 ; 7$ p. m., 86 . Direction of prevalling wind, north. 
in length. The pieces with $7 \frac{1}{2}$-inch face exposed showed very few visible cracks, but some of them were spalled, with the corners and edges washed away. However, on taking the panel down it was found that all the pieces of stone were cracked into lengths of about 4 to 6 inches, the cracks being vertical and running back through the entire stone. The 4-inch layers against the sill at the bottom of the panel were less affected than any others, but were somewhat protected because the brick projected about $1 \frac{1}{2}$ inches beyond them.

Plate XXXII, $A$, shows the face of the panel before firing; Plate XXXII, $B$, shows the face of the panel after firing, but before the application of water; Plate XXXIII, $A$, shows the effect of the water; and Plate XXXIII, $B$, shows the back of the panel after firing and quenching.

\section{PANEL 27 (Building Stone).}

Material.-Panel 27 consisted of blocks of Niagaran magnesian limestone with 4-inch and $7 \frac{3}{8}$-inch faces and was built and backed as in panel 26.

Test.-The test was started at 2.35 p. m. July 8, 1907, and firing was continued for 2 hours and 30 seconds. The panel was cooled by water at $63^{\circ} \mathrm{F}$., applied for 5 minutes. The furnace showed a good uniform temperature, slightly hotter at the bottom. The bulging of the wall was measured on the second header of limestone at the center. This was not quite the center of the panel, but it was deemed advisable to take it there rather than on the brick, which could not be rigidly attached to the face.

In 4 minutes the surface of the blocks on the fired side cracked until several pieces from the $7 \frac{3}{8}$-inch courses fell. At 10 minutes the wall had bulged toward the fire ${ }_{16}^{1}$ inch, and at 20 minutes $\frac{1}{4}$ inch. At 27 minutes vertical cracks showed through the center and also the lower headers on the back side. These cracks were near the middle of the center blocks. Two cracks also developed about equal distances from the end in the upper header on the right-hand side. At the end of 30 minutes the furnace was shut down for 14 minutes in order to clean the burners, into which pieces of the wall had fallen. This interval (14 minutes) was deducted from the elapsed time, so that the actual firing time was 2 hours. At 40 minutes the panel had bulged $\frac{3}{4}$ inch. The right-hand block in the seventh row cracked back to a depth of about 2 inches, and a piece the entire length of the block fell off. The left block in the bottom row acted in the same manner, a piece about two-thirds of the length of the block and 2 inches in depth falling out. At 50 minutes the wall bulged $\frac{13}{6}$ inch, and at 70 minutes $1_{1}^{\frac{1}{1} 6}$ inches. At 75 minutes longitudinal cracks appeared on the fired face of the left-hand large block of the sixth row, also the center block in the third row, and the left-hand block 


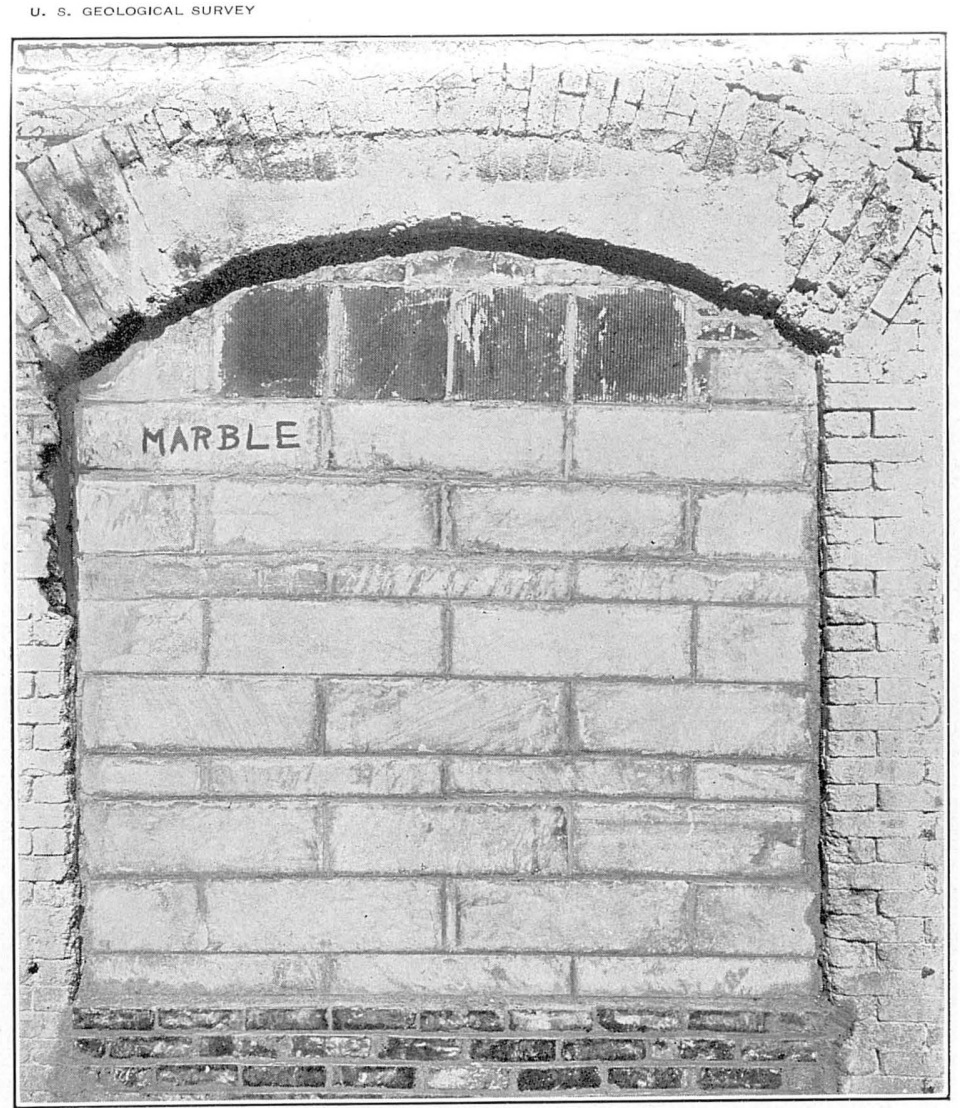

A. FACE OF PANel 26, DRESSED MARBLE, BEFORE FIRING.

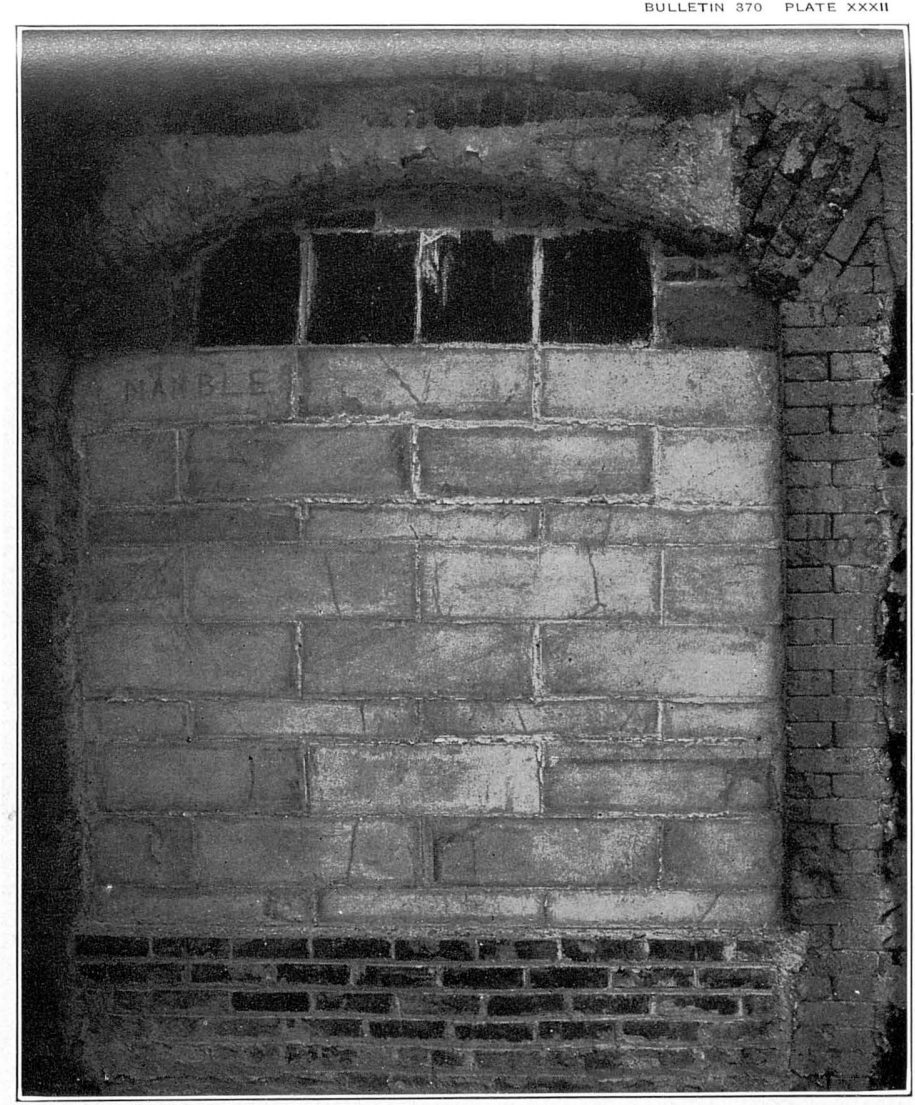

B. FACE OF PANEL 26, DRESSED MARBLE, AFTER FIRING AND BEFORE QUENCHING. 



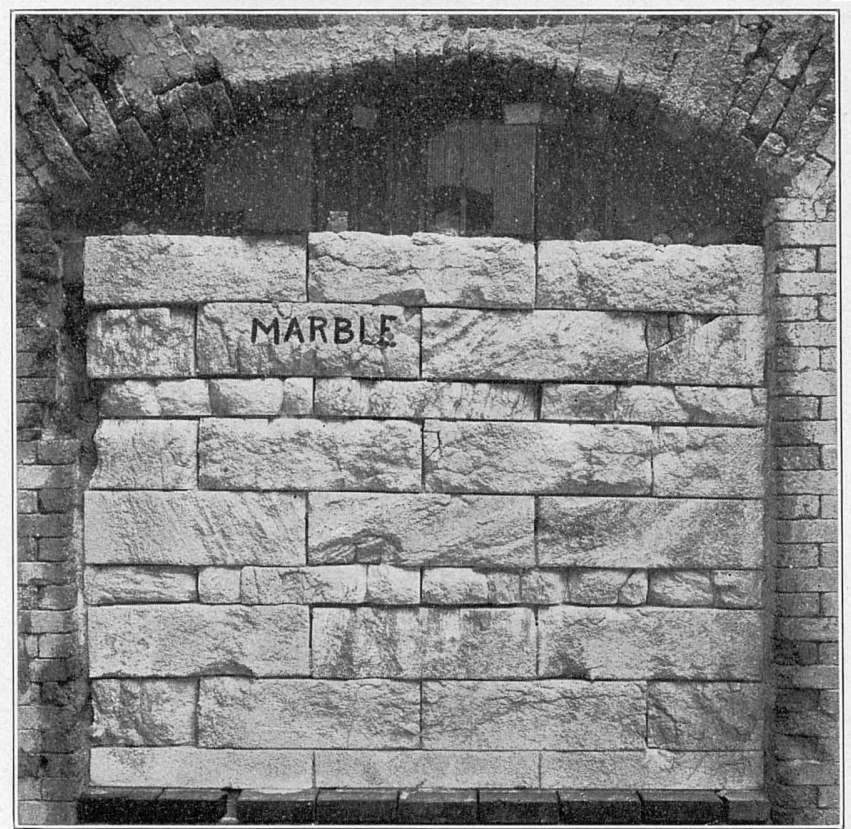

A. FACE OF PANEL 26, DRESSED MARBLE WITH BRICK BACKING, AFTER FIRING AND QUENCHING.

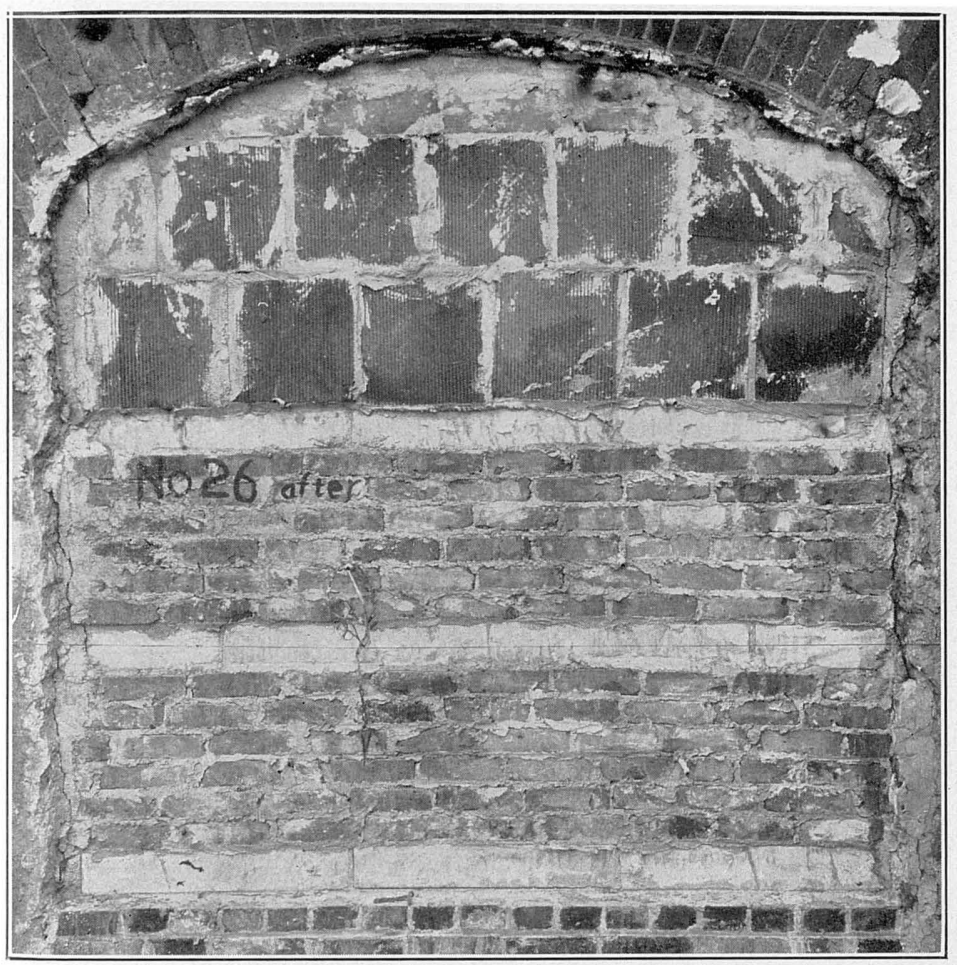

B. BACK OF PANEL 26, DRESSED MARBLE WITH BRICK BACKING, AFTER FIRING AND QUENCHING. 

in the second row. The right-hand block in the fifth row spalled all over the face, starting from the center and running toward the edges. This was also noticed on the right-hand block in the same row. The fire on the right-hand side of the furnace was considerably stronger than on the left-hand side, where the burners were clogged by pieces of the wall that had spalled off. At 80 minutes the panel had bulged $1 \frac{1}{8}$ inches, and at 120 minutes the bulging amounted to $1 \frac{1}{4}$ inches. After cooling bulging amounted to $\frac{15}{1} \frac{5}{8}$ inch.

Curves showing the variations of temperature throughout the test are given in figure 29.

Results.-On removing the panel from the furnace it was found to be of a white, chalky color, and all the blocks were more or less cracked irregularly. On applying the water the surface was washed away, the water being milky white as it came away. The washing on the right-hand side of the panel was from $\frac{1}{4}$ to $\frac{3}{8}$ inch deep, and about $\frac{1}{8}$ inch deep on the left-hand side. The stone snapped and cracked under the application of the water, but no pieces flew off. .A few of the pieces were washed away.

After the door was cooled it was found that on the right-hand side of the furnace the blocks were calcined to a depth of about $\frac{3}{4}$ to $1 \mathrm{inch}$; and were of a whitish color to this depth. The surface was soft and chalky, and the blocks were all cracked into small pieces, about 4 to 6 inches square, most cracks being in the vertical and horizontal planes. The faces could be chipped off in irregular layers, but the body of each block was cracked into small pieces from 4 to 6 inches square. The surface was quite hard, although it flew to pieces when tapped with a hammer.

Plate XXXIV, $A$, shows the face of the panel after firing and quenching; Plate XXXIV, $B$, shows the back after firing and quenching; Plate $\mathrm{XXXV}, B$, shows the appearance of the blocks when removed from the panel.

\section{PANEL 28 (Building Stone).}

Material.-Panel 28 consisted of blocks of Bedford limestone with 4-inch and $7 \frac{3}{8}$-inch faces, and was built and backed as in panels 26 and 27.

Test.-The test was started at 3.02 p. m., July 9, 1907, and firing was continued for 2 hours and 45 minutes. The panel was cooled by water at $64^{\circ} \mathrm{F}$., applied for 5 minutes. The heat in the furnace was fairly uniform, being perhaps a little greater on the right-hand side.

In 10 minutes the wall bulged toward the fire $\frac{1}{2}$ inch at the center, the measurement being taken at the second header. No cracking was observed up to this time. At 18 minutes the surface began to turn a rather chalky color, but no cracks were noticed, nor was any 


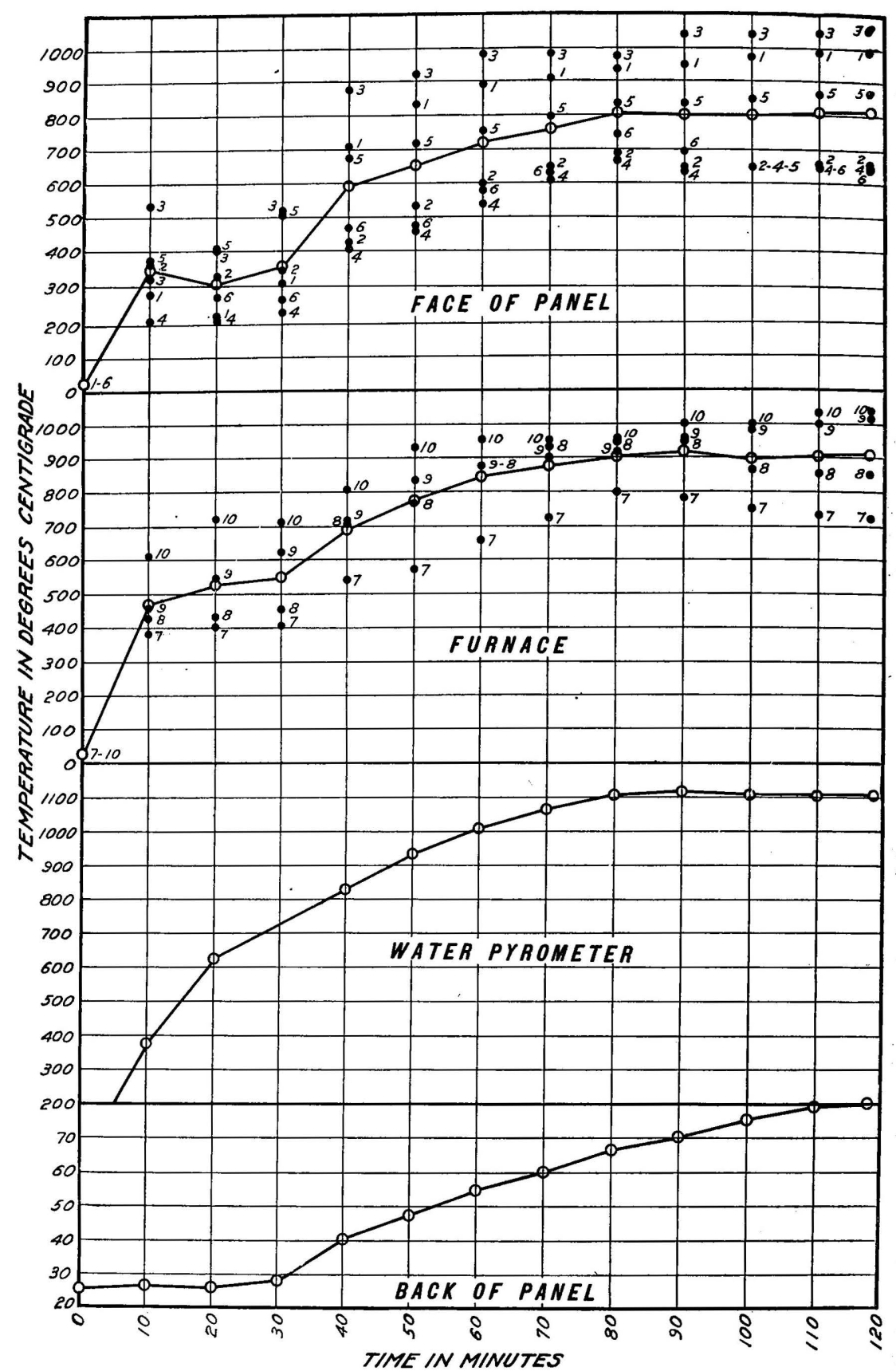

FIGURE 29.-Diagram showing temperature conditions in the furnace and on the back of panel 27. Temperature: Maximum, $85^{\circ}$; minimum, $72^{\circ}$; mean $78^{\circ}$. Relative humidity: 7 a. m., $67 ; 7$ p. m., 58. Direction of prevailing wind, west. 
U. S. GEOLOGICAL SURVEY

BULLETIN 370 PLATE XXXIV

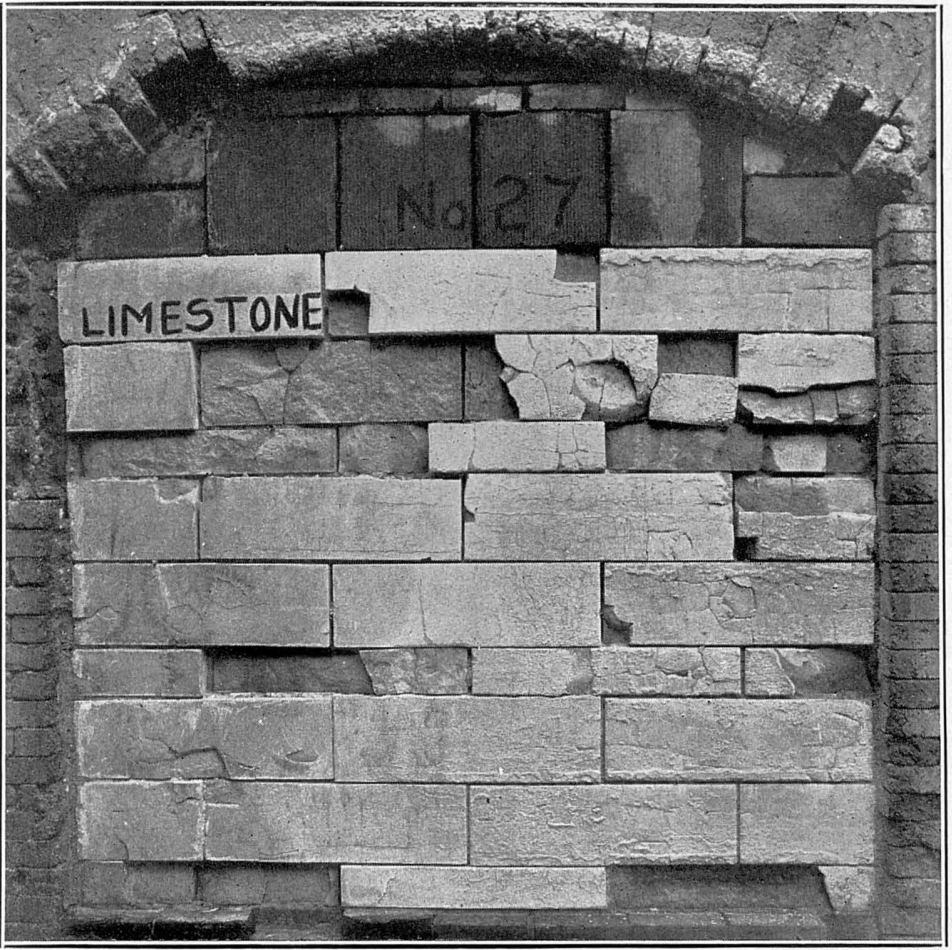

A. FACE OF PANEL 27, DRESSED LIMESTONE WITH BRICK BACKING, AFTER FIRING AND QUENCHING.

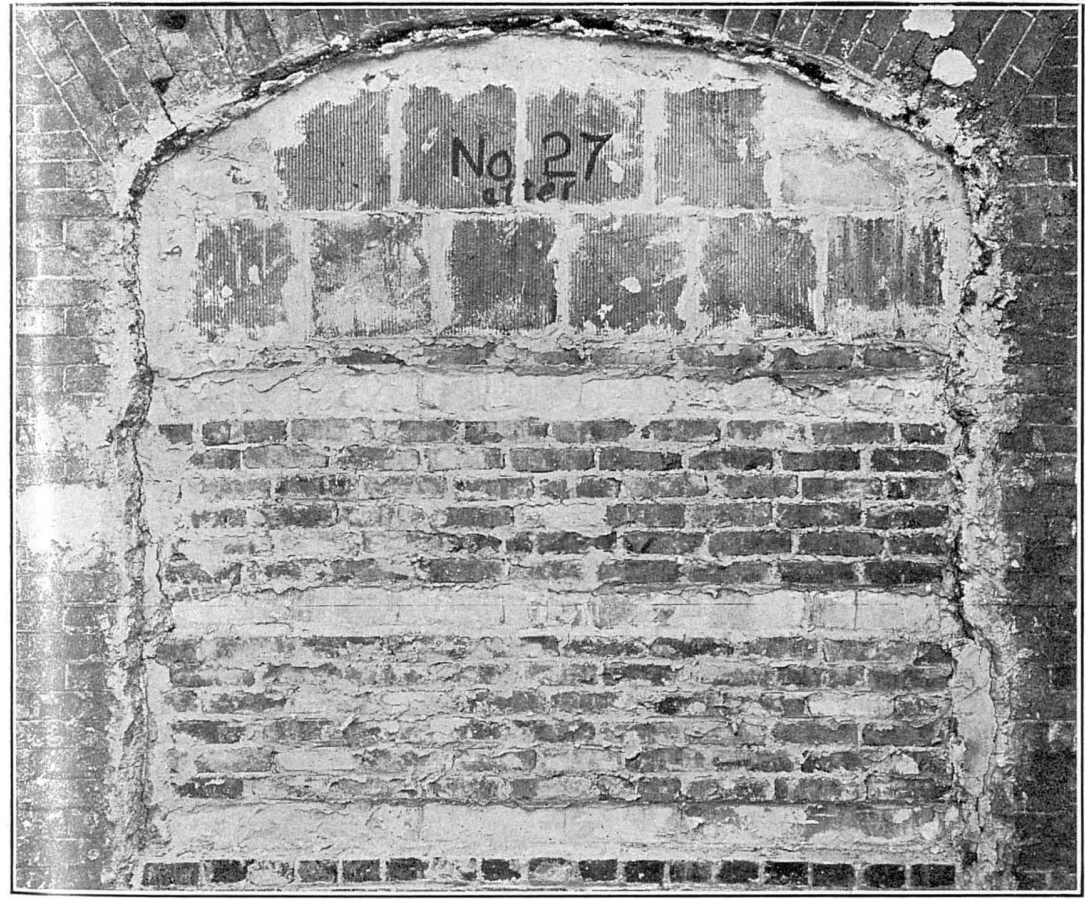

B. BACK OF PANEL 27, DRESSED LIMESTONE WITH BRICK BACKING, AFTER FIRING AND QUENCHING. 

spalling evident. At 20 minutes the wall bulged $\frac{15}{18}$ inch. A vertical crack was noticed about 11 inches from the outer edge on the back of the right-hand stone of the lower tier. This was not visible on the fired side. At 30 minutes the panel had bulged inward about 1 inch. At 45 minutes the stone in the center row on the right-hand side cracked vertically at the center. At 70 minutes the wall bulged $1_{\frac{1}{8}}$ inches, at 80 minutes $1_{1^{3}}^{3}$ inches, and at 110 minutes $1 \frac{1}{4}$ inches, but no cracking or spalling was observed up to this time.

Curves showing the variations in temperature throughout the test are given in figure 30 .

Results.-The panel on removal had a white, chalky color, but no cracks or indications of spalling were in evidence. On the application of water the color changed to a dark grayish blue, and the surface washed away about $\frac{1}{4}$ inch during the treatment.

Cracks developed rapidly in all the pieces during the first 2 minutes, but the surface remained intact. During the next 3 minutes pieces of various dimensions, from $\frac{3}{4}$ inch to, $1 \frac{1}{2}$ inches thick, fell off the panel and at the end of the treatment fully 50 per cent of the surface, varying in thickness from $\frac{3}{4}$ to 3 inches, had fallen away. The remaining surface was badly cracked and could be broken off from a depth of $\frac{3}{4}$ inch to $1 \frac{1}{4}$ inches by gently tapping. This surface was rough and pitted, and also showed considerable calcination, On taking down the panel it was found that all the blocks were broken, and that they crumbled easily on the fired side, the back being very hard. The stones, on removal from the door, fell mostly into pieces from 4 to 12 inches in length, but some were broken into many little cubes ( 2 to 3 inches).

Plate XXXV, $A$, shows the face of the panel after firing, and Plate XXXVI, $A$, shows its appearance after applying water. Plate XXXVI, $B$, indicates the appearance of the blocks after removal from the furnace and gives an idea of the damage wrought.

PANEL 29 (Sand-Lime Brick).

Material.-Sand-lime bricks of medium quality were used in panel 29. They were almost white, but had a slightly brownish tinge and a very few white lime particles scattered through them. The corners and edges were square, the faces smooth, and the bricks uniform in size. The material, however, could be rubbed from the faces with the fingers, and when two bricks were rubbed together the surfaces were abraded considerably. Table 14 gives the physical properties and the strength tests of the bricks used.

The panel was composed of the sand-lime bricks backed with common clay bricks and laid in cement mortar as a standard 8-inch wall, with headers every sixth row. A small portion of the back wall, at the center, was composed of sand-lime bricks. 


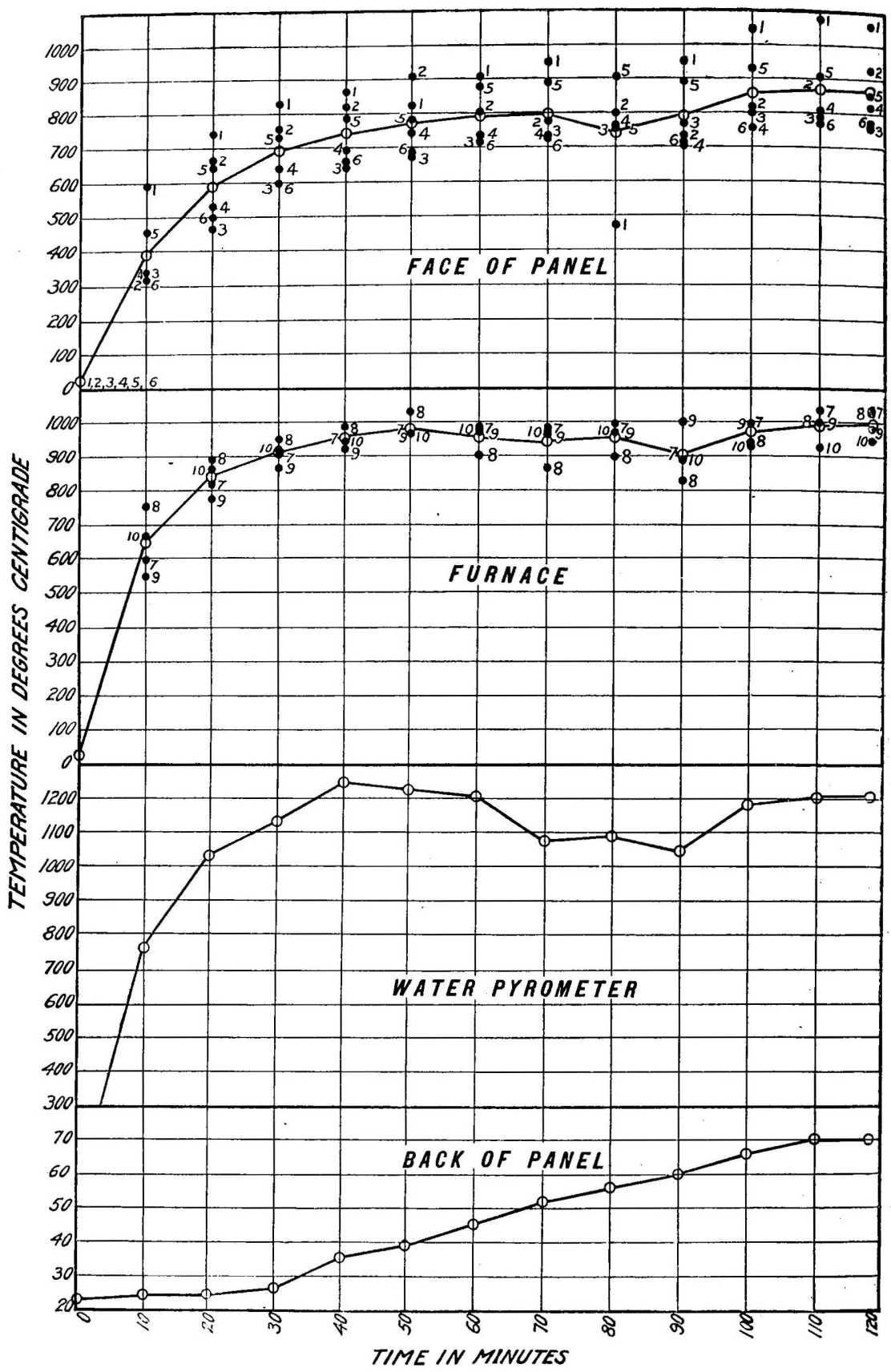

Figure 30.-Diagram showing temperature conditions in the furnace and on the back of panel 28 . Temperature: Maximum, $77^{\circ}$; minimum, $69^{\circ}$; mean, $73^{\circ}$. Relative humidity: 7 a. m., $79 ; 7$ p. m., 84 . Direction of prevaiiing wind, east. 


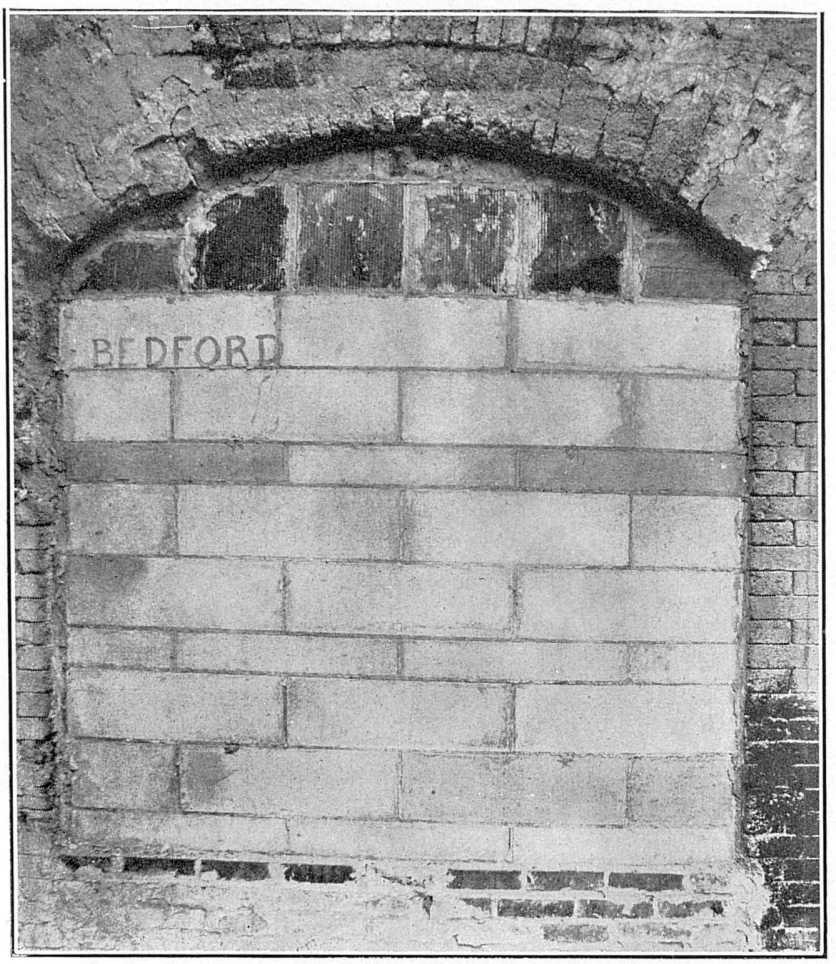

A. FACE OF PANEL 28, DRESSED LIMESTONE, AFTER FIRING AND BEFORE QUENCHING.

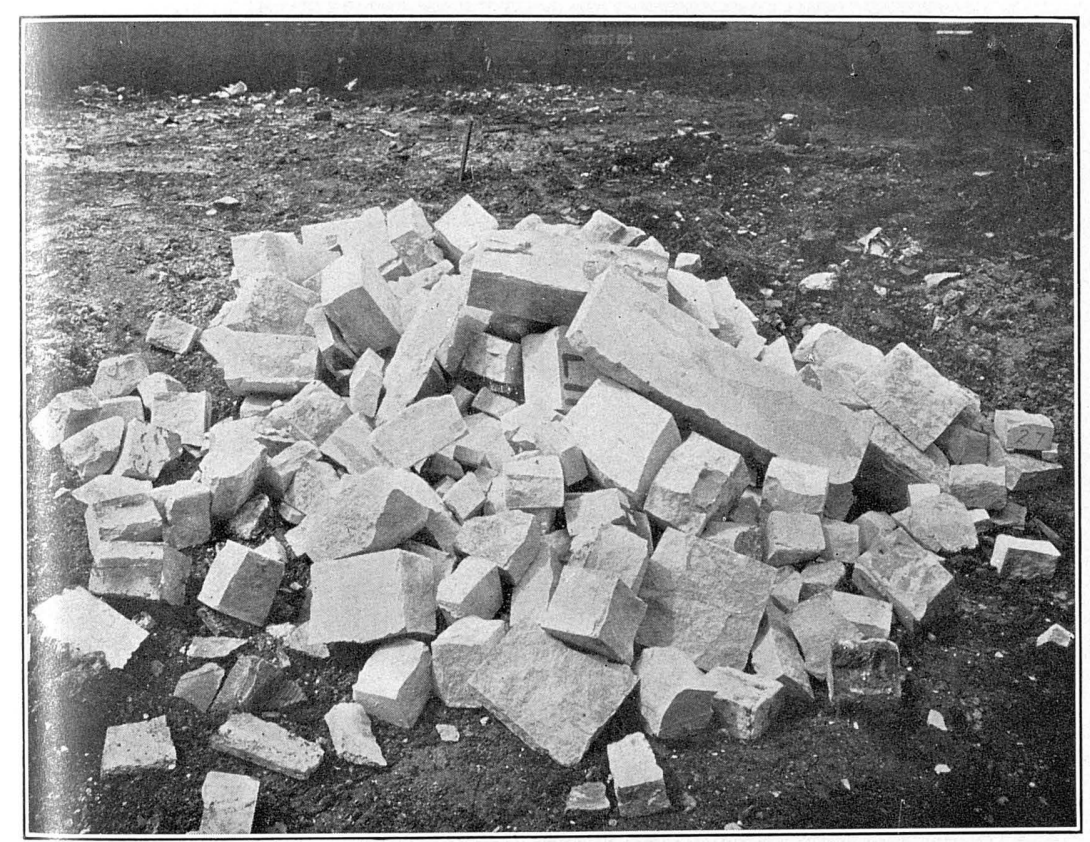

B. DRESSED LIMESTONE. AFTER REMOVAL FROM PANEL 27. 



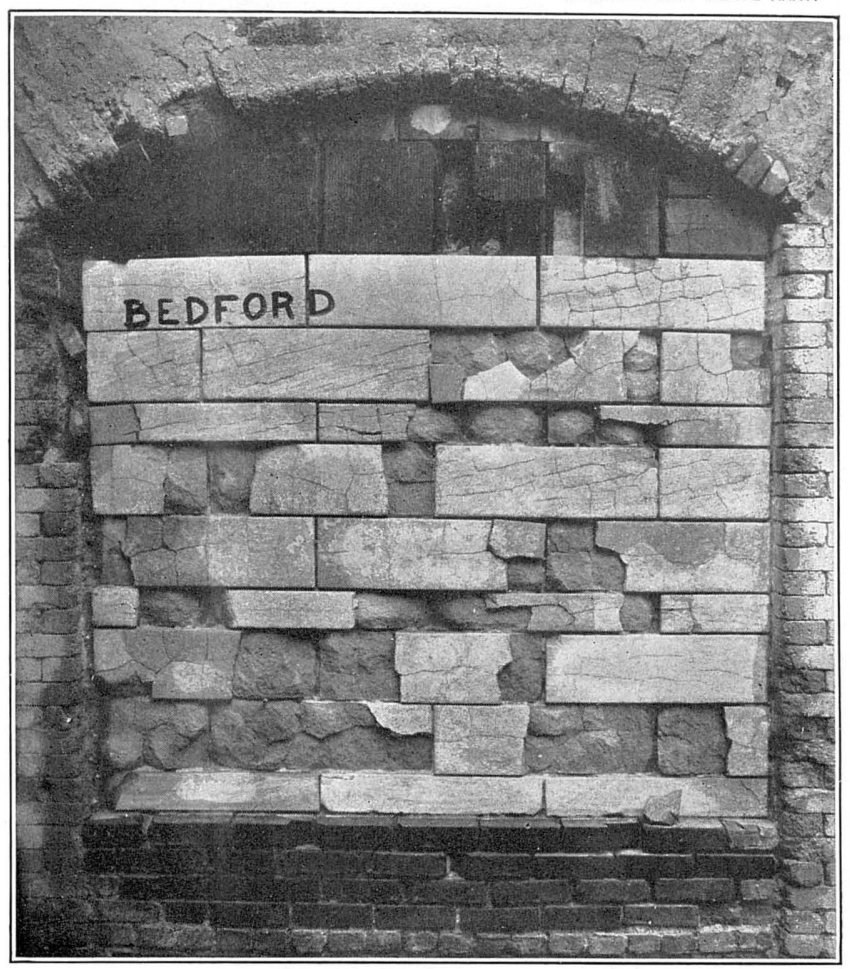

A. FACE OF PANEL 28, DRESSED LIMESTONE, AFTER FIRING AND QUENCHING.

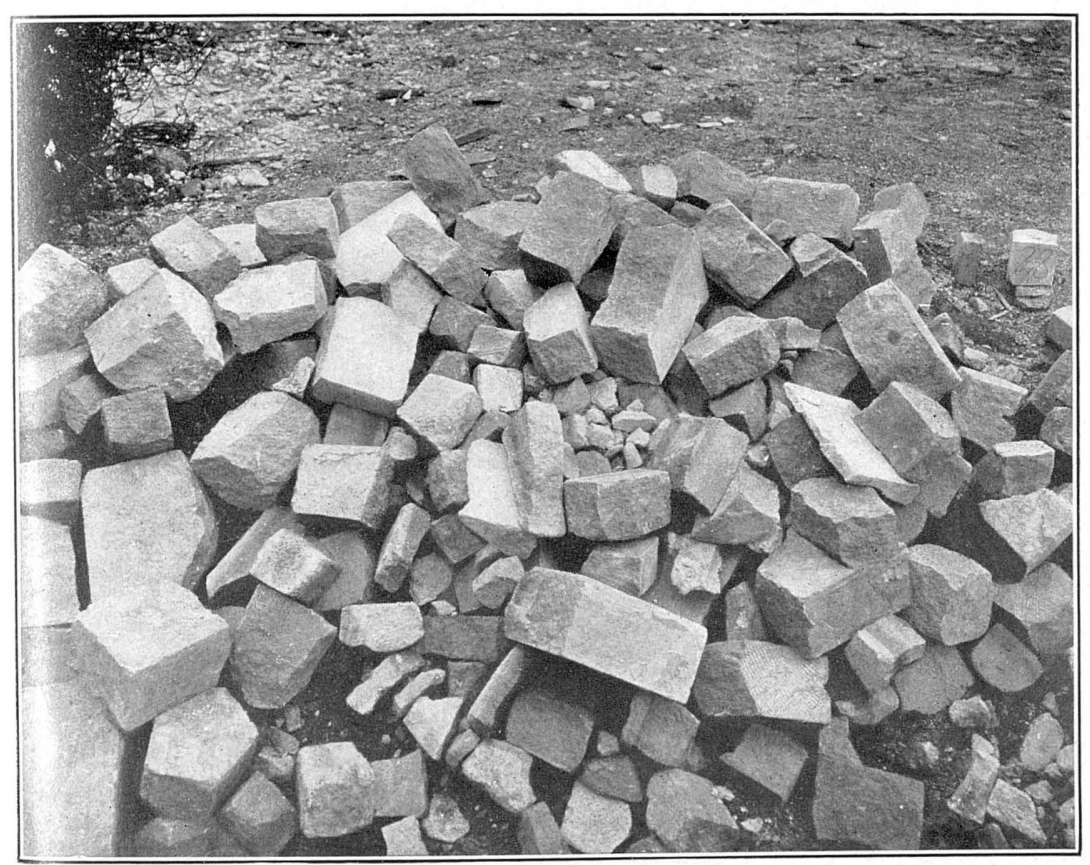

B. BLOCKS OF PANEL 28, DRESSED LIMESTONE, AFTER REMOVAL FROM FURNACE. 

Test.-The test was made on July 11, 1907, and the firing was continued for 2 hours. The panel was cooled by water at $61^{\circ} \mathrm{F}$., applied for 5 minutes and 20 seconds. A fairly uniform furnace temperature, slightly cooler at the bottom at the start, was obtained.

In 10 minutes the wall had bulged at the center about 1 inch. The bulging was measured at the center of the third header from the bottom. At 20 minutes the wall bulged about $\frac{1}{2}$ inch, no apparent change in the surface being noted up to this time. At 30 minutes the wall bulged $\frac{11}{16}$ inch. It was noted that water was forced back through one of the bricks in the fourth header near the center of the wall. There was a small crack on the surface of the brick, apparently due to shrinkage or improper molding. At 40 minutes the wall had bulged to the extent of $\frac{3}{4}$ inch. The surface of the bricks on the fired side had begun to have a chalky appearance, as if calcination of the lime had taken place. At 60 minutes the wall had bulged inward to the extent of $1_{16}^{\frac{3}{16}}$ inches, and at 120 minutes $1_{16}^{\frac{5}{6}}$ inches. After cooling the wall bulged toward the fire $\frac{1}{1} \frac{1}{6}$ inch.

Curves showing the variations of temperature throughout the test are given in figure 31 .

Results.-On removal of the door from the furnace the surface of the panel showed no signs of having spalled, but was chalky white and looked very soft. On the application of water the surfaces washed away from $\frac{1}{8}$ inch in a few places to about $1 \frac{1}{4}$ inches in others. The surfaces of the majority of the bricks in the panel were washed away to the extent of $\frac{3}{8}$ to $\frac{3}{4}$ inch.

After the wall had cooled it was found that the surfaces of the bricks were very rough and were covered with small irregular cracks extending back about 1 inch to $1 \frac{1}{2}$ inches. There were also small pocklike marks in nearly every brick, apparently where lumps of lime had washed away. In one or two places small lumps of sand were also found. The remaining portions of the brick on the faces were soft and crumbled very easily in the fingers. The back portions were nearly as hard as before the fire treatment. When the bricks became thoroughly dry, the surfaces were considerably harder. The header bricks were found to be cracked and crumbled back to a depth of about $1 \frac{1}{2}$ inches, the remainder being apparently hard and unaffected.

On taking down the panel it was found that the stretcher bricks composing the fired side were cracked back vertically from the fired face, usually in two or three pieces. The face was taken down with great care and about 20 per cent of the bricks were removed intact, but nearly all failed in handling, breaking into two or three pieces.

The sand-lime bricks that were laid in the back courses were apparently not affected by the heat and were removed with little loss, but 


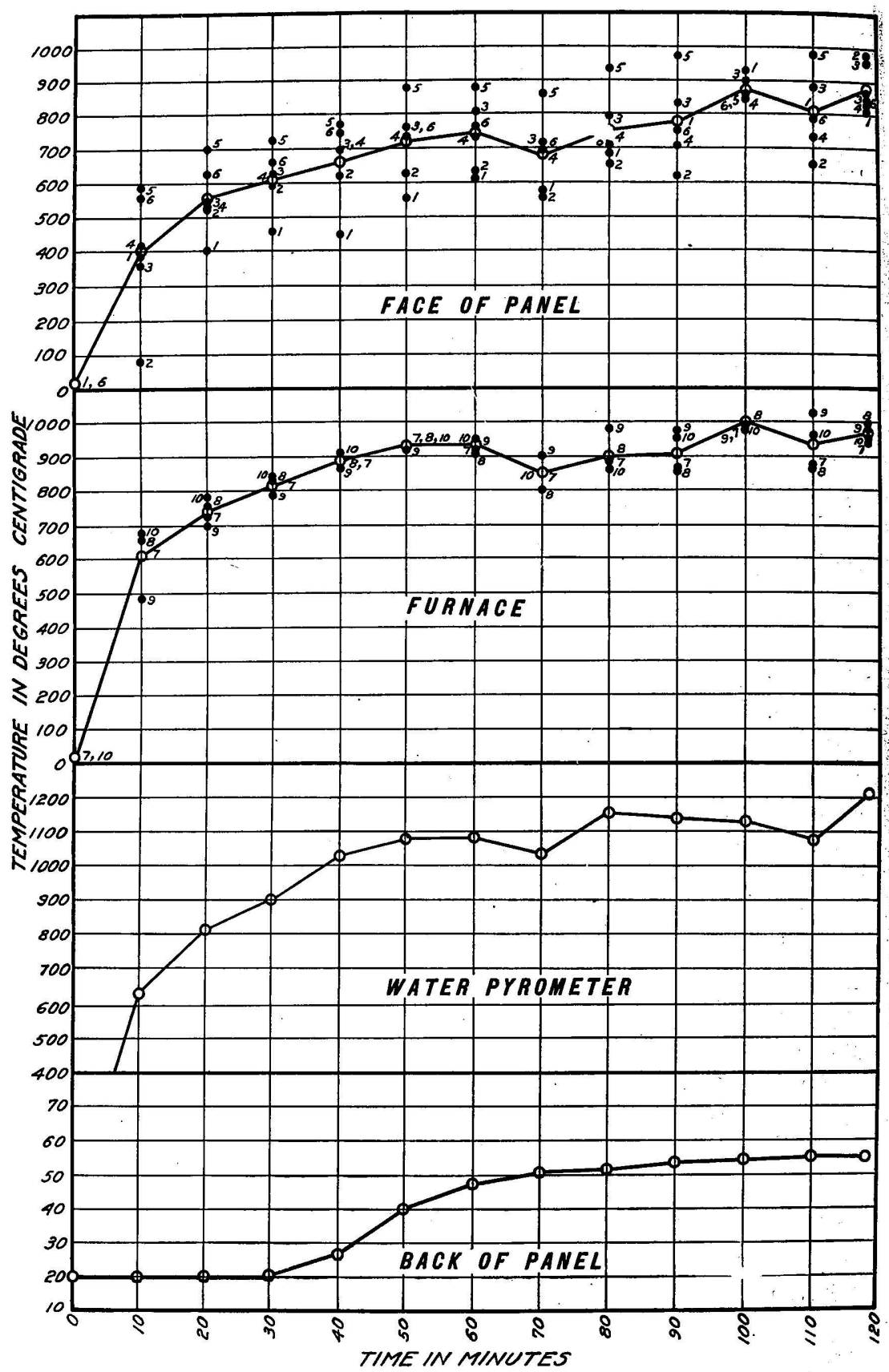

FIGURE 31.-Diagram showing temperature conditions in the furnace and on the back of panel 29. Temperature: Maximum, $71^{\circ}$; minimum, $63^{\circ}$; mean, $67^{\circ}$. Relative humidity: 7 a. m., $87 ; 7$ p. m., 86. Direction of prevailing wind, north. 

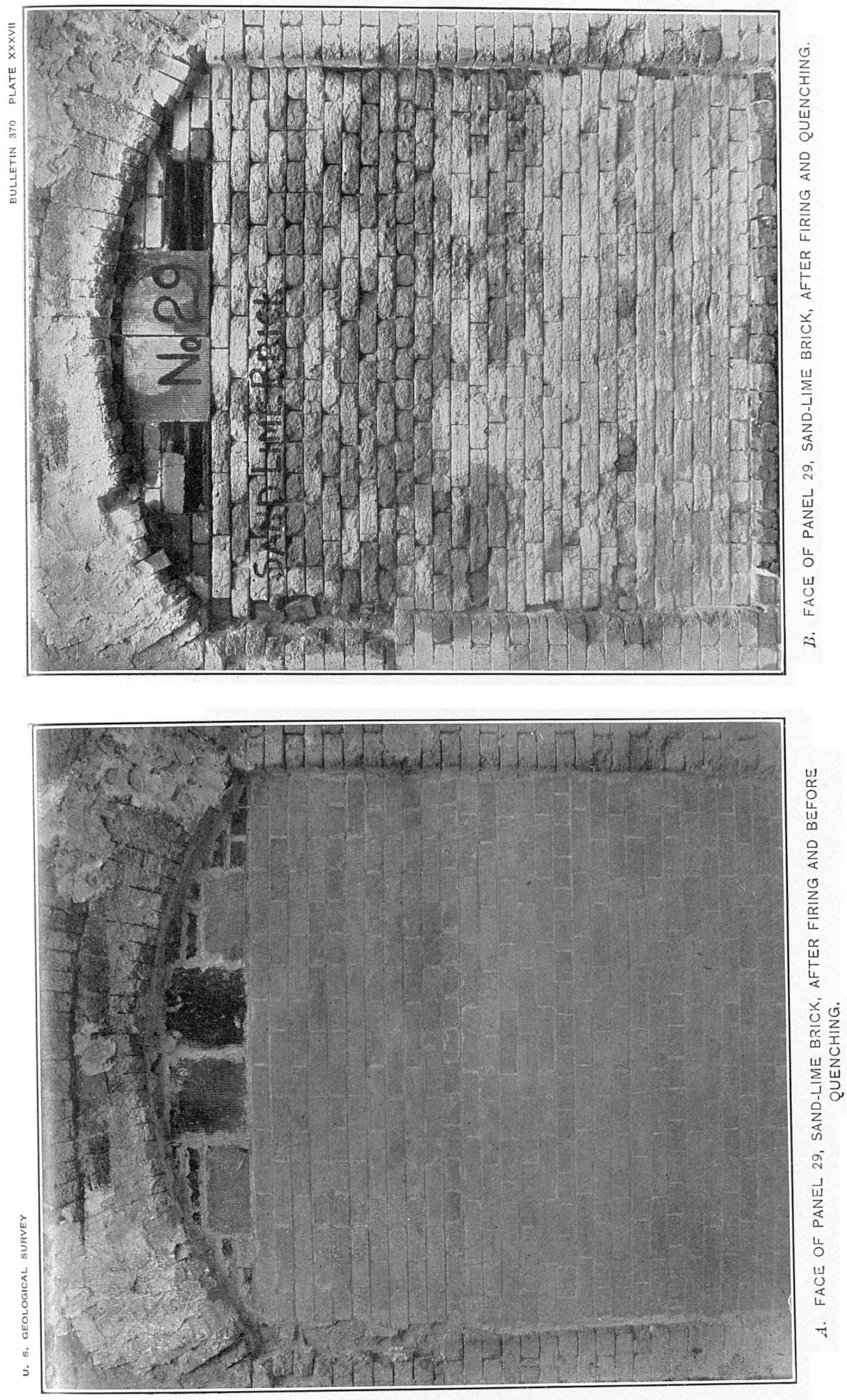

the mortar stuck to the bricks, and they were hard to clean. There was a tendency for the surfaces of the bricks to come away with the mortar as it was chipped off.

Plate XXXVII, $A$, shows the face of the panel after firing; Plate XXXVII, $B$, shows it after the application of water.

PANEL 30 (Tile).

Material. -The material composing panel 30 was 5 by 12 by 12 inch partition tile, having three air spaces (fig. 25). The tiles were laid in cement mortar, with about $\frac{1}{2}$-inch joints, as a 5 -inch partition. They were laid with the core holes vertical and the joints broken. The face of the panel was plastered with ordinary lime plaster containing a little plaster of paris and also some hair, the coating being about $\frac{1}{2}$ inch thick. No hardening coat was put on this panel, as it had been found seriously to interfere with the operation of the furnace by falling into the burners.

The tiles were'sprinkled before laying, as they were so dry that they took the moisture from the mortar too rapidly. The tiles were laid the morning of July 12 ; the fired face was plastered the afternoon of the same day and the back face the morning of July 13, and the panel was shoved into the furnace to protect it from the weather on the afternoon of the 13th.

Test. - The test was started at 10.38 a. m. on July 16, 1907, and firing was continued for 2 hours and 30 minutes. The panel was cooled for 5 minutes by water at $62^{\circ} \mathrm{F}$. A good uniform fire was obtained.

As soon as the fire was started the wall began to snap, and small pieces of plaster cracked off on the fired side.

At the expiration of 4 minutes the furnace was shut down for $6 \frac{1}{2}$ minutes, in order to remove plaster that had fallen into the burners. About one-third of the plaster had fallen off just prior to this period, and during the cleaning of the burners all loose plaster that had bulged away from the panel and not fallen off was removed, in order to avoid the necessity of shutting down again. At 9 minutes a horizontal crack developed on the back between the face and the second row of tiles. A similar crack also developed between the third and fourth rows. These cracks extended clear across the panel. At 10 minutes the wall had bulged inward about $\frac{1}{4}$ inch, the bulging being measured at the center of the fourth row of tiles. At 12 minutes a horizontal crack developed between the second and third rows of tiles, extending across the door. At 14 minutes a vertical crack developed at the edge along the left side of the panel, starting at the top and running down to the joint between the fourth and fifth rows of tiles, and then extending horizontally across the panel. At 17 73087-Bull. 370-09-6 
minutes steam began to come through the lower cracks and along the sides of the panel, and the moisture began to come through the plaster on the back opposite the joints in the tiles. At 19 minutes diagonal cracks from the upper right-hand corner began to show through the plaster and to run off across the door. A vertical crack developed at the bottom on the left-hand side one tier out from the edge and extended up to the joint between the first and second rows, and then ran diagonally across the panel toward the edge. At 20 minutes the wall had bulged $\frac{3}{8}$ inch. At 23 minutes all the remaining plaster on the fired side, except a few small areas (3 to 4 square inches) scattered about the surface, came off, and the furnace was shut down for 3 minutes to clean the burners. This time (3 min-

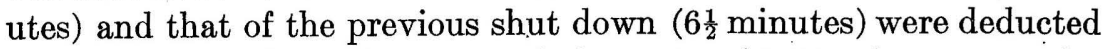
from the elapsed running time of the test. At 30 minutes a series of small diagonal cracks developed at the top of the fourth row of tiles on the left-hand side. The cracks were from 3 to 4 inches long and about 1 inch apart, and extended from about 6 inches off the edge toward the center for a distance of about 2 feet. At 40 minutes the wall had bulged $\frac{5}{8}$ inch. At 44 minutes the tile on the right-hand side of the fourth row cracked horizontally on the fired side, the crack occurring about 2 inches from the lower edge and extending entirely across the tile. The edges of the crack bulged outward and were more or less irregular. At 60 minutes the wall bulged $\frac{11}{16}$ inch. By this time small more or less irregular cracks had developed in both vertical and horizontal directions in the plaster on the back side of the panel around each tile. At 120 minutes the wall bulged $\frac{3}{4}$ inch. After cooling there was a permanent bulging of $\frac{1}{8}$ inch in the panel.

Results. -When the panel was removed from the furnace, the plaster was practically gone. Around the bottom edge and on the upper right-hand and left-hand corners there were small pieces, and a small patch on the second and third rows was still intact. The tiles were more or less cracked, especially the ones that were entirely free from mortar; that is, the second tile from the right-hand side in the third row and the tile nearest the right-hand side in the second row; also a small corner of the second tile on the right-hand side of the bottom row had cracked off. Cracks could not be observed in the other tiles, but they had a thin layer of plaster still sticking to them, which prevented examination.

On applying water the tiles cracked, and after the first minute the faces began to fall off. At the end of 5 minutes about 55 per cent of the faces of the tiles was washed away. This occurred on the lower and right-hand side of the panel. The tiles on the upper left-hand side still were in place. These tiles that were in place, however, were found to be cracked loose from the webs near the fired side, and the 


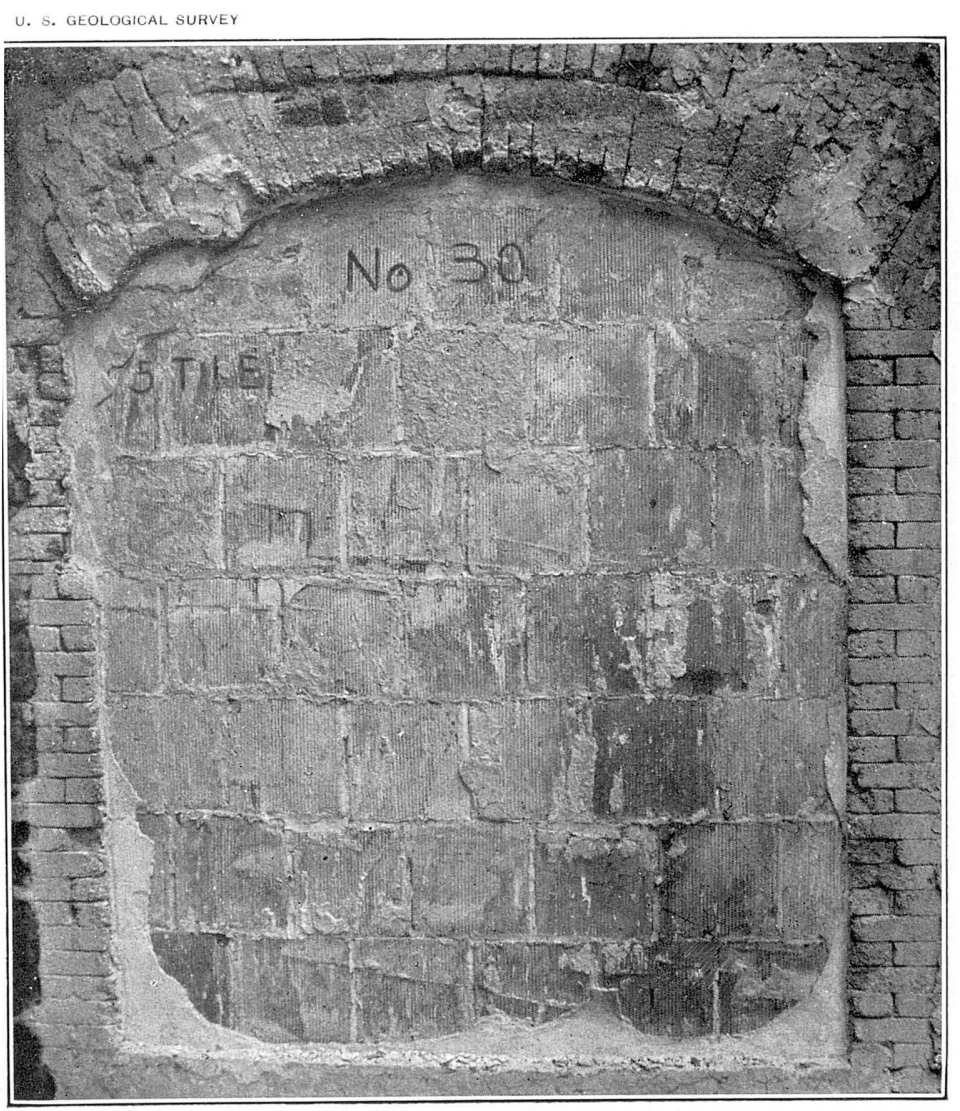

A. FACE OF PANEL 30, PARTITION TILE, AFTER FIRING AND BEFORE QUENCHING

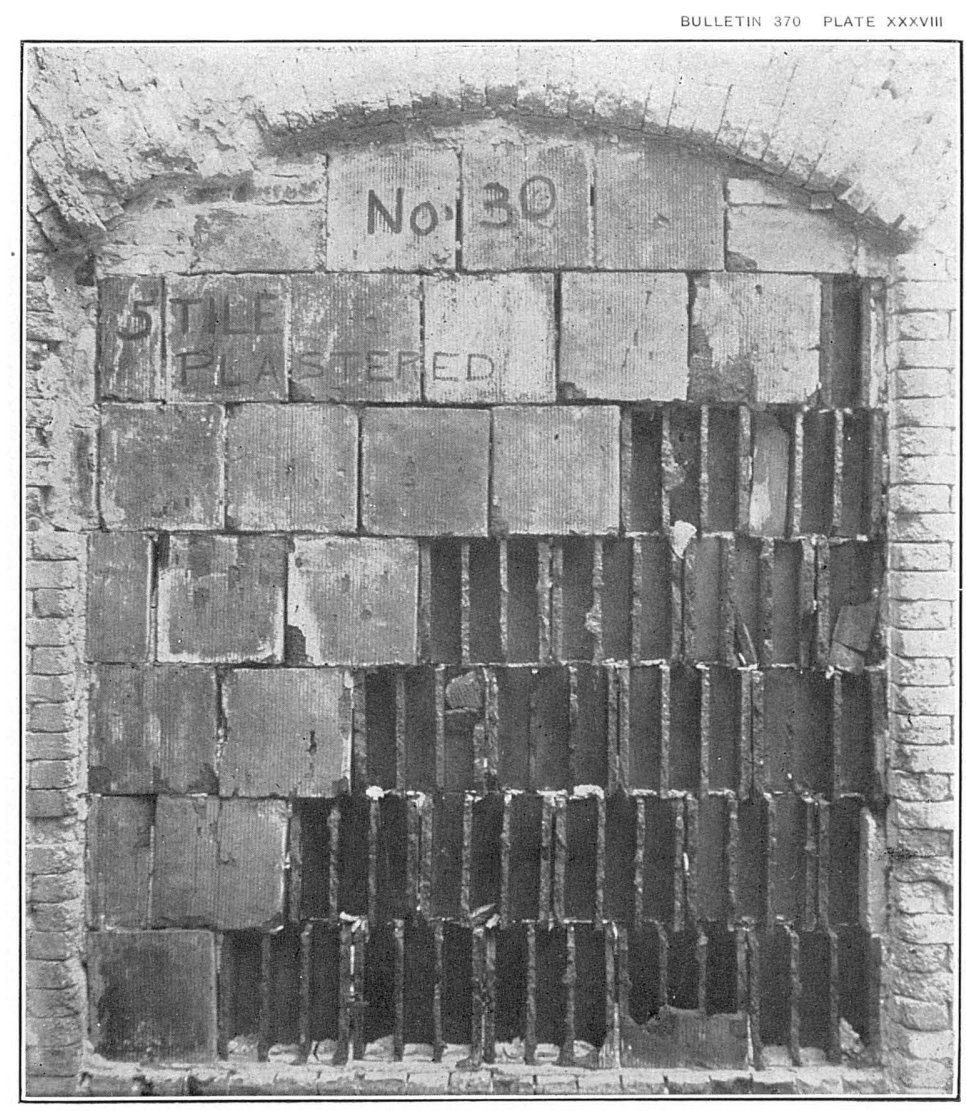

B. FACE OF PANEL 30, PARTITION TILE, AFTER FIRING AND QUENCHING. 



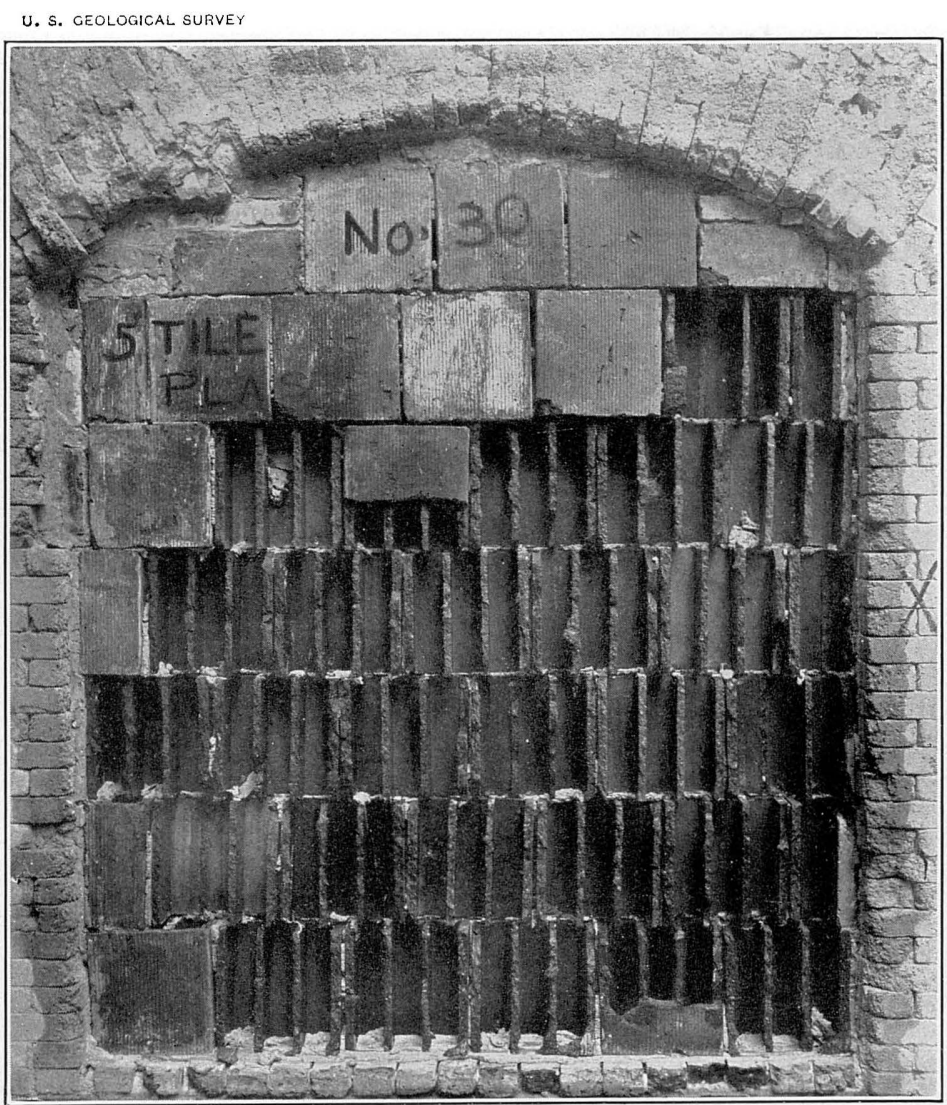

A. FACE OF PANEL 30, PARTITION TILE, AFTER FIRING AND QUENCHING, WITH ALL LOOSE PIECES REMOVED.

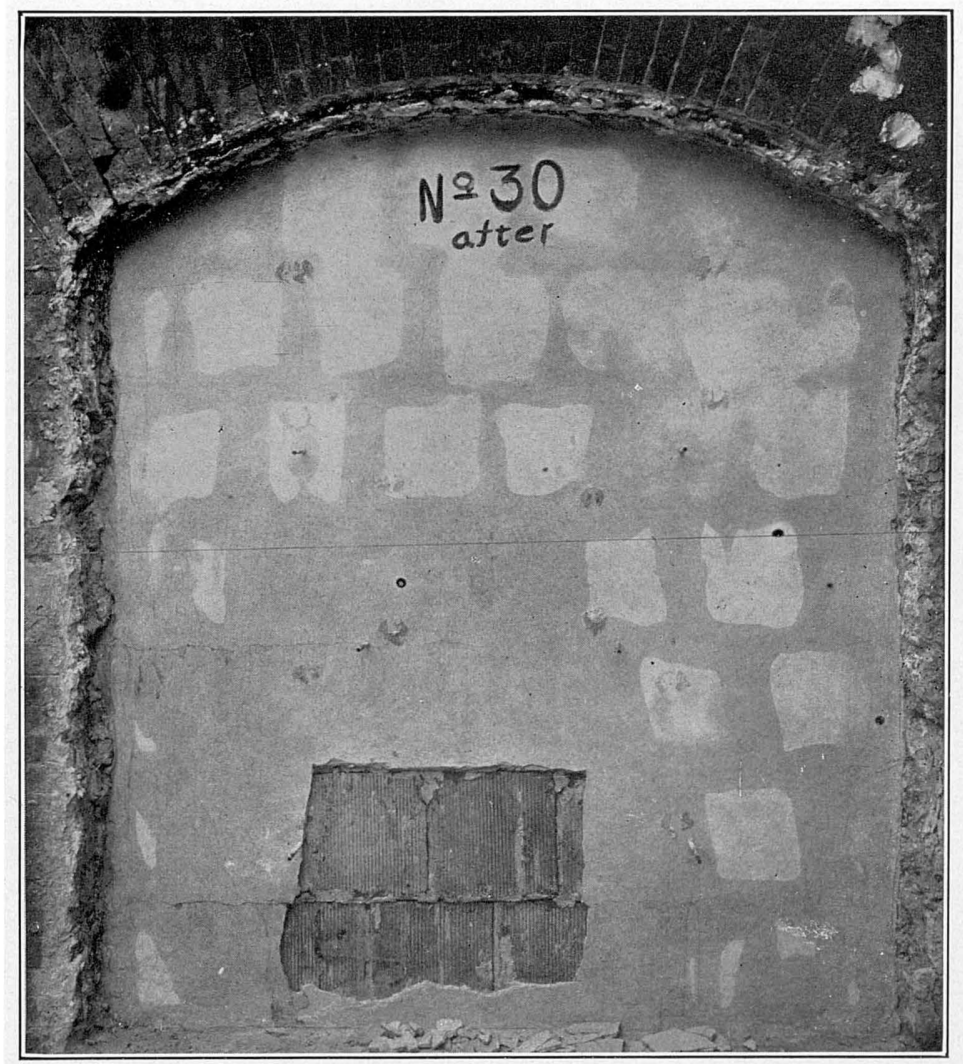

B. BACK OF PANEL 30, PARTITION TILE, AFTER FIRING AND QUENCHING. 

faces were all cracked, the cracks running irregularly and a few of them extending through the face. A few of the faces of the tiles also spalled off to a depth of $\frac{1}{16}$ to $\frac{1}{4}$ inch.

After the wall had cooled it was found that about 55 per cent of the tiles that remained in place could be lifted off. Those that did remain in place were cracked from the webs, and the faces were cracked but were apparently still rigidly attached. The portions of the web remaining attached to the backs and the backs themselves were apparently hard and free from cracks. The fired faces, however, crumbled easily in the hands. The plaster on the back wall was forced off, exposing about five tiles at the bottom of the wall; and although over the remainder of the wall tho plaster remained intact it was badly bulged, and water had come through all the joints.

Curves showing the variations in temperatures throughout the test are given in figure 32 .

Plate XXXVIII, $A$, shows the face of the panel after firing and before water was applied; Plate XXXVIII, $B$; the face of the panel after quenching; Plate XXXIX, $A$, the face of the panel after all loose pieces had been removed; and Plate XXXIX, $B$, the back of the panel after firing and quenching. 


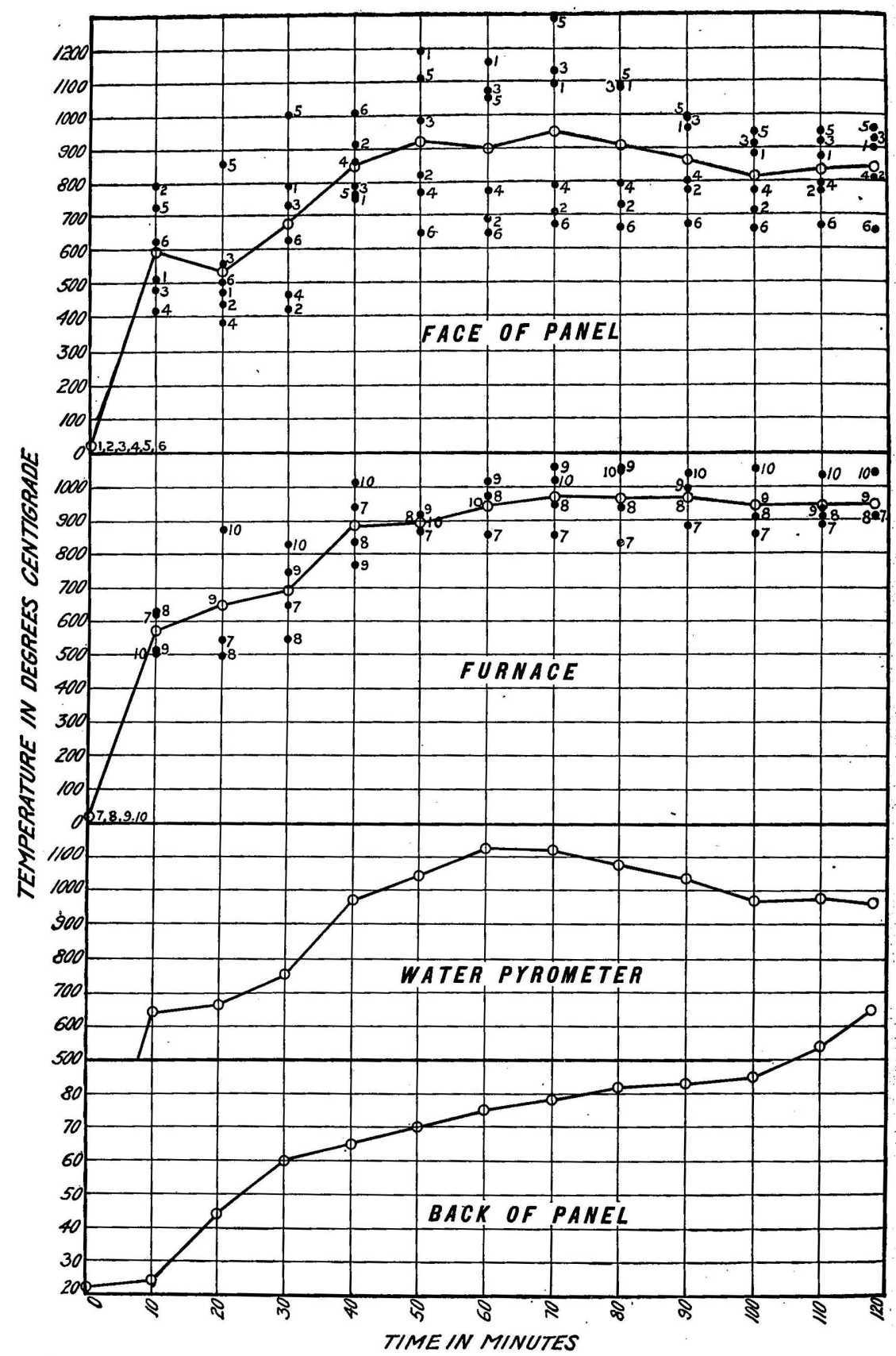

FigURE 32.-Diagram showing temperatureconditions in the furnace and on the back of panel 30. 
TABLES.

TAdLe 1.-Panel 1-Results of compression tests made on portions of one-piece doubleair-space mortar building blocks after fire test.

DAMP BLOCKS.

[In pounds per square inch.]

\begin{tabular}{|c|c|c|c|c|c|c|c|c|c|}
\hline \multirow{3}{*}{ Block No. } & \multicolumn{3}{|c|}{$\begin{array}{l}2 \text { parts sand to } 1 \text { of Port- } \\
\text { land cement. }\end{array}$} & \multicolumn{3}{|c|}{$\begin{array}{l}4 \text { parts sand to } 1 \text { of Port- } \\
\text { land cement. }\end{array}$} & \multicolumn{3}{|c|}{$\begin{array}{l}8 \text { parts sand to } 1 \text { of Port- } \\
\text { land cement. }\end{array}$} \\
\hline & \multirow{2}{*}{$\begin{array}{c}\text { No. of } \\
\text { pieces } \\
\text { crushed. }\end{array}$} & \multicolumn{2}{|c|}{$\begin{array}{l}\text { Average } \\
\text { strength. }\end{array}$} & \multirow{2}{*}{$\begin{array}{c}\text { No. of } \\
\text { pieces } \\
\text { crushed. }\end{array}$} & \multicolumn{2}{|c|}{$\begin{array}{l}\text { A verage } \\
\text { strength. }\end{array}$} & \multirow{2}{*}{$\begin{array}{l}\text { No. of } \\
\text { pieces } \\
\text { crushed. }\end{array}$} & \multicolumn{2}{|c|}{$\begin{array}{l}\text { Average } \\
\text { strength. }\end{array}$} \\
\hline & & $\begin{array}{l}\text { Ex- } \\
\text { posed } \\
\text { face. }\end{array}$ & $\begin{array}{l}\text { Un- } \\
\text { exposed } \\
\text { face. }\end{array}$ & & $\begin{array}{l}\text { Ex- } \\
\text { posed } \\
\text { face. }\end{array}$ & $\begin{array}{l}\text { Un- } \\
\text { exposed } \\
\text { face. }\end{array}$ & & $\begin{array}{c}\text { Ex- } \\
\text { posed } \\
\text { face. }\end{array}$ & $\begin{array}{l}\text { Un- } \\
\text { exposed } \\
\text { face. }\end{array}$ \\
\hline & 2 & & 1,780 & 2 & & 918 & & & \\
\hline & 1 & & 1,754 & 3 & & 1,240 & & & 58 \\
\hline & $\begin{array}{l}4 \\
3\end{array}$ & & 1,594 & $\begin{array}{l}3 \\
2\end{array}$ & & 1,263 & $\dddot{2}$ & & 578 \\
\hline Average. & ㅈ․ & 885 & 1,709 & ......... & 752 & 1,140 & & & 581 \\
\hline
\end{tabular}

MEDIUM BLOCKS.

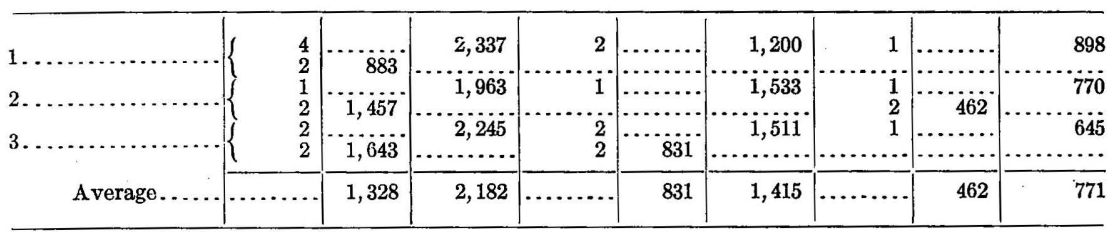

WET BLOCKS.

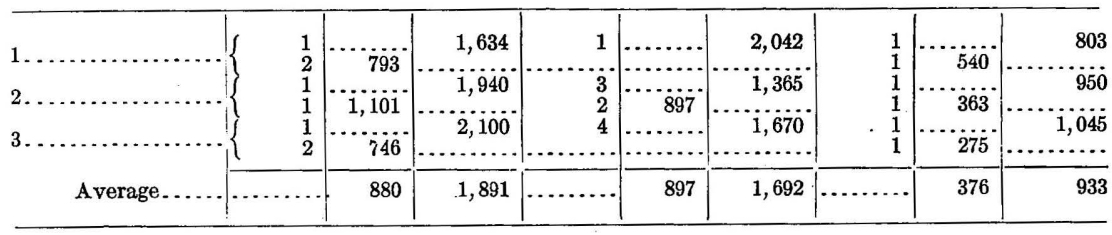


TABLE 2.-Panel 2-Results of compression tests made on portions of one-piece singleair-space mortar building blocks after fire test.

DAMP BLOCKS.

[In pounds per square inch.]

\begin{tabular}{|c|c|c|c|c|c|c|c|c|c|}
\hline \multirow{3}{*}{ Block No. } & \multicolumn{3}{|c|}{$\begin{array}{l}2 \text { parts sand to } 1 \text { of Port- } \\
\text { land cement. }\end{array}$} & \multicolumn{3}{|c|}{$\begin{array}{l}4 \text { parts sand to } 1 \text { of Port- } \\
\text { land cement. }\end{array}$} & \multicolumn{3}{|c|}{$\begin{array}{l}8 \text { parts sand to } 1 \text { of Port- } \\
\text { land cement. }\end{array}$} \\
\hline & \multirow{2}{*}{$\begin{array}{c}\text { No. of } \\
\text { pieces } \\
\text { crushed. }\end{array}$} & \multicolumn{2}{|c|}{$\begin{array}{l}\text { Average } \\
\text { strength. }\end{array}$} & \multirow{2}{*}{$\begin{array}{l}\text { No. of } \\
\text { pieces } \\
\text { crushed. }\end{array}$} & \multicolumn{2}{|c|}{$\begin{array}{l}\text { Average } \\
\text { strength. }\end{array}$} & \multirow{2}{*}{$\begin{array}{l}\text { No. of } \\
\text { pieces } \\
\text { crushed. }\end{array}$} & \multicolumn{2}{|c|}{$\begin{array}{l}\text { Average } \\
\text { strength. }\end{array}$} \\
\hline & & $\begin{array}{l}\text { Ex- } \\
\text { posed } \\
\text { face. }\end{array}$ & $\begin{array}{l}\text { Un- } \\
\text { exposed } \\
\text { face. }\end{array}$ & & $\begin{array}{c}\text { Ex- } \\
\text { posed } \\
\text { face. }\end{array}$ & $\begin{array}{l}\text { Un- } \\
\text { exposed } \\
\text { face. }\end{array}$ & & $\begin{array}{l}\text { Ex- } \\
\text { posed } \\
\text { face. }\end{array}$ & $\begin{array}{c}\text { Un- } \\
\text { exposed } \\
\text { face. }\end{array}$ \\
\hline & $\begin{array}{l}2 \\
2\end{array}$ & 1,338 & 1,702 & $\begin{array}{l}2 \\
2\end{array}$ & 651 & 535 & $\stackrel{2}{2}$ & 531 & 814 \\
\hline & 2 & 1101 & 1,948 & 2 & 712 & 776 & 3 & 327 & 548 \\
\hline & $\begin{array}{l}2 \\
3\end{array}$ & & 1,299 & $\begin{array}{l}2 \\
3\end{array}$ & 595 & $\begin{array}{c}830 \\
\cdots \cdots \\
\end{array}$ & 2 & 344 & ... \\
\hline A verage.. & & 1,016 & 1,650 & ........ & 653 & 714 & & 401 & 681 \\
\hline
\end{tabular}

MEDIUM BLOCKS.

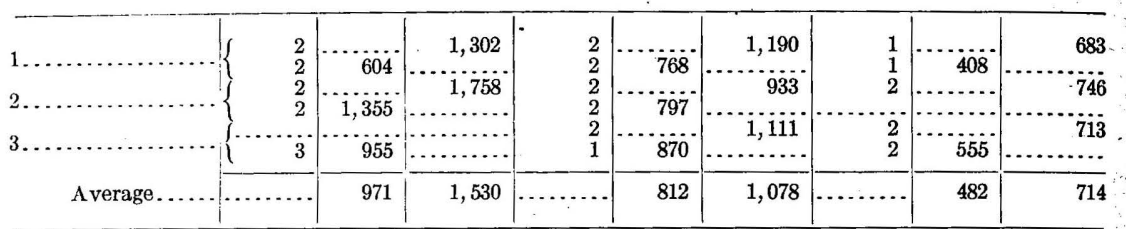

WET BLOCKS.

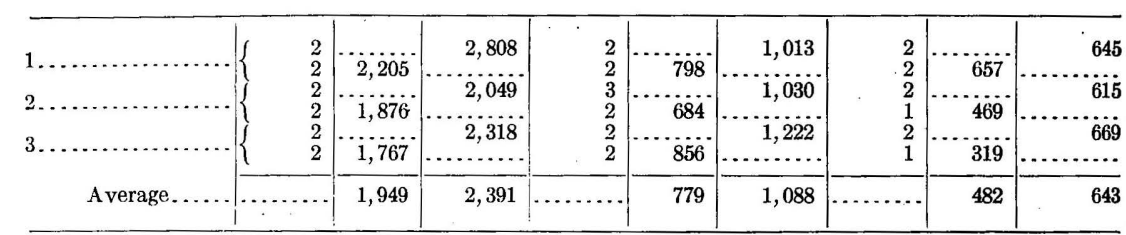


TABLE 3.-Panel 3-Results of compression tests made on portions of one-piece doubleair-space mortar building blocks after fire test.

DAMP BLOCKS.

[In pounds per square inch.]

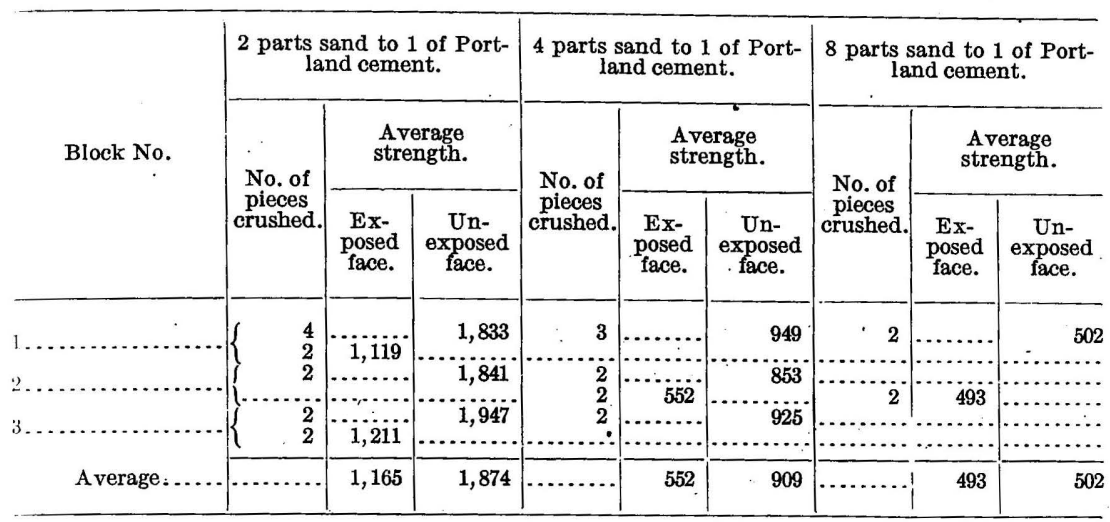

MEDIUM BLOCKS.

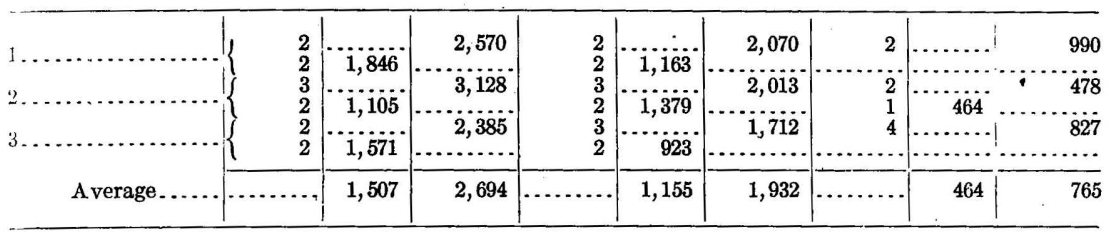

WET BLOCKS.

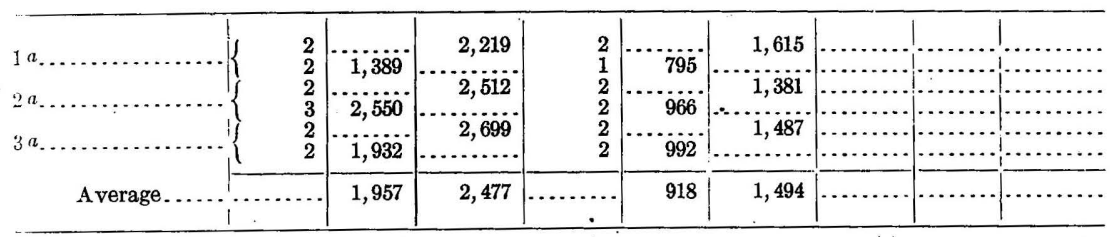

$a$ Blocks of 8 parts sand to 1 of Portland cement were destroyed in transit from Underwriters' Laboratories to Armour Institute. 
TABLE 4.-Panel 4-Results of compression tests made on portions of one-piece singleair-space mortar building blocks after fire test.

\section{DAMP BLOCKS.}

[In pounds per square inch.]

\begin{tabular}{|c|c|c|c|c|c|c|c|c|c|}
\hline \multirow{3}{*}{ Block No. } & \multicolumn{3}{|c|}{$\begin{array}{l}2 \text { parts sand to } 1 \text { of Port- } \\
\text { land cement. }\end{array}$} & \multicolumn{3}{|c|}{$\begin{array}{l}4 \text { parts sand to } 1 \text { of Port- } \\
\text { land cement. }\end{array}$} & \multicolumn{3}{|c|}{$\begin{array}{l}8 \text { parts sand to } 1 \text { of Port- } \\
\text { land cement. }\end{array}$} \\
\hline & \multirow{2}{*}{$\begin{array}{c}\text { No. of } \\
\text { pieces } \\
\text { crushed. }\end{array}$} & \multicolumn{2}{|c|}{$\begin{array}{l}\text { Average } \\
\text { strength. }\end{array}$} & \multirow{2}{*}{$\begin{array}{c}\text { No. of } \\
\text { pieces } \\
\text { crushed. }\end{array}$} & \multicolumn{2}{|c|}{$\begin{array}{l}\text { Average } \\
\text { strength. }\end{array}$} & \multirow{2}{*}{$\begin{array}{c}\text { No. of } \\
\text { pieces } \\
\text { crushed. }\end{array}$} & \multicolumn{2}{|c|}{$\begin{array}{l}\text { Average } \\
\text { strength. }\end{array}$} \\
\hline & & $\begin{array}{l}\text { Ex- } \\
\text { posed } \\
\text { face. }\end{array}$ & $\begin{array}{l}\text { Un- } \\
\text { exposed } \\
\text { face. }\end{array}$ & & $\begin{array}{l}\text { Ex- } \\
\text { posed } \\
\text { face. }\end{array}$ & $\begin{array}{l}\text { Un- } \\
\text { exposed } \\
\text { face. }\end{array}$ & & $\begin{array}{l}\text { Ex- } \\
\text { posed } \\
\text { face. }\end{array}$ & $\begin{array}{l}\text { Un- } \\
\text { exposed } \\
\text { face. }\end{array}$ \\
\hline & 2 & mom & 2,219 & & & & & 360 & \\
\hline & $\begin{array}{l}3 \\
2 \\
2\end{array}$ & 902 & 2,375 & & & & & 30 & \\
\hline & $\begin{array}{l}2 \\
2\end{array}$ & $\begin{array}{r}1,903 \\
.\end{array}$ & $\dddot{1}, 950$ & & & & 1 & 596 & \\
\hline & 1 . & 1,462 & & …. & & $\cdots$ & 3 & 571 & \\
\hline Average.. & ......... & 1,422 & 2,181 & & & & & 512 & \\
\hline
\end{tabular}

MEDIUM BLOCKS.

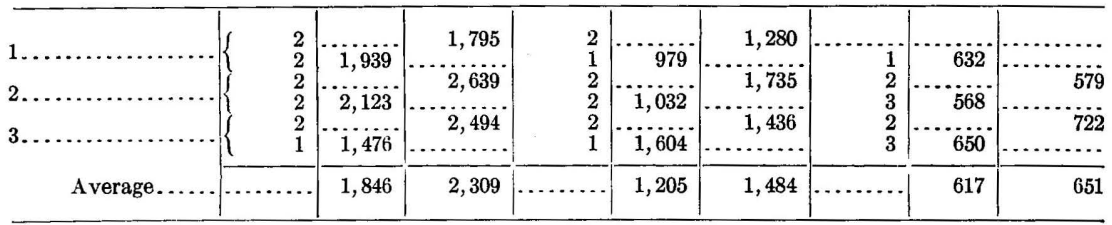

WET BLOCKS.

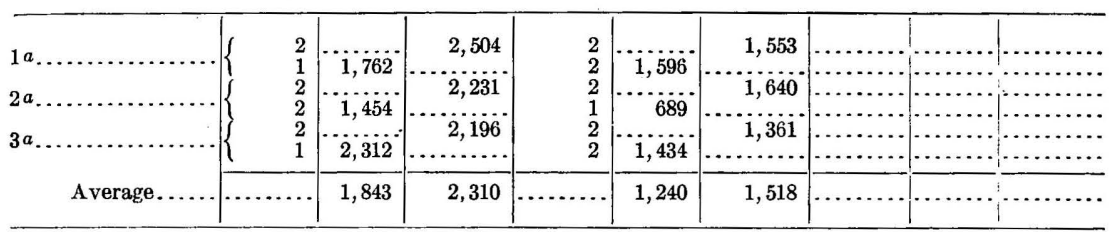

a Blocks of 8 parts sand to 1 of Portland cemen were destroyed in transitfrom Underwriters' Laboratories to Armour Institute. 
TABLE 5.-Panel 5-Results of compression tests made on portions of one-piece singleair-space mortar building blocks after fire test.

DAMP BLOCKS.

[In pounds per square inch.]

\begin{tabular}{|c|c|c|c|c|c|c|c|c|c|}
\hline \multirow{3}{*}{ Block No. } & \multicolumn{3}{|c|}{$\begin{array}{l}2 \text { parts sand to } 1 \text { of Port- } \\
\text { land cement. }\end{array}$} & \multicolumn{3}{|c|}{$\begin{array}{l}4 \text { parts sand to } 1 \text { of Port- } \\
\text { land cement. }\end{array}$} & \multicolumn{3}{|c|}{$\begin{array}{l}8 \text { parts sand to } 1 \text { of Port- } \\
\text { land cement. }\end{array}$} \\
\hline & \multirow{2}{*}{$\begin{array}{c}\text { No. of } \\
\text { pieces } \\
\text { crushed. }\end{array}$} & \multicolumn{2}{|c|}{$\begin{array}{l}\text { A verage } \\
\text { strength. }\end{array}$} & \multirow{2}{*}{$\begin{array}{c}\text { No. of } \\
\text { pieces } \\
\text { crushed. }\end{array}$} & \multicolumn{2}{|c|}{$\begin{array}{l}\text { Average } \\
\text { strength. }\end{array}$} & \multirow{2}{*}{$\begin{array}{c}\text { No. of } \\
\text { pieces } \\
\text { crushed. }\end{array}$} & \multicolumn{2}{|c|}{$\begin{array}{l}\text { Average } \\
\text { strength: }\end{array}$} \\
\hline & & $\begin{array}{c}\text { Ex- } \\
\text { posed } \\
\text { face. }\end{array}$ & $\begin{array}{l}\text { Un- } \\
\text { exposed } \\
\text { face. }\end{array}$ & & $\begin{array}{l}\text { Ex- } \\
\text { posed } \\
\text { face. }\end{array}$ & $\begin{array}{c}\text { Un- } \\
\text { exposed } \\
\text { face. }\end{array}$ & & $\begin{array}{c}\text { Ex- } \\
\text { posed } \\
\text { face. }\end{array}$ & $\begin{array}{l}\text { Un- } \\
\text { exposed } \\
\text { face. }\end{array}$ \\
\hline . & $\frac{1}{2}$ & 1,354 & 1,914 & $\frac{1}{2}$ & 389 & 906 & 1 & & 405 \\
\hline & 1 & 774 & 1,581 & 1 & ${ }^{\circ}$ & 810 & & & \\
\hline & $\begin{array}{l}1 \\
2\end{array}$ & & 1,825 & $\begin{array}{l}1 \\
2\end{array}$ & & 1,246 & i & $408^{\circ}$ & $\cdots \cdot$ \\
\hline Average. & ……... & 1,034 & 1,773 & ....... & 466 & 987 & $\cdots$ & 408 & 405 \\
\hline
\end{tabular}

MEDIUM BLOCKS,

\begin{tabular}{|c|c|c|c|c|c|c|c|c|c|}
\hline $\begin{array}{l}1 \\
2 \ldots \ldots \ldots \\
3 \ldots \ldots \ldots \ldots \ldots\end{array}$ & $\begin{array}{l}1 \\
2 \\
1 \\
2 \\
1 \\
2\end{array}$ & $\left|\begin{array}{c}1,577 \\
1,406 \\
\cdots 1,464\end{array}\right|$ & $\mid \begin{array}{r}1,492 \\
2,152 \\
\cdots 2,498 \\
\cdots \ldots \ldots \ldots\end{array}$ & \begin{tabular}{l|}
2 \\
3 \\
1 \\
2 \\
1 \\
1
\end{tabular} & $\mid \begin{array}{c}655 \\
709 \\
\cdots 958\end{array}$ & $\begin{array}{r}1,242 \\
658 \\
\cdots \\
628 \\
\cdots\end{array}$ & $\begin{array}{l}1 \\
4 \\
1 \\
2 \\
1 \\
1\end{array}$ & $\begin{array}{r}615 \\
822 \\
\cdots 559\end{array}$ & 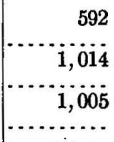 \\
\hline Average...... & $\cdots \ldots$ & 1,482 & 2,047 & .............. & 774 & 843 & $\ldots \ldots \ldots$ & 665 & 870 \\
\hline
\end{tabular}

WET BLOCKS.

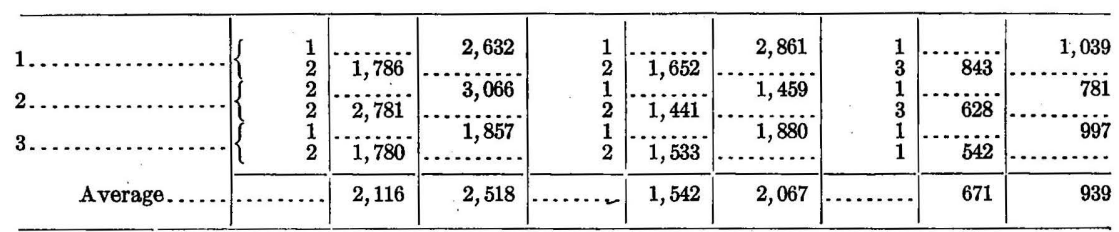


TABLE 6.-Panel 6-Results of compression tests made on portions of one-piece singleair-space mortar building blocks after fire test.

DAMP BLOCKS.

[In pounds per square inch.]

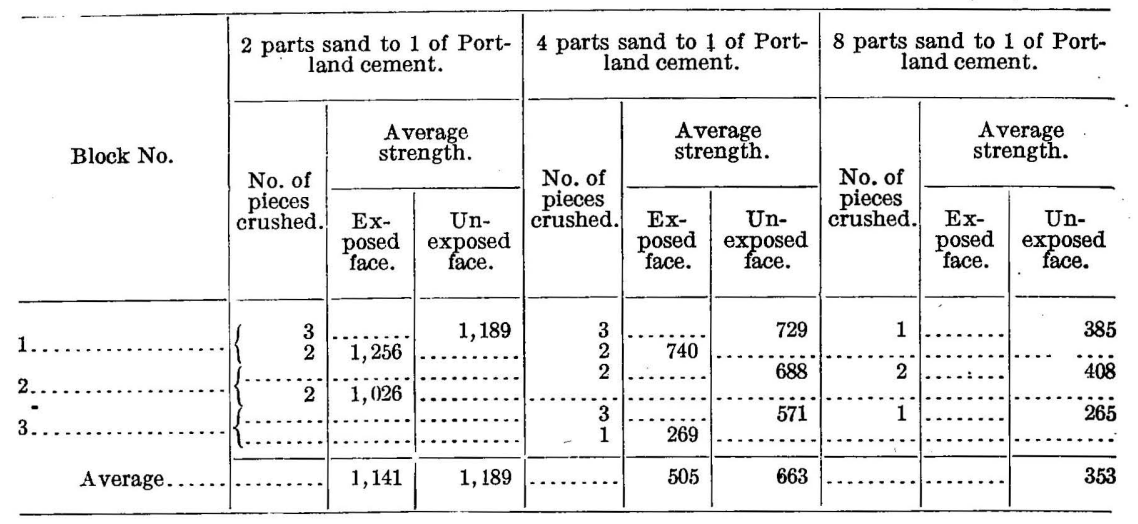

MEDIUM BLOCKS.

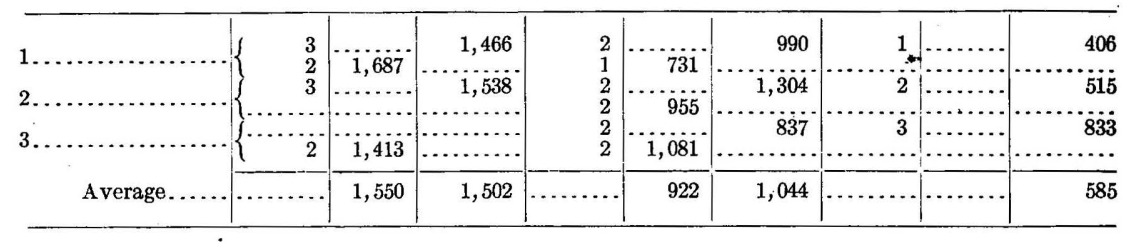

WET BLOCKS.

\begin{tabular}{|c|c|c|c|c|c|c|c|c|c|}
\hline & 2 & & 2,794 & & & & 2 & 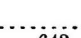 & 827 \\
\hline $2 .$. & 3 & & 2,000 & 3 & & 1,105 & 2 & & $\dddot{9} 9 \ddot{i}$ \\
\hline & & & S & 2 & & i,iii & 2 & 100 & $52 i$ \\
\hline & & & & 2 & 1,291 & & 2 & 697 & .... \\
\hline Average. & & 2,215 & 2,397 & & 1,163 & 1,108 & & 686 & 780 \\
\hline
\end{tabular}


TABLE 7.-Panel 7-Results of compression tests made on portions of one-piece singleair-space mortar building blocks after fire test.

DAMP BLOCKS.

[In pounds per square inch.]

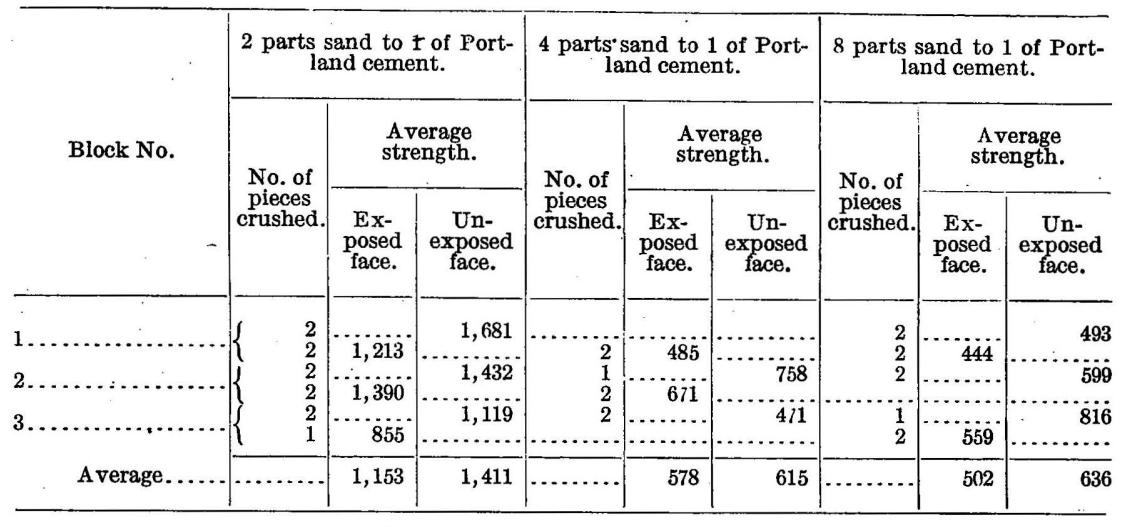

MEDIUM BLOCKS.

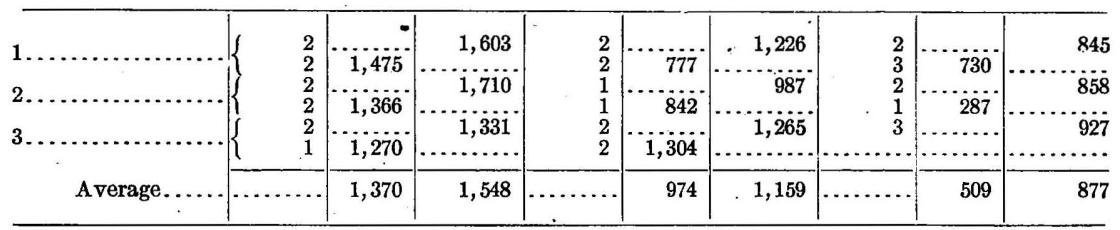

WET BLOCKS.

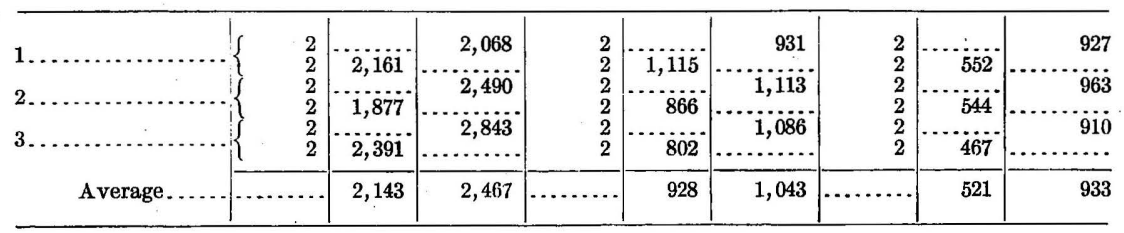


TABLE 8.-Panel 8-Results of compression tests made on portions of one-piece singleair-space mortar building blocks after fire test.

DAMP BLOCKS.

[In pounds per square inch.]

\begin{tabular}{|c|c|c|c|c|c|c|c|c|c|}
\hline \multirow{3}{*}{ Block No. } & \multicolumn{3}{|c|}{$\begin{array}{l}2 \text { parts sand to } 1 \text { of Port- } \\
\text { land cement. }\end{array}$} & \multicolumn{3}{|c|}{$\begin{array}{l}4 \text { parts sand to } 1 \text { of Port- } \\
\text { land cement. }\end{array}$} & \multicolumn{3}{|c|}{$\begin{array}{l}8 \text { parts sand to } 1 \text { of Port- } \\
\text { land cement. }\end{array}$} \\
\hline & \multirow{2}{*}{$\begin{array}{l}\text { No. of } \\
\text { pieces } \\
\text { crushed. }\end{array}$} & \multicolumn{2}{|c|}{$\begin{array}{l}\text { Average } \\
\text { strength. }\end{array}$} & \multirow{2}{*}{$\begin{array}{c}\text { No. of } \\
\text { pieces } \\
\text { crushed. }\end{array}$} & \multicolumn{2}{|c|}{$\begin{array}{l}\text { A verage } \\
\text { strength. }\end{array}$} & \multirow{2}{*}{$\begin{array}{c}\text { No. of } \\
\text { pieces } \\
\text { crushed. }\end{array}$} & \multicolumn{2}{|c|}{$\begin{array}{l}\text { Average } \\
\text { strength. }\end{array}$} \\
\hline & & $\begin{array}{c}\text { Ex- } \\
\text { posed } \\
\text { face. }\end{array}$ & $\begin{array}{c}\text { Un- } \\
\text { exposed } \\
\text { face. }\end{array}$ & & $\begin{array}{l}\text { Ex- } \\
\text { posed } \\
\text { face. }\end{array}$ & $\begin{array}{c}\text { Un- } \\
\text { exposed } \\
\text { face. }\end{array}$ & & $\begin{array}{c}\text { Ex- } \\
\text { posed } \\
\text { face. }\end{array}$ & $\begin{array}{c}\text { Un- } \\
\text { exposed } \\
\text { face. }\end{array}$ \\
\hline & $\begin{array}{l}2 \\
2\end{array}$ & 1,255 & 978 & $\frac{1}{2}$ & 636 & 834 & $\begin{array}{l}1 \\
1\end{array}$ & 431 & 321 \\
\hline & $\ddot{2}$ & 868 & & $\begin{array}{l}1 \\
3\end{array}$ & 1170 & 1,077 & $\begin{array}{l}\mathbf{1} \\
\mathbf{2}\end{array}$ & 263 & 545 \\
\hline & $\begin{array}{l}2 \\
2\end{array}$ & 1,482 & 1,437 & $\begin{array}{l}1 \\
2\end{array}$ & & 612 & $\begin{array}{l}1 \\
1\end{array}$ & 228 & 249 \\
\hline$\Lambda$ verage. & & 1,202 & 1,208 & $\ldots$. & 792 & 841 & & 307 & 372 \\
\hline
\end{tabular}

MEDIUM BLOCKS.

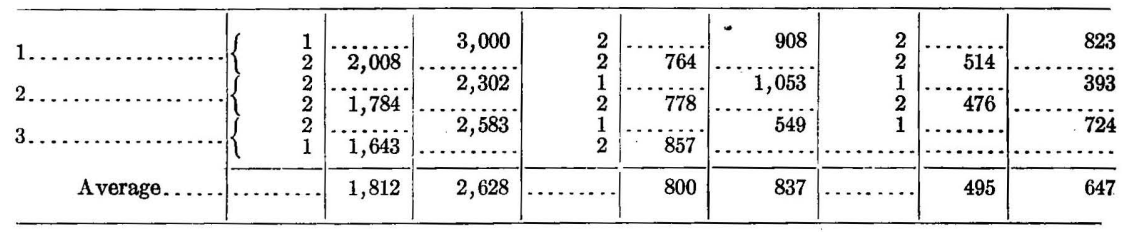

WET BLOCKS.

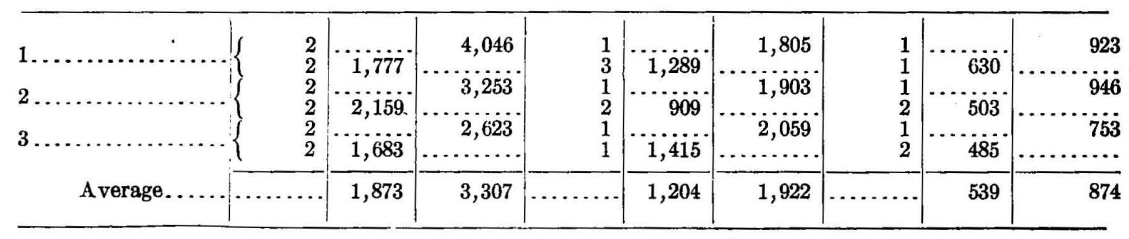


TABLE 9.-Panel 9-Results of compression tests made on portions of two-piece mortar building blocks after fire test.

DAMP BLOCKS.

[In pounds per square inch. ]

\begin{tabular}{|c|c|c|c|c|c|c|c|c|c|}
\hline \multirow{3}{*}{ Block No. } & \multicolumn{3}{|c|}{$\begin{array}{l}2 \text { parts sand to } 1 \text { of Port- } \\
\text { land cement. }\end{array}$} & \multicolumn{3}{|c|}{$\begin{array}{l}4 \text { parts sand to } 1 \text { of Port- } \\
\text { land cement. }\end{array}$} & \multicolumn{3}{|c|}{$\begin{array}{l}8 \text { parts sand to } 1 \text { of Port- } \\
\text { land cement. }\end{array}$} \\
\hline & \multirow{2}{*}{$\begin{array}{l}\text { No. of } \\
\text { pieces } \\
\text { crushed. }\end{array}$} & \multicolumn{2}{|c|}{$\begin{array}{l}\text { Average } \\
\text { strength. }\end{array}$} & \multirow{2}{*}{$\begin{array}{l}\text { No. of } \\
\text { pieces } \\
\text { crushed. }\end{array}$} & \multicolumn{2}{|c|}{$\begin{array}{l}\text { Average } \\
\text { strength. }\end{array}$} & \multirow{2}{*}{$\begin{array}{c}\text { No. of } \\
\text { pieces } \\
\text { crushed. }\end{array}$} & \multicolumn{2}{|c|}{$\begin{array}{l}\text { Average } \\
\text { strength. }\end{array}$} \\
\hline & & $\begin{array}{l}\text { Ex- } \\
\text { posed } \\
\text { face. }\end{array}$ & $\begin{array}{l}\text { Un- } \\
\text { exposed } \\
\text { face. }\end{array}$ & & $\begin{array}{l}\text { Ex- } \\
\text { posed } \\
\text { face. }\end{array}$ & $\begin{array}{l}\text { Un- } \\
\text { exposed } \\
\text { face. }\end{array}$ & & $\begin{array}{l}\text { Ex- } \\
\text { posed } \\
\text { face. }\end{array}$ & $\begin{array}{l}\text { Un- } \\
\text { exposed } \\
\text { face. }\end{array}$ \\
\hline & $\mathrm{r}$ & & & 1 & $\ldots$. & 659 & 1 & & 300 \\
\hline & 2 & 896 & & & & 449 & & & \\
\hline & $\ddot{2}$ & $\ddot{1,007}$ & & $i$ & 350 & & & & 223 \\
\hline & $\begin{array}{l}1 \\
2\end{array}$ & $\begin{array}{l}\cdots \\
\ldots \ldots \ldots\end{array}$ & $\begin{array}{r}1,219 \\
1,313\end{array}$ & 1 & ..... & $\cdots$ & 4 & & 423 \\
\hline A verage. & & 952 & 1,242 & ….... & 350 & 669 & & & 315 \\
\hline
\end{tabular}

MEDIUM BLOCKS.

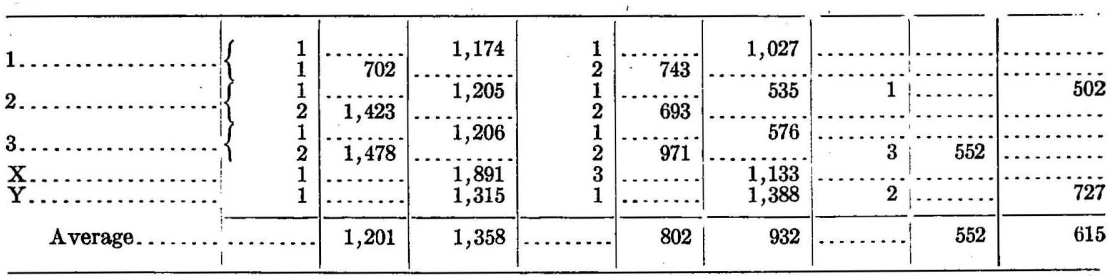

WET BLOCKS.

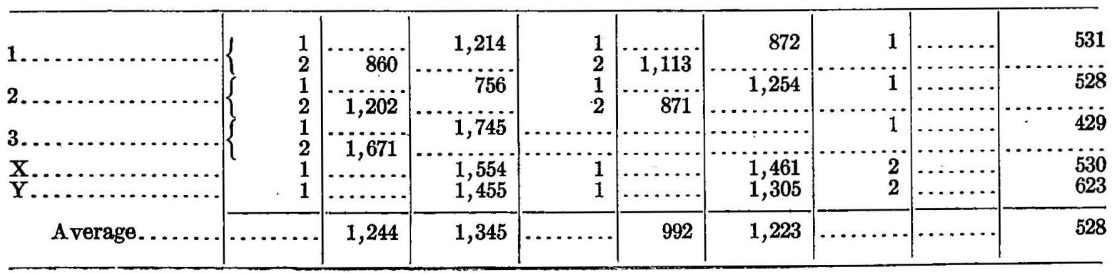


TABLE 10.-Panel 10-Results of compression tests made on portions of two-piece mortar building blocks after fire test.

DAMP BLOCKS.

[In pounds per square inch.]

\begin{tabular}{|c|c|c|c|c|c|c|c|c|c|}
\hline \multirow{3}{*}{ Block No. } & \multicolumn{3}{|c|}{$\begin{array}{l}2 \text { parts sand to } 1 \text { of Port- } \\
\text { land cement. }\end{array}$} & \multicolumn{3}{|c|}{$\begin{array}{l}4 \text { parts sand to } 1 \text { of Port- } \\
\text { land cement. }\end{array}$} & \multicolumn{3}{|c|}{$\begin{array}{l}8 \text { parts sand to } 1 \text { of Port- } \\
\text { land cement. }\end{array}$} \\
\hline & \multirow{2}{*}{$\begin{array}{c}\text { No. of } \\
\text { pieces } \\
\text { crushed. }\end{array}$} & \multicolumn{2}{|c|}{$\begin{array}{l}\text { Average } \\
\text { strength. }\end{array}$} & \multirow{2}{*}{$\begin{array}{l}\text { No. of } \\
\text { pieces } \\
\text { crushed. }\end{array}$} & \multicolumn{2}{|c|}{$\begin{array}{l}\text { Average } \\
\text { strength. }\end{array}$} & \multirow{2}{*}{$\begin{array}{l}\text { No. of } \\
\text { pieces } \\
\text { crushed. }\end{array}$} & \multicolumn{2}{|c|}{$\begin{array}{l}\text { Average } \\
\text { strength. }\end{array}$} \\
\hline & & $\begin{array}{l}\text { Ex- } \\
\text { posed } \\
\text { face. }\end{array}$ & $\begin{array}{l}\text { Un- } \\
\text { exposed } \\
\text { face. }\end{array}$ & & $\begin{array}{l}\text { Ex- } \\
\text { posed } \\
\text { face. }\end{array}$ & $\begin{array}{l}\text { Un- } \\
\text { exposed } \\
\text { face. }\end{array}$ & & $\begin{array}{l}\text { Ex- } \\
\text { posed } \\
\text { face. }\end{array}$ & $\begin{array}{l}\text { Un- } \\
\text { exposed } \\
\text { face. }\end{array}$ \\
\hline 1. & 1 & & 920 & & & & & 473 & \\
\hline & $\begin{array}{l}2 \\
1\end{array}$ & $\begin{array}{c}543 \\
\ldots\end{array}$ & 600 & $\cdots$ & & $\cdots$ & 1 & 410 & 536 \\
\hline & 2 & 377 & & & & & 2 & 470 & $\ldots \ldots \ldots$ \\
\hline $3 .$. & 1 & & 1,034 & & & & $\cdots \cdots$ & & $\cdots$ \\
\hline & 3 & & 987 & & & & & & 537 \\
\hline & & & & & & & & & \\
\hline A verage. & & 464 & 885 & $\ldots \ldots$ & & & & 472 & 537 \\
\hline
\end{tabular}

MEDIUM BLOCKS.

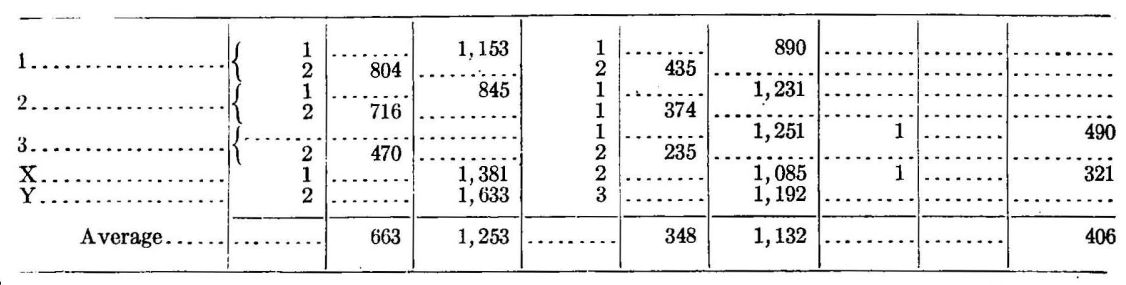

WET BLOCKS.

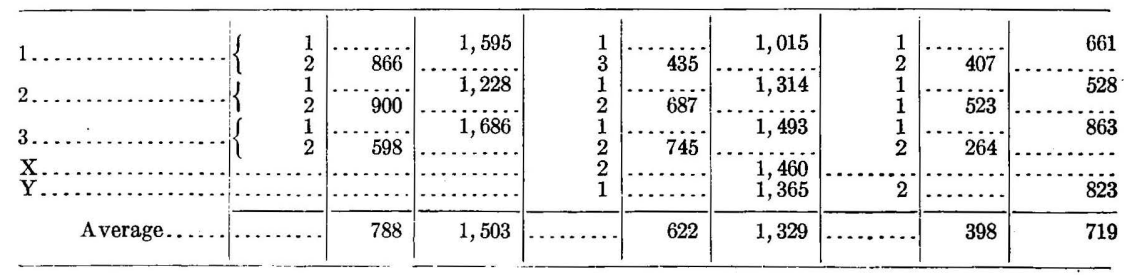


RESULTS OF TESTS.

TABLE 11.-Panel 11-Physical properties of brick before firing.

\begin{tabular}{|c|c|c|c|c|c|c|c|c|c|c|}
\hline \multicolumn{6}{|c|}{ Under normal conditions. } & \multicolumn{2}{|c|}{$\begin{array}{c}\text { Immersed in water } \\
48 \text { hours. }\end{array}$} & \multicolumn{3}{|c|}{$\begin{array}{l}\text { Water absorption, brick } \\
\text { not fired. }\end{array}$} \\
\hline \multicolumn{2}{|c|}{$\begin{array}{l}\text { Transverse strength, } \\
\text { brick not fired. }\end{array}$} & \multicolumn{4}{|c|}{$\begin{array}{l}\text { Compressive strength per } \\
\text { square inch. }\end{array}$} & \multirow{2}{*}{$\begin{array}{l}\text { Com- } \\
\text { pressive } \\
\text { strength } \\
\text { per } \\
\text { square } \\
\text { inch, } \\
\text { brick } \\
\text { not } \\
\text { fired. }\end{array}$} & \multirow{2}{*}{$\begin{array}{l}\text { Reduc- } \\
\text { tion in } \\
\text { strength } \\
\text { in pounds } \\
\text { per } \\
\text { square } \\
\text { inch. }\end{array}$} & \multirow{2}{*}{$\begin{array}{l}30 \text { min- } \\
\text { utes. }\end{array}$} & \multirow[b]{2}{*}{$\begin{array}{c}4 \\
\text { hours. }\end{array}$} & \multirow[b]{2}{*}{$\begin{array}{c}48 \\
\text { hours. }\end{array}$} \\
\hline $\begin{array}{l}\text { Breaking } \\
\text { load. }\end{array}$ & $\begin{array}{l}\text { Modulus } \\
\text { of } \\
\text { rupture. }\end{array}$ & $\begin{array}{c}\text { Brick } \\
\text { from } \\
\text { exposed } \\
\text { face. }\end{array}$ & $\begin{array}{l}\text { Brick } \\
\text { from } \\
\text { center } \\
\text { of wall. }\end{array}$ & $\begin{array}{l}\text { Brick } \\
\text { from } \\
\text { back } \\
\text { of wall. }\end{array}$ & $\begin{array}{l}\text { Brick } \\
\text { not } \\
\text { fired. }\end{array}$ & & & & & \\
\hline $\begin{array}{r}\text { Pounds. } \\
1,056 \\
1,280\end{array}$ & $\begin{array}{l}435 \\
528\end{array}$ & $\begin{array}{r}\text { Pounds. } \\
2,505 \\
3,190\end{array}$ & $\begin{array}{r}\text { Pounds. } \\
2,420 \\
2,865\end{array}$ & $\begin{array}{c}\text { Pounds. } \\
2,912 \\
2,648\end{array}$ & $\begin{array}{c}\text { Pounds. } \\
2,711 \\
2,977\end{array}$ & $\begin{array}{r}\text { Pounds. } \\
2,100 \\
2,100\end{array}$ & $\begin{array}{r}\text { Per cent. } \\
26.5 \\
29.6\end{array}$ & $\begin{array}{r}\text { Per ct. } \\
20.0 \\
16.5\end{array}$ & $\begin{array}{r}\text { Per ct. } \\
20.9 \\
17.2\end{array}$ & $\begin{array}{c}\text { Per ct. } \\
22.0 \\
18.3\end{array}$ \\
\hline ……... & $\ldots \ldots \ldots$ & & 2,034 & 2,420 & 2,110 & $\ldots \ldots \ldots$ & …....... & ........ & $\cdots$ & \\
\hline & & & & & & $\cdots$ & . & & $\ldots \ldots$ & \\
\hline & & 2,452 & 2,59 & 2,70 & $\begin{array}{l}2,400 \\
3,272\end{array}$ & ......... & , & & $\cdots$ & \\
\hline & & 3,718 & 2,922 & 3,435 & 3,342 & .... & ..... & & & \\
\hline & & 2,970 & 2,61 & 2,5 & 3,239 & $\ldots \ldots \ldots$ & $\ldots \ldots \ldots$ & . & $\ldots \ldots$ & $\ldots \ldots$ \\
\hline & & 290 & 2,59 & & 2,684 & $\ldots \ldots \ldots$ & & & & \\
\hline & & $\begin{array}{l}2,890 \\
2,919\end{array}$ & $\begin{array}{l}2,810 \\
2,180\end{array}$ & $\begin{array}{l}2,470 \\
2,430\end{array}$ & $\begin{array}{l}1,393 \\
2,870\end{array}$ & & & & & \\
\hline & & & 2,990 & 2,202 & $\ldots \ldots$ & n........ & & & & \\
\hline & & & & & & $\ldots \ldots \ldots$ & .......... & & & \\
\hline Aver... & 482 & 2,793 & 2,516 & 2,648 & 2,729 & 2,100 & 28.1 & 18.0 & 19.1 & 20.2 \\
\hline
\end{tabular}

TABLE 12.-Panel 12-Physical properties of hydraulic-pressed brick before firing.

\begin{tabular}{|c|c|c|c|c|c|c|c|c|c|c|c|c|c|}
\hline \multicolumn{4}{|c|}{ Normal. } & \multicolumn{4}{|c|}{$\begin{array}{l}\text { Immersed in water } \\
\text { for } 48 \text { hours. }\end{array}$} & \multicolumn{6}{|c|}{ Water absorption. } \\
\hline \multicolumn{2}{|c|}{$\begin{array}{c}\text { Transverse } \\
\text { strength, brick } \\
\text { not fired. }\end{array}$} & \multicolumn{2}{|c|}{$\begin{array}{l}\text { Compressive } \\
\text { strength per } \\
\text { square inch. }\end{array}$} & \multicolumn{2}{|c|}{$\begin{array}{l}\text { Compressive } \\
\text { strength per } \\
\text { square inch. }\end{array}$} & \multicolumn{2}{|c|}{$\begin{array}{l}\text { Increase in } \\
\text { compressive } \\
\text { strength. }\end{array}$} & \multicolumn{2}{|c|}{30 minutes. } & \multicolumn{2}{|c|}{4 hours. } & \multicolumn{2}{|c|}{48 hours. } \\
\hline $\begin{array}{l}\text { Break- } \\
\text { ing } \\
\text { load. }\end{array}$ & $\begin{array}{l}\text { Modu- } \\
\text { lus of } \\
\text { rupture. }\end{array}$ & $\begin{array}{c}\text { Ex- } \\
\text { posed } \\
\text { face. }\end{array}$ & $\begin{array}{l}\text { Unex- } \\
\text { posed } \\
\text { face. }\end{array}$ & $\begin{array}{l}\text { Ex- } \\
\text { posed } \\
\text { face. }\end{array}$ & $\begin{array}{l}\text { Unex- } \\
\text { posed } \\
\text { face. }\end{array}$ & $\begin{array}{c}\text { Ex- } \\
\text { posed } \\
\text { face. }\end{array}$ & $\begin{array}{l}\text { Unex- } \\
\text { posed } \\
\text { face. }\end{array}$ & $\begin{array}{c}\text { Ex- } \\
\text { posed } \\
\text { face. }\end{array}$ & $\begin{array}{l}\text { Unex- } \\
\text { posed } \\
\text { face. }\end{array}$ & $\begin{array}{c}\text { Ex- } \\
\text { posed } \\
\text { face. }\end{array}$ & $\begin{array}{l}\text { Unex- } \\
\text { posed } \\
\text { face. }\end{array}$ & $\begin{array}{c}\text { Ex- } \\
\text { posed } \\
\text { face. }\end{array}$ & $\begin{array}{l}\text { Unex- } \\
\text { posed } \\
\text { face. }\end{array}$ \\
\hline 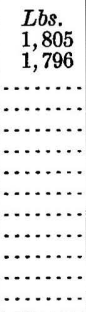 & $\begin{array}{l}720 \\
716 \\
\cdots \\
\cdots \cdots \\
\cdots \cdots \\
\cdots \cdots \\
\cdots \cdots \\
\cdots \cdots \\
\cdots\end{array}$ & $\begin{array}{c}\text { Lbs. } \\
4,067 \\
2,702 \\
3,150 \\
3,480 \\
4,290 \\
2,590 \\
3,480 \\
3,180 \\
4,110 \\
4,710 \\
5,220 \\
4,600 \\
\ldots \ldots \ldots\end{array}$ & $\begin{array}{l}L b s . \\
4,320 \\
5,830 \\
3,600 \\
5,560 \\
3,190 \\
5,040 \\
3,420 \\
4,100 \\
4,220 \\
5,720 \\
3,710 \\
3,830 \\
5,640\end{array}$ & 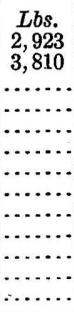 & $\begin{array}{c}\text { Lbs. } \\
4,995 \\
3,881 \\
\cdots \\
\ldots \ldots\end{array}$ & 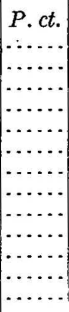 & $\begin{array}{c}P . c t . \\
\cdots \cdots \\
\cdots \cdots \\
\cdots \cdots\end{array}$ & $\begin{array}{r}\text { P.ct. } \\
9.9 \\
11 . z \\
\ldots \ldots\end{array}$ & $\begin{array}{r}P . c t . \\
10.6 \\
10.7 \\
\ldots . . .\end{array}$ & $\begin{array}{c}\text { P.ct. } \\
10.5 \\
11.2 \\
\ldots \ldots . \\
\cdots \ldots . .\end{array}$ & $\begin{array}{r}P_{.} c t . \\
10.6 \\
10.8 \\
\cdots \ldots . . \\
\cdots \ldots . . .\end{array}$ & $\begin{array}{c}P . c t . \\
10.5 \\
11.2 \\
\cdots . . . \\
\cdots \cdots . . \\
\cdots \cdots . . \\
\cdots . . .\end{array}$ & $\begin{array}{l}\text { P.ct. } \\
10.6 \\
10.8 \\
\ldots \ldots \ldots \\
\cdots \ldots \ldots .\end{array}$ \\
\hline A ver. & 718 & 3,701 & 4,440 & 3,367 & 4,438 & -9.1 & -0.1 & 10.6 & 10.7 & 10.9 & 10.7 & 10.9 & 10.7 \\
\hline
\end{tabular}


TABLE 13.-Panel 22-Physical properties of common clay brick before firing.

[No fired bricks were tested.]

\begin{tabular}{|c|c|c|c|c|c|c|c|c|c|c|c|c|c|}
\hline \multicolumn{4}{|c|}{ Normal. } & \multicolumn{4}{|c|}{$\begin{array}{l}\text { Immersed in water for } \\
48 \text { hours. }\end{array}$} & \multicolumn{6}{|c|}{ Water absorption. } \\
\hline \multicolumn{2}{|c|}{$\begin{array}{l}\text { Transverse } \\
\text { strength. }\end{array}$} & \multicolumn{2}{|c|}{$\begin{array}{l}\text { Compressive } \\
\text { strength per } \\
\text { square inch. }\end{array}$} & \multicolumn{2}{|c|}{$\begin{array}{l}\text { Compressive } \\
\text { strength per } \\
\text { square inch. }\end{array}$} & \multicolumn{2}{|c|}{$\begin{array}{l}\text { Increase in } \\
\text { compressive } \\
\text { strength. }\end{array}$} & \multicolumn{2}{|c|}{30 minutes. } & \multicolumn{2}{|c|}{4 hours. } & \multicolumn{2}{|c|}{48 hours. } \\
\hline $\begin{array}{l}\text { Break- } \\
\text { ing } \\
\text { load. }\end{array}$ & $\begin{array}{l}\text { Modu- } \\
\text { lus of } \\
\text { rup- } \\
\text { ture. }\end{array}$ & $\begin{array}{l}\text { Ex- } \\
\text { posed } \\
\text { face. }\end{array}$ & $\begin{array}{l}\text { Unex- } \\
\text { posed } \\
\text { face. }\end{array}$ & $\begin{array}{l}\text { Ex- } \\
\text { posed } \\
\text { face. }\end{array}$ & $\begin{array}{l}\text { Unex- } \\
\text { posed } \\
\text { face. }\end{array}$ & $\begin{array}{l}\text { Ex- } \\
\text { posed } \\
\text { face. }\end{array}$ & $\begin{array}{l}\text { Unex- } \\
\text { posed } \\
\text { face. }\end{array}$ & $\begin{array}{c}\text { Ex- } \\
\text { posed } \\
\text { face. }\end{array}$ & $\begin{array}{l}\text { Unex- } \\
\text { posed } \\
\text { face. }\end{array}$ & $\begin{array}{c}\text { Ex- } \\
\text { posed } \\
\text { face. }\end{array}$ & $\begin{array}{l}\text { Unex- } \\
\text { posed } \\
\text { face. }\end{array}$ & $\begin{array}{l}\text { Ex- } \\
\text { posed } \\
\text { face. }\end{array}$ & $\begin{array}{l}\text { Unex- } \\
\text { posed } \\
\text { face. }\end{array}$ \\
\hline $\begin{array}{l}L b s . \\
5,368 \\
3,442 \\
3,892 \\
3,302 \\
1,367\end{array}$ & $\begin{array}{r}1,819 \\
1,167 \\
1,320 \\
1,119 \\
463\end{array}$ & 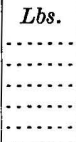 & $\begin{array}{c}L b s . \\
5,563 \\
2,608 \\
2,762 \\
3,466 \\
4,930\end{array}$ & 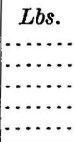 & $\begin{array}{r}\text { Lbs. } \\
6,850 \\
10,230 \\
4,650 \\
6,860 \\
4,867\end{array}$ & $\begin{array}{l}P . c t . \\
\ldots \ldots . \\
\cdots \ldots . . \\
\cdots \ldots . . \\
\cdots \ldots .\end{array}$ & $\begin{array}{r}P . c t . \\
23.1 \\
292.0 \\
68.3 \\
98.0 \\
-1.3\end{array}$ & 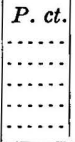 & $\begin{array}{r}P . c t . \\
8.5 \\
1.6 \\
4.7 \\
3.8 \\
4.7\end{array}$ & $\begin{array}{l}P . \text { ct. } \\
\cdots . . . . \\
\cdots \cdots . . . \\
\cdots \cdots . .\end{array}$ & $\begin{array}{r}\text { P.ct. } \\
8.5 \\
2.8 \\
5.8 \\
6.0 \\
4.8\end{array}$ & \begin{tabular}{|l|}
$P . c t$. \\
$\cdots$ \\
\hdashline$\cdots$ \\
$\cdots \cdots$ \\
$\cdots \cdots$ \\
$\cdots \cdots$
\end{tabular} & $\begin{array}{c}\text { P. ct. } \\
8.7 \\
4.6 \\
6.5 \\
6.6 \\
4.8\end{array}$ \\
\hline Aver. & 1,178 & ........ & 3,866 & & 6,691 & ...... & 96.0 & & 4. 7 & & 5.6 & $\ldots .$. & 6.2 \\
\hline
\end{tabular}

TABLE 14.-P'anel 29-Physical properties of sand-lime brick before and after firing.

\begin{tabular}{|c|c|c|c|c|c|c|c|c|}
\hline & \multicolumn{3}{|c|}{ Normal. } & \multicolumn{2}{|c|}{$\begin{array}{l}\text { Immersed in water } \\
\text { for } 48 \text { hours. }\end{array}$} & \multicolumn{3}{|c|}{ Water absorption. } \\
\hline & \multicolumn{2}{|c|}{ Transverse strength. } & \multirow{2}{*}{$\begin{array}{l}\text { Com- } \\
\text { pressive } \\
\text { strength } \\
\text { per } \\
\text { square } \\
\text { inch. }\end{array}$} & \multirow{2}{*}{\begin{tabular}{|c|} 
Com- \\
pressiva \\
strength \\
per \\
square \\
inch.
\end{tabular}} & \multirow{2}{*}{$\begin{array}{c}\text { Reduc- } \\
\text { tion in } \\
\text { com- } \\
\text { pressive } \\
\text { strength. }\end{array}$} & \multirow{2}{*}{$\begin{array}{l}30 \text { min- } \\
\text { utes. }\end{array}$} & \multirow[b]{2}{*}{4 hours. } & \multirow[b]{2}{*}{48 hours. } \\
\hline & $\begin{array}{l}\text { Breaking } \\
\text { load. }\end{array}$ & $\begin{array}{l}\text { Modulus } \\
\text { of rup- } \\
\text { ture. }\end{array}$ & & & & & & \\
\hline Not fired..... & $\left\{\begin{array}{r}\text { Pounds. } \\
913 \\
909 \\
797 \\
684 \\
695 \\
\end{array}\right.$ & $\begin{array}{l}364 \\
362 \\
318 \\
273 \\
277\end{array}$ & $\begin{array}{r}\text { Pounds. } \\
2,020 \\
2,510 \\
2,161 \\
1,923 \\
1,562\end{array}$ & $\begin{array}{r}\text { Pounds. } \\
1,816 \\
1,636 \\
1,604 \\
1,382 \\
963\end{array}$ & $\begin{array}{r}\text { Per cent. } \\
10.1 \\
34.8 \\
25.8 \\
28.1 \\
38.3\end{array}$ & $\begin{array}{r}\text { Per cent. } \\
16.33 \\
16.30 \\
9.81 \\
18.22 \\
13.04\end{array}$ & $\begin{array}{r}\text { Per cent. } \\
16.59 \\
16.60 \\
13.62 \\
18.29 \\
13.91\end{array}$ & $\begin{array}{c}\text { Per cent. } \\
16.59 \\
16.60 \\
13.62 \\
18.29 \\
14.28\end{array}$ \\
\hline \multirow[t]{2}{*}{ Average.. } & 800 & 319 & 2,035 & 1,480 & 27.4 & 14.74 & 15.80 & 15.88 \\
\hline & $\begin{array}{l}642 \\
841 \\
770 \\
789 \\
645 \\
\end{array}$ & $\begin{array}{l}256 \\
336 \\
308 \\
315 \\
258\end{array}$ & $\begin{array}{l}2,117 \\
2,109 \\
1,208 \\
2,430 \\
1,790\end{array}$ & $\begin{array}{r}1,261 \\
976 \\
1,451 \\
1,468 \\
873\end{array}$ & $\begin{array}{r}40.5 \\
53.7 \\
a 20.0 \\
39.6 \\
52.2\end{array}$ & $\begin{array}{l}15.30 \\
11.90 \\
13.72 \\
13.80 \\
16.92\end{array}$ & $\begin{array}{l}15.3 \\
13.45 \\
15.79 \\
14.30 \\
16.92\end{array}$ & $\begin{array}{l}15.3 \\
14.00 \\
15.79 \\
14.30 \\
16.92\end{array}$ \\
\hline A verage. . & 737 & 295 & 1,931 & 1,206 & 33.2 & 14.33 & 15.15 & 15.26 \\
\hline $\begin{array}{l}\text { Brick with ends } \\
\text { exposed ....... }\end{array}$ & $\begin{array}{l}494 \\
756 \\
707 \\
463 \\
551\end{array}$ & $\begin{array}{l}197 \\
302 \\
282 \\
185 \\
220\end{array}$ & $\begin{array}{l}1,952 \\
2,176 \\
2,109 \\
1,306 \\
1,541 \\
\end{array}$ & $\begin{array}{r}1,189 \\
826 \\
1,157 \\
1,444 \\
1,289 \\
\end{array}$ & $\begin{array}{r}39.1 \\
62.0 \\
45.0 \\
a 10.5 \\
164\end{array}$ & $\begin{array}{l}14.65 \\
12.30 \\
13.90 \\
12.00 \\
10.40\end{array}$ & $\begin{array}{l}14.65 \\
13.20 \\
13.90 \\
13.80 \\
12.87\end{array}$ & $\begin{array}{l}14.65 \\
13.20 \\
13.90 \\
13.80 \\
12.87\end{array}$ \\
\hline Average... & 594 & 237 & 1,817 & 1,181 & 30.4 & 12.65 & 13.68 & 13.68 \\
\hline $\begin{array}{c}\text { Brick with face } \\
\text { exposed } . . . .\end{array}$ & $\left\{\begin{array}{r}\cdots \\
\cdots \cdots \\
127 \\
117 \\
126\end{array}\right.$ & $\begin{array}{l}58 \\
53 \\
58\end{array}$ & $\begin{array}{l}1,112 \\
1,794 \\
1,827 \\
1,994 \\
2,024\end{array}$ & $\begin{array}{r}838 \\
1,384 \\
902 \\
1,270 \\
1,536 \\
\end{array}$ & $\begin{array}{l}24.7 \\
22.8 \\
50.6 \\
36.3 \\
24.1\end{array}$ & $\begin{array}{l}19.11 \\
12.70 \\
18.50 \\
16.60 \\
12.82\end{array}$ & $\begin{array}{l}19.30 \\
13.91 \\
18.80 \\
16.60 \\
13.83\end{array}$ & $\begin{array}{l}19.30 \\
14.17 \\
18.80 \\
16.91 \\
14.21\end{array}$ \\
\hline A verage $\therefore$ & 123 & 56 & 1,750 & 1,186 & 31.7 & 15.95 & 16.49 & 16. $t 8$ \\
\hline
\end{tabular}

$a$ Increase. 


\section{BIBLI0GRAPHY.}

\section{SURVEY PUBLICATIONS ON STRUCTURAL MATERIALS.}

The following reports of the Geological Survey relate to structural materials, etc. A copy of any except those that are priced can be had free by applying to the Director, U. S. Geological Survey, Washington, D. C. The others can be obtained by sending price, in cash, to Superintendent of Documents, Government Printing Office, Washington, D. C.

Bulletin 243. Cement materials and industry of the United States, by E. C. Eckel. 1905. 395 pp., 15 pls. $65 \mathrm{c}$.

Bulletrin 260. Contributions to economic geology, 1904. The American cement industry, by E. C. Eckel, pp. 496-505. 1905. 40c.

Bulletin 324. The San Francisco earthquake and fire of April 18, 1906, and their effects on structures and structural materials, by G. K. Gilbert, Richard L. Humphrey, J. S. Sewell, and Frank Soulé. 1907. 170 pp. 50c.

Bulletrin 329. Organization, equipment, and operation of the structural materials testing laboratories at St. Louis, by Richard L. Humphrey. $1908.85 \mathrm{pp.}$

Bulletin 331. Portland cement mortars and their constituent materials; results of tests made at the structural materials testing laboratories, St. Louis, Mo., by Richard L. Humphrey and William Jordan, jr. 1908. 130 pp.

Bulletin 340. Contributions to economic geology, 1907, part 1. Cement and concrete materials, by E. F. Burchard and G. B. Richardson, pp. 383-416. 1908.

BuLLETIN 344. The strength of concrete beams; result of tests made at the structural materials testing laboratories, St. Louis Mo., by Richard L. Humphrey. 1908. $58 \mathrm{pp}$.

Water-Supply Paper 143. Experiments on steel-concrete pipes on a working scale, by J. H. Quinton. 1905.61 pp., 4 pls. $5 c$.

Mineral Resources U. S. for 1901 (70c); 1902, 1903 (70c), 1904, 1905 (\$1), and $1906(50 \mathrm{c})$. Contains statistics of production of building stones, cement, and clay. The volume for 1906 contains Advances in cement technology, by E. C. Eckel. pp. 897-905.

Professional Paper 11. The clays of the United States east of the Mississippi River, by H. Ries. 1903.298 pp. 40c.

Sixtenth Annuai Report, pt. 4. Technology of the clay industry, by H. Ries, pp. $523-575,4$ pls. 1895 . $\$ 1.20$.

\section{FIRE TESTS OF STRUCTURAL MATERIALS.}

The following papers contain mention of most of the fire-resistive tests of structural materials made since 1890 that have been described in the technical press:

Hrmmelwright, A. L. A. Fireproof construction. Eng. Mag., rol. 12, 1896, pp. 460-469. Describes seven tests on different types of floors by the New York Department of Buildings.

73087-Bull. $370-09-7$ 
McFarland, H. B. Tests of the effects of heat on reinforced concrete columns. Eng. News, September 20, 1906, pp. 316-318.

MoKibiben, F. P. Fire and weight test of Columbia fireproof floor. Eng. News, November 21, 1904, p. 378. Describes test of floor of reinforced stone concrete having veneer of cinder concrete.

SAchs, E. O. Facts on fire prevention. The result of tests conducted by the British Fire Prevention Committee. London, 1902. Vol. l, 219 pp.; vol. 2, 226 pp. Tests of materials, vol. 2, deal chiefly with tests of various types of floors, ceilings, and partitions.

Wrllex, D. A. The Underwriters' Laboratories. Sci. Am. Supp., August 22, 1903, pp. 23109-23110. Brief description of plant and work.

Woolson, IRA H. Tests of the strength and fireproof qualities of sand-lime brick. Trials under the requirements of the New York Bureau of Buildings, made at Columbia University. Eng. News, June 14, 1906, pp. 662-664.

Investigation of the effect of heat upon the crushing strength and elastic properties of concrete. Eng. News, July 13, 1905, pp. 35-38. Describes laboratory experiments at Columbia University, on trap rock and limestone aggregates. A bstract of paper before Am. Soc. Testing Mat.

- Investigation of the thermal conductivity of concrete and the effect of heat upon the strength and elastic properties. Eng. News, June 28, 1906, pp. 723-725. Abstract of paper before Am. Soc. Testing Mat. Describes laboratory tests of limestone, trap, cinder, and gravel aggregates at Columbia University.

American Architect. Fireproof construction tests. March 28, 1891. Describes tests at Denver, Colo.

Engineering. The results of some tests with fire-resisting material. November 17, 1905, p. 646. Describes tests and experiments of British Fire Prevention Committee with concrete and reinforced concrete flour arches.

Engineming News. Tests of material for fireproofing columns. September 6, 1894, p. 184. Gives results of tests at Vienna.

_ Tests of fireproof material. September 17, 1896, pp. 182-183. Comparison of concrete and hollow tile by New York Department of Buildings.

Tests of fireproof floor construction. April 22, 1897, pp. 255-256. Describes tests of reinforced concrete systems.

Tests of fireproof partitions by the New York Department of Buildings. December 26, 1901, pp. 482-486. Describes thirteen tests of mortar and plaster blocks, concrete blocks, terra cotta, and protected metal strips and metal lath.

Tests of vulcanite floors. February 8, 1902, p. 116. Describes tests, at Philadelphia, of a steel and concrete construction.

Fire tests of fireproof floors by the New York Department of Buildings. May 29,1902 , pp. 441-442. Gives construction of various types tested at Brunswick, N.J., by F. C. Van Dyck.

Tests to determine the fire resistance and heat conductivity of concrete. August 3, 1905, pp. 115-116. Abstract of report to National Fire Protection Association on tests of beams made of limestone, gravel, and cinder aggregates.

_- Fire tests of reinforced concrete floors. February 1, 1906, p. 115. Describes tests at Brunswick, N. J., by F. C. Van Dyck, of reinforced cinder-concrete slab and steel I-beam construction and of reinforced stone-concrete slab and girder construction.

- Fire tests of a fireproof floor with bays of different aggregates. February 1, 1906, p. 116. Gives results for seven aggregates.

- Comparative resistance to fire of concrete and cinder concrete. May 31, 1906, p. 603. Tests by British Fire Prevention Committee, of gravel concrete and clinker and coke breeze concrete. 
Engineming Record. Fireproof construction. April 4, 1891, p. 288 . Editorial on Denver tests.

- Tests of firepronf arches at St. Louis. May 7, 1892, pp. 376-377. Describes tests of different concrete constructions.

Fireproof construction. October 7, 1893, p. 14. Mentions various types of floors and doors tested at Berlin.

The best fireproof construction for buildings occupied for mercantile purposes. October 9, 1897, pp. 495-498.

- Official test of fireproof floor construction systems. September 18, 1897, pp. 337-340; September 25, pp. 359-363; October 2, pp. 382-387; October 9, pp. 403-408. Describes tests of fourteen floor systems by the New York Department of Buildings in 1896-97. Tests were in kilns over wood fires.

- Tests of a new system of terra-cotta floors. February 25, 1905, pp. 220-221. Describes tests of floor to be used in forty warehouses under construction in Pittsburg. Report by Ira H. Woolson.

Scientific American Supplement. The British Fire Prevention Committee and its work. June 20, 1903, pp. 22959-22960. Describes testing equipment and scope of work. 






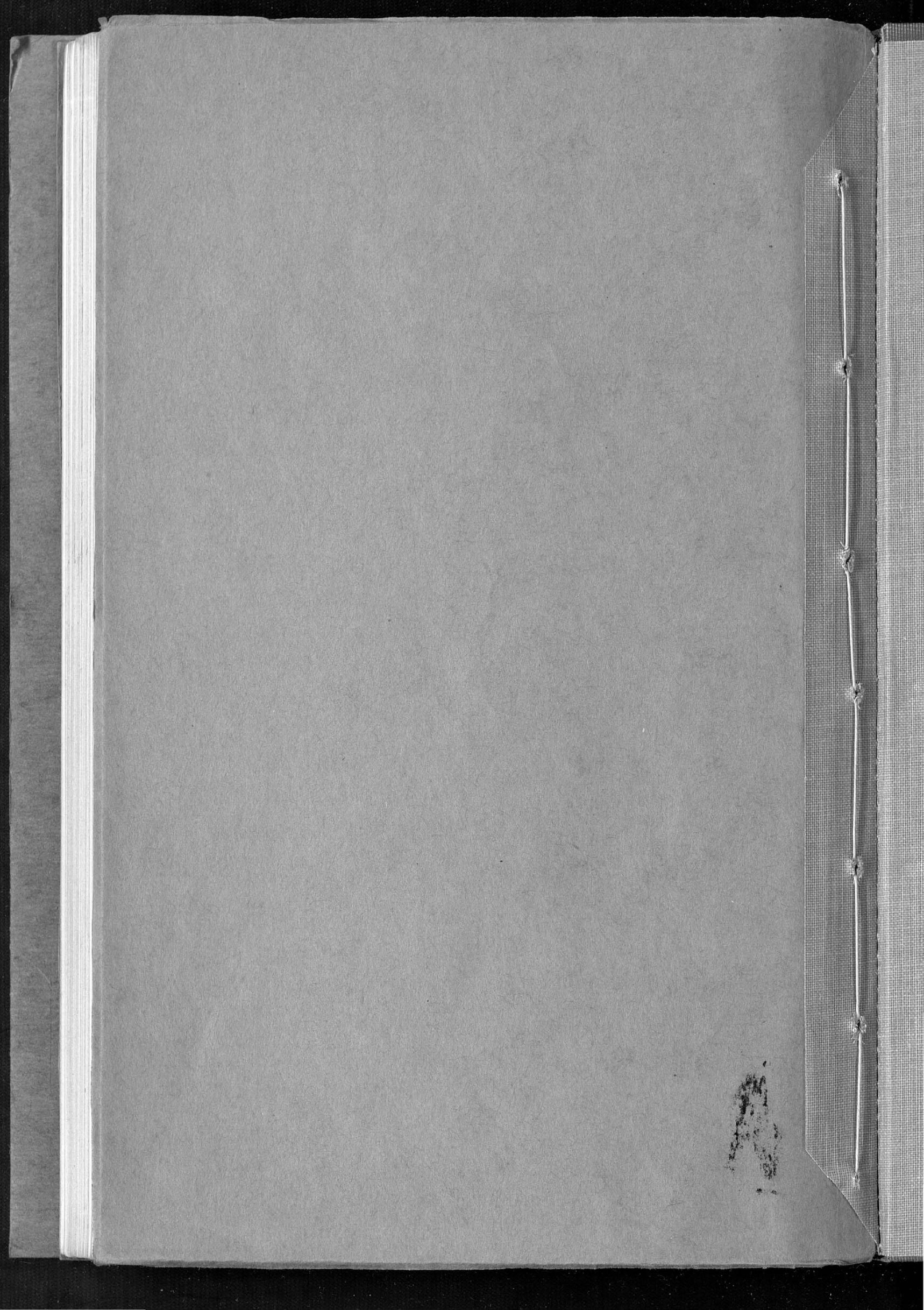









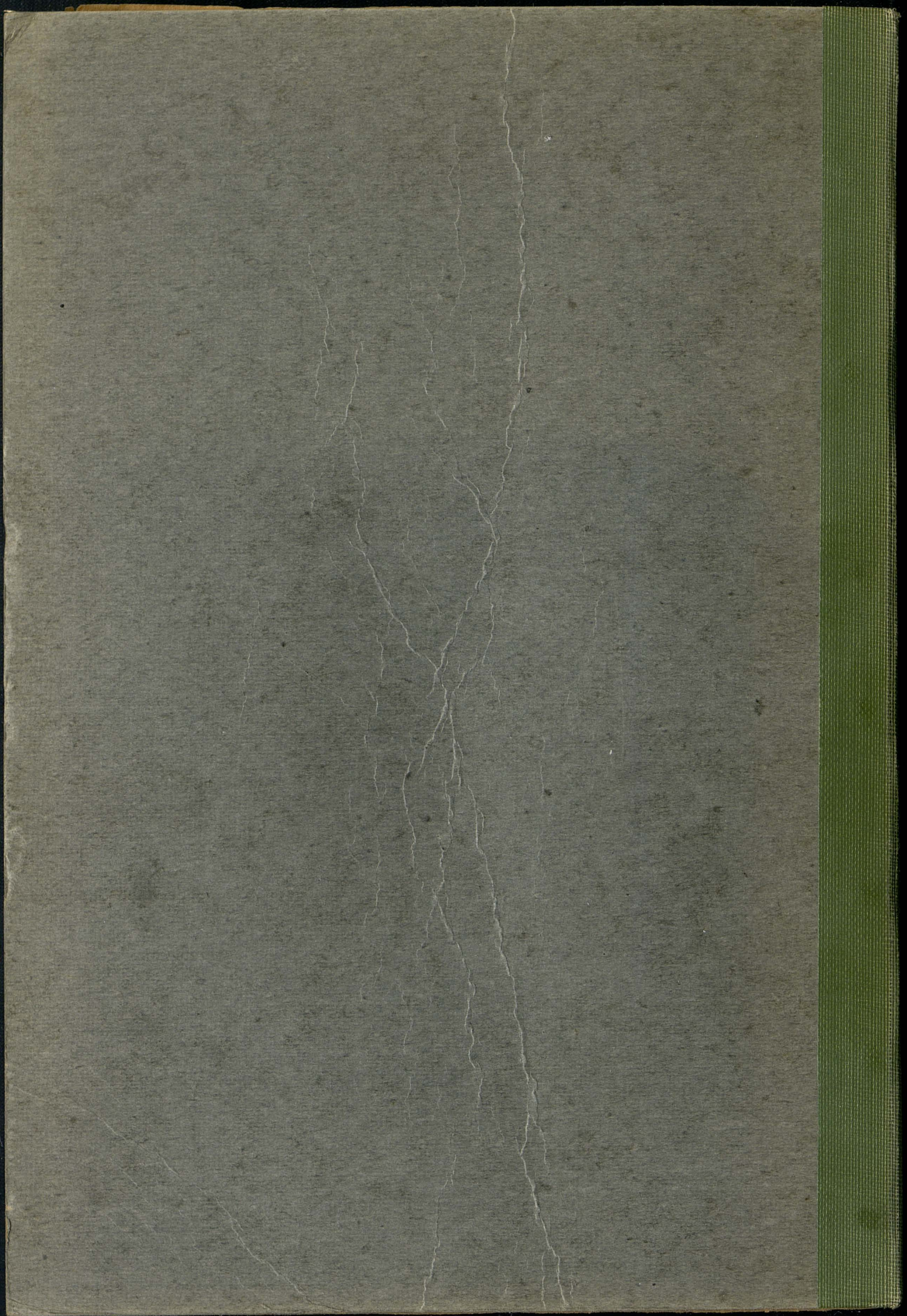

